\title{
New Methodological Perspectives on Observation and Experimentation in Science
}




\section{New Methodological Perspectives on Observation and Experimentation in Science}

Edited by Wenceslao J. Gonzalez 
Coordinador de la Serie de Filosofía y Metodología de la Ciencia

Wenceslao J. González

\section{NEW METHODOLOGICAL PERSPECTIVES ON OBSERVATION AND EXPERIMENTATION IN SCIENCE}

Any form of reproduction, distribution, public communication or processing of this work can only be done with the permission of their owners, except where exempted by law. Contact CEDRO (Spanish Reprographic Rights Center, www.cedro.org) if you need to scan or photocopy any part of this work.

No part of this publication may be reproduced or distributed in any form or by any means, or stored in a database or retrieval system, without the prior written consent of the owners of the copyright, including but not limited to, in any network or other electronic storage or transmission or broadcast for distance learning.

$Q R$ code is a trademark registered by Denso Wave, inc.

Copyright (C) 2010 by Netbiblo

Copyright $(C$ by Wenceslao J. Gonzalez

\section{netbriblo}

www.netbiblo.com

NETBIBLO, S. L.

C/. Rafael Alberti, 6 bajo izq.

Sta. Cristina 15172 Oleiros (La Coruña) - Spain

Tlf: +34981915500 • Fax: +34981915511

www.netbiblo.com

editorial@netbiblo.com

Member of European Union Publishers' Forum

ISBN: 978-84-9745-530-5

Legal Deposit: C-4113-2010

Editorial Manager: Cristina Seco López

Editor: Paola Paz Otero

Production Management: Gesbiblo, S. L

Imagen de cubierta: Jéssica Rey

First Published 2010 by Netbiblo, S.L. 


\section{可残

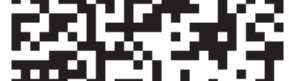

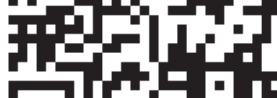 西要}

\section{How can you use it?}

If your mobile does not have a reader, download and freely instal the most suitable for your phone.

Here you will find some recommendations:

D If it is an iPhone, NeoReader is a good option: http://get.neoreader.com

- For Blackberry models, you can instal Beetagg: http://get.beetagg.com

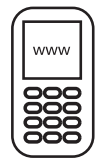

D If you have a Nokia or similar try, for instance, Kaywa Reader: http://reader.kaywa.com

Open the aplication and shoot the QR.

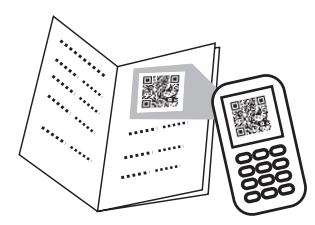

When accepting, a window will be opened with the code content. 


\section{GeNERAL INDEX}

\section{PREFACE}

General Characteristics and Origin of this Book, Wenceslao J. Gonzalez.......................................

1. General Characteristics of this Volume .................................................................................

2. Origin of the Book ...............................................................................................................

3. Publications from the Conferences on Contemporary Philosophy and Methodology

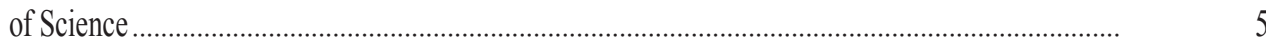

4. Acknowledgments..................................................................................................................

PART I:

VARIATIONS IN THE REFLECTION ON OBSERVATION AND EXPERIMENTATION

\section{Recent Approaches on Observation and Experimentation:}

A Philosophical-Methodological Viewpoint, Wenceslao J. Gonzalez ..........................................

1. The Characterization of Observation in Science.......................................................................

1.1. Some Historical Traits....................................................................................................

1.2. A Relevant Shift in the Natural Sciences: Observation and Theory-Laden............................ 15

1.3. The Social Sciences: From the Acceptance of Observation to the Problem of Experimentation...................................................................................

1.4. From "Traditional" Sciences to the Sciences of Artificial ................................................. 22

1.5. Actual Observations and Simulations ..............................................................................

2. The Concept(s) of "Experiment" used in our Times ................................................................. 26

2.1. The Traditional Approach to the Laboratory Experiments ..................................................... 28

2.2. The Enlarged Vision of the Diversity of Experiments ......................................................... 29

2.3. From the "External Validity" to the "External View" on Experiments .................................. 32

2.4. From Simulations to Computer Simulations in the Context of Experiments..........................

2.5. Two Cases Reconsidered: Thought Experiments and Mathematical Models .......................... $\quad 37$

Bibliography ................................................................................................................. 


\section{PART II: \\ EXPERIENCE AND SCIENTIFIC OBSERVATIONS}

2. 'Voice' and the Facts and Observations of Experience, Mary S. Morgan.......................................

1. Personal Experience in Forms of Knowledge.............................................................................

2. Personal Experience and the Experienced Expert ........................................................................

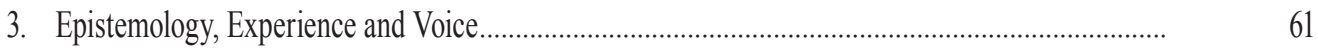

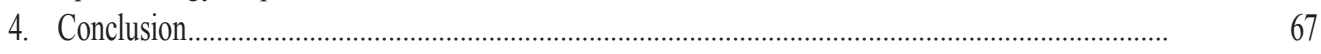

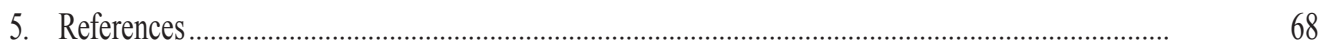

3. New Forms of Scientific Observation and their Epistemological Impact, Amparo Gómez .....................................................................................................................

1. Instruments and Agreements in Computer Based Experiments ..................................................

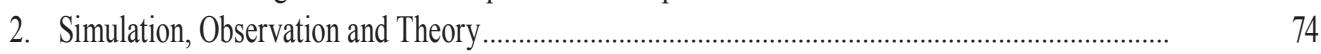

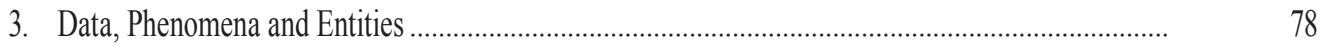

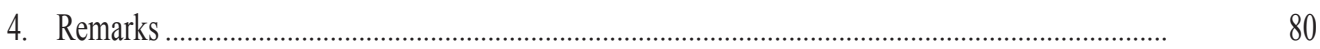

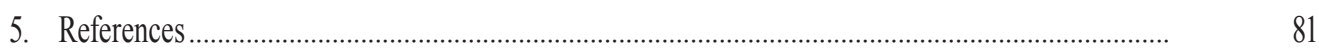

\section{PART III: \\ EMPIRICAL SUPPORT AND EXPERIMENTS IN SCIENCE}

\section{Observation and Experiments in Economics: Analysis of Herbert Simon's} Approach, María G. Bonome.....................................................................................................

1. Herbert Simon's Approach: The Primacy of Empiricism................................................................

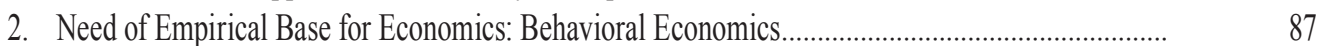

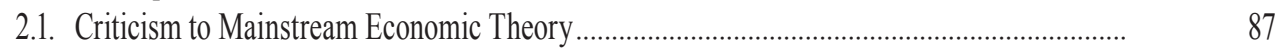

2.2. Appeal to the Psychology-Like Complement of Economics ......................................................

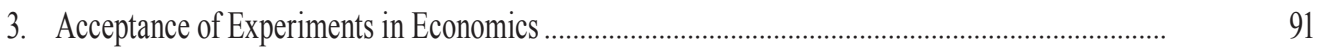

3.1. Institutional Area and Thematic Field ............................................................................... 91

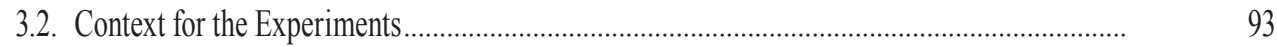

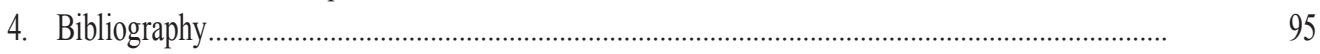

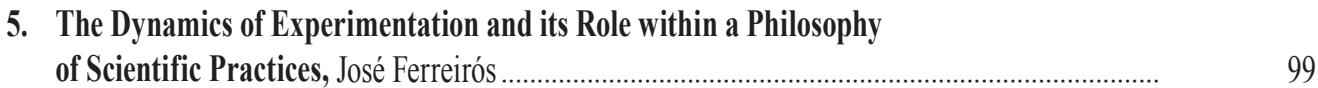

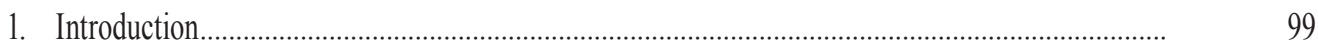

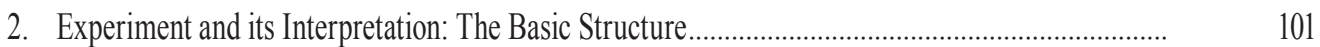

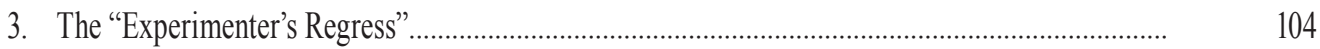

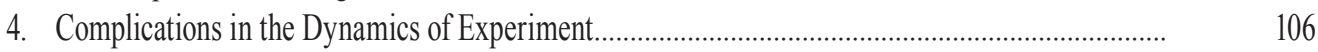

5. From the "Circle" to the Helix of Experimental Research ..................................................................

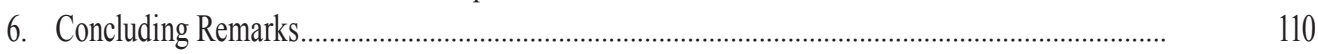

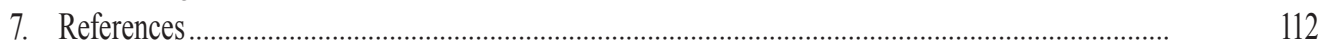




\section{PART IV: \\ CHANGES IN THE FRAMEWORK ON OBSERVATION AND EXPERIMENTATION}

\section{Dimensions of Clinical Observation in the Origins of Scientific Medicine,} José A. López Cerezo.

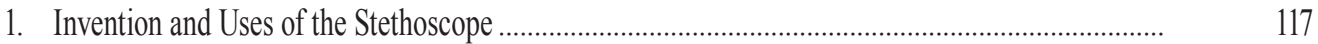

2. Disease Through the Stethoscope

3. Consolidation of the Stethoscope

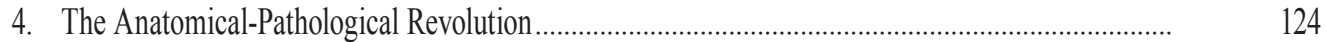

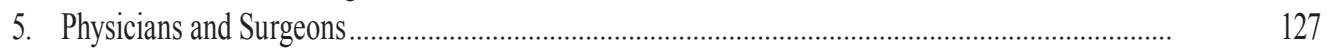

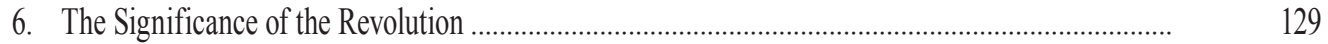

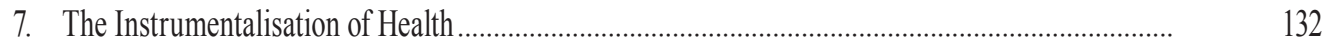

8. Some Conclusions ....................................................................................................................... 134

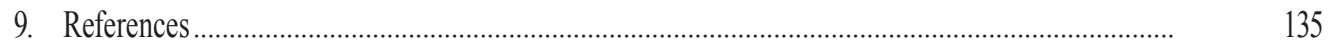

7. Probabilistic Causality, Observation and Experimentation, Maria Carla Galavotti................. 139

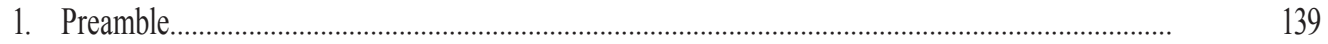

2. The Twofold Nature of the Debate on Probabilistic Causality .............................................................

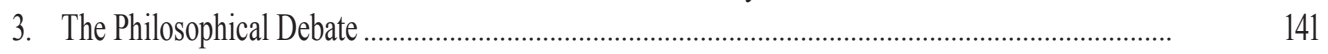

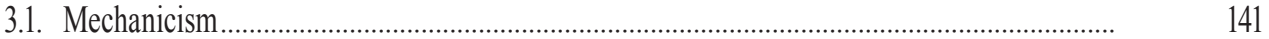

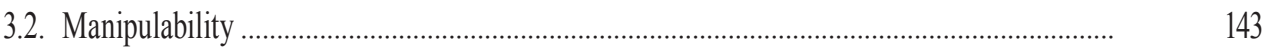

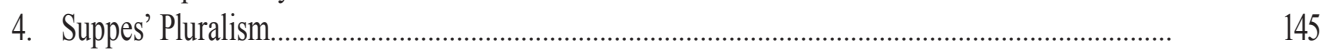

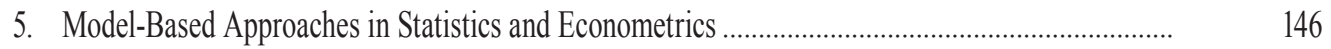

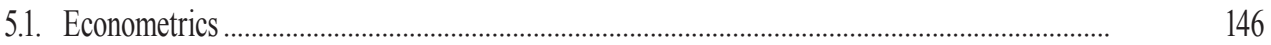

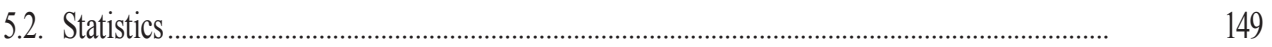

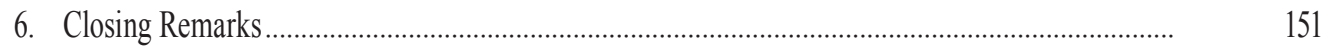

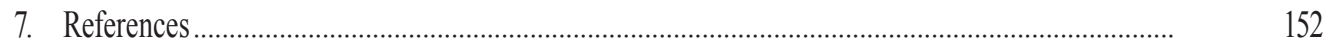

PART V:

ENLARGING THE PHILOSOPHICAL SCOPE: LAW AND ECOLOGY

8. The Role of Experiments in the Theories of Distributive Justice, Obdulia Torres........................ 159

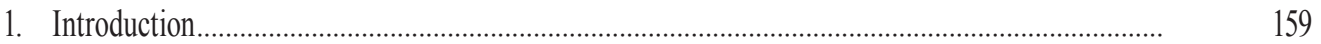

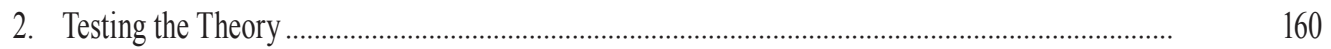

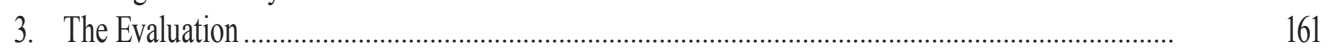

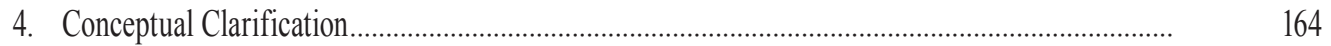

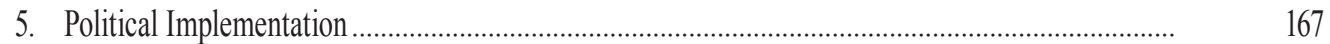

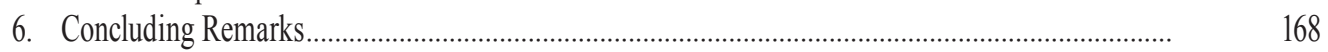

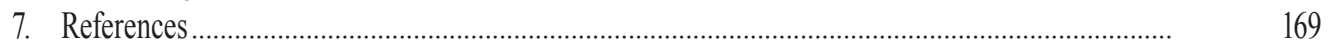




\section{Observation and Experiment in Ecological Research,}

Rafael González del Solar and Luis Marone ..................................................................................

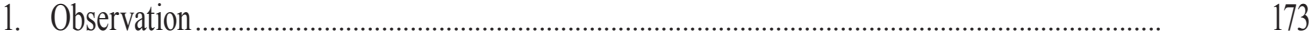

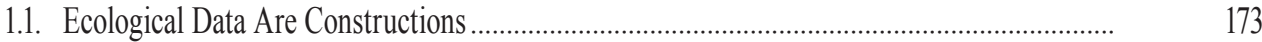

1.2. Observations and Experiments Can Play Different Roles in Ecology .................................... 174

1.2.1 Experiments Can Be Used as Exploration Tools...................................................... 175

1.2.2. Observations Can Be Used to Decide Among Ecological Hypotheses.......................... 176

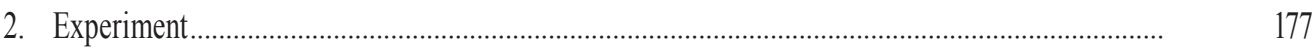

2.1. Limitations of Phenomenological Experiments...................................................................

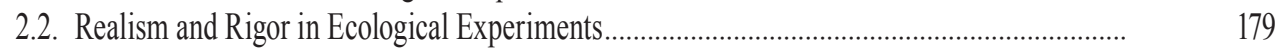

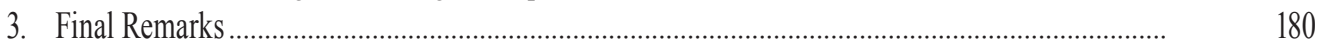

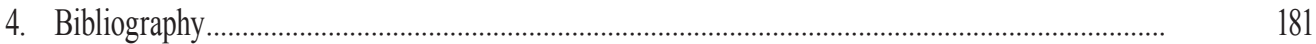

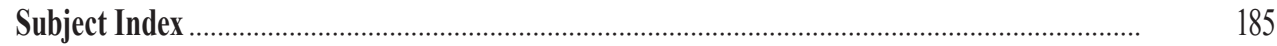

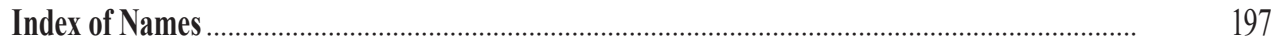




\title{
General Characteristics and ORIGIN OF THIS BOOK
}

\author{
Wenceslao J. Gonzalez
}

\section{General Characteristics of this Volume}

New Methodological Perspectives on Observation and Experimentation in Science is a book that deals with a classic topic that is seen from new angles. Thus, its nine chapters seek "non-traditional" aspects, trying to extend the boundaries of this philosophicalmethodological theme. They are presented in five sections: 1) A Philosophical-Methodological Context; 2) Experience and Scientific Observations; 3) Empirical Support and Experiments in Science; 4) Changes in the Framework on Observation and Experimentation; and 5) Enlarging the Philosophical Scope: Law and Ecology.

In addition to the novelty in the contents, this book has another relevant feature: New Methodological Perspectives on Observation and Experimentation in Science belongs to the new series regarding philosophy and methodology of science published by Netbiblo. On the one hand, from the point of view of the search for academic rigor, it is clearly inspired by the prestigious collections of studies already available; and, on the other hand, this new series is published by a more recent publishing house that has a particular interest in the internet and the new possibilities opened up by the World Wide Web.

Since 2003 this house has been publishing a set of books on philosophy and methodology of science. From the beginning, it was considered a presence in the paper format as well as in the electronic presentation, which is nowadays the case. These books deal with contemporary approaches to the philosophical-methodological realm. Commonly, they look for an enlarged vision of the field and, therefore, they are oriented towards originality. These volumes are now listed under the label of Serie de Filosofía y Metodología de la Ciencia/Philosophy and Methodology of Science Series.

The first book of this series of Netbiblo was in Spanish: Racionalidad, historicidad $y$ predicción en Herbert A. Simon, 2003. But the volumes were published in English very soon: Science, Technology and Society: A Philosophical Perspective, 2005; Contemporary Perspectives in Philosophy and Methodology of Science, 2006; and Evolutionism: Present Approaches, 2008. The list, which is available at the end of this volume, is opened to the future according to a plan of offering to the reader new contributions to this academic sphere.

From the beginning there were two "ideal models" of this new series in philosophy and methodology of science. One of them is the Boston Studies in the Philosophy of Science, a collection published for many years by Kluwer Academic Press and with a prestigious record; and the other is the Poznan Studies in the Philosophy of the Sciences and the Humanities, which belong to Rodopi and whose catalog includes very relevant publications. The new series is also 
rooted in a University — A Coruña — and shares the interest in an international presence, but it has its own character within the framework of academic standards.

\section{Origin of the Book}

Originally, these papers were delivered at the Jornadas sobre Observación y experimentación en la Ciencia: Nuevas perspectivas metodológicas (Conference on Observation and Experimentation in Science: New Philosophical Perspectives), organized by the University of A Coruña with the support of the Society of Logic, Methodology and Philosophy of Science in Spain. The meeting was held at the Campus of Ferrol on 8th and 9th of March 2007. The discussions were oriented towards the main goal: new approaches on scientific observation and recent contributions on experimentation in science. As in the case of the previous Jornadas sobre Filosofía y Metodología actual de la Ciencia (Conferences on Contemporary Philosophy and Methodology of Science), the twelfth edition of these meetings has its central interest in the reflections developed nowadays.

The conference had a keynote speaker: Mary S. Morgan, Professor at the London School of Economics, where she has lectured since 1988, and the University of Amsterdam, where she has taught since 1992. She is a Fellow of the British Academy (2002) and a correspondent member of the Royal Academy of Arts and Sciences of the Netherlands (2002). She has been president of the History of Economics Society (2004-2005). Before her academic career, she worked for the Citibank (London, 1973-1975) and the Bank of England (1978-1979). After her PhD at the London School of Economics (1984), she worked at several universities: York (1984-1987), Duke (1987), ... She have worked in editorial committees such as History of Political Economy (1988), Journal of Economic Methodology (1996), Journal for the History of Economic Thought (1997), ...

Morgan is the author of influential books, such as The History of Econometric Ideas (1990), The Foundations of Econometric Analysis (1995, written with D. F. Hendry), and Methodology and Tacit Knowledge: Two Experiments in Econometrics (1999, prepared with J. R. Magnus). She is also the editor of several books, such as Higgling: Transactors and Their Markets in the History of Economics (1994, with N. de Marchi), From Interwar Pluralism to Post-War Neoclassicism (1998, with M. Rutherford), Models as Mediators (1999, with M. Morrison), ...

Among her papers related to the topics of this conference are "Finding a Satisfactory Empirical Model" (1988), "Design of the Experiment" (1997), "What Makes the Empirical Models-Policy Interaction Successful?" (1998), "Is Data Mining a Methodological Problem?” (2000), "Ceteris paribus Conditions: Materiality and the Application of Economic Theories" (2001, with Marcel Boumans), "Model Experiments and Models in Experiments" (2002), "Experiments without Material Intervention: Model Experiments, Virtual Experiments and Virtually Experiments" (2003), "Simulation: The Birth of a Technology to Create 'Evidence' in Economics" (2004), "Experiments versus Models: New Phenomena, Inference, and Surprise" (2005), ...

Another international speaker was Maria Carla Galavotti. She is Professor of Philosophy of Science at the University of Bologna. She has been a Visiting fellow in a large number of institutions, such as the Department of Philosophy at the University of Princeton, the Center for the Study of Language and Information at the University of Stanford, the Center of Philosophy of Science at the University of Pittsburgh. She is a member of Clare Hall College, Cambridge University, and she works in editorial committees such as Erkenntnis; Vienna Circle Institute Yearbook and Sciences et techniques en perspective. 
Galavotti's main lines of research are focused on the foundations of probability and statistics, scientific explanation, probabilistic causation, the role and structure of the models in natural sciences and social sciences. Among her contributions are several books as editor: Stochastic Causality (2001, co-edited with P. Suppes and D. Costantini), Observation and Experiment in the Natural and Social Sciences (2003), Cambridge and Vienna. Frank P. Ramsey and the Vienna Circle (2006), and Reasoning, Rationality and Probability (2008, with R. Scazzieri, and P. Suppes). She is the author of "Harold Jeffreys' Epistemology between Logicism and Subjectivism" (2003), "Kinds of Probabilism" (2003), and Philosophical Introduction to Probability (2005).

Other invited speakers were several Professors of Logic and Philosophy of Science: Amparo Gómez (University of La Laguna), José Antonio López Cerezo (University of Oviedo), and José Ferreirós (University of Seville). The authors of the contributed papers come from other institutions: Obdulia Torres (University of Salamanca); María G. Bonome (University of A Coruña); and Luis Marone (CONICET, Argentina) and Rafael González del Solar (Autonomous University of Barcelona).

Each one of these participants has developed new angles of the views on observation and experimentation in science, seeing it from a philosophical-methodological perspective. In addition to the papers presented in this conference, the book includes a new chapter prepared by the editor of the volume. On the one hand, the content was written in order to offer the philosophical-methodological context of the topic as well as to contribute in some extent to the discussion on this issue. On the other hand, the initial paper has a practical aim: to be particularly helpful for the reading of other chapters of the book, especially for those that like to move from the general scope to the particular details.

\section{Publications from the Conferences on Contemporary Philosophy and Methodology of Science}

Annually, from 1996 up to now, we have had the Conferences on Contemporary Philosophy and Methodology of Science at the University of A Coruña, Ferrol Campus. The keynote speakers have been so far: Larry Laudan, Ilkka Niiniluoto, Evandro Agazzi, Daniel Hausman, John Worrall, Wesley Salmon, Peter Machamer, Donald Gillies, Kristin Shrader-Frechette, James Lennox, Philip Kitcher, Mary Morgan, Peter Clark, Paul Thagard and Thomas Nickles. All of them have presented two papers in these Jornadas sobre Filosofía y Metodología actual de la Ciencia. In addition, other well-known professors have presented papers: Merrilee H. Salmon, James E. McGuire, Jarret Leplin, Jean Gayon, Maria Carla Galavotti, Matti Sintonen, Subrata Dasgupta, ... These fifteen years had a previous stage in the course given by Nicholas Rescher in 1995. His lectures — in addition with other papers - have been published in his book Razón y valores en la Era científico-tecnológica, Paidós, Barcelona, 1999.

Following the policy of publishing the main papers presented each year plus a chapter of contextualization of the topic, there is a set of publications under the label of Colección Gallaecia. Estudios de Filosofía y Metodología actual de la Ciencia (Gallaecia Collection. Studies in Contemporary Philosophy and Methodology of Science). During the initial years the volumes published were Gonzalez, W. J. (ed.), Progreso cientifico e innovación tecnológica, monographic issue of Arbor, v. 157, n. 620, (1997); Gonzalez, W. J. (ed.), El Pensamiento de L. Laudan. Relaciones entre Historia de la Ciencia y Filosofía de la Ciencia, Publicaciones Universidad de A Coruña, A Coruña, 1998; Gonzalez, W. J. (ed.), Ciencia y valores éticos, 
monographic issue of Arbor, v. 162, n. 638, (1999); Gonzalez, W. J. (ed.), Problemas filosóficos y metodológicos de la Economía en la Sociedad tecnológica actual, monographic issue of Argumentos de Razón técnica, v. 3, (2000); and Gonzalez, W. J. (ed.), La Filosofía de Imre Lakatos: Evaluación de sus propuestas, UNED, Madrid, 2001.

After these volumes, the conferences of the following years were published: GonZALEz, W. J. (ed.), Diversidad de la explicación científica, Ariel, Barcelona, 2002; Gonzalez, W. J. (ed.), Análisis de Thomas Kuhn: Las revoluciones cientificas, Trotta, Madrid, 2004; Gonzalez, W. J. (ed.), Karl Popper: Revisión de su legado, Unión Editorial, Madrid, 2004; GonZalez, W. J. (ed.), Science, Technology and Society: A Philosophical Perspective, Netbiblo, A Coruña, 2005; and Gonzalez, W. J. (ed.), Evolutionism: Present Approaches, Netbiblo, A Coruña, 2008. Although the tradition has been to publish in English since 2005, there is an exception due to the support of the Spanish Ministry of Culture to the topic on evolutionism: GonZaLEz, W. J. (ed), Evolucionismo: Darwin y enfoques actuales, Netbiblo, A Coruña, 2009. In a few months' time, besides the present book, the publication is expected of Gonzalez, W. J. (ed.), Scientific Realism and Democratic Society: The Philosophy of Philip Kitcher, Poznan Studies in the Philosophy of the Sciences and the Humanities, Rodopi, Amsterdam.

\section{Acknowledgments}

When a project becomes real, there are commonly some institutions and persons that have been particularly relevant to the activity. In this regard, my first acknowledgement goes to the City Hall of Ferrol, especially to the councilman for culture, who is well aware of the relevance of this nexus between university and society. My gratitude is also to the Spanish Ministry of Science and Education for the support given to this conference through the Secretary of State for Scientific and Technological Policy (HUM2006-28005-E). My recognition to the Santander bank, the economic entity that facilitates the cultural activities promoted by University of A Coruña.

Regarding persons, I want to mention the Rector of the University of A Coruña, because of his manifest consideration of these Jornadas, and the Vice-rector of Ferrol Campus, who has given support to this congress. My appreciation goes expressly to Mary S. Morgan for accepting my invitation, which has allowed us to go more deeply into the issues on observation and experimentation. My recognition also goes to Maria Carla Galavotti, who is a very well known figure in the European philosophy of science. I am grateful for the presence of my colleagues Amparo Gómez, José Antonio López Cerezo and José Ferreirós. In addition, I am happy with the authors of the contributed papers.

Within the closer sphere of collaborators, I thank the work done by the people of the support team. They have been especially helpful for material and organizational matters. In this regard, my gratitude is greater in the case of those persons that have been collaborating in all the editions of these Jornadas. Furthermore I am thankful to those who have assisted me in administrative matters. In addition, I am grateful to the media that have informed of this activity. Obviously, I have a warm recognition to those who have cooperated in editorial tasks: José Fco. Martínez Solano and Jéssica Rey.

Ferrol, 2 March 2010 


\section{I}

\section{Variations in the Reflection on Observation and Experimentation}

1. Recent Approaches on Observation and Experimentation:

A Philosophical-Methodological Viewpoint 


\title{
Recent Approaches on ObSERVATion ANd Experimentation: A Philosophical-Methodological Viewpoint*
}

\author{
Wenceslao J. Gonzalez
}

Observation and experimentation are among the central topics of philosophy and methodology of science. ${ }^{1}$ From the beginning of these studies, the empirical sciences have been commonly associated to observational and experimental processes, because they have been considered crucial for testing their contents. Thus, observation and experimentation have received attention from different angles, and they have been historically relevant in the advancement of science. The general context for their philosophical-methodological analysis should include some key aspects, which are those related to axiological, epistemological and methodological issues.

Axiologically, the scientific values associated with observation and experimentation are those connected to the degree in the control of reality independent of the human mind. Thus, the main aims of observation and experimentation in science are to guarantee the reliability and validity of empirical evidence used in those empirical sciences. Epistemologically, observation and experimentation are valuable for basic science as well as for applied science. ${ }^{2}$ Thus, on the one hand, observation and experimentation can be used to enlarge our knowledge of the world (natural, social or artificial); and, on the other hand, they can be utilized to solve specific problems within a well-defined realm. Methodologically, observation and experimentation are used for testing scientific theories. But the methods based on them can do more that: they might have a large number of different purposes, ${ }^{3}$ including, obviously, the practical ones.

Underlying this general philosophical-methodological context of analysis in empirical sciences, there are many features on observation and experimentation to be considered. Among them are the following epistemological and methodological aspects. (i) Frequently, empirical sciences are divided in two large groups: the natural sciences and the social sciences. Nevertheless, there is a third important group: the sciences of the artificial, in general, ${ }^{4}$ and the sciences of design, in particular. These disciplines have developed strongly development in

\footnotetext{
This research is supported by the Spanish Ministry of Science and Innovation (FFI2008-05948).

1 The bibliography included in this chapter illustrates the interest in this topic, which has drawn the attention from quite different angles. Among the large list of publications in this regard in recent times, see GalavotTi, M. C. (ed.), Observation and Experiment in the Natural and the Social Sciences, Kluwer, Dordrecht, 2003, and FrankLin, A., Experiment, Right or Wrong, Cambridge University Press, Cambridge, 2008.

2 On the notion of "applied science" see Nirniluoto, I., "The Aim and Structure of Applied Research," Erkenntnis, v. 38, (1993), pp. 1-21.

3 Cf. Bogen, J., "Experiment and Observation," in Machamer, P. and Silberstein, M. (eds.), The Blackwell Guide to the Philosophy of Science, Blackwell, Oxford, 2002, pp. 128 and 144.

4 Cf. Simon, H., The Sciences of the Artificial, 3rd ed., The MIT Press, Cambridge, MA, 1996 (1st ed., 1969; 2nd ed., 1981).
} 
recent times, and they present special difficulties regarding this methodological framework. ${ }^{5}$ (ii) Although observation is widely assumed in the natural sciences and the social sciences, the role of experimentation in the social sciences is still controversial, including sciences such as economics. ${ }^{6}$ (iii) If "observation" is understood in a very active way (i.e., as an effective cognitive control of an empirical event, different from a passive perception of a phenomenon), then its conceptual dissimilarity with "experiment" might be more complicated. (iv) There are a large number of conceptions on "experiment." Some of them, such as "thought experiment" or simulations made by computer, do not follow the usual connection between experiment and "intervention" (according to a previous design and with a material contact).

Here the main focus of attention is on recent approaches, taking into account the general context on observation and experimentation pointed out as well as the epistemological and methodological aspects mentioned. In addition, some elements of historical background are needed as a starting point for the present situation. Thus, the analysis on the characterization of observation in science will follow five steps: a) some historical traits of this concept, elements that are presented in order to see its philosophical-methodological roots; b) the existence of a relevant shift in the natural sciences regarding observation and theory-ladenness; c) the change from the use of observation in the social sciences to the explicit acceptance of experiments in them, which raises the problem of experimentation in these sciences (i.e., possibility and limits); d) the variation from the study of "traditional" sciences to the elucidation of the sciences of the artificial; and e) the difference between actual "observations" and "simulations," which has consequences for "computer simulations."

Later on, the analysis in this chapter shifts towards experiments. The emphasis will be in the existence of relevant differences about "experiments," which might be seen as concepts of experiment rather than as a unifying and simple notion of it. In this regard, there will first be an analysis of the traditional approach of the laboratory experiments. Secondly, the enlarged vision of the diversity of experiments will be considered, insofar as it has broadened the perspective on what an experiment is. Thirdly, the issue of the "external validity" will be pointed out, followed by the external view developed by Bruno Latour and Steven Woolgar on the social construction scientific facts, which leads to "ethnomethodology." 7 Fourthly, the focus will move to the differences between "simulations" and "computer simulations," which are useful in the sciences of the artificial, in general, and in the sciences of design, in particular. ${ }^{8}$ Finally, the attention will be placed on reconsidering thought experiments and mathematical models, which have been especially relevant in some natural sciences, such as biology. ${ }^{9}$

\footnotetext{
5 Cf. Gonzalez, W. J., "Configuración de las Ciencias de Diseño como Ciencias de lo Artificial: Papel de la Inteligencia Artificial y de la racionalidad limitada," in Gonzalez, W. J. (ed.), Las Ciencias de Diseño: Racionalidad limitada, predicción y prescripción, Netbiblo, A Coruña, 2007, pp. 41-69; and GonZalEz, W. J., "Rationality and Prediction in the Sciences of the Artificial: Economics as a Design Science," in Galavotti, M. C., Scazzieri, R. and Suppes, P. (eds.), Reasoning, Rationality and Probability, CSLI Publications, Stanford, 2008, pp. 165-186.

6 Cf. Gonzalez, W. J., "The Role of Experiments in the Social Sciences: The Case of Economics," in Kuipers, T. (ed.), General Philosophy of Science: Focal Issues, Elsevier, Amsterdam, 2007, pp. 275-301.

7 Cf. Latour, B. and Woolgar, S., Laboratory Life: The Social Construction of Scientific Facts, Princeton University Press, Princeton, NJ, 1979 (2nd edition, 1986.), and Latour, B., Science in Action: How to Follow Scientists and Engineers Through Society, Harvard University Press, Cambridge, MA, 1987.

8 Cf. Simon, H., The Sciences of the Artificial, 3rd ed., pp. 4, 13-15, 17, 21, 66, 82, 177, and 180.

9 On the first case see Lennox, J. G., "The Evolution of Darwinian Thought Experiments," in Gonzalez, W. J. (ed.), Evolutionism: Present Approaches, Netbiblo, A Coruña, 2008, pp. 63-76; and LenNox, J. G., "Thought Experiments in Evolutionary Biology Today,” in Gonzalez, W. J. (ed.), Evolutionism: Present Approaches, pp. 109-120.

The mathematical models have been crucial for some branches in biology, such as the mathematical population genetics of Ronald A. Fisher, J. B. S. Haldane, and Sewall G. Wright.
} 


\section{The Characterization of Observation in Science}

Commonly, the features of the distinction between "observation" and "experiment" are oriented towards some elements. When the focus is on science as a human activity, they are usually related to ends, procedures and outcomes. a) The ends of observation are usually connected to the existence of a course of events (natural, social or artificial) whose perception is searched in order to be represented, whereas experiment involves in principle a more direct intervention on the event, within a deliberately prepared setting. b) The researcher in the procedure of observation has a presumptive lower level of control of the phenomena studied than in the case of a process of experimentation. c) Prima facie, the outcome of the observation might be less reliable than the result of the experiment, especially when the phenomenon observed is not repeatable.

Usually, observation is considered as an indispensable element in any empirical science, both in the basic sciences and the applied sciences. But the question 'What is the characteristic set of elements of "observation"?' might be less clear that it initially appears. A key issue is the relation between observation and language. In this regard, Ian Hacking has pointed out two possibilities about observation that are connected with some philosophical fashions. "One is the vogue for what Quine calls semantic ascent (don't talk about things, talk about the way we talk about things). The other is the domination of experiment by theory. The former says not to think about observation, but about observation statements - the words used to report observations. The latter says that every observation statement is loaded with theory - there is no observing prior to theorizing." 10

Hacking's perspective on the characterization of "observation" in science has led him to accept some "untheoretical" and "unlinguistic" aspects. 1) Observations either provide the data that test theory or are the basis upon which theory is built. 2) There are some observations of unexpected outcomes of experiments that can lead to new knowledge. 3) The role of observation is commonly in initiating the inquiry, because later work is conducted by experimentation. 4) Observation is a human skill that can be improved by training and practice. 5) The relations between observations and theory need to take into account the existence of "pre-theoretical observation statements," whose presence in science is not frequent. 6) Scientific observations are generally made through instruments. At least in natural sciences, observations are seldom made by unaided human senses. ${ }^{11}$

Besides these epistemological claims, which are usually thought of sciences such as physics and chemistry, there are many methodological aspects of observation, which are relevant. Traditionally, the focus has been on how they affect basic sciences - natural and social ones-, but those aspects are also crucial for applied sciences such as medicine, which are less in the front line of the philosophical discussion. In branches of medicine, such as rheumatology, "much of the criticism of observational studies concerns the often nonobjective, potentially biased methodology involved in subject selection, data collection, analysis, and interpretation, although even case reports and case series as descriptive studies might occasionally yield important clinical information." 12

\footnotetext{
10 Hacking, I., Representing and Intervening, Cambridge University Press, Cambridge, 1983, p. 167.

11 Hacking, I., Representing and Intervening, pp. 167-168.

12 Chakravarty, E. F. and Fires, J. F., "Science as Experiment; Science as Observation," Natural Clinical Practice, v. 2, n. 6, (2006), p. 287.
} 
Generally, when observation is compared with experimentation in basic science and in applied science, the former appears with less methodological weight than the latter. This lower level of authority of observational processes is sometimes associated to a minor degree in the control of the variables than in the case of experimentation. Another frequent reason for this lesser methodological validity lies in the presence of subjective components in observational processes. In this regard, it can be stated for any science that "the quality, validity, and reliability of observational studies depend on the rigor with which data is collected, outcome measures are selected, possible confounders and biases are identified and addressed, and appropriate statistical techniques are applied." 13

Yet, in spite of the traditional link of observation with the search for reliable knowledge and adequate procedures for the objects studied, the characterization of "observation" cannot be reduced to epistemological and methodological issues. De facto, there are many cases where observation has additional problems to those focused on knowledge and method. Medicine is a realm that exemplifies this situation quite well. On the one hand, there are axiological problems in research designs related to observation. ${ }^{14}$ On the other hand, there are increasing ethical concerns on controlled observation related to clinical trials. Thus, how observations are performed in medical research, and how the evidence, in general, is gathered in clinical trials have raised special ethical concerns. ${ }^{15}$

\subsection{Some Historical Traits}

Historically, the interest in observation can usually be found in any scientist researching empirical phenomena. Moreover "observation, as a primary source of data, has always been a part of natural science." ${ }^{16}$ It was commonly used from the beginning of "modern science" in the seventeenth century. Since then, observation has had a relation to epistemological controversies, such as rationalism and empiricism, as well as to methodological discussions around deduction and induction (and, to a lesser extent, on abduction too). In addition, observation also has a role in the logico-methodological distinction between "explanation" and "prediction," and it is also connected to the issue of the "symmetry" or "asymmetry" between them. ${ }^{17}$

Seeking the historical roots, Francis Bacon's Novum Organum appears as a central piece on observation and experimentation. ${ }^{18}$ According to Urbach, "unlike most of his predecessors, who also pressed for a more empirical approach to the acquisition of knowledge, Bacon attempted to supply details and to set an example." 19 In his approach, (i) we need precise and varied observations, because a collection containing only similar instances would not serve; (ii) not all observations are of equal relevance in the inductive process; and (iii) some observations do not have a significant probative role but might be heuristically useful.

13 Chakravarty, E. F. and Fires, J. F., “Science as Experiment; Science as Observation,” p. 287.

14 Cf. Concato, J., Shah, N. and Horwitz, R. I., "Randomized, Controlled Trials, Observational Studies, and the Hierarchy of Research Designs," New England Journal of Medicine, v. 342, n. 25, (2000), pp. 1887-1892.

15 Cf. Worrall, J., "Why Randomize? Evidence and Ethics in Clinical Trials," in Gonzalez, W. J. and Alcolea, J. (eds.), Contemporary Perspectives in Philosophy and Methodology of Science, Netbiblo, A Coruña, 2006, pp. 65-82.

16 Hacking, I., Representing and Intervening, p. 167.

17 Cf. SAlmon, W. C., "On the Alleged Temporal Anisotropy of Explantion," in Earman, J., Janis, A., Massey, G. and Rescher, N. (eds.), Philosophical Problems of the Internal and External Worlds, University of Pittsburgh Press, Pittsburgh, 1993, pp. 229-248.

18 Cf. BAcon, F., Novum Organum sive iudicia vera de interpretatione naturae et regno hominis, J. Billium, London, 1620. Translated into English and edited by Peter Urbach and John Gibson: Novum Organum, Open Court, La Salle, IL, 1994.

19 Urbach, P., Francis Bacon's Philosophy of Science, Open Court, La Salle, IL, 1987, pp. 171-172. 
Bacon's views seems to be bi-directional in the relations between theory and experience, insofar as "he insisted that the inductive method will go back and forth, using observations to generate hypotheses and hypotheses to generate new observations," ${ }^{20}$ which includes correcting old ones. He also had special interest in phenomena not observed or not known before. In this regard, "the second book of the Novum Organum contains numerous predictions derived from theories which Bacon advanced, and which he intended should be checked in experiment." ${ }^{21}$

But long before that modern period, observation was a process known by authors such as Aristotle. He considered its systematic use in his biological studies on the parts of the animals. ${ }^{22}$ In this regard, it seems wrong to claim that "before positivism, observation is not central." 23 Moreover, to some extent, the link between science and empirical knowledge involves, in one way or another, the acceptance of a sort of observation in order to grasp the world as well as the use of observation to evaluate our theories. Even in the mathematical approaches to nature developed by key scientists, such as Galileo, observation has a relevant role in testing theories (and later in his career he included the methodological role of experiments as well). ${ }^{24}$

At least since modern times, history of science shows a general tendency to consider "observation" as conceptually different from "experiment." Sometimes this distinction is implicit rather than explicit. Blaise Pascal — according to William Shea - was in favor the experimental method, "meaning the active questioning of nature under conditions defined by the experimenter rather than the mere observation of the phenomena that spontaneously present themselves." 25 Later, in the nineteenth century, William Herschel - the discoverer of Uranus - establishes a clear distinction between both concepts in A Preliminary Discourse on the Study of Natural Philosophy. ${ }^{26}$ Observation is rather passive: it is a matter of noticing facts as they occur; there is no attempt to influence the frequency of their occurrence. Meanwhile, experimentation is active: it is a matter of putting in action causes and agents over what they have control, which includes varying the possible combination and noting what effects takes place. ${ }^{27}$

Through the positivism of the 19th century and the different conceptions in the 20th century connected with the primacy of empirical knowledge (such as logical positivism, logical empiricism, the "received view," ${ }^{28}$ Michael Dummett's anti-realism, ${ }^{29}$ Bas Van Fraassen's

\footnotetext{
20 Urbach, P., Francis Bacon's Philosophy of Science, p. 155.

21 Francis Bacon's Philosophy of Science, p. 156.

22 Cf. Aristotle, On the Parts of Animals, translated with an Introduction and Commentary by James G. Lennox, Clarendon Press, Oxford, 2001, p. 123.

23 Hacking, I., Representing and Intervening, p. 168.

24 Cf. SHeA, W. R., Galileo's Intellectual Revolution: Middle Period, 1610-1632, Science History Publications, New York, 1977. On Galileo's views on experiments, see several papels published in Machamer, P. (ed.), The Cambridge Companion to Galileo, Cambridge University Press, Cambridge, 1998, pp. 38, 45, 67-71, 149, 155, 234, 239 , and 402.

25 SHEA, W. R., Designing Experiments and Games of Change. The Unconventional Science of Blaise Pascal, Science History Publications, Canton, MA, 2003.

26 Cf. Herschel, J. F. W., A Preliminary Discourse on the Study of Natural Philosophy, Longman, London, 1830; reprinted by The University of Chicago Press, Chicago, 1987.

27 Cf. Bogen, J., "Experiment and Observation," in Machamer, P. and Silberstein, M. (eds.), The Blackwell Guide to the Philosophy of Science, p. 129.

28 Cf. Ayer, A. J. (ed.), Logical Positivism, Free Press, N. York, 1959, pp. 14, 18, 20-21, 109, 147-153, 155, 160-161, 215-216, 220, 228, 230-231, 233, 236, ...; and Suppe, F., "The Search for Philosophic Understanding of Scientific Theories," in Suppe, F. (ed.), The Structure of Scientific Theories, University of Illinois Press, Urbana, 1974, (2nd ed. 1977), pp. 1-241.

29 Cf. Gonzalez, W. J., "El realismo y sus variedades: El debate actual sobre las bases filosóficas de la Ciencia," in Carreras, A. (ed.), Conocimiento, Ciencia y Realidad, SIUZ-Ediciones Mira, Zaragoza, 1993, pp. 11-58; especially, pp. 33-34 and 54; and GonZalEZ, W. J., "Semántica anti-realista: Intuicionismo matemático y concepto de verdad," Theoria, v. 12-13, (1990), pp. 149-170.
} 
"constructive empiricism," ${ }^{30}$ etc.), the interest in observation is central. Thus, notions such as "verification," "verifiability," "confirmation," ... are all —in one way or another - related to observation of nature (and occasionally to observation of social events). Commonly, these approaches associate observation to empirical statements (protocol sentences/Protokollsätze, etc.), frequently understood as a sort of foundation for theoretical statements.

Within the mainstream line on observation between 1920s and 1960s (logical positivism, logical empiricism, the received view), observation was commonly an epistemological attitude that was more passive than active, even though this kind of relation to phenomena might be depicted many times as subjective representation rather than objective knowledge. Frequently, the link of observation and linguistic views led to a rather intersubjective approach. A sophiscated version on this issue within the then mainstream line is in Carl Gustav Hempel, who distinguishes between "observable characteristic," "observation predicate," and "observation sentence." 31

For Hempel, an observable characteristic is a property or characteristic of physical objects that, under suitable circumstances, may be ascertained through direct observation. "Thus, the terms 'green,' 'soft,' 'liquid,' 'longer than,' designate observable characteristics, while 'bivalent,' 'radioactive,' 'better electric conductor', and 'introvert' do not. Terms that designate observable characteristics will be called observation predicates. Finally, by an observation statement we shall understand any sentence which - correctly or incorrectlyasserts of one or more specifically named objects that they have, or that they lack, some specific observable characteristic." 32

Ernst Nagel was aware of some of the problems related to observation. He thought of "observation expressions" that refer to things, properties, relations, processes, etc. He recognized that "the distinction between observation expressions and other descriptive ones is admittedly vague, especially since different degrees of stringency may be used in different contexts in deciding what matters are to count as observable ones." ${ }^{33}$ Nevertheless he thought that the distinction was unavoidable in scientific inquiry and everyday practice. The problem of the characterization of "non-observable" was also an issue of serious concern. ${ }^{34}$

Meanwhile, in his alternative view to the epistemological empiricist perspective on observation, Karl Popper connects it with "perception" and suggests an interpretation of observation in the light of a scientific theory. ${ }^{35}$ In The Logic of Scientific Discovery he is particularly interested in the problem of the empirical basis. In this context, he maintains that

30 Cf. Van Fraassen, B. C., "Theory Construction and Experiment: An Empiricist View," Proceedings of the Philosophy of Science Association, v. 2, (1980), pp. 663-677; Van FraAsen, B. C., The Scientific Image, Clarendon Press, Oxford, 1980; Van Fraassen, B. C., Quantum Mechanics: An Empiricist View, Oxford University Press, Oxford, 1991; and Van FraAssen, B. C., Scientific Representation: Paradoxes of Perspective, Oxford University Press, Oxford, 2008.

31 Cf. Hempel, C. G., "Problems and Changes in the Empiricist Criterion of Meaning," Revue Internationale de Philosophie, v. 4 (1950), pp. 41-63; reprinted as Hempel, C. G., "The Empiricist Criterion of Meaning," in Ayer, A. J. (ed.), Logical Positivism, pp. 108-129.

32 Hempel, C. G., “The Empiricist Criterion of Meaning," in Ayer, A. J. (ed.), Logical Positivism, pp. 109-110.

33 Nagel, E., The Structure of Science, Harcourt, Brace and World, New York, 1961, p. 350.

34 Sir Peter Strawson, a moderate empiricist, recognizes that the sphere of human knowledge can go beyond immediate experience: "it would be perverse to deny that we have access, through observation and testimony, to data which demand explanation of the kind which we call 'historical' or 'social'," Strawson, P. F., "The Incoherence of Empiricism,” The Aristotelian Society, supp. vol. 66, (1992), pp. 142-143.

35 Cf. Popper, K. R., Logik der Forschung, Julius Springer Verlag, Vienna, 1935 (reprinted in J. C. B. Mohr -P. Siebeck-, Tubingen, 1994). English translation: The Logic of Scientific Discovery, Hutchinson, London, 1959 (rev. edic., Harper and Row, New York, 1968), pp. 75, 80, 131, 280, and 423. 
"observations and perceptions may be psychological, but observability is not." ${ }^{36} \mathrm{He}$ recognizes that he has "no intention of defining the term 'observable' or 'observable event' (...) I think that it should be introduced as an undefined term which becomes sufficiently precise in use: as a primitive concept whose use the epistemologist has to learn, much as he has to learn the use of the term 'symbol', or as the physicist has to learn the use of the term 'mass-point'." 37

Popper insisted on the critical rationalist idea of observation as an active process. Thus, in the 1960s he added a vision of an evolutionary approach to knowledge, where there is selection in knowing the reality. This starts from the very beginning: he accepted inborn dispositions oriented towards discovering regularities and rules. ${ }^{38}$ Hence, for him, observation was an active event in knowing our environment instead of being a passive procedure. He dismissed the naive observations, and he gave to theory an important role: for him, observation is guided by ideas - in an implicit or explicit search — rather than a human being impressed by sense data. Therefore, knowing was seen as a "logical" procedure rather than as a "psychological" event. ${ }^{39}$

\subsection{A Relevant Shift in the Natural Sciences: Observation and Theory-Laden}

During the second half of the last century - and also in this first decade of the present century-, two philosophical tendencies on observation have received special attention. On the one hand, there is an approach based on a linguistic vision of observation. Thus, instead of talking about "observation" as such, we should talk of "observation statements" insofar as the key is in the words used to report observation. On the other hand, there is an emphasis on the theory when we are doing an observation. In this case, "every observation statement is loaded with theory." 40

According to the first approach, there is an interweaving between semantic aspects and epistemological ones: the linguistic items seem to displace epistemological observations. Thus, in W. v. O. Quine's point of view, ${ }^{41}$ observation sentences should replace "observation." A sentence is then observational when there is an agreement between members of the speech community witnessing the same occasion. Those witnesses, who are fluent in the language used, will agree about what they observe on the spot. Quine is writing against all observations being theory-loaded, but what we get in him it is an intersubjective discourse rather than an actual observation about the properties of the real world.

Previously, for Nagel, observation statements are "a large class of singular statements that either formulate the observations on the subject matter regarded as the province of the science or describe the overt procedures instituted in conducting some actual inquiry within that discipline." " ${ }_{2}$ The emphasis is not then on the "sense data" understood as the exclusive objects of the "direct experience." This allows meaningful statements about the past ("There was a total eclipse of the sun in North Brazil on May 29, 1919') and even about the future (e.g.,

36 Popper, K. R., The Logic of Scientific Discovery, rev. edic., p. 103.

37 The Logic of Scientific Discovery, rev. edit., p. 103.

38 Popper, K. R., Unended Quest. An Intellectual Autobiography, Fontana/ Collins, London, 1976 (enlarged version, Routledge, London, 1992), p. 49.

39 Cf. Popper, K. R., "Epistemology Without a Knowing Subject," in Popper, K. R., Objective Knowledge. An Evolutionary Approach, Clarendon Press, Oxford, 1972 (5th ed. revised, 1979; reprinted in 1989), pp. 106-152.

40 Hacking, I., Representing and Intervening, p. 167.

41 Cf. Quine, W. v. O., The Roots of Reference, Open Court, La Salle, IL, 1974, pp. 36-39.

42 NAGEL, E., The Structure of Science, p. 348. 
on climate change). In this regard, "observation statements may on occasion formulate initial and boundary conditions for a theory or law; they may also be employed to confirm or refute theories and laws." 43

Following the second approach, we reach the discussions on "theory-laden" conception of observation as well as some issues on the problem of the undetermination of theory by data. Norwood Russell Hanson develops the idea of observation loaded with theory in his book Patterns of Discovery: An Inquiry into the Conceptual Foundations of Science. ${ }^{44} \mathrm{He}$ criticizes the view - still dominant at that moment - that scientific research relies on bedrock when it is based on an observational language. His thesis is that observation and facts include a "theory-ladenness." Thus, he dismisses the proposal of "foundational propositions" of science that are neutral regarding the theory used. The observation of the phenomenon is then shaped by the previous knowledge possessed by the observer.

Hanson utilizes some Gestalt perspectives for understanding scientific believes. This perceptual view seems quite interesting to Thomas Kuhn, ${ }^{45}$ who is in tune with Hanson's idea of analyzing the meaning of the scientific terms within a context. Furthermore, he received Hanson's influences on how to interpret historical aspects of science, such as Isaac Newton's legacy. ${ }^{46}$ Nevertheless, in his initial philosophical-methodological conception, Kuhn goes far beyond that with his characterization of the paradigms. Then, he develops a relativistic view on observation: "The proponents of competing paradigms practice their trade in different worlds... Practicing in different worlds, the two groups of scientists see different things when they look from the same point in the same direction." ${ }^{47}$

Imre Lakatos criticized the Kuhnian views to the extent that they were relativistic. But he was also in favor of a "theory-laden" conception. It appears when he was dealing with the problem of scientific prediction, because he defended a theoretical approach on prediction: "while theories may be said to be supported by evidence, 'predictions' are supported by theories." 48 This view is related to the problem of observation and "theory-ladenness," which received a lot of attention later on. In this regard, John Worrall considers that ultimately there must be sentences whose truth value we can decide upon independently of theory. (Otherwise, the whole scientific enterprise would be without foundation. $)^{49}$

Nicholas Rescher has proposed a more complex framework insofar as he thinks of two kinds of limitations on observations and theories. Putting it differently, there is an underdetermination of scientific theories and data. On the one hand, observational data undetermine theories because those observations are always finite, enumerable and episodic, while scientific theories are general and not finite (i.e., the generic feature go beyond a specific

\footnotetext{
43 The Structure of Science, p. 348.

44 Hanson, N. R., Patterns of Discovery: An Inquiry into the Conceptual Foundations of Science, Cambridge University Press, Cambridge, 1958.

45 Cf. Kunn, TH. S., The Structure of Scientific Revolutions, International Encyclopedia of Unified Science: Foundations of the Unity of Science, vol. 2, n. 2, The University of Chicago Press, Chicago, 1962; 2nd ed., 1970, p. 113.

46 Cf. Kunn, Tн. S., The Structure of Scientific Revolutions, 2nd ed., p. 78. Cf. Hanson, N. R., Patterns of Discovery, pp. 99-105.

47 Kunn, Tн. S., The Structure of Scientific Revolutions, 2nd ed., p. 150.

48 Lakatos, I., "Changes in the Problem of Inductive Logic," in Lakatos, I. (ed.), The Problem of Inductive Logic, North Holland, Amsterdam, 1968. Reprinted in Lakatos, I., Mathematics, Science and Epistemology. Philosophical Papers. vol. 2, edited by J. Worrall and G. Currie, Cambridge University Press, Cambridge, 1978, p. 192.

49 Cf. Worrall, J., Personal communication, March 2000.
} 
place and moment). On the other hand, theories undetermine observable facts, because scientific theories might be represented by several forms or different models. In this regard, there is a level of ambiguity open to new alternatives to explain or predict those realities that the theory intent to grasp. ${ }^{50}$

Following this complex framework on observation and theory, Rescher presents de facto a bi-directional relation of non-exhaustive content between scientific theory and observational data. a) There is an actual complexity in the real world, which is beyond the descriptive resources of scientific language. Then the observational data available do not exclude the possibility of an alternative theory for those phenomena. b) Any scientific theory that tries to describe and control empirical phenomena has a limit insofar as the reality itself exceeds the resources - explanatory and predictive - of the scientific theorization. Thus, he dismisses the idea of empirical science as "complete" or "perfect." 51

These aspects on observation and theory should not be read in a relativist way. They can be seen as a part of a human activity - the scientific enterprise - that is bounded in several ways: linguistic, cognitive, procedural, etc. They work on a reality, which is independent of our mind, which requires theories to explain and predict (basic science) or to predict and prescribe (applied science). ${ }^{52}$ Thus, an observation statement is related to something real: it "is the result of some sensory input interpreted, whether consciously or unconsciously, using a set of theories." 53

Certainly, theory-ladenness is not groundless: observations do require a conceptual framework given by theories, otherwise we cannot identify many elements of what we are observing. In addition to the conceptual framework, observations are frequently made through instruments (at least in advance natural science, both basic and applied). These instruments are supported by a theoretical construction. "In that case, theories of the instrument are part of the set of theories used to interpret the sensory input." 54 These theories are made according to our capacities and cognitive structure as human beings.

\subsection{The Social Sciences: From the Acceptance of Observation to the Problem of Experimentation}

Recurrently, the philosophical reflection on observation -and, above all, on experimentation - has been focused on the natural sciences, in general, and on physics, in particular. Then the methodological scrutiny has paid great attention to case-studies. ${ }^{55}$ Because of this tradition - and due to the relevance of the problems posed by the methods in the social

50 Cf. Rescher, N., Razón y valores en la Era cientifico-tecnológica, Paidós, Barcelona, 1999; chapter 1, pp. 51-59; especially, pp. 52-54. See also Rescher, N., A System of Pragmatic Idealism. Vol. I: Human Knowledge in Idealistic Perspective, Princeton University Press, Princeton, 1992; Rescher, N., Reason and Reality: Realism and Idealism in Pragmatic Perspective, Rowman and Littlefield, Lanham, MD, 2005; and JACQUETTE, D. (ed.), Reason, Method, and Value: A Reader on the Philosophy of Nicholas Rescher, Ontos Verlag, Frankfurt, 2009.

51 Cf. Rescher, N., Razón y valores en la Era científico-tecnológica, pp. 51-59.

52 On the case of applied social sciences, cf. Gonzalez, W. J., "Prediction and Prescription in Economics: A Philosophical and Methodological Approach", Theoria, v. 13, n. 32, (1998), pp. 321-345.

53 Gillies, D. A., Philosophy of Science in the Twentieth Century. Four Central Themes, B. Blackwell, Oxford, 1993, p. 146.

54 Gillies, D. A., Philosophy of Science in the Twentieth Century. Four Central Themes, p. 146.

55 Among the "classical examples" of the studies of experiments in natural sciences, cf. Harré, R., Great Scientific Experiments. 20 Experiments that Changed our View of the World, Phaidon, Oxford, 1981. In recent times, a particular relevant case can be seen in CHANG, H., Inventing Temperature, Oxford University Press, Oxford, 2004. 
sciences, especially in recent decades - ${ }^{56}$ the emphasis will be here on the analysis of the sciences that research social and human undertakings. In this regard, what seems remarkable is the methodological change in the social sciences - mainly in economics - from the acceptance of observation to the discussion of the problem of experimentation in them. This has involved the consideration of the existence and limits of experiments in the social milieu.

Since the beginning of the social sciences (history, economics, sociology, psychology, philology, etc.), observation has been accepted as a methodological tool for research. For several centuries, controlled observations have been commonly accepted as a valid procedure to test and evaluate scientific statements in the social sciences. Meanwhile the role of experiments in the social sciences has received a wary attitude for a long time. ${ }^{57}$ Even more, from time to time, the existence of experiments as a methodological procedure in social affairs has been openly questioned or has even been explicitly neglected. ${ }^{58}$ The challenge is in the origin, because it comes from the methodological starting point, which is the possibility itself of "experiments" in this realm of social phenomena.

To be sure, questioning the role of experiments in the social sciences has a long tradition. This attitude is connected to the insistence on the ontological difference with phenomena studied by natural sciences, due to the singularity attributed to human events (such as a historical fact, a psychological character, an economic decision, etc.). Consequently, it comes the acceptance of a clear methodological gap - a dichotomy - between the natural sciences and the social sciences, which is the topic of the Erklären-Verstehen controversy. In this methodological controversy, "explanation"-"understanding," which has changed several times from the original version to more recent presentations, the main critics of experimentation in the social sciences are the supporters of a strong version of Verstehen. ${ }^{59}$

In recent times, this questioning of the experiments in the social sciences can be seen in the case of economics. Thus, Tony Lawson dealt few years ago with the problem of "how social scientific research can proceed in the absence of real possibilities of experimental control." ${ }^{60} \mathrm{He}$ assumes the existence of controlled observations in economics while rejecting the actual possibility of experiments in this realm: "despite the lack of opportunities for controlled experimentation in the social sciences I remain optimistic about the social scientific prospects." ${ }^{1}$

Currently there is a dominant new stance on this issue, due to the current changes in the concepts of "observation" and "experimentation." In addition, there exists a genuine progress in the social sciences. De facto, the wary attitude - sometimes a skeptic view- on the role of experiments in the social sciences has changed progressively. The acceptance of the possibility

\footnotetext{
56 In some cases, such as economics, the methodological debate on empirical support seems particularly intense, cf. ReIss, J., Error in Economics. Towards a More Evidence-based Methodology, Routledge, London, 2008.

57 The analysis in this section works upon Gonzalez, W. J., "The Role of Experiments in the Social Sciences: The Case of Economics," in KuIPERs, T. (ed.), General Philosophy of Science: Focal Issues, pp. 275-277 and 282-283.

58 In the case of economics, this can be seen in Samuelson, P. and Nordhaus, W. D., Economics, 12th edition, McGraw-Hill, N. York, 1983, p. 8. Usually, the critics of experiments in the social sciences are thinking of laboratory experimentation.

59 Cf. Gonzalez, W. J., "From Erklären-Verstehen to Prediction-Understanding: The Methodological Framework in Economics," in Sintonen, M., Ylikoski, P. and Miller, K. (eds.), Realism in Action: Essays in the Philosophy of Social Sciences, Kluwer, Dordrecht, 2003, pp. 33-50; especially, pp. 34-37.

60 Lawson, T., Economics and Reality, Routledge, London, 1997, p. 199. See the chapter entitled "Economic Science without Experimentation," pp. 199-226.

61 Lawson, T., Economics and Reality, p. 199.
} 
of experiments in social sciences is now explicit in economics. This includes a neat attempt to explore new aspects of experimentation in human affairs.

Two kinds of approaches have driven the new situation in the social sciences: (i) the idea of science as "human activity" — instead of a mere "content" - has led new philosophicalmethodological analyses in science, in general, and in social sciences, in particular; ${ }^{62}$ and (ii) the existence of an important amount of contributions in different fields within the realm of the scientific research on human affairs (economics, psychology, etc.).

An important boost came from the analysis of experiments made on the basis of a new consideration of the scientific practice, which is also connected to the development of a social concern about science. ${ }^{63}$ In this regard, the philosophy and methodology of science has changed the previous emphasis on the contents of science (semantic, logical, epistemological, ...) in favor of science as a human activity developed in a social environment (i.e., the laboratories as institutions where scientists intervene).

This perspective involves a direct reflection on the practice of laboratory experimentation. ${ }^{64}$ Furthermore, the scope of the philosophical and methodological analysis has been enlarged with new light shed on applied science and on applications of science, because "it is important to distinguish applied science from the applications of science. The former is a part of knowledge production, the latter is concerned with the use of scientific knowledge and methods for the solving of practical problems of action (e.g., in engineering of business), where a scientist may play the role of a consult[ant]." ${ }^{65}$

Another important boost came from the scientific research on social events, which has widened the original fields in the last decades, mainly in the sciences of psychology and economics. Consequently, some new territories have been embraced with these methodological procedures. A well-known case is "experimental economics." ${ }_{66}$ In 2002, this branch of economics received public recognition in the form of a Nobel Prize awarded to Vernon Smith ${ }^{67}$ and Daniel Kahneman. ${ }^{68}$

62 This focus has its roots in the "historical turn" developed in the sixties and seventies. It sheds more light than the previous emphasis on science as knowledge and opens up more clearly the nexus with the social setting.

63 Cf. Gonzalez, W. J., "Novelty and Continuity in Philosophy and Methodology of Science," in GonZalez, W. J. and Alcolea, J. (eds.), Contemporary Perspectives in Philosophy and Methodology of Science, pp. 1-28; especially, pp. 9-11.

64 Cf. Galison, P., How Experiments End, The University of Chicago Press, Chicago, 1987. On the philosophical and methodological analysis of experiments (characteristics, kinds, ...), cf. Gooding, D., Pinch, T. and Schaffer, S. (eds.), The Uses of Experiment, Cambridge University Press, Cambridge, 1989; and RADDER, H. (ed.), The Philosophy of Scientific Experimentation, University of Pittsburgh Press, Pittsburgh, 2003.

65 Niniluoto, I., "The Aim and Structure of Applied Research," Erkenntnis, v. 38, (1993), p. 9. To be sure, the epistemic and practical aspects can also be seen in the context of the social setting, cf. Kitcher, PH., Science, Truth, and Democracy, Oxford University Press, Oxford, 2001, especially, pp. 85-91.

66 See the papers published in Roтн, A. E. (ed.), Laboratory Experimentation in Economics-Six Points of View, Cambridge University Press, Cambridge, 1987; Hey, J. D. and LoomEs, G. (eds.), Recent Developments in Experimental Economics, E. Elgar, Aldershot, 1993, vol. I and II; and KAgel, J. H. and Roth, A. E. (eds.), Handbook of Experimental Economics, Princeton University Press, Princeton, NJ, 1995.

67 It should be pointed out that V. Smith has shown an explicit interest in the philosophy of science, cf. SMith, V. L., McCabe, K. A. and Rassenti, S. J., "Lakatos and Experimental Economics," in Marchi, N. DE and Blaug, M. (eds.), Appraising Economic Theories, E. Elgar, Aldershot, 1991, pp. 197-227.

68 D. Kahneman's interests are in connecting psychology and economics, cf. Kahneman, D., Knetsch, J. L. and Thaler, R. H., "Experimental Tests of the Endowment Effect and the Coase Theorem," Journal of Political Economy, v. 98, n. 6, (1990), pp. 1325-1348, reprinted in Hey, J. D. and Loomes, G. (eds.), Recent Developments in Experimental Economics, vol. I, pp. 206-229. 
It happens that since the mid-1980s experimental economics is a scientific branch that has been the focus of increasing attention. It may be considered a recent realm, insofar as - according to a key expert - "experimental economics as a field of economic research did not emerge before the 1960s." ${ }^{69}$ The connection with mathematical methods is clear insofar as several Nobel laureates that have focused on game theory, such as John F. Nash ${ }^{70}$ and Reinhard Selten, ${ }^{71}$ have also developed economic experiments.

Both in the dominant views in philosophy of science and in the recent developments within social sciences there is a new situation. The methodological framework is now different from the successive versions of the alternatives between Erklären and Verstehen. Thus, instead of a clear dichotomy between natural sciences and social sciences, the present methodological perspectives stress the existence of experiments as a common ground between the natural sciences and the social sciences.

Nevertheless, both kinds of sciences also have differences in their activities, and therefore in their aims, processes and results. These new analyses of philosophy and methodology of the social sciences work with an enlarged vision of experiment. Moreover, the sciences themselves use de facto new views on experiments. The changes indicate that the notion of "experiment" is not restricted anymore to a material sort of human intervention based on a previous design. There are other possibilities. But sometimes the analysis goes further than one might expect, because there are conceptions of experimentation that go beyond that point of novelty, and accept the possibility of "natural experiments."

Even now "natural experiments" might be considered as an uncommon view, insofar as it seems close to the traditional idea of "observation" (i.e., noting the ongoing events) and avoids the feature of human intervention, which has been characteristic of the notion of experiment. It is a route taken by James Woodward: "the important and philosophically neglected category of 'natural experiments' typically involves the occurrence of processes in nature that have the characteristics of an intervention but do not involve human action or at least are not brought about by deliberate human design." 72

However, this idea is not completely new, because a somewhat similar idea is found in an econometrician, and several decades earlier: in 1944. It appears in Trygve Haavelmo, when he writes that "the stream of experiments that Nature is steadily turning out from her own enormous laboratory." 73 To some extent, "natural experiments" is an understandable expression for some phenomena in nature, such as hurricanes (e.g., the case of 'Katrina,' which hit New Orleans

\footnotetext{
69 Selten, R., "In Search of a Better Understanding of Economic Behavior," in HeErtje, A. (ed.), Makers of Modern Economics, Harverster Wheatsheaf, London, 1993, p. 118.

70 J. F. Nash was involved in experimentation in the social sciences at least since 1952, when a conference on "The Design of Experiments in Decision Processes" was held in Santa Monica, CA, cf. Roтн, A., "Introduction to Experimental Economics," in Kagel, J. H. and Roth, A. (eds.), Handbook of Experimental Economics, pp. 10-11. Thereafter Nash wrote an important paper: Kalisch, G. K., Milnor, J. W., Nash, J. F. and Nering, E. D., "Some Experimental n-Person Games," in Thrall, R. M., Coombs, C. H., and Davis, R. L. (eds.), Decision Processes, J. Wiley, N. York, 1954, pp. 301-327.

71 Cf. Gonzalez, W. J., "Rationality in Experimental Economics: An Analysis of R. Selten's Approach," in GaLAVotti, M. C. (ed.), Observation and Experiment in the Natural and the Social Sciences, pp. 71-83.

72 Woodward, J., "Experimentation, Causal Inference, and Intrumental Realism," in Radder, H. (ed.), The Philosophy of Scientific Experimentation, p. 94.

73 Cf. Hanivelmo, T., "The Probability Approach in Econometrics," supplement to Econometrica, v. 12, (1944), pp. 14-15.
} 
in August 2005. It was accurately predicted in the previous days, and those predictions were tested during the hurricane.) Even so, some features commonly associated with the concept of experiment, such as "repeatability" or "reproducibility," can hardly be found in a singular case.

Still, when the presence of experimentation in the social sciences is discussed, one of the debates is the possibility of accepting a "passive experimentation," a facet that accompanies the idea of "natural experiments." This has been proposed in econometrics, because "unlike the lab experiment, the 'experiments' of econometrics are not actual ones but statistical ones, conducted on 'passive data': data thrown up by the uncontrolled experiments of Nature (the Economy), incorporating all the multiple variation of the interacting factors with which the econometrician must deal as best he/she can ex post." ${ }^{74}$

Haavelmo's methodological position seems to be assumed in this proposal, insofar as econometrics cannot control circumstances directly, and this position accepts that we are passive observers of a stream of experiments that Nature (here, the economic world) is turning out from within, like an enormous laboratory. ${ }^{75}$ Accordingly, the case of econometric experimentations relies on the possibility of having "natural experiments" and their statistical control: "the econometric model is first built and estimated as a passive experiment and then is used as if it were a mathematical model." "76

Subsequent to the acceptance of a "passive experimentation," which accompanies the idea of "natural experiments" (and, therefore, a material environment), there is a vision of econometrics as a case of experimentation between the laboratory experiments made in the context of the material world and the thought experiments related to a non-material. If this case is compared with the methods of laboratory experimentation, then the statistical methods of the econometric experiment - a passive one - might be interpreted as providing a substitute kind of control at the level of measurement process. In this regard, it is an indirect control of the circumstances, and it requires statistical assumptions that are sometimes unrealistic.

Obviously, the problem is then the application to the real economic world of those results obtained through this indirect way of econometric research and, specifically, what are the possible causal inferences regarding economic activity. Not only is causality a debatable question in this context, but so also are the characteristics of reproducibility and replicability of econometric experiments (understood as "passive experiments") in comparison with laboratory experimentation (or "active experiments").

When the econometricians follow a traditional notion of "experiment," then they disregard the possibility of experimentation in econometrics: "econometric theory is the study of the properties of data generation processes, techniques for analysing data, methods of estimating numerical magnitudes of parameters with unknown values and procedures for testing economic hypotheses; it plays an analogous role in primarily non-experimental disciplines to that of statistical theory in inexact experimental sciences (...). As expressed by [H. O. A.] Wold (1969) $\left[{ }^{77}\right]$, 'Econometrics is seen as a vehicle for fundamental innovations

\footnotetext{
74 Boumans, M. and Morgan, M. S., "Ceteris paribus Conditions: Materiality and the Application of Economic Theories," Journal of Economic Methodology, v. 8, n. 1, (2001), p. 18.

75 That is the idea of T. Haavelmo, cf. Morgan, M. S., The History of Econometric Ideas, Cambridge University Press, Cambridge, 1990, p. 245.

76 Boumans, M. and Morgan, M. S., "Ceteris paribus Conditions: Materiality and the Application of Economic Theories," p. 19.

77 Wold, H. O. A., “Econometrics as Pioneering in Non-Experimental Model Building,” Econometrica, v. 37, (1969), pp. 369-381.
} 
in scientific method, above all, in the development of operative forecasting procedures in non-experimental situations'. In Wold's view, econometrics needs to overcome both a lack of experimentation (which precludes reproducible knowledge) and the passivity of forecasts based on extrapolative methods." 78

\subsection{From "Traditional” Sciences to the Sciences of Artificial}

Contemporary contributions to empirical sciences include some novelties that are related to observation: (i) there are new methodological perspectives on "traditional" sciences (natural and social); and (ii) there has been the development of new scientific realms, such as the sciences of the artificial. This second movement should not be seen as a linear process, insofar as the advance of the new sciences of design, such as artificial intelligence, also has had a repercussion on the first perspective (the research in "traditional" empirical sciences, both basic and applied). In this regard, the sciences of the artificial have played an instrumental role for the growth of natural and social sciences.

Concerning the new methodological perspectives on well-known disciplines, we can note the progress through the use of a careful observation of empirical reality. A good example is the "behavioral economics," which has challenged the mainstream of economics (usually labeled as "neoclassical economics") based on observation of the conduct of the economic agents in the decision-making. Thus, the bounded rationality view replaces the economic perspective of rationality based on the maximization of subjective expected utilities. Furthermore, bounded rationality offers a general approach to rationality in the social science different from very influential conceptions. ${ }^{79}$

De facto, the observational methodology of economic behavior has shown in this case epistemological consequences: a theory of rationality related to the decision-making. Moreover, it was an interdisciplinary project, because the psychologists working on the "cognitive approach" have also gathered evidence in this regard. While Simon was developing specific economic applications of bounded rationality, "numerous researchers in both psychology and economics have also been busy applying the (jointly produced) theory to economic phenomena (for example, Bromiley, Kahneman and Tversky, Vernon Smith, Selten, Gingerich, and so on)." 80

Neuroeconomics is another example of recent methodological perspectives in the "traditional" science of economics. It focuses on how the human brain interacts with its environment —institutional and social — to make economic decisions. "Neuroeconomics begins with the observation that humans face many opportunity cost tradeoffs in their daily activities. These tradeoffs are modelled as a strategy that maps information sets into actions." ${ }^{81}$ Following

\footnotetext{
78 Hendry, D. F., Econometrics: Alchemy or Science? Essays in Econometric Methodology, new edition, Oxford University Press, Oxford, 2000 (1st edition, 1993), p. 13.

79 Cf. Simon, H. A., "Bounded Rationality in Social Science: Today and Tomorrow," Mind and Society, v. 1, n. 1, (2000), pp. 25-39. On this topic see also SELTEN, R., "Bounded Rationality," Journal of Institutional and Theoretical Economics, v. 146, n. 4, (1990), pp. 649-658; Selten, R., "Features of Experimentally Observed Bounded Rationality," European Economic Review, v. 42, (1998), pp. 413-436; and Selten, R., "What is Bounded Rationality?," in Gigerenzer, G. and Selten, R. (eds.), Bounded Rationality: The Adaptive Toolbox, The MIT Press, Cambridge, MA, 2001, pp. 13-36.

80 Simon, H. A., "On Simulating Simon: His Monomania, and Its Sources in Bounded Rationality," Studies in History and Philosophy of Science, v. 32, n. 3, (2001), p. 502.

81 McCabe, K. A., "Neuroeconomics and the Economic Sciences," Economics and Philosophy, v. 24, n. 3, (2008), p. 349.
} 
Simons's ideas, the strategies of bounded rationality "are likely to be encoded in the brain as a mapping from partitions of circumstances into partitions of actions together with inferential (...) and reasoning mechanisms (...) that modify and scale these partitions." 82 The understanding of those encodings and mechanisms requires both strategies models and experimental methods of economics as well as computational models and experimental methods of cognitive sciences.

Methodologically, research in neuroscience starts with observation but soon ends up in experiment. This study of human decision-making combines procedures based on natural sciences (the neuronal research) and the processes of a social science - economics-, which is also a science of the artificial in the case of the rationality of the decision-making. ${ }^{83}$ This mixture of several components raises questions of several kinds, due to the combination of the levels of analysis at stake and the difficulties of interpretation of the results.

Prima facie, it seems that a better understanding of how the brain operates should help us to understand more about observational economic behavior. But the critics point out that they do not learn much about the broad substantive issues of economics reviewed. Thus, the "concern is whether neuroeconomists have added insight to already-confused experimental designs, or just covered up those confusions and promoted one plausible story over another." ${ }^{4}$ They are afraid of getting the latter and of adding neural correlates to pre-confused designs, which does not help in order to improve scientific research.

A propos of the development of new scientific realms, we have several subjects directly related to observation, the topic here considered. Some of the cognitive sciences developed within the sciences of the artificial fit in this group, such as artificial intelligence. They are purposeful insofar as they are sciences of design: they seek some aims and prepare some processes in order to get certain results. Within the cognitive realm, these subjects have analyzed aspects connected to observation, such as "simulation" and "computer simulation." Herbert Simon was interested in all these aspects. Initially, instead of the expression "artificial intelligence," he preferred phrases like "complex information processing" and "simulation of cognitive processes." 85

Evidently, not all simulations are "computer simulations." In addition to the indispensable use of the computers, there is a difference in the utilization of the "analog simulations," such as using fluids to simulate the case of the dynamics of black holes. ${ }^{86}$ Simulation is connected to the idea of resemblance of reality. In this regard, Simon stated that "we now call the imitation 'simulation,' and we try to understand the imitated systems by testing the simulation in a variety of simulated, or imitated, environments." ${ }^{87}$ Meanwhile, he considered that computer simulation has a wider range of possibilities because it is more creative than simulation. For him, computer simulation is useful for the social sciences: it is "a tool for achieving a deeper understanding of human behavior." 88

\footnotetext{
82 McCABE, K. A., "Neuroeconomics and the Economic Sciences," p. 349.

83 Cf. Gonzalez, W. J., "Rationality and Prediction in the Sciences of the Artificial: Economics as a Design Science," in Galavotti, M. C., Scazzieri, R. and Suppes, P. (eds.), Reasoning, Rationality and Probability, pp. 165-186; especially, pp. 171-179.

84 Harrison, G. W., "Neuroeconomics: A Critical Reconsideration,” Economics and Philosophy, v. 24, n. 3, (2008), p. 339.

85 Cf. Simon, H., The Sciences of the Artificial, 3rd ed., p. 4.

86 Cf. Winsberg, E., “A Tale of Two Methods," Synthese, v. 169, (2009), p. 576.

87 Simon, H., The Sciences of the Artificial, 3rd ed., p. 13.

88 The Sciences of the Artificial, 3rd ed., p. 21.
} 
With the sciences of the artificial there is de facto an amplification of the possibilities for scientific research. In a strict sense, "the models built and manipulated in computer science (...) are not physical at all. Computer science is a science concerned with the study of computational process." ${ }^{89}$ The computational process is different from an electrical process or other empirical processes, insofar as it is studied in ways that ignore its physical nature. However, Simon conceived artificial intelligence as an empirical science, ${ }^{90}$ and he thought that it could be tested through methods of observation and experimentation.

Ontologically, the components of the artificial world are different from the events in nature or the social actions. In addition, the models used in artificial intelligence that present computer simulations are commonly inspired by abstract entities. ${ }^{91}$ Methodologically, artificial intelligence has two main options in this regard: a) to develop intelligent tasks without imitating the human mind, or b) to simulate the human case. Besides the acceptance of the first option, the mimesis is explicitly defended by Simon: "The claim for simulation of human thought is that brain and computer, using quite different machinery, can execute the same programs, thereby carrying out the same functions organized in the same way." ${ }^{92}$ Epistemologically, the programs that imitate human processes can enlarge human knowledge. ${ }^{93}$ They do things faster than bounded human mind and with a quite different size on storage of information.

Moreover, besides the contributions of the artificial intelligence, there are other angles of simulation in recent times. Some come from the cognitive sciences related to certain psychological aspects. In this case, simulation is associated to the attempt of grasping the mental states (thoughts, feelings, etc.) of others. There are two different ways actually considered: a mode that is theorizing on other minds based on the observed behavior of other people, whereas Alvin Goldman and Kelby Mason propose to predict the mental states by simulating them. In this cognitive use of the word "simulation," the link is with empathy, imagination and projection on other minds of what is in our mind.

Their basic idea here on simulation is "that in predicting the target's mental states, we try to simulate or reproduce in our minds the same state, or sequence of states, that they are in." 94 In this way, these authors maintain that "simulation can be considered a kind of empathy, if empathy is understood as feeling one's way into another's position by identifying with them, or imaginatively projecting oneself into their position. Alternatively, simulation can be understood as automatically matching or replicating another person's mental state, without any deliberate imagination or projection. Simulation also has conceptual ties to psychological research or perspective —and role-taking and egocentric attribution." 95 Thus, simulation is

\footnotetext{
89 Colburn, T., "Methodology of Computer Science," in Floridi, L. (ed.), The Blackwell Guide to the Philosophy of Computing and Information, Blackwell, Oxford, 2004, p. 318.

90 Cf. Simon, H. A., “Artificial Intelligence: An Empirical Science,” Artificial Intelligence, v. 77, n. 1, (1995), pp. 95-127.

91 Cf. Winsberg, E., “A Tale of Two Methods,” p. 578.

92 Simon, H. A., "Artificial Intelligence," in Kazdin, A. E. (ed.), American Psychological Association Encyclopedia of Psychology, vol. 1, Oxford University Press, N. York, 2000, p. 254.

93 Cf. Simon, H. A., "Machine as Mind," in Ford, K. M., Glymour, C. and Hayes, P. J. (eds.), Android Epistemology, AAAI/The MIT Press, Menlo Park, CA, 1995, p. 25.

94 Goldman, A. and Mason, K., "Simulation," in Thagard, P. (ed.), Philosophy of Psychology and Cognitive Science, Elsevier, Amsterdam, 2007, p. 267.

95 Goldman, A. and Mason, K., "Simulation," in Thagard, P. (ed.), Philosophy of Psychology and Cognitive Science, p. 272.
} 
understood sometimes as beyond a mere resemblance of a given reality to be seen as consistent "replication" - in the sense of coherent reproduction - of an observed phenomenon.

\subsection{Actual Observations and Simulations}

Actual observations look for a reliable representation of what is perceived. a) They include a perceptual component of a kind of entity that is already available, be it either a tangible reality or a virtual construction that might be perceived. b) This orientation towards an alter reality has an epistemological characteristic: the perception is made through a process of a careful attention to something present (which distinguishes an actual observation from something observable). c) Commonly, the observation can serve methodologically for as a starting point of research (for example, in an inductive or in abductive procedure) or it can perform the role of an ingredient in an evaluation, which is made by means of a control mechanism focused on some specific variables. d) Scientific observations have a patent aim: they seek to control phenomena in a systematic way.

Undoubtedly, a simulation is different from an actual observation insofar as simulation includes a creative facet that is basically either imitative or innovative. (i) A simulation might be a resemblance of something real, either present or past. This is the use as "imitation," which is initially pointed out in Simon's The Sciences of the Artificial. (ii) A simulation can also be more creative in order to innovate some possibilities regarding the future, which is a common task of "computer simulations." ${ }^{96}$ Sometimes this second case of simulation can be used as a sort of "thought experiment." The sciences of design include both uses, because the knowledge in designing benefits from imitations and innovations.

Clearly, both directions of simulation - the imitative and the innovative - have characteristics that differ from actual observations. In the first case, simulation is connected to observation in an analogical way, insofar as the imitative simulation has a part that comes from an observed reality and a part that goes beyond what might be observed in the real world (e.g., a computer that imitates events of the human brain). This "analogical" path is used to explore the unknown based upon what is already known: it is not simple "imitation" because heuristically it has a purpose. In the second case, the connection to actual observations is weaker than in the previous situation. When the aim is innovative, the simulation - commonly made by computer - can go far beyond the observed processes and might reach new possibilities (e.g., in the artificial world by means of the digital simulation). In the innovative case, the target is not a mere resemblance of real world but rather an enlargement of human possibilities.

Though there is a caveat: the need for the distinction between "simulations" and "replications." It is a corollary of the criticisms made by John Searle to some approaches in artificial intelligence (those that take for granted that similarities in performance indicate similarities in intelligence) ${ }^{97}$ According to this distinction, some systems simulate one another when they generate the same outputs from the same inputs, whereas some systems replicate

\footnotetext{
96 "Computer simulations involve no direct physical interaction between the machine they are run on and the physical systems they use to investigate," Barberousse, A., Franceschelli, S. and Imbert, C., "Computer Simulations as Experiments," Synthese, v. 169, (2009), p. 557.

97 The critique is known as "the Chinese Room," and it is used as a counterexample of the Turing test, cf. SEARLE, J. R., "Minds, Brains, and Programs," The Behavioral and Brain Sciences, v. 3, (1980), pp. 417-424; reprinted in BoDEN, M. (ed.), The Philosophy of Artificial Intelligence, Oxford University Press, Oxford, 1990, pp. 67-88.

There are several versions of "the Chinese Room", cf. Copeland, B. J. and Proudfoot, D., "Artificial Intelligence: History, Foundations, and Philosophical Issues," in Thagard, P. (ed.), Philosophy of Psychology and Cognitive Science, Elsevier, Amsterdam, 2007, pp. 429-482; especially, pp. 456-463.
} 
one another when they generate the same outputs from the same inputs by means of the same processes or procedures. ${ }^{98}$

Some cognitivist seems to use "replicate" in a broader sense of "reproducing." Apparently, this is the case when they claim that "simulation does not require that the simulated state replicate the target state exactly (...) All that is required is that one try to replicate, in some significant aspects, the state. When this point is kept in mind, it becomes highly plausible that at least some forms of imaginery are simulations." 99 But to imitate the visual imagining of someone is not identical to "replicating" those forms of imagery. In addition, it should be taken into account that "simulations involve complex inferences as they move from theory to data, and they certainly generate new knowledge." 100

If we look for a broader philosophical-methodological framework for observation and the role of simulation, then some features can be pointed out. 1) Fallibilism is a feature of empirical knowledge, which also has repercussions for observation. In this regard, every source of primary data is in principle fallible. Observation is liable to correction in the light of reflection or subsequent experience. ${ }^{101}$ 2) Observational processes can be used for testing, but the sphere of human knowledge can certainly go beyond immediate experience. Observation and testimony might be used for historical knowledge and as a basis for future knowledge. ${ }^{102}$ 3) Empirical knowledge utilized in science (natural, social or artificial) cannot exclude non-observational concepts. Thus, the simulation of human behavior should take into account that an explanation (or an understanding) of persons requires concepts such as "intentional human action" (there is not a purely physical "behavior"). ${ }^{103} 4$ ) In the social sciences and in the sciences of design, human knowledge needs intensional concepts: "any attempt to purify the theory of knowledge of all intensional notions is doomed to failure." ${ }^{104}$ In this regard, the simulations as well as the computer simulations require intentionality to grasp the observational human behavior or to make new designs intelligible.

\section{The Concept(s) of "EXPeriment" uSED IN OUR Times}

Looking at the characterization of "experiment" there are several aspects to be considered in order to present this notion in our times. They are related to central factors of science. ${ }^{105}$ I) Semantically, experiment originally has a sense and a reference that differs from

98 Cf. Fetzer, J. H., “The Philosophy of AI and its Critique," in Floridi, L. (ed.), The Blackwell Guide to the Philosophy of Computing and Information, p. 122.

99 Goldman, A. and Mason, K., "Simulation," in Thagard, P. (ed.), Philosophy of Psychology and Cognitive Science, p. 272.

100 Winsberg, E., "A Tale of Two Methods," pp. 578-579.

101 Cf. Strawson, P. F., “The Incoherence of Empiricism,” pp. 140-141.

102 Most of the work done on testimony is from a justificationist perspective in which philosophers try to justify our reliance on testimony in some way. The Popperian view is different, cf. Diller, A., "Testimony from a Popperian Perspective," Philosophy of the Social Sciences, v. 38, n. 4, (2008), pp. 419-456.

103 Cf. "The Incoherence of Empiricism," p. 142. On the distinction between "action" and "behavior," cf. GonZALEZ, W. J., "Rationality in Economics and Scientific Predictions: A Critical Reconstruction of Bounded Rationality and its Role in Economic Predictions," Poznan Studies in the Philosophy of the Sciences and the Humanities, v. 61, (1997), pp. 205-232; especially, section 3.

104 Strawson, P. F., "The Incoherence of Empiricism,” p. 143.

105 On the central factors of science, cf. GonZalez, W. J., "The Philosophical Approach to Science, Technology and Society," in Gonzalez, W. J. (ed.), Science, Technology and Society: A Philosophical Perspective, Netbiblo, A Coruña, 2005, section 2, pp. 10-11. 
"observation." II) Logically, experiment is a structural ingredient of science that is different from "theory" and, in principle, it is also distinct from "model." III) Epistemologically, experiment is related to a kind of reliable knowledge acquired through a non-immediate process. IV) Methodologically, experiment is connected to a process that should be repeatable and, thus, it is commonly associated to reproducibility and repeatability. V) Ontologically, experiment is related to the idea of otherness (i.e., something — real or not- which is used to test). VI) Axiologically, the experiments can be oriented through different values according to distinct aims (i.e., experiments in basic science could be diverse from experiments in applied science). VII) Ethically, there is concern about some kinds of experiments, mainly when they are related to certain human affairs (either to people as individuals or to society as a whole). ${ }^{106}$

These aspects of a general characterization of "experiment" can be developed in different ways, in accordance with the kind of variables to be controlled and the type of procedure used to control them. This variety accounts for the diversity of experiments - in the material and non-material spheres - that may be accepted in the enlarged vision of "experiment." But, as it has been pointed out, many authors have questioned in the past — or even now - the possibility of experiments in the social sciences, including economics, if they are understood according to the traditional notion. In this view, "experiment" is a human intervention suggested by a theory, and there are some variables to be controlled in a repeatable material context. ${ }^{107}$

Although "experiment" and "control experiment" could be considered almost synonymous, sometimes a distinction is used between experiments at large and specifically controlled experiments. Thus, particularly in the social sciences, the idea is to distinguish between a broad sense of "experiment" and the strict sense of this notion. In the first case, the reference is commonly the society as a whole or a large-group, whereas in the second case there is a small or medium size group that could be controlled in a clearer way. This emphasizes the difference between large-scale groups, where a controlled experiment seems hard or is even virtually impossible, and small or medium size groups (communities, micro-societies, ...) where the actual process of control is possible. Following this distinction, large-scale groups rely on comparative analysis ("field research") based on observation, and the level of control is then usually inferior to the controlled experiments.

Reliable knowledge and repeatability are then emphasized, even though the possibility in science of having the "same" experiment raises some questions. ${ }^{108}$ When we are working on controlled experiment, the aim is "to reproduce the conditions required by a theory and then to manipulate the relevant variables in order to make measurements of a particular scientific parameter or to test the theory. When the data are not collected under controlled conditions or are not from repeatable experiments, then the relationship between the data and the theoretical laws is likely to be neither direct nor clear-cut. This problem was not

\footnotetext{
106 Cf. Gonzalez, W. J., "The Role of Experiments in the Social Sciences: The Case of Economics,” p. 278. The present section on experiments in science works upon the contents of "The Role of Experiments in the Social Sciences: The Case of Economics," pp. 278-282 and 284-286. There is here an updated and enlarged vision of the points discussed in the previous paper.

107 "In experiments we actively interfere with the material world. In one way or another, experimentation involves the material realization of an experimental process (the object[s] of study, the apparatus, and their interaction)," RADDER, H., "Towards a More Developed Philosophy of Scientific Experimentation," in RadDER, H. (ed.), The Philosophy of Scientific Experimentation, p. 4.

108 Cf. Urbach, P., “On the Utility of Repeating the 'Same' Experiment," American Journal of Physics, v. 59, (1981), pp. 151-162.
} 
(...) unique to economics; it arose in other social sciences and in natural sciences where controlled experiments were not possible." 109

\subsection{The Traditional Approach to the Laboratory Experiments}

Traditionally, laboratory experiment was the exemplar for the concept of "experiment." 110 This was the case in modern science as well as for many contemporary scientists. Even now laboratory experiment is often considered as the archetype of what an experiment is in science. Thus, besides the human intervention and the repeatability for getting a reliable knowledge, a laboratory experiment is performed in a material setting. Moreover, as the history of science frequently describes, there is a specific scenery where the experiment can be carefully conducted. In laboratory experimentation, the relevant factors are commonly epistemological and methodological. The environment should be under the control of the experimenter.

Consequently, "this distinguishes laboratory experiments from 'field' experiments, in which relatively few aspects of the environment can be controlled, and in which only limited access to most of the economic agents may be available. It is precisely this control of the environment, and access to the agents (sufficient to observe and measure attributes that are not controlled) that give laboratory experiments their power." ${ }^{111}$ If the research is on economics, the basic level is in the study of some economic processes (bargaining, exchange relations, etc.) and the search is for stable or structural features of economic behavior associated to them (while bargaining, in auctions, etc.).

Much of what is done in laboratory experiments is thought of as addressing problems that are not studied in other ways. In this regard, it seems that aims, processes and results of laboratory experiments in economics relate to aspects of economic phenomena that, in principle, are not investigated by other kinds of economic research. Methodologically, the experiment starts with a design, which should consider the parameters and the procedures to be used. Then it follows the "experiment" itself: the process of control of the behavior of trial subjects in laboratory situations that are of interest for economic science. Thereafter, the experiment can get some results (e.g., of auction markets or of bargaining) that should be compared with other experiments made.

Insofar as it is a human activity, laboratory experimentation can be designed with different aims in mind. When the case is economics, the design can be originally oriented towards economic theory (thinking of descriptive economics) or to applied economics (mainly towards policy guidance). Thus, (i) an experiment can be designed to test some particular formal hypothesis (e.g., on the preference reversal phenomenon), looking for observations that may support a relatively general conclusion; and (ii) the experiment may be designed to resemble some complex reality (such as a market), where the observations which are made seek to be relevant for a particular issue of policy (e.g., on market stability). ${ }^{112}$ The experiments seek "to collect data on interesting phenomena and important institutions, in the hope of detecting unanticipated regularities." 113

\footnotetext{
109 Morgan, M. S., The History of Econometric Ideas, p. 9.

110 In the seventeenth century "experiment was officially declared to be the royal road to knowledge," HaCKING, I., Representing and Intervening, p. 149.

111 Rотн, A., "Laboratory Experimentation in Economics: A Methodological Overview," The Economic Journal, v. 98, (1988), p. 974 (reprinted in Hey, J. D. and Loomes, G. (eds.), Recent Developments in Experimental Economics, vol. I, p. 3).

112 Cf. Roth, A., "Laboratory Experimentation in Economics, and its Relation to Economic Theory," in Rescher, N. (ed.), Scientific Inquiry in Philosophical Perspective, University Press of America, Lanham, 1987, p. 160.

113 Rотн, A., "Laboratory Experimentation in Economics," Economics and Philosophy, v. 2, (1986), p. 246.
} 
As regard the process itself of laboratory experimentation, there are several options, which are connected with the aims of the research proposed. In the case of economics the process is often used to test a theory from the point of view of prediction. Even so, there are several possibilities, according to the objectives of the methodological task of testing: "In the case of experiments that test the predictions of existing theories, it will be useful to distinguish between those that test a theory in its specified domain of application, and those that explore its applicability outside the strict confines of this domain. We will also want to know whether the results of these experiments falsify the predictions of the theory or support it" "114 (i.e., evidence that fails to falsify the theory).

Thereafter, we get the results of laboratory experimentation. The variety of aims and the diversity of processes can lead us to a large range of results. They are normally interpreted in the context of the specific aims of each experiment carried out in the laboratory. These results obtained by means of laboratory experimentation in economics can show us that well-established conceptions, such as the assumption that economic agents move according to an expected utility function, have serious problems with empirical data. ${ }^{115}$ Moreover, it happens that a substantial body of empirical work offers a number of systematic ways in which individual preferences of economic agents fail to exhibit the regularities represented by an expected utility function. ${ }^{116}$

Hitherto, laboratory experiments in economics have been criticized in several ways. 1) In laboratory situations trial subjects are commonly university students (and above all economics students), which may offer different results from other kinds of economic agents. Hence, the experimental design should consider a broad class of agents in order to avoid biases. 2) The process itself of laboratory experiment is clearly artificial. Thus, its completeness regarding the whole real picture as well as its resemblance with the actual economic world may be questioned (and, consequently, the reliability of the economic knowledge which is obtained). 3) The results obtained through experiments in economics might be of limited applicability. De facto, even some important economic experimentalists are cautious when they expect that "patient experimental research will yield new behavioral theories of limited application" 117 (i.e., comprehensive theories can appear only in the long run).

\subsection{The Enlarged Vision of the Diversity of Experiments}

Up to now, the existence has been pointed out of a difference between a traditional conception of experiment - mainly, the "laboratory experiment"- and the enlarged vision of experiment, which involves a diversity of experiments. This distinction is made here based above all on "internal" criteria (especially, epistemological and methodological) rather than on the basis of "external" factors (social, cultural, institutional, economic, etc.). The difference between the traditional conception and the enlarged vision is both historical and structural. In addition, the dynamics is also different, as can be seen in the aims, processes and results.

\footnotetext{
114 Rотн, A., "Laboratory Experimentation in Economics, and its Relation to Economic Theory," p. 148.

115 I recall several conversations with Herbert Simon (in 1993, 1996 and 1999) where he insisted on the idea of gathering empirical data through experiments in order to refute well-established assumptions of the mainstream of economics. The set of publications in this regard are pointed out in GonZalez, W. J., "Herbert A. Simon: Filósofo de la Ciencia y economista (1916-2001)," in Gonzalez, W. J. (ed.), Racionalidad, historicidad y predicción en Herbert A. Simon, Netbiblo, A Coruña, 2003, pp. 7-63; especially, pp. 29-63.

116 Cf. Roтн, A., "Laboratory Experimentation in Economics," p. 248.

117 Selten, R., "Emergence and Future of Experimental Economics," p. 68.
} 
From the point of view of experiment as a human activity, the diversity in the kinds of experiments in science comes principally from different aims, processes and results. They are related to an environment, which has a role for testing. Thus, among the components of the traditional view on experiment there are several elements related to a given situation. As happens in the laboratory experimentation, they are commonly connected to a material setting (which frequently includes very specific instruments):

a) An experiment is an intervention in the world. Thus it includes a manipulation of some aspects of reality to identify certain items, such as causal mechanisms, or to test a theory about those phenomena. b) Experiments are thought of as a way of grasping certain relatively enduring structures of the world. Then, they involve mechanisms that act in a characteristic manner when there are some specific circumstances. c) The experiment is an active interference in order to enable or trigger the mechanism that is under investigation. But it could also be used to prevent any countervailing mechanism. ${ }^{118}$

Repeatedly, the critics of experiments in the social sciences maintain that all of them - and specifically economics - are not in a position to isolate, control and manipulate social (in this case, economic) conditions. ${ }^{119}$ Thus, Lawson asserts that "it is certainly reasonable to doubt that controlled experimentation will ever be particularly meaningful in economics due to the impractically of manipulating social structures and mechanisms in order to more clearly identify them." ${ }^{120}$ What he acknowledges is the existence of social regularities (or "partial regularities") that come from the reproducibility of certain mechanisms of a social world that is open, dynamic and changing.

Nonetheless, there is a full branch of economics - experimental economics - that focuses on laboratory experimentation and then assumes the traditional notion of "experiment," which includes a purposeful intervention. Furthermore, "economic experiments in the laboratory aspire to the standards of laboratory experiments found elsewhere in science. Depending on the experiment in question, economists may focus their design aim on the control of the environment in which the experiment takes place, on controlling the communication between subjects, on setting limits on the range of input behaviour allowed and the variation of output responses and so forth." ${ }^{121}$ This economics in the laboratory raises new methodological issues, such as those on completeness of economic theory. ${ }^{122}$

However, besides laboratory experimentation, it has also been common in the past to use "thought experiment" (Gedanken experiment) as a heuristic tool. This was the case both in natural sciences (physics, ${ }^{123}$ biology, etc.) and in social sciences (history, ${ }^{124}$ economics, political

118 Cf. Lawson, T., Economics and Reality, pp. 202-203.

119 On Trygve Haavelmo and this issue, cf. Morgan, M. S., The History of Econometric Ideas, pp. 245-246.

120 Lawson, T., Economics and Reality, pp. 203-204.

121 Boumans, M. and Morgan, M. S., "Ceteris paribus Conditions: Materiality and the Application of Economic Theories,” p. 17. Cf. Friedman, D. and Sunder, S. (eds.), Experimental Methods: A Primer for Economists, Cambridge University Press, Cambridge, 1994.

122 Cf. Guala, F., "Economics in the Lab: Completeness vs. Testability," Journal of Economic Methodology, v. 12, n. 2, (2005), pp. 185-196. See also Guala, F., The Methodology of Experimental Economics, Cambridge University Press, Cambridge, 2005.

123 It is well-known that the Gedanken experiment was used by Albert Einstein, which can be seen in his paper on relativity: EINSTEIN, A., "Zur Elektrodynamik bewegter Körper," Annalen der Physik, v. 17, (1905), pp. 891-921.

Thomas Kuhn has emphasized this fact as well as that "thought experiments have more than once played a critically important role in the development of physical science," Kunn, TH. S., "A Function for Thought Experiments," in CoHEN, I. B. and Taton, R. (eds.), Mélanges Alexandre Koyré, v. 2: L'aventure de la science, Hermann, Paris, 1964, p. 307. Reprinted in Kunn, TH. S., The Essential Tension. Selected Studies in Scientific Tradition and Change, The University of Chicago Press, Chicago, 1977, p. 240.

124 Cf. Reiss, J., "Counterfactuals, Thought Experiments, and Singular Causal Analysis in History," Philosophy of Science, v. 79, n. 5, (2009), pp. 712-723. 
science, etc.). Certainly, whether being related to a counterfactual or not, there is no material intervention in a thought experiment: it could be seen as an imaginative narrative to test a specific theory or a hypothesis. In effect, the thought experiment considers hypothetical or imaginary test conditions, where some particular instantiations of a real process - it maybe a causal one - that is identified by the theory, and the thought experiment displays a concrete state of affairs that needs an explanation as the end result of the process that is being studied. ${ }^{125}$

Nowadays, in the empirical sciences (natural, social and artificial), we work de facto with an enlarged notion of "experiment." Nevertheless, the experiments with material intervention - laboratory experiments - are still the archetype among them. Furthermore, there is a discussion on the acceptability as experiment of some of them. Commonly, the criteria used to distinguish the diversity of experiments are features related to epistemological, methodological and ontological elements. They are mainly the following: 1) the range of controllability of the variables; 2) the level of materiality of the processes employed in the research; and 3) the sphere - real, ideal, a hybrid, ... - to be analyzed. Again, among these sciences, economics is an interesting case study to see the differences between laboratory experimentation and other experiments, because it is a science that uses a variety of experiments.

1) As for epistemological issue of the range of controllability of the variables, there are at least three possibilities: (i) direct control; (ii) indirect control (or statistical control); and (iii) assumption in model. Concerning the kind of control of variables, the last one is the most complex, especially if we follow the analysis made by Alan Musgrave on the Milton Friedman approach on the lack of realism of the assumptions. For Friedman, an economic theory should not be criticized for containing "unreal assumptions," because he considers that the important point in order to evaluate a theory is successful predictions. ${ }^{126}$ Musgrave thinks instead that Friedman's dictum (the so-called "F-twist") is false according to three types of assumption: negligibility assumptions, domain assumptions, and heuristic assumptions. ${ }^{127}$

2) Regarding the methodological issue of the level of materiality of the processes employed in the research, there are relevant aspects. ${ }^{128}$ The differences are noticeable, and in the case of economics regarding several possibilities: a) the empirical domain of laboratory experimentation (when a material realm is under direct control); b) the "passive experimentation" of the econometric case (when a material realm receives an indirect control or statistical control); c) the simulations and, above all, computer simulations (when the quasi-material realm or the pseudomaterial sphere depends on the assumptions in the model); and d) the thought experiments (when the non-material realm depends upon the assumptions in the model). ${ }^{129}$

\footnotetext{
125 Cf. Lennox, J. G., “Thought Experiments in Evolutionary Biology Today,” in GonZalez, W. J. (ed.), Evolutionism: Present Approaches, pp. 109-120.

126 Cf. Friedman, M., "The Methodology of Positive Economics," in Friedman, M., Essays in Positive Economics, University of Chicago Press, Chicago, 1953 (6th repr., 1969), pp. 3-43.

127 Cf. Musgrave, A., “Unreal Assumptions' in Economic Theory: The F-Twist Untwisted,” Kyklos, v. 34, n. 3, (1981), pp. 377-387. "Negligibility assumptions state that some factor has a negligible effect upon the phenomenon under investigation. Domain assumptions specify the domain of applicability of the theory. Heuristic assumptions are a means of simplifying the logical development of the theory," Musgrave, A., "'Unreal Assumptions' in Economic Theory: The F-Twist Untwisted," p. 386.

128 There is an ongoing discussion on the relevance of materiality for experiments and computer simulations. Cf. PARKer, W. S., "Does Matter Really Matter? Computer Simulations, Experiments, and Materiality," Synthese, v. 169, (2009), pp. 483-496.

129 Cf. Boumans, M. and Morgan, M. S., "Ceteris paribus Conditions: Materiality and the Application of Economic Theories," p. 20. Although the origin of this distinction is in the analysis of ceteris paribus conditions, I think that the main differences which are drawn in this differentiation have a rather general consideration for the methodological process.
} 
3) Both the range of controllability of the variables and the level of materiality of the processes employed in the research are related to the ontological issue of the sphere - real, ideal, a hybrid, ... - to be analyzed. Unquestionably the sphere to be analyzed by experiments varies from real (a direct tangible object of study or statistical data based on previous evidence) to clearly ideal (a thought experiment or a purely mathematical model). Between these poles - real, although artificially constructed, ${ }^{130}$ and ideal - there is the realm of hybrids (e.g., in simulations) which could be quasi-material or pseudo-material.

If these epistemological, methodological and ontological distinctions on the kind of experiments are basically correct, then there are clear differences in the methodological processes to test scientific predictions (which is a central issue in the methodology of economics). Experimental economics - mainly in the case of Selten - is well aware of this question, and he tries to emphasize the laboratory experimentation as the most reliable kind of experimentation to deal with the predictive success (and, therefore, with the notions of accuracy and precision). ${ }^{131}$ Nevertheless, he also points out limits: "experimental research (...) cannot replace field research. The institutional environment of economic participants must be investigated in the real world. Once we are sure we have modeled such an environment, however, we can and must test or redevelop the behavioral assumptions of theory in the laboratory." 132

\subsection{From the "External Validity" to the "External View" on Experiments}

Once the analysis of experiments in "internal" terms (epistemological, methodological, etc.) has been made, the focus can move to the "external" consideration. In this regard, two different directions on experiments can be pointed out here. The first one affects what, from a methodological perspective, is originally extrinsic or peripheral to the actual realm of research that is being experimented on. Meanwhile, the second view emphasizes the contextual aspects around the experiment, seeing them as relevant or even crucial for understanding the experimentation made. However, although the "external validity" is discussed in the former case, the primacy is still in the philosophical-methodological approach, whereas in the latter option the predominance is in the contextual values (social, cultural, economic, political, ecological, etc.).

Philosophically, "internal validity"-“external validity" of experiments is an issue connected with the discussion on artificiality in experiments, especially in the social sciences. ${ }^{133}$ The question is then if the stylized form of experimental institutions allows us to make legitimate conclusions about the "real world." In other words, to what extent is it valid for the complex real world of economic affairs that have been obtained in a limited setting of a laboratory? Thus, the problem of artificiality for experiments — which can have various goals - is associated to the external validity of experiments out of the sample, when there is a search of empirical regularities for testing a theory.

\footnotetext{
130 "In the laboratory an artificial economic reality is constructed, for example a market or an auction," SELTEN, R., "Emergence and Future of Experimental Economics," in Galavotti, M. C. (ed.), Observation and Experiment in the Natural and the Social Sciences, p. 63.

131 On the distinction between "accuracy" and "precision," cf. GonZalez, W. J., "The Role of Experiments in the Social Sciences: The Case of Economics," section 5, pp. 295-298.

132 Selten, R., "Emergence and Future of Experimental Economics," p. 68.

133 Cf. Schram, A., "Artificiality: The Tension Between Internal and External Validity in Economic Experiments," Journal of Economic Methodology, v. 12, n. 2, (2005), pp. 225-237.
} 
Initially, this discussion about the internal versus external validity was particularly important in psychology, in the search for the factors relevant to the validity of experiments in social settings. ${ }^{134}$ The approach is methodological: "an internally valid design will yield results that are robust and replicable. External validity refers to the possibility of generalizing the conclusions to situations that prompted the research." ${ }^{135}$ Meanwhile, in the option that prefers external values (social, cultural, economic, political, etc.), the issue is the possibility that those external values can determine the support of evidence in favor of a theory, ${ }^{136}$ instead of those contextual values being merely elements to understand the acceptance of a scientific theory. Hence, the discussion includes the role of the environment of the laboratory when the scientists perform an experiment. Frequently, this view has philosophical roots in Kuhnian approaches on contextual influences, but it reaches positions far beyond Kuhn's actual conception. ${ }^{137}$

Behind the first case is the issue of the range in the results of the scientific research. In this regard, "an experiment result is internally valid when the experimenter is genuinely learning about the actual system he or she is manipulating - when, that is, the system is not being unduly disturbed by outside interferences. An experimental result is externally valid when the information learned about the system being manipulated is relevantly probative about the class of systems that are of interest to the experimenters." ${ }^{138}$ This methodological distinction is sensible, and it affects what is "extrinsic" or "peripheral" to the phenomena actually studied - it might be an expansion - rather than genuinely "external" or "contextual" to the experiment made. Moreover, in this distinction the activity itself of experimenting still has more weight than the environment around it.

Quite different is the external view of the experiment due to the "social turn" in philosophy and methodology of science, which is behind the second case. According to the social turn, there is a new panorama in the philosophical approach to science and technology. Instead of the previous ideas on scientific findings and technological contributions, which were frequently thought of as context-independent (mainly, as epistemic contents and instruments to control our surroundings), the new "external" vision presents a different picture where contextual values (cultural, political, economic, ecological etc.) have a central role in science and technology. Moreover, the landscape is then an interdisciplinary endeavor, where the empirical studies on science and technology commonly accompany the philosophical reflections on scientific activity and technological doing. ${ }^{139}$

Ethnomethodology is one of the consequences of the "social turn," in general, and of external characterization of experiments by Latour ${ }^{140}$ and Woolgar, ${ }^{141}$ in particular. An

134 Cf. CAmpbell, D., "Factors Relevant to the Validity of Experiments in Social Settings," Psychological Bulletin, v. 54, (1957), pp. 297-312.

135 Cf. Schram, A., "Artificiality: The Tension Between Internal and External Validity in Economic Experiments,” p. 226.

136 Cf. Bogen, J., "Experiment and Observation,” p. 136.

137 Cf. Gonzalez, W. J., "Las revoluciones científicas y la evolución de Thomas S. Kuhn,” in Gonzalez, W. J. (ed.), Análisis de Thomas Kuhn: Las revoluciones cientificas, Trotta, Madrid, 2004, pp. 15-103; especially, pp. 36-43.

138 Winsberg, E., "A Tale of Two Methods," p. 579, note 6.

139 Cf. Gonzalez, W. J., "The Philosophical Approach to Science, Technology and Society," in Gonzalez, W. J. (ed.), Science, Technology and Society: A Philosophical Perspective, pp. 3-49.

140 See note 7 in this chapter. Cf. Latour, B., The Pasteurisation of France, Harvard University Press, Cambridge, MA, 1988; and Latour, B., We have Never been Modern, Harvester, Brighton, 1993 (translated by C. Porter.)

141 Cf. Woolgar, S., "Critique and Criticism: Two Readings of Ethnomethodology," Social Studies of Science, v. 11, n. 4, (1981), pp. 504-514; Woolgar, S., Science: The Very Idea, Tavistock, London, 1988; and Woolgar, S. (ed.), Knowledge and Reflexivity: New Frontiers in the Sociology of Knowledge, Sage, London, 1988; and LyNCH, M. and Woolgar, S. (eds.), Representation in Scientific Practice, The MIT Press, Cambridge, 1990. 
ethnomethodological study of the activity developed in the laboratory is a kind of social anthropology of science. The social interests (or even the political attitudes), the negotiation among the agents that develop the experiments, the sort of leadership presented, etc., are then analyzed through the methodology of "participant observation." According to Barry Barnes, Latour "wanted to erode the distinction between 'scientific' and 'political' actions, and began to speak as if all the actions of the scientists without exception were political." ${ }^{142}$

Barnes criticizes that, in analyzing the performance in the laboratories, Latour went on to describe the actions of the scientists "using metaphors draw on from aggressively individualistic forms of economic and political theory, offering a picture of science as a form of Hobbesian war. And it was a still greater surprise when this particular aspect of Latour's work was acclaimed with enthusiasm by sociologists, for whom a tradition going back to Durkheim had decisively demonstrated (or so I had imagined) that not even war of the usual kind could be possibly Hobbesian war." ${ }^{143}$ Thus, this social anthropological view - the ethnomethodological approach — is seen as built upon an "unsociological sociology," insofar as the focus is only in individual agency in normalized societies.

Undeniable is the existence of a social dimension of experimentation, because it is a human activity in a social setting and there are important institutional elements around it. Obviously, there are some non-epistemic factors that can influence laboratory experimentation or other forms of experiment. But it seems that Latour goes very far with his "model of political contests in which competitors employ rhetorical and other devices to gain and consolidate support." 144 The key for understanding laboratory experimentation should not be in "external" factors, such as those on the intersubjective dynamics of potential friends and foes. In this regard, when Kuhn insisted on the historical character of scientific experimentation within a social setting of scientific communities, he still gave more relevance to the internal constituents of science than to the external factors of the scientific environment. ${ }^{145}$ This justifies putting more attention on "internal" factors of the analysis on experiments, considering its different kinds.

\subsection{From Simulations to Computer Simulations in the Context of Experiments}

Until now, the philosophical-methodological reflections on simulations - and, above all, computer simulations - have been focused on their status in the relations between theory and experiment. Basically, there are three main approaches available in the literature: the first view considers that the simulations are a new kind of experiment, different from the laboratory experiment; the second perspective emphasizes that simulations have a singular status between experiments and theories; and the third option sees the computer simulation as an advance in quantitative terms (i.e., in the speed in the use of information), but does not deem them as an actual change for methodology of science. ${ }^{146}$

\footnotetext{
142 Barnes, B., "Thomas Kuhn and the Problem of Social Order in Science," in Nickles, Th. (ed.), Thomas Kuhn, Cambridge University Press, Cambridge, 2003, pp. 134-135.

143 Barnes, B., "Thomas Kuhn and the Problem of Social Order in Science," p. 135.

144 Bogen, J., "Experiment and Observation,” pp. 136-137.

145 Kuhn is very explicit in his criticisms to the Edinburgh School, one of the key lines in the social turn: "I am among those who have found the claims of the strong program absurd: an example of deconstruction gone mad," KuHN, TH. S., The Road Since Structure. Philosophical Essays, 1970-1993, with an Autobiographical Interview, edited by James Conant and John Haugeland, The University of Chicago Press, Chicago, 2000, p. 110.

146 Cf. Lenhard, J., "Computer Simulation: The Cooperation between Experimenting and Modeling," Philosophy of Science, v. 74, n. 2, (2007), pp. 176-194; especially, p. 188.
} 
After dismissing the third option, due to the methodological improvements introduced by the computer simulations in the three realms of science (natural, social, and artificial), the first view and the second perspective should be taken into account: they are somehow complementary. The reason is this: computer simulations are methodologically a hybrid, insofar as they combine mathematical models with experimental ones. Increasingly, simulations —and, above all, computer simulations ${ }^{147}$ — have been characterized as "experiments" or, what is more appropriate, as "virtual experiments." 148

Simulations, in general, and computer simulations, in particular, can be used for quite different purposes, including those related to social life, such as traffic flow and automobile driver behavior under different sorts of conditions. From a descriptive perspective, computer simulation in these cases can be readily compared with real world behavior, and from a prescriptive point of view, road management can improve if the rules take into account that information and are well designed. Thus, they can be used in "descriptive models" of basic science (i.e., the simulation as an approximation to facts of the world) as well as in "prescriptive models" of applied science (i.e., the patterns of solution of concrete problems based on a simulation).

Considered as "virtual experiments," computer simulations seem to fit the characterization of economics quite well: "This kind of experimental activity has a comparatively long tradition in economics, predating the computer simulations of the type so familiar nowadays. It consists of statistical or mathematical models that are simulated, or 'run', to generate output series with the aim of mimicking observed economic time-series data. For example, one of the most commonly available, but least understood, sets of economic data is that of stock market prices." 149

Epistemologically, in this sphere of research there is an interweaving between the character of social science and the dimension of science of the artificial (understood as "science of design"). ${ }^{150}$ This is the case of economics. ${ }^{151}$ (i) Simulations can use empirical information of the world that might be obtained through observations or even through experiments (including laboratory experiments); and (ii) simulations include a nonmaterial component that seeks to resemble aspects of the world (a virtual representation oriented towards an imitative representation of the real world). The point of this hybrid of social and artificial seems to me clear: to produce new outcomes in areas where other kinds of research seem infeasible or defective.

Frequently it happens that simulations, in general, and computer simulations, in particular, can play a similar role to "thought experiments." ${ }^{152}$ In fact, they can contribute to establishing

\footnotetext{
147 On this issue, cf. Keller, E. F., "Models, Simulation, and 'Computer Experiments'," in Radder, H. (ed.), The Philosophy of Scientific Experimentation, pp. 198-215.

148 Mary Morgan distinguishes between "virtual experiments" and "virtually experiments:" "Virtual experiments (entirely nonmaterial in object of study and in intervention but which may involve the mimicking of observations) and virtually experiments (almost a material experiment by virtue of the virtually material object of input)," MoRGAN, M. S., "Experiments without Material Intervention. Models Experiments, Virtual Experiments, and Virtually Experiments," in RAdDER, H. (ed.), The Philosophy of Scientific Experimentation, p. 233. An analysis of her views is in PARKER, W. S., "Does Matter Really Matter? Computer Simulations, Experiments, and Materiality," pp. 484 and 488-496.

149 Morgan, M. S., "Experiments without Material Intervention. Models Experiments, Virtual Experiments, and Virtually Experiments," pp. 224-225.

150 Cf. Gonzalez, W. J., "Configuración de las Ciencias de Diseño como Ciencias de lo Artificial: Papel de la Inteligencia Artificial y de la racionalidad limitada," in Gonzalez, W. J. (ed.), Las Ciencias de Diseño: Racionalidad limitada, predicción y prescripción, pp. 41-69.

151 Cf. Gonzalez, W. J., "Rationality and Prediction in the Sciences of the Artificial: Economics as a Design Science," pp. 165-186, especially, pp. 171-179.

152 This was accepted by Simon in The Sciences of the Artificial, 3rd ed., p. 14.
} 
some phenomena as possible and to ruling out certain events as impossible. However, not all thought experiments are eo ipso simulations: they can follow different heuristic routes. But both share the consideration of nonmaterial elements (or, at least, non tangible components). Methodologically, simulations can be considered "virtual experiments" - they work on a hypothetical data stream in the case of economics - and ontologically they rely on constructed items within the artificial world (e.g., a resemblance of the real economic processes).

Unfortunately, as Alvin Roth has pointed out, there is a "distressing tendency to confuse computer simulations, and the kind of investigations one can do with them, with experiments involving the observation of real people in controlled environments. (...) Computer simulations are useful for creating and exploring theoretical models, while experiments are useful for observing behaviour." 153 De facto, there is a difference between the conclusions obtained by computer simulation (e.g., in the case of computer "tournaments" reported by R. Axelrod ${ }^{154}$ ) and the experimental results obtained in the laboratory (e.g., in the experiments made by R. Selten and R. Stoecker ${ }^{155}$ ).

Roth emphasizes the difference in results, which is connected to the difference between computer simulations and actual experiments: "While the computer simulations which produce this result were conducted with an element of experimental flavour that is missing from conventional computer simulations (in that tournament entries were solicited from others), experiments with human subjects introduce a certain amount of open-ended complexity in the form of human behavior, that is absent from a tournament in which individuals are represented by short (or even moderately long) computer programs." 156

Again, the emphasis is on "experiment" as something artificial (with a purposeful target) that depends on a human intervention in order to control a phenomenon or a set of phenomena. But this cannot be the whole picture: there is — in my judgment — an increasing complexity in the study of the economic events, according to the scale of phenomena. Thus, the investigation may start from computer simulations - a clear artificial situation-. Then, through the analysis of controlled experiments in the laboratory environment —a less artificial case than the previous one - the research of economic phenomena may reach the following steps of complexity: the real economic activity of human beings. ${ }^{157}$ In this search the historical character of economics plays a relevant role, ${ }^{158}$ which should be considered as well.

153 Rотн, A., "Laboratory Experimentation in Economics: A Methodological Overview," p. 1000 (reprinted in Hey, J. D. and Loomes, G. (eds.), Recent Developments in Experimental Economics, vol. I, p. 29). A different view is this: "computer simulation studies are material experiments in a straightforward sense," PARKER, W. S., "Does Matter Really Matter? Computer Simulations, Experiments, and Materiality," p. 483.

154 Cf. Axelrod, R., "Efective Choice in the Iterated Prisoner's Dilemma," Journal of Conflict Resolution, v. 24, (1980), pp. 3-25; Axelrod, R., "More Efective Choice in the Prisoner's Dilemma," Journal of Conflict Resolution, v. 24, (1980), pp. 379-403; and Axelrod, R., The Evolution of Cooperation, Basic Books, N. York, 1984.

155 Cf. Selten, R. and Stoecker, R., "End Behavior in Sequences of Finite Prisoner's Dilemma Supergames: A Learning Theory Approach," Journal of Economic Behavior and Organization, v. 7, n. 1, (1986), pp. 47-70.

156 Rотн, A., "Laboratory Experimentation in Economics: A Methodological Overview," p. 1001.

157 On complexity as a typical feature or economic reality, cf. GonZALEz, W. J., "Economic Prediction and Human Activity. An Analysis of Prediction in Economics from Action Theory," Epistemologia, v. 17, (1994), p. 262; and Gonzalez, W. J., "Complexity in Economics and Prediction: The Role of Parsimonious Factors," in Dieks, D., Gonzalez, W. J., Hartman, S., Stadler, F., Uebel, Th. and Weber, M. (eds.), Explanation, Prediction, and Confirmation: New Trends and Old Ones Reconsidered, Springer, Dordrecht, forthcoming.

158 Alvin Roth sees a parallel between evolutionary biology and economics because they deal "largely with historical data," Rотн, A., "Laboratory Experimentation in Economics," p. 270. 


\subsection{Two Cases Reconsidered: Thought Experiments and Mathematical Models}

Thought experiments were used a long time before computer experiments were available. ${ }^{159}$ However, computer experiments and thought experiments have some epistemological, methodological and ontological similarities insofar as virtual and mental are different from empirical. In this way, computer simulations can be "experimental" in an analogous sense in which a thought experiment is "experimental." ${ }^{160}$ Important differences lie in the process employed: the computer permits the working out of the implications of a hypothesis more rapidly than the speed of thought, and can also consider a large range of variables at a specific moment.

Originally thought experiments are a creative procedure related to a non-material domain but their aims, processes and results are oriented towards the real world. Thus, thought experiments are used to show the possibility and the impossibility of natural phenomena and social events as well as their limits in our world. Thought experiments belong to an ideal context when aims are designed, and while processing the information. But their results can be used for other kinds of experiments as well as for theoretical contributions. Moreover, they have been connected to computer experiments and to mathematical models, as can be seen in several sciences, such as economics.

Econometrics might be seen as offering a tertium quid between the experimentation made in the economic laboratory and the thought experiments. (i) An econometric model shares with laboratory experimentation the constructed character of the process and the artificial nature of the environment, even though in the laboratory there are real agents (and then there is a direct control of variables). Meanwhile in an econometric model there is a package of statistical data related to economic phenomena (and then the control of variables is indirect). (ii) An econometric model has no clear-cut relation to the circumstances of economic undertakings (above all when the model relies on a process of generating data), and the thought experiments work on a sphere of possibilities (and also impossibilities) rather than on an actual environment.

Unmistakably, there is a relevant methodological connection between thought experiments and mathematical models. Morgan has insisted on the link: "in the post-1950s period, economists have become avid users of mathematical models. (...) I suggested that their usage involved being able to trace through deductively the answers to 'what if' or 'let us assume' type questions about the economic world represented in the model $\left[{ }^{161}\right]$ (...) We can portray this modern use of mathematical models as extending economists' verbal thought experiments of earlier times that were limited by the capacity of the mind to follow the paths of more than two or three variables in a system. In characterizing such model usage in terms of (...) thought experiments, we can see how asking questions and exploring answers with mathematical models have allowed economists to think through in a consistent and logically deductive way how a large number of variables may interrelate and find the solutions to systems with a large number of units." 162

\footnotetext{
159 Thought experiments has also been used in philosophical approches, cf. Rescher, N., What if? Thought Experimentation in Philosophy, Transaction, N. Brunswick, 2005.

160 Cf. Keller, E. F., "Models, Simulation, and 'Computer Experiments',” p. 204.

161 Cf. Morgan, M. S., "Models, Stories and the Economic World," Journal of Economic Methodology, v. 8, (2001), pp. 361-384.

162 Morgan, M. S., "Experiments without Material Intervention. Models Experiments, Virtual Experiments, and Virtually Experiments," p. 218. See has developed other aspects on models and experiments in Morgan, M. S., "Model Experiments and Models in Experiments," in Magnani, L. and Nersessian, N. (eds.), Model-Based Reasoning: Science, Technology, Values, Kluwer, New York, 2002, pp. 41-58; and Morgan, M. S., "Experiments versus Models: New Phenomena, Inference, and Surprise," Journal of Economic Methodology, v. 12, n. 2, (2005), pp. 317-329.
} 
Mathematical model exploration works in basic science and in applied science. It can be related to questions on theories (such as economic theory) and issues connected to policy problems from the real world (such as applied economics). In the first case, the models can be used to develop the scientific theory (i.e., explanation and prediction), whereas in the second case they can perform a task to resolve concrete problems of the world (i.e., prediction and prescription). However, the utilization of mathematical models understood as experiments — similar to laboratory experiments - requires us to take into account some important differences.

Fundamentally the differences are three. First, how the experimental control is achieved in both cases is different, because the material world has limits on intervention (i.e., control and manipulation), while the mathematical models should always place care on the capacity of their assumptions to represent the world properly. Second, the production of experimental results is also different: in laboratory experimentation it is material (for the particular situation found in the experimental setup), whereas in the mathematical model experiments are based on the (deductive) reasoning power of mathematics to derive the results. Third, the range of potential inference is different as well: the case of the results of experiments made in the laboratory differs from those obtained by mathematical model experiments. ${ }^{163}$

\section{BiBLIOGRAPHY}

Above and beyond the task of giving the references of the publications used for this chapter, the present bibliography tries to offer relevant books and papers devoted to observation and experimentation in science, because this chapter has been thought of as a general framework of the ongoing discussions on this central topic of philosophy and methodology of science. Needless to say, the aim of this bibliography is not to be exhaustive but rather an orientation on publications to be taken into account in this regard. Some of the books pointed out here have a large number of references.

Achistein, P. and Hannaway, O. (eds.), Observation, Experiment, and Hypothesis in Modern Physical Science, The MIT Press, Cambridge, MA, 1985.

Anguera, M. T., Metodología de la observación en Ciencias Humanas, Cátedra, Madrid, 1978.

Anguera, M. T., “Observational Tipology," Quality and Quantity, v. 13, (1979), pp. 449-484.

Aristotle, On the Parts of Animals, translated with an Introduction and Commentary by James G. Lennox, Clarendon Press, Oxford, 2001.

Ayer, A. J. (ed.), Logical Positivism, Free Press, N. York, 1959.

Axelrod, R., "Effective Choice in the Iterated Prisoner's Dilemma," Journal of Conflict Resolution, v. 24, (1980), pp. 3-25.

Axelrod, R., "More Effective Choice in the Prisoner's Dilemma," Journal of Conflict Resolution, v. 24, (1980), pp. 379-403.

Axelrod, R., The Evolution of Cooperation, Basic Books, N. York, 1984.

Bacon, F., Novum Organum sive iudicia vera de interpretatione naturae et regno hominis, Joannem Billium, London, 1620. Translated into English and edited by Peter Urbach and John Gibson: Novum Organum, Open Court, La Salle, IL, 1994.

163 Cf. "Experiments without Material Intervention. Models Experiments, Virtual Experiments, and Virtually Experiments," pp. 219-221. On how the results relate to the world in both cases (laboratory and non-material), cf. Morgan, M. S., "Experiments without Material Intervention. Models Experiments, Virtual Experiments, and Virtually Experiments," pp. 227-232. 
Barberousse, A., Franceschelli, S. and Imbert, C., "Computer Simulations as Experiments," Synthese, v. 169, (2009), pp. 557-574.

Bardsley, N., "Experimental Economics and the Artificiality of Alteration," Journal of Economic Methodology, v. 12, n. 2, (2005), pp. 239-251.

Barnes, B., "Thomas Kuhn and the Problem of Social Order in Science," in Nickles, Th. (ed.), Thomas Kuhn, Cambridge University Press, Cambridge, 2003, pp. 122-141.

Bogen, J., "Experiment and Observation," in Machamer, P. and Silberstein, M. (eds.), The Blackwell Guide to the Philosophy of Science, Blackwell, Oxford, 2002, pp. 128-148.

Boumans, M. and Morgan, M. S., "Ceteris paribus Conditions: Materiality and the Application of Economic Theories," Journal of Economic Methodology, v. 8, n. 1, (2001), pp. 11-26.

Brown, H. I., "Observation and the Foundations of Objectivity," Monist, v. 62, (1979), pp. 470-481.

Brown, H. I., Observation and Objectivity, Oxford University Press, Oxford, 1987.

Brown, H. I., "A Theory-Laden Observation Can Test the Theory," British Journal for the Philosophy of Science, v. 44, (1993), pp. 555-559.

Campbell, D., "Factors Relevant to the Validity of Experiments in Social Settings," Psychological Bulletin, v. 54, (1957), pp. 297-312.

Chakravarty, E. F. and Fires, J. F., "Science as Experiment; Science as Observation," Natural Clinical Practice, v. 2, n. 6, (2006), pp. 286-287.

Chang, H., Inventing Temperature, Oxford University Press, Oxford, 2004.

Colburn, T., "Methodology of Computer Science," in Floridi, L. (ed.), The Blackwell Guide to the Philosophy of Computing and Information, Blackwell, Oxford, 2004, pp. 318-326.

Concato, J., Shah, N. and Horwitz, R. I., "Randomized, Controlled Trials, Observational Studies, and the Hierarchy of Research Designs," New England Journal of Medicine, v. 342, n. 25, (2000), pp. 1887-1892.

Copeland, A. H., "Mathematical Proof and Experimental Proof," Philosophy of Science, v. 33, (1966), pp. 303-316.

Copeland, B. J. and Proudfoot, D., "Artificial Intelligence: History, Foundations, and Philosophical Issues," in Thagard, P. (ed.), Philosophy of Psychology and Cognitive Science, Elsevier, Amsterdam, 2007, pp. 429-482.

Culp, S., "Objectivity in Experimental Inquiry: Breaking Data-Technique Circles," Philosophy of Science, v. 62, n. 3 (1995), pp. 438-458.

Cummins, S. C. J., "From Observation to Experimentation: One Prescription for a Geography of Public Policy," Area, v. 35, n. 2, (2003), pp. 220-223.

Cyert, R. M., Simon, H. A. and Trow, D. B., "Observation of a Business Decision," Journal of Business, v. 29, (1956), pp. 237-248. Reprinted in Simon, H. A., Models of Bounded Rationality. Vol. 2: Behavioral Economics and Business Organization, The MIT Press, Cambridge, MA, 1982, pp. 275-286.

Davis, D. D. and Holt, Сн. A. (eds.), Experimental Economics, Princeton University Press, Princeton, NJ, 1993.

Diller, A., "Testimony from a Popperian Perspective," Philosophy of the Social Sciences, v. 38, n. 4, (2008), pp. 419-456.

Einstein, A., "Zur Elektrodynamik bewegter Körper," Annalen der Physik, v. 17, (1905), pp. 891-921. 
Ferber, R. and Hirsch, W. Z., Social Experimentation and Economic Policy, Cambridge University Press, Cambridge, 1982.

Fetzer, J. H., "The Philosophy of AI and its Critique," in Floridi, L. (ed.), The Blackwell Guide to the Philosophy of Computing and Information, Blackwell, Oxford, 2004, pp. 119-134.

FLoridi, L. (ed.), The Blackwell Guide to the Philosophy of Computing and Information, Blackwell, Oxford, 2004.

Franklin, A., "The Epistemology of Experiment (review of Ian Hacking's Representing and Intervening)," British Journal for the Philosophy of Science, v. 35, (1984), pp. 381-390.

Franklin, A. ET AL., "Can a Theory-Laden Observation Test the Theory?," British Journal for the Philosophy of Science, v. 40, (1989), pp. 229-231.

Franklin, A., "How to Avoid the Experimenters' Regress," Studies in History and Philosophy of Science, v. 25, n. 3, (1994), pp. 463-491.

Franklin, A., Experiment, Right or Wrong, Cambridge University Press, Cambridge, 2008.

Friedman, D. and Sunder, S. (eds.), Experimental Methods: A Primer for Economists, Cambridge University Press, Cambridge, 1994.

Friedman, M., "The Methodology of Positive Economics," in Friedman, M., Essays in Positive Economics, The University of Chicago Pres, Chicago, 1953 (6th repr., 1969), pp. 3-43.

Galavotti, M. C. (ed.), Observation and Experiment in the Natural and the Social Sciences, Kluwer, Dordrecht, 2003.

Galison, P., How Experiments End, The University of Chicago Press, Chicago, 1987.

Gillies, D. A., Philosophy of Science in the Twentieth Century. Four Central Themes, B. Blackwell, Oxford, 1993.

Gilman, D., "What's a Theory to Do... with Seeing? Or Some Empirical Considerations for Observation and Theory," British Journal for the Philosophy of Science, v. 43, (1992), pp. 287-309.

Glymour, C., Theory and Evidence, Princeton University Press, Princeton, 1980.

Goldman, A. and Mason, K., "Simulation," in Thagard, P. (ed.), Philosophy of Psychology and Cognitive Science, Elsevier, Amsterdam, 2007, pp. 267-293.

Gomez, A., Filosofía y Metodología de las Ciencias Sociales, Alianza Editorial, Madrid, 2003.

GonZALEZ, W. J., "Semántica anti-realista: Intuicionismo matemático y concepto de verdad," Theoria, v. 12-13, (1990), pp. 149-170.

Gonzalez, W. J., "El realismo y sus variedades: El debate actual sobre las bases filosóficas de la Ciencia", en Carreras, A. (ed.), Conocimiento, Ciencia y Realidad, SIUZ-Ediciones Mira, Zaragoza, 1993, pp. 11-58.

Gonzalez, W. J., "Economic Prediction and Human Activity. An Analysis of Prediction in Economics from Action Theory," Epistemologia, v. 17, (1994), pp. 253-294.

Gonzalez, W. J., "Rationality in Economics and Scientific Predictions: A Critical Reconstruction of Bounded Rationality and its Role in Economic Predictions", Poznan Studies in the Philosophy of the Sciences and the Humanities, v. 61, (1997), pp. 205-232.

Gonzalez, W. J., "Prediction and Prescription in Economics: A Philosophical and Methodological Approach", Theoria, v. 13, n. 32, (1998), pp. 321-345.

Gonzalez, W. J., "Lakatos's Approach on Prediction and Novel Facts,” Theoria, v. 16, n. 3, (2001), pp. 499-518. 
Gonzalez, W. J., "Rationality in Experimental Economics: An Analysis of R. Selten's Approach," in Galavotti, M. C. (ed.), Observation and Experiment in the Natural and the Social Sciences, Kluwer, Dordrecht, 2003, pp. 71-83.

Gonzalez, W. J., "Herbert A. Simon: Filósofo de la Ciencia y economista (1916-2001)," in Gonzalez, W. J. (ed.), Racionalidad, historicidad y predicción en Herbert A. Simon, Netbiblo, A Coruña, 2003, pp. 7-63.

Gonzalez, W. J., "From Erklären-Verstehen to Prediction-Understanding: The Methodological Framework in Economics," in Sintonen, M., Ylikoski, P. and Miller, K. (eds.), Realism in Action: Essays in the Philosophy of Social Sciences, Kluwer, Dordrecht, 2003, pp. 33-50.

Gonzalez, W. J., "Las revoluciones científicas y la evolución de Thomas S. Kuhn," in Gonzalez, W. J. (ed.), Análisis de Thomas Kuhn: Las revoluciones cientificas, Trotta, Madrid, 2004, pp. 15-103.

Gonzalez, W. J., "The Philosophical Approach to Science, Technology and Society," in Gonzalez, W. J. (ed.), Science, Technology and Society: A Philosophical Perspective, Netbiblo, A Coruña, 2005, pp. 3-49.

Gonzalez, W. J., "Novelty and Continuity in Philosophy and Methodology of Science," in Gonzalez, W. J. and Alcolea, J. (eds.), Contemporary Perspectives in Philosophy and Methodology of Science, Netbiblo, A Coruña, 2006, pp. 1-28.

Gonzalez, W. J., "Configuración de las Ciencias de Diseño como Ciencias de lo Artificial: Papel de la Inteligencia Artificial y de la racionalidad limitada," in Gonzalez, W. J. (ed.), Las Ciencias de Diseño: Racionalidad limitada, predicción y prescripción, Netbiblo, A Coruña, 2007, pp. 41-69.

Gonzalez, W. J., "The Role of Experiments in the Social Sciences: The Case of Economics," in Kuipers, T. (ed.), General Philosophy of Science: Focal Issues, Elsevier, Amsterdam, 2007, pp. 275-301.

Gonzalez, W. J., "Rationality and Prediction in the Sciences of the Artificial: Economics as a Design Science," in Galavotti, M. C., Scazzieri, R. and Suppes, P. (eds.), Reasoning, Rationality and Probability, CSLI Publications, Stanford, 2008, pp. 165-186.

Gonzalez, W. J., "Complexity in Economics and Prediction: The Role of Parsimonious Factors," in Dieks, D., Gonzalez, W. J., Hartman, S., Stadler, F., Uebel, Th. and Weber, M. (eds.), Explanation, Prediction, and Confirmation: New Trends and Old Ones Reconsidered, Springer, Dordrecht, forthcoming.

Gooding, D., Pinch, T. and Schaffer, S. (eds.), The Uses of Experiment, Cambridge University Press, Cambridge, 1989.

Gooding, D., Experiment and the Making of Meaning. Human Agency in Scientific Observation and Experiment, Kluwer, Dordrecht, 1990.

Grandy, R. E. (ed), Theories and Observation in Science, Prentice-Hall, Englewood Cliffs, 1973.

Guala, F., "Models, Simulations, and Experiments," in Magnani, L. and Nersessian, N. (eds.), Model-Based Reasoning: Science, Technology, Values, Kluwer, New York, 2002, pp. 59-74.

Guala, F., "Economics in the Lab: Completeness vs. Testability," Journal of Economic Methodology, v. 12, n. 2, (2005), pp. 185-196.

Guala, F., The Methodology of Experimental Economics, Cambridge University Press, Cambridge, 2005.

Haavelmo, T., "The Probability Approach in Econometrics," supplement to Econometrica, v. 12, (1944), pp. 1-118.

HaCkInG, I., Representing and Intervening, Cambridge University Press, Cambridge, 1983. 
Hacking, I., "Philosophers of Experiment," Proceedings of the Philosophy of Science Association, v. 2, (1988), pp. 147-156.

Hacking, I., "The Self-Vindication of the Laboratory Sciences," in Pickering, A. (ed.), Science as Practice and Culture, The University of Chicago Press, Chicago, 1992, pp. 29-64.

Hanson, N. R., Patterns of Discovery: An Inquiry into the Conceptual Foundations of Science, Cambridge University Press, Cambridge, 1958.

Hanson, N. R., Observation and Explanation: A Guide to Philosophy of Science, Harper and Row, N. York, 1971.

Harré, R., Great Scientific Experiments. 20 Experiments that Changed our View of the World, Phaidon, Oxford, 1981.

Harrison, G. W., "Neuroeconomics: A Critical Reconsideration," Economics and Philosophy, v. 24 , n. 3, (2008), pp. 303-344.

HarsanYi, J. C., "The Work of John Nash in Game Theory," Journal of Economic Theory, v. 69, (1996), pp. 158-161.

Hempel, C. G., "Problems and Changes in the Empiricist Criterion of Meaning," Revue Internationale de Philosophie, v. 4 (1950), pp. 41-63; reprinted as "The Empiricist Criterion of Meaning," in Ayer, A. J. (ed.), Logical Positivism, Free Press, New York, 1959, pp. 108-129.

Hendry, D. F., Econometrics: Alchemy or Science? Essays in Econometric Methodology, new edition, Oxford University Press, Oxford, 2000 (1st edition, 1993).

Herschel, J. F. W., A Preliminary Discourse on the Study of Natural Philosophy, Longman, London, 1830; reprinted by The University of Chicago Press, Chicago, 1987.

Hey, J. D. and Loomes, G. (eds.), Recent Developments in Experimental Economics, E. Elgar, Aldershot, 1993, vol. I and II.

Holland, J. H., Holyoak, K. J., Nisbett, R. E. and Thagard, P. R., Induction: Processes of Inference, Learning, and Discovery, The MIT Press, Cambridge, MA, 1986.

Holton, G. J., "Einstein, Michelson, and the 'Crucial' Experiment," Isis, v. 60, (1969), pp. 133-197.

JACQuette, D. (ed.), Reason, Method, and Value: A Reader on the Philosophy of Nicholas Rescher, Ontos Verlag, Frankfurt, 2009.

Kahneman, D., Knetsch, J. L. and Thaler, R. H., "Experimental Tests of the Endowment Effect and the Coase Theorem," Journal of Political Economy, v. 98, n. 6, (1990), pp. 1325-1348, reprinted in Hey, J. D. and Loomes, G. (eds.), Recent Developments in Experimental Economics, E. Elgar, Aldershot, 1993, vol. I, pp. 206-229.

Kalisch, G. K., Milnor, J. W., Nash, J. F. and Nering, E. D., "Some Experimental n-Person Games," in Thrall, R. M., Coombs, C. H., and Davis, R. L. (eds.), Decision Processes, J. Wiley, New York, 1954, pp. 301-327.

Keller, E. F., "Models, Simulation, and 'Computer Experiments'," in Radder, H. (ed.), The Philosophy of Scientific Experimentation, University of Pittsburgh Press, Pittsburgh, 2003, pp. 198-215.

Kitcher, Ph., Science, Truth, and Democracy, Oxford University Press, Oxford, 2001.

Knez, M. and Smith, V. L., "Hypothetical Valuations and Preference Reversals in the Context of Asset Trading," in Rотн, A. E. (ed.), Laboratory Experimentation in Economics-Six Points of View, Cambridge University Press, Cambridge, 1987, pp. 131-154.

KöRnER, S. (ed.), Observation and Interpretation, Dover, N. York, 1957.

Kunn, Tн. S., The Structure of Scientific Revolutions, International Encyclopedia of Unified Science: Foundations of the Unity of Science, vol. 2, n. 2, The University of Chicago Press, Chicago, 1962; 2nd ed., 1970. 
Kunn, Th. S., "A Function for Thought Experiments," in Cohen, I. B. and TAton, R. (eds.), Mélanges Alexandre Koyré, v. 2: L'aventure de la science, Hermann, Paris, 1964, pp. 307-334. Reprinted in Kunn, Tн. S., The Essential Tension. Selected Studies in Scientific Tradition and Change, The University of Chicago Press, Chicago, 1977, pp. 240-265.

Kunn, Th. S., The Road Since Structure. Philosophical Essays, 1970-1993, with an Autobiographical Interview, edited by James Conant and John Haugeland, The University of Chicago Press, Chicago, 2000.

Kulkarni, D. and Simon, H. A., "Experimentation in Machine Discovery," in Shrager, J. and Langley, P. W. (eds.), Computational Models of Scientific Discovery and Theory Formation, Morgan Kaufmann, San Mateo, CA, 1990, chapter 9.

Lakatos, I., "Changes in the Problem of Inductive Logic," in Lakatos, I. (ed.), The Problem of Inductive Logic, North Holland, Amsterdam, 1968, pp. 315-417. Reprinted in LaKatos, I., Mathematics, Science and Epistemology. Philosophical Papers. vol. 2, edited by J. Worrall and G. Currie, Cambridge University Press, Cambridge, 1978, pp. 128-200.

Lakatos, I., "The Role of Crucial Experiments in Science," Studies in History and Philosophy of Science, v. 4, (1974), pp. 309-325.

Latour, B. and Woolgar, S., Laboratory Life: The Social Construction of Scientific Facts, Princeton University Press, Princeton, NJ, 1979 (2nd edition, 1986.)

Latour, B., Science in Action: How to Follow Scientists and Engineers Through Society, Harvard University Press, Cambridge, MA, 1987.

Latour, B., The Pasteurisation of France, Harvard University Press, Cambridge, MA, 1988.

Latour, B., We have Never been Modern, Harvester, Brighton, 1993 (translated by C. Porter.)

Lawson, T., Economics and Reality, Routledge, London, 1997.

Lenhard, J., "Computer Simulation: The Cooperation between Experimenting and Modeling," Philosophy of Science, v. 74, n. 2, (2007), pp. 176-194.

Lennox, J. G., "The Evolution of Darwinian Thought Experiments," in Gonzalez, W. J. (ed.), Evolutionism: Present Approaches, Netbiblo, A Coruña, 2008, pp. 63-76.

Lennox, J. G., “Thought Experiments in Evolutionary Biology Today,” in Gonzalez, W. J. (ed.), Evolutionism: Present Approaches, Netbiblo, A Coruña, 2008, pp. 109-120.

Little, D., "The Heterogeneus Social: New Thinking About the Foundations of the Social Sciences," in Mantzavinos, C. (ed.), Philosophy of the Social Sciences, Cambridge University Press, Cambridge, 2009, pp. 154-178.

Lynch, M. and Woolgar, S. (eds.), Representation in Scientific Practice, The MIT Press, Cambridge, 1990.

Machamer, P. (ed.), The Cambridge Companion to Galileo, Cambridge University Press, Cambridge, 1998.

Magnani, L. and Nersessian, N. (eds.), Model-Based Reasoning: Science, Technology, Values, Kluwer, N. York, 2002.

Marshall, T. W., Santos, E. and Selleri, F., "Local Realism has not been Refuted by Atomic Cascade Experiments," Physical Letters, v. 98/1-2, (1983), pp. 5-9.

Martínez Solano, J. F., El problema de la verdad en K. R. Popper: Reconstrucción históricosistemática, Netbiblo, A Coruña, 2005.

McCabe, K. A., "Neuroeconomics and the Economic Sciences," Economics and Philosophy, v. 24, n. 3, (2008), pp. 345-368. 
McKinney, W. J., "Experimenting on and Experimenting with: Plywater and Experimental Realism," British Journal for the Philosophy of Science, v. 42, (1991), pp. 295-307.

Morgan, M. S., The History of Econometric Ideas, Cambridge University Press, Cambridge, 1990.

Morgan, M. S. and Morrison, M. (eds.), Models as Mediators, Cambridge University Press, Cambridge, 1999.

Morgan, M. S., "Models, Stories and the Economic World," Journal of Economic Methodology, v. 8, (2001), pp. 361-384.

Morgan, M. S., "Model Experiments and Models in Experiments," in Magnani, L. and Nersessian, N. (eds.), Model-Based Reasoning: Science, Technology, Values, Kluwer, New York, 2002, pp. 41-58.

Morgan, M. S., "Experiments without Material Intervention. Models Experiments, Virtual Experiments, and Virtually Experiments," in Radder, H. (ed.), The Philosophy of Scientific Experimentation, University of Pittsburgh Press, Pittsburgh, 2003, pp. 216-235.

Morgan, M. S., "Experiments versus Models: New Phenomena, Inference, and Surprise," Journal of Economic Methodology, v. 12, n. 2, (2005), pp. 317-329.

Morgenstern, O., On the Accuracy of Economic Observations, 2nd ed., Princeton University Press, Princeton, 1963.

Musgrave, A., “'Unreal Assumptions' in Economic Theory: The F-Twist Untwisted,” Kyklos, v. 34, n. 3, (1981), pp. 377-387.

Muth, J. F., "Rational Expectations and the Theory of Price Movements," Econometrica, v. 29, (1961), pp. 315-335, reprinted in LuCAS, R. E. and SARGENT, TH. J. (eds.), Rational Expectations and Econometric Practice, G. Allen and Unwin, London, 1981, pp. 3-22.

Nagel, E., The Structure of Science, Harcourt, Brace and World, New York, 1961.

Nagel, E., "Theory and Observation," in Nagel, E., Bromberger, S. and GrünBaum, A. (eds.), Observation and Theory in Science, The Johns Hopkins University Press, Baltimore, MD, 1971, pp. 15-43.

NASH, J., "The Work of John Nash in Game Theory,” Journal of Economic Theory, v. 69, (1996), pp. 182-183.

Niniluoto, I., “The Aim and Structure of Applied Research,” Erkenntnis, v. 38, (1993), pp. 1-21.

Norton, S. and Suppe, F., "Why Atmospheric Modeling in Good Science," in Miller, C. and EDWARDS, P. N. (eds.), Changing the Atmosphere: Expert Knowledge and Environment Governance, The MIT Press, Cambridge, 2001, pp. 67-105.

Oberkampf, W., Trucano, T. and Hirsch, C., "Verification, Validation, and Predictive Capability in Computational Engineering and Physics," Applied Mechanics Review, v. 57, n. 5, (2004), pp. 345-384.

Omelianovsky, M. E., "On the Principle of Observability in Modern Physics," Foundations of Physics, v. 2, (1972), pp. 223-238.

PARKer, W. S., "Does Matter Really Matter? Computer Simulations, Experiments, and Materiality," Synthese, v. 169, (2009), pp. 483-496.

Plotт, Ch. R., "Some Policy Applications of Experimental Methods," in Roth, A. E. (ed.), Laboratory Experimentation in Economics-Six Points of View, Cambridge University Press, Cambridge, 1987, pp. 193-219.

Popper, K. R., Logik der Forschung, Julius Springer Verlag, Vienna, 1935 (reprinted in J. C. B. Mohr - P. Siebeck- Tubingen, 1994). English translation: The Logic of Scientific Discovery, Hutchinson, London, 1959 (rev. edit., Harper and Row, N. York, 1968). 
Popper, K. R., "Epistemology Without a Knowing Subject," in Popper, K. R., Objective Knowledge. An Evolutionary Approach, Clarendon Press, Oxford, 1972 (5th ed. revised, 1979; reprinted in 1989), pp. 106-152.

Popper, K. R., Unended Quest. An Intellectual Autobiography, Fontana/ Collins, London, 1976 (enlarged version, Routledge, London, 1992).

Quine, W. v. O., The Roots of Reference, Open Court, La Salle, IL, 1974.

Radder, H. (eds.), The Philosophy of Scientific Experimentation, University of Pittsburgh Press, Pittsburgh, 2003.

Radder, H., "Towards a More Developed Philosophy of Scientific Experimentation," in Radder, H. (ed.), The Philosophy of Scientific Experimentation, University of Pittsburgh Press, Pittsburgh, 2003, pp. 1-18.

ReIss, J., Error in Economics. Towards a More Evidence-based Methodology, Routledge, London, 2008.

ReIss, J., "Counterfactuals, Thought Experiments, and Singular Causal Analysis in History," Philosophy of Science, v. 79, n. 5, (2009), pp. 712-723.

Rescher, N., A System of Pragmatic Idealism. Vol. I: Human Knowledge in Idealistic Perspective, Princeton University Press, Princeton, 1992.

Rescher, N., Razón y valores en la Era científico-tecnológica, Paidós, Barcelona, 1999.

Rescher, N., Reason and Reality: Realism and Idealism in Pragmatic Perspective, Rowman and Littlefield, Lanham, MD, 2005.

Rescher, N., What if? Thought Experimentation in Philosophy, Transaction, N. Brunswick, 2005.

Rотн, A., "Laboratory Experimentation in Economics," Economics and Philosophy, v. 2, (1986), pp. 245-273.

Rотн, A. E. (ed.), Laboratory Experimentation in Economics-Six Points of View, Cambridge University Press, Cambridge, 1987.

Rотн, A., "Laboratory Experimentation in Economics, and its Relation to Economic Theory," in Rescher, N. (ed.), Scientific Inquiry in Philosophical Perspective, University Press of America, Lanham, 1987, pp. 147-167.

Rотн, A., "Laboratory Experimentation in Economics: A Methodological Overview," The Economic Journal, v. 98, (1988), pp. 974-1031; reprinted in Hey, J. D. and LoOmES, G. (eds.), Recent Developments in Experimental Economics, vol. I, E. Elgar, Aldershot, 1993, p. 3-60.

Rотн, A., "Introduction to Experimental Economics," in Kagel, J. H. and Roth, A. (eds.), Handbook of Experimental Economics, Princeton University Press, Princeton, NJ, 1995, pp. 3-109.

Salmon, W. C., "On the Alleged Temporal Anisotropy of Explantion," in Earman, J., Janis, A., Massey, G. and Rescher, N. (eds.), Philosophical Problems of the Internal and External Worlds, University of Pittsburgh Press, Pittsburgh, 1993, pp. 229-248.

Samuelson, P. and Nordhaus, W. D., Economics, 12th edition, McGraw-Hill, New York, 1983.

SARgent, R. M., The Diffident Naturalist: Robert Boyle and the Philosophy of Experiment, The University of Chicago Press, Chicago, 1995.

Sauermann, H. and Selten, R., "Ein Oligopolexperiment," Zeitschrift für die gesamte Staatswissenschaft, v. 115, (1959), pp. 427-471; reprinted in Sauermann, H. (ed.), Beiträge zur experimentellen Wirtschaftsforschung, J. C. B. Mohr (Paul Siebeck), Tübingen, 1967, pp. 9-59.

Schram, A., "Artificiality: The Tension Between Internal and External Validity in Economic Experiments," Journal of Economic Methodology, v. 12, n. 2, (2005), pp. 225-237. 
Searle, J. R., "Minds, Brains, and Programs," The Behavioral and Brain Sciences, v. 3, (1980), pp. 417-424; reprinted in Boden, M. (ed.), The Philosophy of Artificial Intelligence, Oxford University Press, Oxford, 1990, pp. 67-88.

Selten, R. and Krischker, W., "Comparison of Two Theories for Characteristic Function Experiments," in Tietz, R. (ed.), Aspiration Levels in Bargaining and Economic Decision Making, Springer, Berlin, 1982, pp. 259-264.

Selten, R., "Equal Division Payoff Bounds for Three-Person Characteristic Function Experiments," in Tietz, R. (ed.), Aspiration Levels in Bargaining and Economic Decision Making, Springer, Berlin, 1982, pp. 265-275; reprinted in Selten, R., Models of Strategic Rationality, Kluwer, Dordrecht, 1988, pp. 301-311.

Selten, R. and Stoecker, R., "End Behavior in Sequences of Finite Prisoner's Dilemma Supergames: A Learning Theory Approach," Journal of Economic Behavior and Organization, v. 7, n. 1, (1986), pp. 47-70.

Selten, R., "Equity and Coalition Bargaining in Experimental Three-Person Games," in Roth, A. E. (ed.), Laboratory Experimentation in Economics-Six Points of View, Cambridge University Press, Cambridge, 1987, pp. 42-98.

Selten, R., "Bounded Rationality," Journal of Institutional and Theoretical Economics, v. 146, n. 4, (1990), pp. 649-658.

Selten, R., "Properties of a Measure of Predictive Success," Mathematical Social Sciences, v. 21, n. 2, (1991), pp. 153-167.

Selten, R., "In Search of a Better Understanding of Economic Behavior," in Heertje, A. (ed.), Makers of Modern Economics, Harverstern Wheatsheaf, London, 1993, pp. 115-139.

Selten, R., "Features of Experimentally Observed Bounded Rationality," European Economic Review, v. 42, (1998), pp. 413-436.

Selten, R., "Game Theory, Experience, Rationality," in Leinfellner, W. and KöHLer, E. (eds.), Game Theory, Experience, Rationality, Kluwer, Dordrecht, 1998, pp. 9-34.

Selten, R. and Ockenfels, A., "An Experimental Solidarity Game," Journal of Economic Behavior and Organization, v. 34, n. 4, (1998), pp. 517-539.

Selten, R., "What is Bounded Rationality?," in Gigerenzer, G. and Selten, R. (eds.), Bounded Rationality: The Adaptive Toolbox, The MIT Press, Cambridge, MA, 2001, pp. 13-36.

Selten, R., "Emergence and Future of Experimental Economics," in Galavotti, M. C. (ed.), Observation and Experiment in the Natural and the Social Sciences, Kluwer, Dordrecht, 2003, pp. 63-70.

Shea, W. R., Galileo's Intellectual Revolution: Middle Period, 1610-1632, Science History Publications, New York, 1977.

SheA, W. R., Designing Experiments and Games of Change. The Unconventional Science of Blaise Pascal, Science History Publications, Canton, MA, 2003.

Simon, H. A. and Siklossy, L. (eds.), Representation and Meaning: Experiments with Information Processing Systems, Prentice-Hall, Englewood Cliffs, NJ, 1972.

Simon, H. A., "Artificial Intelligence: An Empirical Science," Artificial Intelligence, v. 77, n. 1, (1995), pp. 95-127.

Simon, H. A., "Machine as Mind," in Ford, K. M., Glymour, C. and Hayes, P. J. (eds.), Android Epistemology, AAAI/The MIT Press, Menlo Park, CA, 1995, pp. 23-40.

Simon, H. A., The Sciences of the Artificial, 3rd ed., The MIT Press, Cambridge, MA, 1996 (1st ed., 1969; 2nd ed., 1981). 
Simon, H. A., "Artificial Intelligence," in Kazdin, A. E. (ed.), American Psychological Association Encyclopedia of Psychology, vol. 1, Oxford University Press, N. York, 2000, pp. 248-255.

Simon, H. A., "Bounded Rationality in Social Science: Today and Tomorrow," Mind and Society, v. 1, n. 1, (2000), pp. 25-39.

Simon, H. A., "On Simulating Simon: His Monomania, and its Sources in Bounded Rationality," Studies in History and Philosophy of Science, v. 32, n. 3, (2001), pp. 501-505.

Smith, V. L., McCabe, K. A. and Rassenti, S. J., "Lakatos and Experimental Economics," in Marchi, N. De and Blaug, M. (eds.), Appraising Economic Theories, E. Elgar, Aldershot, 1991, pp. 197-227.

Solomon, M., Social Empiricism, The MIT Press, Cambridge, MA, 2001.

Stacey, R. and Griffin, D. (eds.), A Complexity Perspective on Research Organizations: Taking Experience Seriously, Routledge, London, 2005.

Strawson, P. F., “The Incoherence of Empiricism," Proceedings of The Aristotelian Society, vol. sup. 66, (1992), pp. 139-143.

Suppe, F., "The Search for Philosophic Understanding of Scientific Theories," in Suppe, F. (ed.), The Structure of Scientific Theories, University of Illinois Press, Urbana, 1974, (2nd ed. 1977), pp. 1-241.

Thagard, P. (ed.), Philosophy of Psychology and Cognitive Science, Elsevier, Amsterdam, 2007.

Tiles, J. E., "Experiment as Intervention," British Journal for the Philosophy of Science, v. 44, (1993), pp. 463-475.

Tversky, A., Slovic, P. and Kahneman, D., "The Causes of Preference Reversal," American Economic Review, v, 80, (1990), pp. 204-217, reprinted in HeY, J. D. and Loomes, G. (eds.), Recent Developments in Experimental Economics, E. Elgar, Aldershot, 1993, vol. I, pp. 147-160.

Urbach, P., "On the Utility of Repeating the 'Same' Experiment," American Journal of Physics, v. 59, (1981), pp. 151-162.

Urbach, P., Francis Bacon's Philosophy of Science, Open Court, La Salle, IL, 1987.

VAn FraAssen, B. C., "Theory Construction and Experiment: An Empiricist View," Proceedings of the Philosophy of Science Association, v. 2, (1980), pp. 663-677.

Van Fraassen, B. C., The Scientific Image, Clarendon Press, Oxford, 1980.

Van Fraassen, B. C., Quantum Mechanics: An Empiricist View, Oxford University Press, Oxford, 1991.

Van Fraassen, B. C., Scientific Representation: Paradoxes of Perspective, Oxford University Press, Oxford, 2008.

WinsBerg, E., "Sanctioning Models: The Epistemology of Simulation," Sience in Context, v. 12, n. 2, (1999), pp. 275-292.

Winsberg, E., "Simulated Experiments: Methodology for a Virtual World," Philosophy of Science, v. 70, n. 1, (2003), pp. 105-125.

Winsberg, E., “A Tale of Two Methods,” Synthese, v. 169, (2009), pp. 575-592.

Wold, H. O. A., "Econometrics as Pioneering in Non-Experimental Model Building," Econometrica, v. 37, (1969), pp. 369-381.

Woodward, J., "Experimentation, Causal Inference, and Instrumental Realism," in RAdDER, H. (ed.), The Philosophy of Scientific Experimentation, University of Pittsburgh Press, Pittsburgh, 2003, pp. 87-118. 
Woolgar, S., "Critique and Criticism: Two Readings of Ethnomethodology," Social Studies of Science, v. 11, n. 4, (1981), pp. 504-514.

Woolgar, S., Science: The Very Idea, Tavistock, London, 1988.

Woolgar, S. (ed.), Knowledge and Reflexivity: New Frontiers in the Sociology of Knowledge, Sage, London, 1988.

Worrall, J., "Fresnel, Poisson and the White Spot: The Role of Successful Predictions in the Acceptance of Scientific Theories," in Gooding, D., Pinch, T. and Schaffer, S. (eds.), The Uses of Experiment, Cambridge University Press, Cambridge, 1989, pp. 135-157.

Worrall, J., "Why Randomize? Evidence and Ethics in Clinical Trials," in Gonzalez, W. J. and Alcolea, J. (eds.), Contemporary Perspectives in Philosophy and Methodology of Science, Netbiblo, A Coruña, 2006, pp. 65-82.

Zahar, E., “'Crucial' Experiments: A Case Study,” in Radnitzky, G. and Andersson, G. (eds.), Progress and Rationality in Science, Reidel, Dordrecht, 1978, pp. 71-97.

Zahar, E., "Feyerabend on Observation and Empirical Content," British Journal for the Philosophy of Science, v. 33, (1982), pp. 397-409. 


\section{II}

\section{Experience and Scientific Observations}

2. 'Voice' and the Facts and Observations of Experience

3. New Forms of Scientific Observation and their Epistemological Impact 


\title{
'Voice' and The FACTS ANd ObSERVATIONS OF EXPERIENCE ${ }^{1}$
}

\author{
Mary S. Morgan
}

The facts of social sciences are ones that stem from scientific expertise, but in the social world, everyone is their own expert. Everyone lives in society, and experiences either first-hand, or closely second-hand, the same phenomena that social scientists investigate. Consequently, people are not only the subjects of scientific investigation, but are themselves amateur reflexive scientists: observing and making sense of their own experiences in social and economic affairs. And, in a democratic community, such personal experience claims a legitimate place in knowledge discussions. These two qualities mean that the observations from personal experience can not be so lightly dismissed by the social scientist in the same way that the traditional observations of folk-lore can be trumped by the facts of scientific knowledge in the natural sciences. Yet, these facts of personal experience may not travel easily, for the possibilities of voicing that experience depend in part on the nature of the social science involved and in part on the civic epistemology of the environment within which they can be expressed. The considerations which underlie the successful articulation of experienced knowledge suggest that 'voice' differs from both 'engagement' and 'understanding' as a way to characterize public participation in social science - as opposed to natural scienceknowledge discussions.

\section{Personal Experience in Forms of Knowledge}

I approach the idea that a public's social science knowledge can be understood as the observations and facts of their experience by beginning with a case that lies neatly at the intersection of the natural sciences and the social sciences, namely the well-known MMR case in medicine. ${ }^{2}$ The Measles, Mumps and Rubella triple vaccine is the standard vaccine, but in the late 1990 s and early 21 st century in the UK came to be associated in the public mind with the triggering of particular conditions including the onset of autism in children. This prompted

\footnotetext{
This paper originated in a shorter paper originally entitled "Facts of Expertise and Facts of Experience" given at a conference on The Social Sciences and Democracy: A Philosophy of Science Perspective at Gent University, September 2006. It was heavily revised for the conference Observation and Experiment in Science: New Methodological Perspectives at University of A Coruña, 8-9th March 2007 at the invitation of Wenceslao J. Gonzalez. I thank participants at both meetings for their comments.

I also thank for their help: Tiago Mata, Trisha Greenhalgh, and my colleagues from "The Nature of Evidence: How Well Do 'Facts' Travel?" project (funded by The Leverhulme Trust and the ESRC grant F/07 004/Z, at the Department of Economic History, London School of Economics) which supported this research; and Nat Ishino for her research assistance. Comments are welcome: m.morgan@1se.ac.uk. C M. S. Morgan 2010.

2 This paper intersects with the work of two broad literatures: the public understanding of science discussions, and standpoint theories of knowledge. I discuss the former in various places in the text and in footnotes 6 and 33; the latter is only briefly referenced in footnote 30 .
} 
many exhortations from the relevant state officials to parents not to forgo the vaccine on the grounds that: the vaccine was safe; that medical knowledge was certain; and that the dangers from not having the vaccination were real. In the UK context, such medical science facts did not travel well to a public which had learnt to distrust governmental assurances about the certainty and content of scientific knowledge. The crisis also prompted further medical research, and the medical establishment in due course re-affirmed their view that there was no evidence that the vaccine was harmful or triggered these particular conditions. ${ }^{3}$ At the end of all this, Richard Horton, the editor of The Lancet (which had published the initial findings relating the vaccine to the onset of the conditions based on a small sample of children, parts of the subsequent medical debates, and a partial "retraction" of the original paper) said (in a seminar) that you could not tell a mother that her child's autism was not the result of the MMR vaccine despite the negative findings of the scientific work. ${ }^{4}$ Why not?

No doubt there are many reasons why not, for the MMR case is highly complex in its cultural, social, medical and scientific aspects and I am not trying to judge these in any substantive way. ${ }^{5}$ The aim here is merely to explore the epistemic and cognitive difficulties of persuading a parent about some aspect of their child's health of which they have observed experience. On this ground, we can, at first sight, interpret this case as an example of the public's failure to understand science: the implication is that such a parent cannot have understood either the nature of the evidence or the specific medical findings. The public appears stupid and the medical profession both more discerning (about the nature of scientific evidence) and more knowledgeable (about the medical conditions involved). This aligns with the standard "deficit model" of the public understanding of science literature, here seen as a two-fold deficit, about both the content of scientific knowledge and about methods of scientific enquiry. ${ }^{6}$ But Horton was serious and not belittling the mother in question. So the question "Why not?" still requires an answer: why can't you tell a mother that her child's autism is not the result of the MMR vaccine? What is involved in the knowledge structure of such a situation that might lead Horton to make such a statement?

\footnotetext{
3 For one particularly interesting example of this review work, see SMEETH, L. ET AL., "MMR Vaccination and Pervasive Developmental Disorders: A Case-control Study," The Lancet, v. 364, September 11, 2004, pp. 963-969. (I am grateful to Trisha Greenhalgh for pointing me to this work.) See also the statistical work discussed in HorTON, R., MMR Science and Fiction, Granta Books, London, 2004; and references to other studies in both sources.

4 Horton's comments were made at a seminar at the Centre for Philosophy of Natural and Social Science (London School of Economics), 7th December, 2005.

5 See Horton's book MMR Science and Fiction for an account by one of the main participants and Mike Fitzgerald's account comes from a general practitioner and parent of an autistic child in FitzGERALD, M., MMR and Autism, Routledge, London, 2004. An example of social science research into the social and cognitive complexity of the problem from the point of view of parents is POLTORAK, M. ET AL., "MMR talk' and Vaccination Choices: An Ethnographic Study in Brighton," Social Science and Medicine, v. 61, (2005), pp. 709-719.

For a science studies perspective, see Collins, H. and Pinch, T., Dr Golem: How to Think about Medicine, The University of Chicago Press, Chicago, 2005, and the DEMOS report: STILgOe, J., IRwin, A. and Jones, K., The Received Wisdom, DEMOS, London, 2006, which concludes its discussion of the case: "While the experts and the government were noisily talking about the facts, parents were quietly asking about uncertainty," p. 50.

6 This deficit model is associated with the "public understanding of science" project, which in the UK case, arose from the Royal Society's 1985 paper of that title, though most serious scholars have found it wanting as a conceptual tool and show a healthy scepticism about the public's ignorance. For example, see Ziman, J., "Public Understanding of Science," Science, Technology, and Human Values, v. 16, n. 1, (1991), pp. 99-105. He summed up the general situation of public knowledge about science thus: "a simple 'deficit' model, which tries to interpret the situation solely in terms of public ignorance or scientific illiteracy, does not provide an adequate analytical framework for many of the results of our research," Ziman, J., "Public Understanding of Science," p. 101. Wynne described the deficit model as "discredited ... more an ideological construct than a research model," Wynne, B., "Public Uptake of Science: A Case for Institutional Reflexivity," Public Understanding of Science, v. 2, (1993), p. 322.
} 
First, the fact that, in many cases taken together, there is no statistical evidence for such a connection between the vaccine and the condition suggests that a general relationship between them is unlikely, but does not necessarily disprove a relation between the events in one particular individual case. Such an inference would conflate the probability-based, population or sample level finding with a definite claim for one individual (that is, for one observation, or potential observation in the statistical data set). This is not a comment on the quality of the statistical work in this field, but a comment on the epistemic scope and relevance of statistical reasoning when applied to individual cases. ${ }^{7}$ Statistical findings and probability reasoning apply to populations and samples, and are not epistemologically fitted to give an account of any one observation or individual case in situations - as here - where there is a large amount of variability in such individuals' behaviour and complex responses in medical and social terms.

The case of smoking and cancer provides a parallel example, where there is a more accepted understanding of the nature of the problem of reasoning from statistical evidence to an individual case. Statistical evidence and reasoning on a large data base was used to uncover the positive co-relationship between smoking and lung cancer. But while the findings are based on large samples, the probability of the connection is not $100 \%$; and for any one individual with lung cancer, there will be a particular combination of smoking and other causes and of background conditions to the onset of the disease. So, some people who do smoke don't get lung cancer and some who don't nevertheless do get lung cancer.

Of course the smoking case was of a significant and positive correlation, and here with the MMR case, we have no significant correlation. Yet the epistemic structure of the problem remains similar. We can speculate that despite the statistical findings, amongst the total population of children who received the MMR vaccination, a particular very finely stratified sample might throw up a significant positive correlation between the vaccine and the conditions, so that a link might be made for any rare or idiosyncratic case that fell into that sub-class. ${ }^{8}$ In this situation, even the most carefully constructed study that shows that the MMR and autism are not statistically related in a large sample of children does not provide a fully effective argument that disproves an apparent trigger in any one case. The epistemic structure of the situation makes it difficult to persuade a mother that her child's autism is not the result of the MMR vaccine on the basis of the statistical results.

Second, the problem also depends on another potential dissonance - in epistemic terms between the clinical medical knowledge of doctors which is case-based, and that of medical research based on statistical work, that is, between clinical and epidemiological traditions. This difficulty was recognised in the nineteenth century when statistical arguments were first used in medical contexts. By a long traditional understanding, clinical knowledge and expertise relies on experience of a series of individual cases and this knowledge is then applied to further specific individual cases. This is the pattern that typically creates the "experienced expert." For such a modern clinician, unless their medical knowledge based on learning from the laboratory or experimental work taken in conjunction with their clinical knowledge, and their experience of this particular case, all accord, it may well be difficult for an individual doctor - in spite of the statistical or epidemiological information — to tell an individual mother that their child's autism

\footnotetext{
Nor does this discussion consider the very real problems that both medics and patients have in understanding probability and statistical reasoning, on which there is a considerable literature; nor the differences between different modes of such reasoning, on which there is an even more extensive literature!

8 As Horton himself noted, cf. MMR Science and Fiction, p. 25.
} 
was not triggered by the MMR vaccine. ${ }^{9}$ Of course, the patient's (or their parents') medical knowledge is even more case-based: usually they only experience one such case. The observations of such individual personal experience even in the single case may be very powerful. A mother may recognise more than her clinician the signs of what has happened and when it happened by observing two closely related events - because it is her own child, whom she knows more about and has watched more carefully and consistently than a doctor ever could - even though she may not know why, that is, the nature of any connection between them. ${ }^{10}$

This brings us to the third point: for both doctor and mother, there is no 'why' answer in the statistical studies. The non association between the vaccine and autism in epidemiological studies says nothing about why autism occurs, and the causes of autism are little understood. If we asked the question the other way around: What would convince a mother that the vaccine did not cause her child's autism?, the answer would probably require the doctor to know and explain some already established causes of autism. ${ }^{11}$ Thus, for both parties, having no explanation, no definite causal determinants of the condition, is a severe problem that makes it very difficult to convince a mother that her child's autism was not due to the MMR vaccine. The experienced expert: the clinician, may not have the explanatory means to trump the observations of individual personal experience. ${ }^{12}$

The fourth reason is to do with recent changes in the knowledge relations between doctors and patients. Medical knowledge is no longer compellingly authoritative in the UK and patients are more demanding in their requirements. On the one hand, patients have been rebranded as consumers and are expected to make informed consumer choices. Medical treatment occurs in a market place inside and outside a state provided service. ${ }^{13}$ The consumer rights of patients gives them the power (oftentimes only nominal) to pick and choose amongst a set of medical "services" provided by the various medical practitioners. On the other hand, doctors - particularly at general practice level — have become less "all-knowing" and other sources of information about treatment (the internet etc.) have to some extent made the information relationship more even. Patients have not only the power to question, but to research and bring their own findings from the publicly available knowledge about medical science to the

\footnotetext{
9 The hierarchy of "scientificity" of medical knowledge methods involves not just epidemiological (statistical) but experimental investigations of various kinds in contrast to the clinical knowledge of practising doctors with their experiential case-based knowledge of individual patients. (This may make the general practitioner also a member of the "public" in this case, though clearly one with high medical knowledge - I am indebted to Tiago Mata for pointing this out.) These different epistemic approaches have different ways of investigating causes, but it is not clear that the hierarchy of methods for finding knowledge of associations meshes well with methods for clarifying knowledge of how causes work. Thus, in the parallel smoking case, the standard account is that the epidemiological finding persuaded some people to give up smoking, but others were not convinced until the causal links were established through experimental work.

10 See for comparison, the account of medical versus parental knowledge of Down syndrome discussed in Stilgoe, J., Irwin, A. and Jones, K., The Received Wisdom, p. 32.

11 For example, the idea that autism may be genetically related has a long history, but the evidence is still being gathered (see Amsterdamska, O., Making Autism Genetic, How Well Do 'Facts' Travel?, Workshop paper, LSE, March 2008).

12 Ziman's general claim seems apt here: "It cannot be assumed that their [the public's] formal ignorance of science makes them quite unwise in their actions," Ziman, J., "Public Understanding of Science," p. 103.

13 Of course, the history of medicine is largely a history of a market, which only turned into a near state monopoly in the UK after WWII. Although some 'private' (i.e. market) medicine continued in the intervening years, the state monopoly is now turning private again. For an interesting discussion of the implications of this pertinent to this argument, see Downie, R. and Randall, F., "Choice and Responsibility in the NHS," Clinical Medicine, v. 8, n. 2, (2008), pp. 182-185; I am grateful to Erika Mattila who brought this paper to my attention.
} 
consulting room. ${ }^{14}$ Changes in information and in culture have combined to alter the accepted boundaries of knowledge, and so power, between doctor and patient in terms of legitimate discussion about scientific knowledge as well as to choices and rights to treatment. These changes in the personal relations of knowledge between doctor and patient have made it not so easy for a doctor to say with easy authority to a mother that her child's autistic condition is not due to the vaccine. And, on the other side of the relationship, the increased expectation that patients (rather than doctors) will be the ones to make responsible and informed medical choices gives parents particular worries where that responsibility is their child's future health. Recent changes in the way we think about medical knowledge no longer treats it as "other" knowledge - knowledge that only scientists understand and therefore make decisions about. Rather it has become an area of shared responsibility and sharing of knowledge.

\section{Personal Experience and the Experienced Expert}

Understanding the epistemic structure of the situation in which an informed doctor cannot tell a mother that her child did not develop autism from the MMR vaccine gives insight into another set of cases, which share some of the same characteristics, but in the social sciences. ${ }^{15}$

The BBC often has a science slot in its early morning Radio 4 news. If this is a natural science story - the scientist is interviewed, and questioned about his/her discovery and is asked to explain his/her work and its potential relevance, usually with a certain deference to his/her particular and superior knowledge. If this is a social science or medical treatment news item, there is less deference to the learning of the scientist interviewed, and there is nearly always someone else brought in to provide 'balance': usually a non-scientist -i.e. a single mother, a social worker, a teacher, a parent, a charity worker, a patient, or so forth. The BBC format pits the expert from NICE (the UK National Institute for Clinical Excellence) vs the patient as they do the education expert from a university vs the parent or school governor of a school. This BBC habit of pairing scientist and non-scientist may be interpreted as an example of a double standard in which natural sciences are understood to make or discover knowledge compared to the less effective and objective social sciences, and so the provision of an alternative voice in these circumstances seemed to be for the purpose as ensuring a balance of opinions, as in political interviews and debates. No doubt there maybe some element of this "two cultures" divide. ${ }^{16}$ But following the discussion above, I now understand what is happening here somewhat differently, for these BBC social science enactments have the same structure as the MMR situation depicted by Horton. These second interviewees brought in to confront the scientists are not 'lay' persons

\footnotetext{
14 This phenomenon is known as the "expert patient" in health policy circles (again, thanks to Trisha Greenhalgh for supplying this point). See the discussion of general practitioners' responses to this development in the STILGOE, J., Irwin, A. and Jones, K., The Received Wisdom, pp. 41-43.

15 I concentrate here on the knowledge of personal experience versus that of the scientist, but there are other characteristics that these social science cases often share with the MMR case. For example, both the MMR and the smoking case were characterised by difficulties in applying the science of the population to individual cases. Exactly the same thing can happen in economics, where the individual observations of statistics travel easily into the aggregate, but it is not so easy to reverse this. Den Butter provides relevant examples of this "road back from macro to micro" (Den Butter, F., "National Accounts and Indicators," in Boumans, M. (ed.), Measurement in Economics: A Handbook, Elsevier, Amsterdam, 2007, p. 223), such as the problems of applying measures of inflation relevant at the general level to specific kinds of households (such as pensioner households).

16 I thank Tiago Mata for bringing to my attention Dunwoody's paper about the coverage by science writers of the social sciences: Dunwoody, S., "When Science Writers Cover the Social Sciences," in GoldSTEIN, J. H. (ed.), Reporting Science: The Case of Aggression, Lawrence Erlbaum, Hillsdale, NJ, 1986, pp. 67-82.
} 
with opinions: this is the wrong label. Rather, they are individuals with personal experience, or they are experienced experts, in the field of the social science and its knowledge sets. ${ }^{17}$

A good example of this BBC news genre - in medical science- occurred on 27th October 2006 when a respected medical scientist, Dr Tom Jefferson, was interviewed about his findings on the efficacy of influenza vaccination (to be published the following day in the British Medical Journal). ${ }^{18}$ He argued that there was currently insufficient evidence, based on his survey of a wide set of investigations, that flu jabs worked sufficiently effectively to justify the policy of annual widespread vaccination against the flu. He was paired in the science slot with Mrs Fish, who suffered from asthma, and had had flu vaccinations annually for 12 years. She reported having experienced no respiratory/chest infections during that period compared to frequent ones in the years before. In the interview, Jefferson stressed that the evidence was weak on certain groups (the elderly), and not always consistent when taking account of different background medical conditions, and those in different living circumstances (e.g. nursing homes versus the community). His science based evidence did not actually contradict the personal experience of Mrs Fish and it was clear that he recognised the validity of her experience. At the end of the interview, he was asked what has become the standard question in these interchanges: "If you had an elderly mother who'd been going to get vaccines each year, would you be advising her to get it this year?" to which he replied "It's a personal thing. I wouldn't."'19 The question immediately makes the case a non-abstract, personal, one to match the experience of Mrs Fish, but in the British context, its use indicates both the public lack of trust in the scientific knowledge and an associated willingness to see personal experience as offering some equally valid knowledge. It is worth noting also that in these situations, there is no such catch question to Mrs Fish, for an interviewer cannot possibly cast doubt on her experience except by casting doubt on her truthfulness.

What is there about the structure of these situations which allows this recognition of the validity of personal knowledge, a recognition that we find also in the social science interviews? First, there is the mismatch between the epistemic scope of the scientific work (a meta-survey of the existing research findings) being reported and the personal experience expressed on the subject considered. In equivalent cases of social science knowledge, much of the social science work reported is either statistical work or survey work. Survey work is an interesting combination of the personal with the statistical: asking sufficient people about their experiences

\footnotetext{
17 I am told by my colleagues at the University of Amsterdam that similar pairings occur in the Dutch news media, for example, see footnote 52 .

18 The pairing can be heard at the BBC News Section, "Listen Again" facility for 27th October, 2006, 7.34 am. available at: $w w w . b b c . c o . u k /$ radio4/tomorrowtoday/pip/archive.

Jefferson was writing as "co-ordinator" of the vaccines section of the influential Cochrane Collaboration; his survey of the evidence is found in JefFerson, T., "Influenza Vaccination: Policy versus Evidence," British Medical Journal, v. 333, n. 7574, (2006), pp. 912-915. He also featured in the MMR debate by writing critically of the methodology of adverse event studies; see Price, D. and Jefferson, T., "Methodological Problems in the Interpretation of Adverse Event Data Included in a Systematic Review of Adverse Events Following MMR Immunisation," 4th Symposium on Systematic Reviews: Pushing the Boundaries, Jefferson, Oxford, July 2002.

19 Although the interviewer's motivation here may have been to establish "balance" by finding a divergence between the scientific and personal knowledge, this did not occur and the scientific and personal evidence, listened to carefully, did not conflict. Nevertheless, the question was an important one in this context, and might be called the "Gummer question." This is named after a government minister who asked his daughter to eat a beefburger in front of the TV cameras in order to persuade the British public that beef was safe to eat during the BSE (mad cow disease) crisis. Of course, as it turned out, it was not safe and the event has ever since typified the British public's reason to mistrust scientific expert judgements when heavily endorsed by the state.
} 
to enable statistical analysis to be done with the answers. In these radio interchanges, the social scientist is rarely faced with an individual actually included in the survey (for such surveys respect the anonymity of the respondents), but rather by a person from the set of people who might have been surveyed, or by a worker who works with such a group - for example of drug addicts, of single parents, of adoptive parents, of pensioner households etc. In both these kinds of one-to-one exchanges, the individual experience is set against the social scientists' knowledge of the population or sample surveyed. Such survey work is presented as the more obviously scientific method of knowledge gathering, but in these BBC set-ups, as in the Jefferson-Fish interchange, it is not seen as necessarily providing a more legitimate mode of knowing or of producing a more salient piece of knowledge. An example of this juxtaposition was the pairing of Professor Sue Hallam reporting her survey on the musical instruments that children chose to play with a successful female trumpeter, Alison Balsom. ${ }^{20}$ It seems, according to the social survey research, that children choose musical instruments pretty equally in their primary school, but by the time they reach secondary school (or by age 11-12yrs) a gender difference has set in (e.g., boys choose to play brass instruments, girls woodwind ones). The discussion was about how, when, and why, this occurred, comparing the survey findings with the individual experience of Ms Balsom. Once again, both sides of the pairing found ways to show how their knowledge and experience were complementary rather than contradictory.

So, what exactly is the knowledge set against the scientific knowledge here? My second point is (as with the medical case) to suggest that the alternative knowledge responses are not based on ignorance or stupidity - rather such knowledge is personal knowledge of experience..$^{21}$ The facts of social sciences are ones that stem from scientific knowledge, but in the social world, everyone is their own expert. Everyone lives in society, and experiences either first-hand, or closely second-hand, the same phenomena that social scientists investigate. Everyone acts in the market place, has experience of working, choosing what to buy, and so forth. Everyone has an education, knows someone who is a single parent, or is a pensioner. Everyone has seen police in action, entangled with bureaucracy and dealt with corporations, if not directly themselves, at close hand to someone else. Consequently, people are not only the subjects of scientific investigation, but are themselves observing and making sense of their own experiences in social and economic affairs. Just like individual parents who watch their child, personal observations and personal experience creates both some kinds of factual knowledge and some insight into relevant relationships.

Very often, the "non scientist" in such pairings may be an individual who has long experience of working with other people and so they draw on a range or set of repeated experiences: a teacher with twenty years experience of five year olds in a classroom; a social worker with years of experience of housing problems; etc. This results not in one individual case-based knowledge to be set against statistical knowledge or survey-based scientific knowledge. Rather, in such experienced people, we find a somewhat broader personal knowledge, not the scientific knowledge of a social scientist, but akin to the many-cases knowledge of the clinician, an accumulated knowledge: so the personal knowledge on offer is the knowledge of experience of someone who, in their daily life, is a professional dealing with such experiences, ie, the experienced expert.

20 This pairing occurred on 11th April, 2008, 7.42 am (see footnote 18 for web-reference). Hallam, a professor at the University of London's Institute of Education (and sometime professional musician) researches issues of musical education. Her paper is Hallam, S., Rogers, L., and Creech, A., "Gender Differences in Musical Instrument Choice," International Journal of Music Education, v. 26, n. 1, (2008), pp. 7-19.

${ }_{21}$ To use the term "personal knowledge" requires a reference to Polanyi, M., Personal Knowledge, Routledge, London, 1958, though this paper has been more informed by Polanyi, M., The Tacit Dimension, Routledge, London, 1967. My sense of personal knowledge might be understood as lying between the personal and articulated nature of scientific knowledge discussed in his former book and the un-articulated but individual knowledge of his latter. 
Because it is personal and experiential, such experienced expert knowledge may sometimes be labelled in these interchanges as "opinions" by the professional social scientist as a way of downgrading its legitimacy and validity, but this is clearly a rhetorical strategy. Nor is this knowledge expressing "values," i.e., left or right political values, or about ideological elements. (This is not to say that these are not involved; rather that, in the fields of social science, such elements are equally found embodied in the knowledge of the professional social scientist. ${ }^{22}$ ) Nor are we talking about "tacit" knowledge, the kind of personal craft knowledge of materials and technologies that is revered, but remains mysterious precisely because it can not be articulated. Rather, this social science experiential knowledge of the experienced expert is a personal but articulated knowledge of facts and relations; it is the kind of knowledge that - gained under careful observational circumstances, or from long-standing interaction with the circumstances and cases - can be quite well articulated and analysed. Indeed, judging by the BBC science slots, such experienced expert knowledge is often better articulated than the knowledge held by the conventionally labelled "scientist"! Knowledge obtained from observation and experience is not a folklore category, rather it refers to the method of acquiring scientific knowledge that goes back to the Baconian tradition, well before the method of experiment developed in the seventeenth and eighteenth centuries while statistical evidence and reasoning became an acceptable scientific way of finding knowledge only in the nineteenth and twentieth centuries.

Of course not all social scientists have the same kinds of methods. Some social (and human) sciences are particularly dependent upon methods of careful observation: ethnographies, case work and survey work. These modes of research are either consistent with individual experience (for example, case studies dominate management sciences, some areas of sociology, and history) or privilege personal experience (survey and ethnographic work in sociology, psychology and anthropology). Other social sciences have tended to eschew the individual experience and been more heavily dependent - as economics - on statistics and models. ${ }^{23}$ Scientists in fields which privilege personal or self-reporting accounts, or operate ethnographically may be more likely to accept the personal knowledge of individuals. Those that operate through more technocratic methods - as economics - are less likely to do so, and indeed, professional economists are rarely faced at the $\mathrm{BBC}$ with an opposing personal knowledge account as are sociologists. Instead, the $\mathrm{BBC}$ prefers to conduct single interviews of a professional economist from either academic or business life, or to enact a debate between those with similar knowledge levels. ${ }^{24}$ Stephen Turner's observation that economics, despite its technocratic nature, has a weak cognitive authority is relevant here. ${ }^{25}$ Jokes about economists who say to any question "it all depends," or that "ask any two economists and you will obtain at least three solutions," are one aspect of this weak cognitive authority. If one doubts this, a simple comparison between the way medical authorities pronounced on the MMR vaccination crisis and economists on the 2007-8 financial crisis is instructive. Whereas members of the medical establishment pretty much agreed amongst themselves in the former case, in the latter case we see this weak cognitive authority in the way that the media often produce several different academic and experienced economic experts,

\footnotetext{
22 For a classic statement, see Schumpeter, J., "Science and Ideology," American Economic Review, v. 39, (1949), pp. 345-359.

23 A new interest in the directly expressed individual economic experience in the work on 'happiness' and in behavioural economics is returning economists to the survey method last used in the field in the late 19th century.

24 Business people are treated by the BBC more like politicians, to be questioned not for their knowledge, but to account for their actions, for example in allowing prices to rise, or for giving loans too easily, or not easily enough. Their personal experience is seen as an expression of self interest, not as experience relevant to knowledge questions.

25 Cf. Turner, S., "What is the Problem with Experts?," Social Studies of Science, v. 31, (2001), pp. 123-149; especially, p. 132 .
} 
who discussed different symptoms, gave different diagnoses, offered different treatments and dissected different elements of what they all considered a complex economic crisis.

Yet, even in the field of economics, we can find spaces in the media where personal experience and experienced experts are given voice in the same public domain. The single most important economic policy moment in the UK year is the annual "Budget." This is not just an accounting of forthcoming governmental income and expenditures. Rather, it involves documents and a speech by the Chancellor (the chief economic and financial minister and usually the second most powerful political figure after the Prime Minister) which survey the current state of the economy, forecast its future path, and announce a wide range of economic policy changes for the forthcoming period. In its coverage of this event, the serious UK newspapers have developed a mode of reporting which manages to be both educational and informative while reporting the analysis and responses of both scientific experts, experienced experts, and a range of personal experiences. Even the Financial Times, generally regarded as the most focussed on economics matters, follows this path. In the 2007 budget, for example, it gave space to three of the most senior policy economists in the UK for their "viewpoints" in which they gave general but critical comments on the budget. ${ }^{26}$ Experienced experts appear equally with academic economists in particular analyses. Thus, an article on productivity and the budget quoted two professors of economics, while one on growth used two business economists (considered both professional and experienced experts in these contexts). An article on the economics of science involved comments from leaders of science lobbying groups, university commentators, the President of the Royal Society (the most prestigious science body) and the union leader representing technical workers in science. An article on low income families incorporated interview material from the heads of the main charities involved, namely One Parent Families and the Child Poverty Action Group. All these different academic and experienced experts were given equal status in the way their knowledge was reported.

None of this is surprising given that the Financial Times is aimed at those who are professionally interested in these matters. It is more surprising however that the knowledge of personal experience was also brought in and given direct expression in the pages of the Financial Times, in ways which seems to be specific to its budget coverage. This was not just the personal experience of those in the business community, which was well covered with columns of quotes (for example on research and development or on investment) under the headline "Business Speaks." More space was actually given to an alternative set of reports offering insights from a greater variety of personal economic experience under the heading: "My Budget." Each of these boxed items contained a photo, and an account, from a series of individuals. ${ }^{27}$ These people were named, but also labelled: the chief executive, the manufacturer, the environmental campaigner, the entrepreneur, the professor, the health service worker, and the pensioner. Each person was interviewed by an "economics reporter," and given space to react with an analytical and critical stance to the budget, and to reflect not on their own position, but as someone who held specific personal knowledge according to their given labels, eg, whether the budget was helpful for the environment, or the National Health Service, or for pensioners in general. The Financial Times's 2008 coverage employed the same device and reported some trenchant and insightful criticisms from its chosen people: the tailor, the regeneration specialist, the

26 In "Three economists give their viewpoints" (Financial Times, 22/03/07, p. 11 of Budget Supplement) the economists were Robert Chote, Director, Institute of Fiscal Studies; De Anne Julius, Chairman of Chatham House (and ex Bank of England Monetary Policy Committee and ex professional business economist); and Martin Weale, Director, National Institute of Economic and Social Research.

27 Each was from the same marginal parliamentary seat, though not much was made of this point. 
professor (a university leader), the commuter, the pensioner, the brewer and the entrepreneur. "The brewer" pointed to a failure to use economic policy to affect a big social and health problem: "You do despair. We have been getting lots of lectures about tackling binge drinking and had been looking for some long-term vision from the government. But lifting duty [tax] across the board just raises more cash for the government - and will not prevent drink being sold by supermarkets as a loss-leader." "The entrepreneur" commented, succinctly but equally effectively on the $£ 60 \mathrm{~m}$ set aside for training: "It doesn't seem like a lot of money to train a country." ${ }^{28}$ In other words, these people were using their personal experiences and specific working knowledge to give a response to a general policy decision.

The Times offered something similar, presenting a double page spread under the heading "The Jury." 29 These eleven people (with their households) were first described according to their economic situation (their occupation, age, income, and main assets), and they were clearly chosen to represent a cross-section of individuals in the economy: small business owner, professional couple, single pensioner, young professional, tradesman, nurse, retired couple, student, single mother, disabled worker, and company director. After the description, each provided a "verdict" about the budget impact on them, and on something general that they had experience of: for example, the "disabled worker" commented favourably, not on disability benefits, but on increasing money to defence (because she had three sons who were in the forces), the nurse discussed investment in the National Health Service, but noted that more money was unlikely to be spent on what she thought were the right things (buildings and cleaners).

What we find here then is the use of individual people labelled by the characteristics of their household or their occupational or their geographical position, and given the chance to offer insights from their own economic experience into some of the details of the economic policy in the budget. What kind of representing quality do these chosen few share. It seems not to be occupational classes according to our normal socio-economic characteristics, nor does it seem to be any statistical notion of representativeness (that is, there is no sense in which tailors are a statistically significant class of workers). Indeed, these labels seem more like a modern version of the children's counting rhyme: "tinker, tailor, soldier, sailor, rich man, poor man, beggar man, thief" - a cross section of occupations and income, rather than a well accepted set of categories of people.

The notion that these people are chosen and act like a jury captures the notion of representation going on here. These selected individuals represent a range of economic experiences and socio-demographic characteristics, and, having heard the Chancellor's speech, give their verdicts. But they do not directly represent economic classes nor always give comments that reflect an occupational or income group that they come from: it appears that they are not chosen individually for their representativeness, but collectively for their ability jointly to represent the public voice, the voice of an economy rather than a society. ${ }^{30}$ And, as in a legal jury, their verdicts can not have been made on hearing just one expert witnesses, in

28 The Financial Times Budget 2008, Thursday March 13th, 2008.

29 Cf. The Times, London, 22/03/08, pp. 10-11.

30 This account of voice has much in common with standpoint theory which also provides an epistemology based on personal experience. This discussion of juries may have clarified a difference in emphasis here: the individual speaks not as a member of a particular group because of certain shared characteristics with other members of that group but rather as individuals, or experienced experts, with personal experience relevant to a particular question. (See Anderson, E., "Feminist Epistemology and Philosophy of Science," in Stanford Encyclopedia of Philosophy at http:// plato.standord.edu/entries/feminism-epistemology, access on 17th April, 2008, for an introduction to the literature on standpoint theory in the context of feminist epistemology.) 
this case, the Chancellor, for this would not be enough evidence for them to make the critiques they do. Rather, as in other juries, they each judge his analysis and his policies by weighing up his Budget's claims against their own lifetime experience and understanding of the economy. ${ }^{31}$ They are not a lay public commenting on an economic matter, but a economic jury of citizens, using their experiential knowledge of the economy to judge — on behalf of their peers, i.e., citizens - the adequacy of the analysis and policies for the future of the economy. ${ }^{32}$

\section{EPISTEMology, Experience ANd Voice}

What enables such personal and experienced-based knowledge to gain voice in the public sphere. It is important to stress here that my question is about the articulation of personal knowledge from experience by participants in the society and economy. It is not about the attempts to understand science made by a public who are generally defined and framed, in the literature on natural science, as an audience or consumer of science. There, it is generally assumed that the public cannot fully understand and participate in that same knowledge space as the scientists because it is knowledge of another kind of content and acquired in another way, that they, by definition, do not hold.$^{33}$ Nevertheless, the literature on public engagement, rather than understanding, does prove useful in clarifying certain issues of the public's knowledge of social sciences. ${ }^{34}$ We can investigate the knowledge gap between the public and the traditional sciences in terms of three elements in science "its intellectual contents, its research methods, and its organizational forms of ownership and control." ${ }^{35}$ This triad is equally useful in considering the relationships between the knowledge of the experienced expert compared

31 This account of using the knowledge of personal experience in providing "a jury of peers" contrasts with the discussion of lay juries (i.e. non expert) for science policy decisions, see Evans, R. and Plowys, A., "Listening without prejudice? Rediscovering the value of the disinterested citizen," University of Cardiff, website paper, $w w w$. cf.ac.uk/socsi/contactsandpeople/harrycollins/expertise-project/expertisepreprints.html\#listening (access on 26th April, 2008), pp. 17-18.

32 How these token economic citizens are chosen is an interesting question raised by Tiago Mata.

33 See also footnote 6 . Science studies tend to treat public engagement with science as an engagement with "the other": the public are not the scientists and do not have the scientists' knowledge and so must always effectively remain in some deficit. The discussion about expertise and experience in these circles is sophisticated, yet the base assumption remains that the experience or expertise of the lay public must be qualitatively different than that of the scientists because the content of the sciences are about something other than them as people, or their experience, or their social arrangements. (Of course, this important assumption is the very one that does not hold here.) Thus, even where there is recognition that there may be groups with relevant expertise or experience, it remains knowledge that has to be constructed or found - not experienced, and so of something that remains "other." References and recent reviews of this literature are found in Collins, H. and Evans, R., "The Third Wave of Science Studies: Studies of Expertise and Experience," Social Studies of Science, v. 32, (2002), pp. 235-296, and in the various responses to it by Jasanoff, Rip and Wynne (cf. JasAnoff, S., "Breaking the Waves in Science Studies," Social Studies of Science, v. 33, (2003), pp. 389-400; Rip, A., "Constructing Expertise: In a Third Wave of Science Studies," Social Studies of Science, v. 33, (2003), pp. 419-434; and Wynne, B., "Seasick on the Third Wave? Subverting the Hegemony of Propositionalism," Social Studies of Science, v. 33, (2003), pp. 410-417).

34 Brian Wynne's work is particularly useful for he tends neither to privilege the status of science and scientists, nor treats such scientific knowledge as an other kind of knowledge, nor assumes an unbridgeable ignorance in the public (see Wynne, B., "Knowledges in Context," Science, Technology and Human Values, v. 16, (1991), pp. 111-121; Wynne, B., "Misunderstood Misunderstanding: Social Identities and Public Uptake of Science," Public Understanding of Science, v. 1, (1992), pp. 281-304; and Wynne, B., "Public Uptake of Science: A Case for Institutional Reflexivity," pp. 321-337). Another exception, and one of the few treatments that pitches this issue of cognitive authority in the context of liberal political traditions, and without treating the public as "the other," is offered in TuRNER, S., "What is the Problem with Experts?," pp. 123-149.

35 As Wynne suggests in "Knowledges in Context," p. 120. His distinctions seem obvious, but like all obvious distinctions, they were and remain immensely useful in sorting out confusions: they help to locate exactly where the public mis-understanding or mistrust of scientists lies in any particular case. 
to scientific knowledge in the social sciences. While the knowledge of experienced experts maybe about the same stuff as that of social scientists, their research methods may be different and the mode of organisation will also likely be different.

There are scientific fields where amateur scientists can still claim discoveries and make valid scientific contributions: the amateur botanist perhaps or the amateur astronomer. These sciences are in part dependent on meticulous observation and description by the individual working on their own, observing particular aspects of the world with patience over long periods, taking note of variety and of changes in the most ephemeral of things and of the smallest of deviations in the natural world that surrounds them. Some sciences indeed have been historically dependent upon such contributions of amateur scientists. These amateur scientists have followed the same kinds of knowledge paths as their professional colleagues, they are specialists in somewhat the same kinds of ways. It is these same grounds that give them voice in the scientific world. ${ }^{36}$

In the social sciences, there are people who work in this same kind of way as in these natural sciences, observing with patience the particularities of behaviour of people, social events, cultural changes, economic cycles and so forth. But, in contrast to amateur astronomers, such amateur social scientists rarely claim expertise in the scientific ways of knowing recognised by social scientists. They do not know about social science from using the modes of social science research: surveys, event studies, statistics, modelling — rather, they know things about society and economy from personal experience because they live in the world, they observe that world, and they interact within that world. Such events and behaviour are not separate objects to be studied from afar, but part of their life. The characteristics of such personal knowledge fit ill with the stereotyped "deficit model" of the public understanding of science project, which fails to have quite the same resonance in dealing with the social sciences as with various natural sciences. The fact that everyone lives in society and knows something of it, mean that the facts about events and relationships drawn from personal experience cannot simply be dismissed as ignorance just because they are not known through the methods of science. ${ }^{37}$

We may hone this idea of personal knowledge in the social sciences further by contrast with other characterizations of personal scientific knowledge based on experience. Brian Wynne outlined the notion of "lay expertise" based on his research with the hill farmers of NW England during the period after the Chernobyl disaster. ${ }^{38}$ The knowledge of farmers was presented as complementary to the knowledge of scientists dealing with the effects of the fall out: they had different kinds of knowledge and about different aspects of the problem of how to decontaminate the sheep from nuclear fall-out. The farmers' knowledge was a personal craftbased knowledge, articulated in the sense that it was shared and discussed with other farmers and equally applied in their own decision making (in the same way as mothers share similarly acquired knowledge of their children's health). The contrast I want to point to is that such "lay expertise" (e.g., of how lambs behave, how farming goes on) is seen as complementary knowledge to the "scientific expertise" (e.g., of the life of radioactive fall-out) because they

36 The ways in which such amateur scientists' knowledge intersects with professional knowledge is of course a complex matter; for an example especially pertinent to this paper, see SECORD, A., "Science in the Pub: Artisan Botanists in Early Nineteenth-century Lancashire," History of Science, v. 32, (1994), pp. 269-315.

37 This is perhaps why economists like counter-intuitive findings so much, because they are less likely to accord with personal knowledge, which can then be seen as folklore (for example, J. M. Keynes in the Great Depression advised people: don't save for a worse rainy day, go out and spend!).

38 See Wynne, B., "Misunderstood Misunderstanding: Social Identities and Public Uptake of Science,” pp. 281-304. 
are different not just in origin - how that knowledge was acquired - but in content. Such personal knowledge can thus be dismissed by natural scientists on two grounds - content and method. In contrast, in social science cases, although the personal knowledge and the scientific knowledge may be differently acquired, they are not necessarily different in content. The parent whose child is taught spelling and reading by phonetics has experience which may agree with, or may contradict, the findings of the educational specialist who researches how learning by phonetics occurs using social scientific techniques of investigation. That is, it is knowledge about the same problem, even though differently acquired.

We can get a bit closer than this to the way these two different sources of knowledge - personal knowledge from experience and scientific knowledge - fit together in social sciences. I return again to commentary by Wynne in 1991, for while his discussion is oriented towards more traditional fields (for example, of the knowledge held and used by patients and families about a specific medical condition, or by local communities about the variability of local pollutants), his findings prove particularly relevant to the claims made here about the social sciences. He observes that the extra knowledge about a particular situation or condition held by such individuals and groups is often "more specifically accurate" about that problem even while "less generally authoritative" than the knowledge held by professional scientists. This more specifically situated knowledge may even "confound formal scientific authorities" and "come into conflict with the generalized claims of the more remote technical specialists." ${ }^{39}$ And, as he noted, the content of this additional knowledge from personal experience even proved sufficiently close to that of the scientists to be used by these personal or experienced experts to measure or judge the quality of the knowledge offered by scientists. ${ }^{40}$

These characteristics of personal experience are likely to be more generally relevant to discussions of the social sciences where there is likely to be a much wider base of knowledge based on experience than in cases based on natural science and their technologies. Wynne's finding are certainly consistent with my examples of personal experience knowledge of social sciences reported in the print and radio media discussed above. In these, it seems that knowledge from experience consists of facts about situations and events, and some understanding of relationships, the kind of knowledge which can be built up without necessarily having the theories and concepts that we associate with scientific knowledge and which allow scientists to make more general claims. As we would expect, the knowledge of personal experience is less theorized and less conceptualized than the knowledge from the scientific community. ${ }^{41}$ This does not mean that social scientists rejected the situated knowledge of experienced experts as inaccurate. In the cases I have reported, for example, the flu vaccine and the musical instruments cases, the academic expert and the person with experience did not confound or contradict each other (though in the former case, there was the potential for the evidence of personal experience to be inconsistent with that from the expert; as it was, his evidence was inconclusive) and when we listen to them carefully, we find that the scientist was able to accommodate the specific personal knowledge within their wider more general knowledge.

39 Quotes in the previous and in this sentence come from Wynne, B., "Knowledges in Context," pp. 114 and 118 , respectively.

40 This process in turn depends on people's social and institutional experience of such interactions with scientific experts (cf. Wynne, B., "Knowledges in Context," p. 115).

${ }^{41}$ My reflections here rely on a close listening and reading of the media uses of personal experience, rather than any ethnographic or survey of experienced experts in the social sciences. There seems much less work done on the public understanding of social sciences and its manifestations than on the natural sciences. 
Where then lies the difference between my notion of voice and that of public engagement? The significant point about the voicing of personal knowledge in the social sciences is that it comes from a general democratic right of the expression of social and economic experience. Amateur social scientists - individuals and our experienced experts - claim a voice in the social scientists' account of that world not from following a social scientific mode of enquiry (as their botanist and astronomer cousins do) but because of their position as citizens in their own society: everyone has the right to be expert in their own experience and to express it. If someone has been ill-treated by the police, they have a right to say so; if someone has personal knowledge of drug addiction through working in rehabilitation, they have a right to share in discussion on that topic. In a democratic society and economy, everyone has a right not just to express their opinions, but to evaluate and tell the facts of their experience of the social, economic and political world. Thus, the voicing of experience (from personal or accumulated experience) comes from the right of expression in a democratic society; from the rights of citizens to use their own experience to argue about political, economic and social arrangements that affect them, their clients, their students or their children, directly. And, as political and economic rights are extended into other domains, eg, medical ones, then those rights of the expression of experience follow on. Remember the case of Mrs Fish — she cannot be called a liar by the BBC interviewer, but nor by the medical expert that is lined up against her, even if his wider and more general evidence had been sufficiently strong to be contradictory to the facts of her personal history. Such personal experience knowledge has not just a legitimate claim to be voiced, but to be listened to.

These citizenship claims to articulate the knowledge of economic and social experience are both stronger and more generic (less specialised) than the rights associated with the notion of stakeholders, which seem more like property rights. Again, a comparison with the sheep farmers case is instructive. As Wynne presented that case, the scientists were unable to take advantage of farmers' significant lay knowledge in the behaviour of sheep and economics of hill farming to make their own scientific knowledge relevant and effective and thus reduce their own scientific ignorance about how to decontaminate the sheep. And while the farmers felt their specialist knowledge had a right to be expressed and wanted to make use of it to save their own economy, its expression was mired in difficulties for both sides in dealing with each other. Farmers found the power of the bureaucracy over their decisions, the scientists' modes of decision making, their own lack of trust towards the scientists, and the community relations that the hill farmers had with the workers at the Sellafield nuclear plant, all intervened. The scientists faced their own parallel set of constraints in communicating with the farmers. Neither side were able to articulate their knowledge to each other in such a way as to solve the problems they faced in an effective manner. While Jasanoff has interpreted the failure of both sides to use their complementary knowledge as due to their radically different ways of understanding the world, ${ }^{42}$ Wynne's three way distinction (noted earlier) suggests that the lack of communication between these groups came not from their different knowledge sets, nor their different ways of knowing such knowledge but from the distrust — based on experience - by the sheep farmers of the institutional set up of the nuclear science knowledge and, on the scientists' side, by the lack of an institutional basis for the farmer's knowledge.

Yet this last interpretation undervalues the stakeholder rights of the farmers to express their own experience - this was not just a matter of safety of themselves and their families,

42 Cf. JASANOFF, S., "Breaking the Waves in Science Studies," p. 392. 
but of their economic livelihood, a right that seems to have been hardly recognised by the scientists. Why didn't the sheep farmers make their stakeholder knowledge heard? There are many occasions in which stake-holders' rights, voices, and experiences, are brushed aside in the economic world, for example, by capital holders who believe a firm belongs only to them and ignore the rights and knowledge or their workforce or the experiences of their pensioners. Stakeholder rights nearly always overlap with the rights of others, which is why their expression is so often resisted. But even when not resisted, such experienced knowledge claims are expected to be expressed within the terms and limits of those stakeholder rights. For example it is a legitimate right of workers to express their personal experience of the pay system in their company, and so those paid below the minimum wage are expected to report their employers for not doing so (though here, as in many other such situations, the relative power of those involved will intervene to prevent that expression). Yet their rights to voice other aspects of their knowledge which might be regarded as beyond their particular stakeholder rights, for example, commercial secrets about a production innovation, would generally fall outside this legitimate range of expression. That is, the expression of personal experiences are usually restricted to those aspects of knowledge defined as relevant to the particular interests of such a stakeholder (which is why they carry the intuitions of property rights). Thus the problems of "whistleblowing" arise where the interpretation of these stakeholder rights differs between the company (or state) and the whistle blower: where the organisation may regard the voicing of such personal knowledge as dangerous and inappropriate and the whistle blower may have the view that it is dangerous and inappropriate not to voice the knowledge - for example, about pollution caused by the company's activities. ${ }^{43}$ The classical economic analysis of such problems suggests that the choice that the individual must make is between leaving the situation, expressing their knowledge as a way of changing the situation, or staying and keeping quiet: exit, voice or loyalty. ${ }^{44}$

In contrast, the citizen's legitimate expression of personal knowledge of social and economic experience is restricted only by general social conventions (expressed, for example, in the laws of slander and libel). This makes such knowledge potentially more powerful in a very particular sense. Voice: the citizens' articulation of experienced knowledge, is not just an expression of such knowledge but - because it is unrestricted - contains the power and gives the means to question the framing of the issues and thus to contest both the questions and analysis offered in the social scientific research. For example, whereas the academic expert Sue Hallam was worried about the negative aspects of gendered decisions by children (such as the likelihood of boys who chose to play the flute being teased), Alison Balsom, the trumpeter, effectively

\footnotetext{
43 In the UK, civil servants are covered by the Official Secrets Act, which stops people voicing their experience as civil servants, a particularly problematic blanket charge which, nevertheless, proves my point that citizens will otherwise take this expression as a right.

44 This choice - for individuals in failing institutions such as firms or states - has been analysed most memorably in the social science literature by Albert Hirschman in Hirschman, A. O., Exit, Voice and Loyalty: Responses to Decline in Firms, Organisations and States, Harvard University Press, Cambridge, 1970, where he associates voice with both stakeholder rights and with citizenry rights. In my account here, voice is more narrowly defined as the articulation of knowledge, not the choice between actions.

Of course, there are other reasons, often more powerful, such as the relative funding which opens or closes access to media, courts and so forth that limit the effective expression of personal or experienced knowledge and restrict the travels of that knowledge to the relevant communities or decision makers (for an example from climate science, see for example Oreskes, N., "My Facts Are Better than Your Facts: Spreading Good News about Global Warming," in Howlett, P. and Morgan, M. S., How Well Do Facts Travel?, Cambridge University Press, Cambridge, forthcoming).
} 
reframed the question by turning it around onto the positive aspects of being different ${ }^{45}$ The budget respondents in the Financial Times reinterpreted and reframed the economic policy of the budget to make it relevant to much narrower concerns than the broad brush groups and categories such as "pensioners" or "families" or "education spending" offered in much of the Budget and its commentary. The voice of experienced knowledge does not just add to the knowledge of the social scientists, but can reframe their questions or findings.

The denial of voice is therefore not just the denial of the knowledge of experience, but the denial of citizens' abilities to frame and interpret their own experience and so affect the way a question is discussed. This is how 'voice' contrasts with 'engaging' the public in one-sided knowledge discussions, or carrying out projects to make them 'understand' science, or even the legitimate but limited expression of stakeholder interests. ${ }^{46}$ That is, the denial of voice is about the exclusion of particular problems, issues, and the framing of particular meanings rather than just the exclusion of people with relevant knowledge. The possibility that the experienced expert enjoys to frame the questions and meanings of the debates in their own terms follows from their rights as citizens, not as stakeholders. ${ }^{47}$

It might reasonably be argued that, as it is, this is only one particular national account of personal or experienced knowledge, and the account will not travel well! Of course, this is a national story: voice is only heard within a particular 'civic epistemology' which creates the environment within which the facts of experience can be made to travel. While the chance to voice personal knowledge of experience is a feature of a democratic society, the ways in which voice can be expressed, or may be heard, are shaped by the local civic values, mores and laws of any particular society.

We can see how the expression of this individual, personal but articulated, experiential knowledge of social sciences is shaped by looking more closely at this notion of "civic epistemology," a notion that Sheila Jasanoff defines by asking how scientific and technical knowledge come to be seen as reliable in public spaces, so that collective choices can be made based on publicly shared knowledge ${ }^{48}$ Civic epistemology is the process by which democratic societies come to know about and make decisions about science and technology matters. Jasanoff treats this civic epistemology as based on tacit-knowledge, not at the level of individuals but at the level of society: "modern technoscientific cultures have developed tacit knowledge-ways through which they assess the rationality and robustness of claims that seek to order their lives." ${ }^{49}$ This civic epistemology contrasts with the personal articulated knowledge of citizens that I have been describing. But they are not inconsistent.

\footnotetext{
45 Mrs Fish effectively reframed the question about the flu vaccine: whereas much of the medical evidence surveyed was an analysis of deaths and hospital admissions that were likely to have been avoided by the vaccination programme, her experience was about illness without hospitalisation, and the medical analysis might not even have counted the benefits of her experiences even though it would count the costs of the vaccine.

46 These are one-sided not just in knowledge asymmetry, but because the public is usually "engaged" within the framework defined by the scientists.

47 Wynne, in his provocative critique of Collins and Evans' "third wave" paper noted of his sheep farmers' case, that "the power to define the meaning of the questions remained with the ... scientists and officials" (Wynne, B., "Seasick on the Third Wave? Subverting the Hegemony of Propositionalism," p. 408). My point may be seen as the positive other side of this coin: in the social sciences, such reframing power comes with the citizen's rights to voice experience which, as I noted, is stronger than his farmers' stakeholder rights.

48 Cf. JASANOFF, S., Designs on Nature: Science and Democracy in Europe and the United States, Princeton University Press, Princeton, 2005, chapter 10, pp. 247-271.

49 JASANOFF, S., Designs on Nature, p. 255.
} 
How civic epistemology is constituted depends on the society one lives in for it is defined as "culturally specific, historically and politically grounded, public knowledge-ways." ${ }^{50}$ The particularities of different national civic epistemologies that she presents from her case studies (with respect to bio-technologies in agricultural and biomedical sciences) are presented as having a wider cultural grip. As such, they intersect with the possibilities for expression of the kind of personal yet articulated knowledge of the social sciences - citizenry personal knowledge — that I am discussing here. For example, Jasanoff's three way comparison of the US, Germany and the UK points - for the UK - to the relatively strong role of empirical science in demonstration practices, the importance of the expertise of experience (relative to the professional skills required in the US mode, or the training and accredited skills of the German expert), and the relatively high value placed on consultation rather than formal reasoning. These are all consistent with a public mode of civic epistemology for the social sciences in which people with non-accredited expertise - i.e., knowledge based on experience not qualifications - are valued and able to voice that knowledge. Thus Jasanoff's characterization of the civic epistemology of the UK fits with my observations about social sciences in the UK. ${ }^{51}$ The fact that civic epistemologies differ suggests either that other societies are likely to see social science personal knowledge experience somewhat differently, or that their citizenry's personal knowledge might have a less powerful voice in their civic epistemology, or that its range and places of expression may be different, but not that in other societies voice does not exist, albeit in various different forms. ${ }^{52}$

\section{Conclusion}

Societies have different ways to develop democratic process with respect to scientific knowledge within the context of various civic epistemologies. Yet most of the literature that treats questions about public scientific knowledge does so in the context of natural science where the public is seen as handicapped compared to the knowledge of the scientist. This paper has explored the structure of situations in medical and social science where the observations of experience or the experienced knowledge held by citizens, is presented as valid knowledge of these topics.

While voice represents the citizens' right to express, not just their opinions, but, their knowledge based on experience, the articulation of that knowledge is always going to depend on the local civic context. For this reason it is difficult to generalise about how the individual gets the facts of their personal experience to travel into the public domain. By implication, the pragmatics of the articulation of personal social science knowledge need to be explored, analysed and compared in different societies. Until then, "voice" offers a generic concept, a way to understand why social science personal knowledge has a different validity, and so is likely to be expressed in different ways, than public expertise about other sciences. This in turn

\footnotetext{
50 JaSAnOFf, S., Designs on Nature, p. 249.

51 In the context of the civic epistemology of the UK, current ideas about governance argue for stake-holders, users and lay persons to be part of governance structures of most organizations. I suggest that, over a range of questions in the social and economic realm, their importance is not as "lay" persons, or as "disinterested" persons but as interested citizens bringing relevant social science experience to those organisations and voicing it.

52 For example, my Dutch colleagues report examples from The Netherlands where governmental claims about the rising real incomes of the population due to government policy were challenged in TV news slots by individuals whose incomes had fallen, with ministers faced across the media table by a personal case evidencing the limitation of their statistical claims about the events in the economy — see DEN BUTTER, F., "National Accounts and Indicators," pp. 189-230.
} 
suggests that neither the public engagement literature nor the public understanding literature applies to the social sciences without some re-consideration. (In-between fields, such as those of medical treatments, might also appear differently in this new frame.) Making use of the concept of "voice" not only shows how and why personal knowledge may be complementary to the scientific work of social scientists, but why it has the possibility to challenge and reframe that knowledge of social scientists more effectively than the processes of civic epistemology do for the natural sciences.

\section{REFERENCES}

Amsterdamska, O., Making Autism Genetic, How Well Do 'Facts' Travel?, Workshop paper, LSE, March 2008.

Anderson, E., "Feminist Epistemology and Philosophy of Science," in Stanford Encyclopedia of Philosophy at http://plato.standord.edu/entries/feminism-epistemology, access on 17th April, 2008.

Collins, H. and Evans, R., "The Third Wave of Science Studies: Studies of Expertise and Experience," Social Studies of Science, v. 32, (2002), pp. 235-296.

Collins, H. and Pinch, T., Dr Golem: How to Think about Medicine, The University of Chicago Press, Chicago, 2005.

Den Butter, F., "National Accounts and Indicators," in Boumans, M. (ed.), Measurement in Economics: A Handbook, Elsevier, Amsterdam, 2007, pp. 189-230.

Downie, R. and Randall, F., "Choice and Responsibility in the NHS," Clinical Medicine, v. 8, n. 2, (2008), pp. 182-185.

Dunwoody, S., "When Science Writers Cover the Social Sciences," in Goldstein, J. H. (ed.), Reporting Science: The Case of Aggression, Lawrence Erlbaum, Hillsdale, NJ, 1986, pp. 67-82.

Evans, R. and Plowys, A., "Listening without prejudice? Rediscovering the value of the disinterested citizen," University of Cardiff, website paper, www.cf.ac.uk/socsi/contactsandpeople/ harrycollins/expertise-project/expertisepreprints.html\#listening, access on 26th April, 2008.

FitzGerald, M., MMR and Autism, Routledge, London, 2004.

Hallam, S., Rogers, L., and Creech, A., "Gender Differences in Musical Instrument Choice," International Journal of Music Education, v. 26, n. 1, (2008), pp. 7-19.

Hirschman, A. O., Exit, Voice and Loyalty: Responses to Decline in Firms, Organisations and States, Harvard University Press, Cambridge, 1970.

Horton, R., MMR Science and Fiction, Granta Books, London, 2004.

JASANOFF, S., "Breaking the Waves in Science Studies," Social Studies of Science, v. 33, (2003), pp. 389-400.

JASANOFF, S., Designs on Nature: Science and Democracy in Europe and the United States, Princeton University Press, Princeton, 2005.

Jefferson, T., "Influenza Vaccination: Policy versus Evidence," British Medical Journal, v. 333, n. 7574, (2006), pp. 912-915.

Oreskes, N., "My Facts Are Better than Your Facts: Spreading Good News about Global Warming," in Howlett, P. and Morgan, M. S., How Well Do Facts Travel?, Cambridge University Press, Cambridge, forthcoming.

Polanyi, M., Personal Knowledge, Routledge, London, 1958.

Polanyi, M., The Tacit Dimension, Routledge, London, 1967. 
Poltorak, M. et AL., “'MMR talk' and Vaccination Choices: An Ethnographic Study in Brighton," Social Science and Medicine, v. 61, (2005), pp. 709-719.

Price, D. and Jefferson, T., "Methodological Problems in the Interpretation of Adverse Event Data Included in a Systematic Review of Adverse Events Following MMR Immunisation," 4th Symposium on Systematic Reviews: Pushing the Boundaries, Jefferson, Oxford, July 2002.

RIP, A., "Constructing Expertise: In a Third Wave of Science Studies," Social Studies of Science, v. 33, (2003), pp. 419-434.

Schumpeter, J., "Science and Ideology,” American Economic Review, v. 39, (1949), pp. 345-359.

SECORD, A., "Science in the Pub: Artisan Botanists in Early Nineteenth-century Lancashire," History of Science, v. 32, (1994), pp. 269-315.

Smeeth, L. ET AL., "MMR Vaccination and Pervasive Developmental Disorders: A Case-control Study," The Lancet, v. 364, September 11, 2004, pp. 963-969.

Stilgoe, J., Irwin, A. and Jones, K., The Received Wisdom, DEMOS, London, 2006.

Turner, S., "What is the Problem with Experts?," Social Studies of Science, v. 31, (2001), pp. 123-149.

Wynne, B., "Knowledges in Context," Science, Technology and Human Values, v. 16, (1991), pp. 111-121.

Wynne, B., "Misunderstood Misunderstanding: Social Identities and Public Uptake of Science," Public Understanding of Science, v. 1, (1992), pp. 281-304.

Wynne, B., "Public Uptake of Science: A Case for Institutional Reflexivity," Public Understanding of Science, v. 2, (1993), pp. 321-337.

Wynne, B., "Seasick on the Third Wave? Subverting the Hegemony of Propositionalism," Social Studies of Science, v. 33, (2003), pp. 410-417.

Ziman, J., "Public Understanding of Science," Science, Technology, and Human Values, v. 16, n. 1, (1991), pp. 99-105. 


\title{
New Forms of Scientific Observation ANd THEIR EPISTEMOLOGICAL IMPACT ${ }^{1}$
}

\author{
Amparo Gómez
}

The field of scientific research has widened with the appearance of new forms of observation which involve non-material aspects in their objects and interventions, i.e., simulations or computer based experiments. These non-traditional forms of observation have become increasingly important in science. They have been developed in contexts involving highly complex phenomena in which material experimentation has difficulties. Computer based experiments have an important use in social sciences and biology, physics and engineering. In cognitive science, they have almost become the principal resource for research, and have been developed to a high level. ${ }^{2}$

Computer based observation has given rise to interesting methodological and epistemological analyses. ${ }^{3}$ In the epistemological field, a number of relevant questions are posed in relation to, for example, materiality, simplicity, differences between deriving and producing results, or between models and simulations. Some of these topics will be dealt with in this essay, although it will be focused in two important questions. Firstly, to what extent do computer based observation give rise to scientific knowledge? In other words, is it a resource for increasing scientific knowledge? And secondly, to what extent the results obtained in computer based observation can be applied to the corresponding material systems -albeit with sufficient approximation using Giere's terminology? The answer to these two questions will help us to establish whether simulations offer scientific knowledge about empirical systems and whether there are any essential epistemic differences between material and computer based observation. ${ }^{4}$

The main aim of this article is to try to sketch an answer to these questions. It will be analyzed to what extent the computer based observation depends of instruments, agreements and scientific theories, whether it happens in a different degree or way than in the material observation and therefore, whether it involves new epistemological problems.

\footnotetext{
This chapter has been supported by the Spanish Ministry of Science and Innovation (Research Project FFI2009-09483). I am very grateful to Michela Massimi for insightful comments and suggestions on earlier drafts of this paper.

2 Cf. Peschel, M. F. and Scheutz, M., "Explicating the Epistemological Rol of Simulation in the Development of Theories of Cognition," in Korta, K. and Larrazabal, J. M. (eds.), Truth, Rationality, Cognition and Music: Proceedings of 7th International Colloquium of Cognitive Science, Kluwer, Dordrecht, 2004, pp. 274-281.

3 See Fox Keller's considerations about the computational physics and her answer to the question "what exactly is that is so distinctive about this new endeavour?," Keller, E. F., "Models, Simulation, and 'Computer Experiments"," in Radder, H. (ed.), The Philosophy of Scientific Experimentation, University of Pittsburgh Press, Pittsburgh, 2003, p. 200.

4 The term material is used to refer to laboratory experiments in which inputs, intervention and outputs are material.
} 


\section{Instruments and Agreements in Computer Based Experiments}

Scientific observation involves active and constructive elements; it implies design, preparation, instruments, techniques, procedures, manipulation and control. An experiment is an extreme case of empirical observation, in which the operations of comparison, manipulation and control are extremely strict and technology has an important role. Therefore, at the base of science we do not find simple observations, but rather observations mediated technically.

The conventional nature of the procedures, instruments and measurements in scientific observation has been highlighted in philosophy of science. The fact that they are conventional means that said procedures, measurements or instruments are feasible in a specific stage of scientific development, and that scientists accept them as valid. These agreements are basic in science.

However, in spite of this conventional dimension of observation, scientists consider the data obtained through the application of instruments and procedures as data on the objects they are observing. Instruments and procedures are conventional, but what can be done with them and the results thus obtained are not. I am $1.60 \mathrm{~m}$. tall. This is a fact, once we have accepted the metre as our unit of measurement. Any subject who repeats the operation exactly will obtain the same result as me, if said operation is executed correctly. As Agazzi affirms, "what is observed using certain instruments, applying the correct rules of uses, is what scientific community accepts without objection and is what everyone may verify by repeating the same experiment." ${ }^{5}$

Data thus obtained enable researchers to formulate basic propositions of science about phenomena. These propositions are accepted precisely because they are established through inter-subjectively agreed-upon operative procedures. In this sense, Agazzi notes that if we agree to research using a pair of scales, a chronometer and a rigid rule, we can establish propositions which contain predicates such as mass, duration and length according to standard measurement procedures. From here, we can then establish a whole series of basic affirmations, and make empirical assertions of classical mechanics. Later, we can, for example, introduce infinitesimal analysis and other concepts, and use them to gradually construct the theoretical edifice of mechanics. ${ }^{6}$

In the case of computer based observation, it is possible to find an increasing number of agreements among scientists regarding the procedures involved in modelling, mathematical operations, computational techniques or constrictions and controls. An important effort is being carried out to agree what similarities and differences can be established among material experiments, computer based experiments and models. In this context it is a key question the Morgan's distinction between computer based experiments on highly idealised representations of the material object (what she designates as "like a virtual experiment") and computer based experiments on very realist computerised representations of the material object. The latter type of experiment is what Morgan terms "experiments with semi-material objects (or inputs)". An example of this second type of experiment given by Morgan is a section of hipbone which is converted in a computerized image with "a high degree of verisimilitude of structure," being

5 Agazzi, E., "Il significato dell'oggettività nel discorso scientífico," in Minazzi, F. (ed.), L'oggettività Della conoscenza scientifica, Ed. Franco Angeli, Milano, 1996, p. 31.

6 Agazzi, E., "Problemi di epistemologia contemporanea," Quaderni Della Società Filosofica Italiana, n. 1-2, (1979), p. 39. 
carried out a simulation of what happens when the hipbone structure is subjected to extreme stress. ${ }^{7}$ This class of experiment is considered by Morgan to be virtually experiments. ${ }^{8}$

In both types of experiment computer resources are used: there is a model of the object, an intervention model, and mechanical resources are replaced by mathematical ones. Despite these parallelisms, in the first case (like virtual experiment) the experiment is more similar to the manipulation on mathematical models, while in the second (virtually experiment) it is more akin to material experiments. In words of Morgan, "despite of the role of mathematics in the intervention (...) I want to describe at least the first of these two interventions (virtually experiments) as close to a regular experiment." 9

Differences between virtually and like virtual experiments affects the status of the experimental results. It is not possible to extend the results of the second type of experiments to the material systems. In the case of virtually experiments it is possible to extend them, albeit approximately, but, this is not very different to what occurs in the laboratory experiments -which also involve idealisation and abstraction. As Hacking points out, experiments include to work on accurate images and representations, and he affirms: "We study photographs taken with microscope (...) Any image can be digitized and retransmitted on a screen (...) Suppose I take an electronic paint brush and paint, on a television screen, an accurate picture (a) of a cell that I have previously studied, say by using a digitized and reconstituted image (b)." 10

One example of experiment with highly idealised objects is the simulation of the behaviour of diverse animal species, including humans. Here, simulation is conducted with highly schematised creatures which react in accordance with a set of a priori defined rules. The results of the simulation are already built into the model that we construct and are revealed through simulation. The situation is more akin to that which occurs in the manipulation of formal or mathematical models than to laboratory experiments: researchers intervene by deriving rather than producing results. Morgan affirms that "this difference between deriving or producing results is the contrast between mathematical demonstration and experimental demonstration." 11 On the other hand, in this type of experiment, simulation sometimes produces results that may surprise the researcher, but not confuse him (this last is a property of virtually experiments).

Virtually experiments share with laboratory experiments the control over circumstances and variables. The researcher makes an effort to take into consideration all the conditions and factors that interfere or may interfere in the process. Disturbing causes are controlled, some because of

\footnotetext{
7 Cf. Morgan, M. S., "Experiments Without Intervention: Model Experiments, Virtual Experiments and Virtually Experiments," in RadDER, H. (ed.), The Philosophy of Scientific Experimentation, p. 223. She affirms: "his team converts a real cow hipbone into a computerized image... making a photographic digital image of the slice. These digital image of the slices are reassembled in the computer to provide a high-quality 3-D image of that particular real hipbone," Morgan, M. S., "Experiments Without Intervention: ...," p. 222. For her, "the computer experiment calculates the effect of the 'force' on individual elements in the grid and assembles the individual effects into an overall measure of the strength due to structure," in "Experiments Without Intervention: ...," p. 222.

8 Cf. Morgan, M., "Experiments Without Intervention: Model Experiments, Virtual Experiments and Virtually Experiments," pp. 224 and 232.

9 "Experiments Without Intervention: ...," p. 223 (parenthesis is mine). The essential difference is in the process of creating a 3-D computer image of the bone structure, the "model was constructed a new by the scientist first visualizing the bone structure along radically idealized lines: a simple grid structure is hypothesized," MorGAN, M., "Experiments Without Intervention: Model Experiments, Virtual Experiments and Virtually Experiments," p. 223.

10 Hacking, I., Representing and Intervening. Introductory Topics in the Philosophy of Natural Science, Cambridge University Press, Cambridge, 1983, pp. 206-207.

11 Morgan M., "Experiments without Intervention: ...,” p. 220.
} 
their absence from the experiment, others because they are controlled by procedures that keep them constant during the experiment, and yet others because they are considered to be of minor importance and their effects are not taken into consideration. However, what is relevant here is that disturbing causes are identified, they are known, can be explained and their effects can be calculated. This enables us to extend the results of the experiment to the material object. ${ }^{12}$

\section{Simulation, Observation and Theory}

The arguments expressed above imply a close relationship between instruments, procedures and observation. Instruments of course involve theory, the theory of the instrument, but this is somewhat different from that maintained by theorist perspectives about the relationship between theory and observation. For these perspectives the key relationship is between specific theories and observation, any form of observation not determined by theory is unthinkable. ${ }^{13}$

Theory plays some role in observation, but this role is not necessarily that specified by holistic, relativist and theorist theses, among other reasons because observation is not always based on questions formulated in the context of a specific theory. Many experiments are developed not to test a specific theory, but rather to resolve problems, to establish new data, to complete models of certain phenomena, to introduce new concepts or adjust existing ones, or to increase our knowledge about the behaviour of the objects (the example of the experiment with the structure of a hipbone falls into this last category). ${ }^{14}$ As Hacking point out - from the analysis of diverse experiments-, although in some cases theory precedes to experiment in other experiment and observation precede to theory.

There is a greater independence between theory and observation than that affirmed by post-empiricist philosophy through the famous Hanson thesis of theory-ladenness of observation. This independence is based, at least, on the following postulates: a) the existence of a world independent of our senses and theories with which our senses interact to produce our sensations and the regularities of our experience, b) the possibility of scientific access to the empirical world not completely determined by the theory. ${ }^{15}$

These two basic theses are shared by scientific realists, experimental and entities realists or empiricists in spite of the remarkable differences among these approaches. In this sense,

12 The situation is very different with computer based experiments in social sciences. Firstly, the representations of material objects are highly idealised; and secondly, there is a lack of knowledge regarding disturbing causes and, therefore, a lack of control of said causes and their effects. Ceteris paribus clauses assume that all factors are constant, but these factors intervene in the material systems. For this topic, see GómEz, A., "Rational Choice Theory and the Economics Laws. The Rol of Shared Values," in Agazzi, E. Echeverría, J. and Gómez, A. (eds.), Epistemology and the Social, Rodopi, Amsterdam, 2008, pp. 191-206.

13 The social constructivism perspective of science radicalizes this thesis. For an intelligent critique of this perspective, see Gonzalez, W. J., "The Philosophical Approach to Science, Technology and Society," in Gonzalez W. J. (ed.), Science Technology and Society: A Philosophical Perspective, Netbiblo, A Coruña, 2005, pp. 21-24.

14 Morgan affirms, "The conventional belief from outside the experimental community is that the function of experiments in economics is for testing theories. This seems to be understood in the rather strong sense that experiments are conducted to confirm or deny some well specified economic theory. Of course, some experiments are indeed the place where theories can be tested, but to restrict the legitimate role of experiments to just this one function seems unnecessarily limited," Morgan, M. S., "Experiments versus Models: New Phenomena, Inference and Surprise," Journal of Economic Methodology, v. 12, n. 2, (2005), p. 317.

15 This thesis is affirmed for example for Longino, H., Science as Social Knowledge, Princeton University Press, Princeton, NJ, 1990, p. 57. As Gonzalez affirms regarding the idea of objectivity: "To accept the idea of objectivity in science means, on the one hand, to assume that there is an independent reality (natural, social or artificial) to be known (...)," GonZalez, W. J., "The Philosophical Approach to Science, Technology and Society," p. 23. 
Longino affirms - from an empiricism that implies a minimal realism, as she points out — that scientific access to the empirical events of the world (states of affairs in her terminology) is not determined theoretically to the extent that we see different things from different theories. ${ }^{16}$ Communication between different theoretical frameworks is feasible. Galileans and Aristotelians do not "see" different things in the Kuhnian sense, they simply "see" some different aspects of the same thing, which they explain in very different ways. It supposes a minimum level of shared experience, what means that, "there is always some minimal level of description of the common world to which we can retreat when our initial descriptions of what is the same state of affairs differs." "17 Without this minimum level of shared experience, we would not even know in which aspects scientists with different theories differ. We can communicate, engage in critical discussion and even agree, albeit partially, through that level of shared experience. Therefore, as Longino notes, "there is no need to suppose that Galilean or Aristotelian must fail to see aspects that interest the other, nor to suppose that there is no a description of the situation that both could accept and that would then form the basis for discussion of differences." 18

This approach implies to reject Gestalt's theory and its postulate of theory-ladenness of all levels of observation. Access to states of affairs of the world is made through experience, and experience means an active intervention in the world including manipulation, interaction, measurement, and artefacts. Observation is not determined by a theory in such a way, and to such an extent, that the theory simply justifies itself. Observation can be used as independent tests of theories since "data can be specified independently of hypotheses and theories". ${ }^{19}$ Data express the response of reality subjected to manipulation. Once the technical procedures and instruments through which we access to the reality have been established (and this is something conventional), the behaviour of reality is not arbitrary, and therefore, neither are the results.

Could this approach be applied to simulations or computer based experiments? Would results express the response of reality in this case? Results would obviously express the response of the computerised reality, however, would they express the response of the material reality? Strictly speaking, no, but a less restrictive interpretation is also possible. In the case of virtually experiments with semi-material objects the data obtained express, in a scientifically relevant sense, the response that the material object would have if it were subjected to the conditions of the simulation. It is possible to make a valid inference from the results found on the semi-material object of the simulation to the material object. Indeed, this is what scientists do since their aim is to obtain information about the material object, even if said information is obtained indirectly through the computer based experiments. In other words, the aim of virtually experiments is

\footnotetext{
16 Longino, H., Science as Social Knowledge, p. 46. She differentiates between states of affairs and relevant evidence for a hypothesis (or theory). What is interpreted from data as relevant evidence for a hypothesis is what is dependent from theories and background assumptions.

17 Longino, H., Science as Social Knowledge, p. 222. And, in my opinion, in some cases this description can include the phenomenological statements on properties of the entities, but not necessarily.

18 Science as Social Knowledge, p. 54. The thesis of not totally theory-dependent access to empirical world has been affirmed by Kukla when, following Fodor, admits that what we perceive (perceptual process) is one thing and how we relate what we perceive to concepts and theory (that is, how we interpret it) is quite another. For this reason, scientists with different theories do not necessarily or inevitably see different things. Nor is it true that we cannot understand the beliefs held from alternative theories or that we cannot reach a minimum level of description upon which we can agree. This means, note Kukla, that we can even learn to see a phenomenon as it is described from the perspective of an alternative theory. We can understand combustion as it is described by the theory of phlogiston without necessarily having to accept or share this theory. This is enough to resolve the problem of radical incommensurability, cf. KUKLA, A., Studies in Scientific Realism, Oxford University Press, New York, 1998.

19 Longino, H., Science as Social Knowledge, p. 56.
} 
to obtain results that can be applied to the material object. Morgan affirms on this question: "I relied on a particular hipbone to produce a model object that maintained (I suggest) enough material qualities necessary to establish valid experimental results about that one real bone." ${ }^{20}$

Therefore, results obtained from experimental manipulations (including Morgan virtually experiments) tell us about reality and its changes. If experimental manipulations did not provide information about reality scientific development would be a miracle.

This approach is near to Hacking's proposal, which underlines that since the same structure can be observed using different instruments - for example, microscopes based on diverse principles which involve different physical theories - , then there are good reasons for accepting that the structures observed exist. As Hacking point us: "we are convinced because instruments using entirely different physical principles lead us to observe pretty much the same structure in the same specimen." ${ }^{21}$

In the case of virtually experiments, Hacking's approach poses some problems, since what is observed are the interactions with a computerised representation of structure. However, we have good reasons to accept that the properties observed through simulated manipulation are approximately real in those cases in which: a) we have a realist representation of the material object, b) the results obtained through the simulation can be extended to the material system, and c) these results are consistent with the data provided by other different material experiments.

On the other hand, it is necessary to remember that also in the case of some laboratory experiments it is not easy to separate what is observed from the utilized instrument to observe it. This happens, as Morgan reminds us, with the "apparatus Bohrian complexes" (so called by Rom Harré) in which the observed phenomena are properties of a complex unit: the apparatus and the entities of the world. ${ }^{22}$ But this does not mean to put in question the existence of such entities of the world.

It is true that in a simulation we are not physically interfering with structures in the sense proposed by Hacking, but the simulated interference is based on both, scientific knowledge and knowledge of how to interfere scientifically. This enables us, in the case of virtually experiments with semi-material objects to assume that the interference in a laboratory with real forces would have the same results as the simulated interference, therefore we can "are convinced about the structures we seem to see (...)." ${ }^{23}$ On the other hand, the Hacking's notion of "manipulation" can be understood in a weak way as "to employ." 24 In the hipbone experiment we have weak manipulation since it has been "employed" stress inputs to simulate what happens with the hipbone structure.

The developed argument provides: a) we have sufficient scientific knowledge of the material structure to develop a realist representation of it; b) the results of simulated manipulation can

\footnotetext{
20 Morgan, M., "Experiments versus Models: New Phenomena, Inference and Surprise,” p. 230. As John M. Prausnitz and Bruce E. Poling wrote, "since 1958 such computer experiments have added more to the knowledge of molecular structure of simple liquids than all the theoretical work of the previous century (...)." Quoted in Keller, E. F., "Models, Simulation, and 'Computer Experiments'," p. 208.

21 Hacking, I., Representing and Intervening, p. 209.

22 Morgan, M., "Experiments versus Models: New Phenomena, Inference and Surprise," p. 322.

23 Hacking, I., Representing and Intervening, p. 209.

24 See Shapere, D., "Astronomy and Anti-Realism," Philosophy of Science, v. 60, (1993), pp. 134-150; and Massimi, M., "Non-defensible Middle Ground for Experimental Realism: Why we are Justified to Believe in Colored Quarks," Philosophy of Science, v. 71, n. 1, (2004), pp. 36-60.
} 
be extended to the material structure; and c) it is possible to access the material structure also through laboratory experiments. If these three conditions are not satisfied the reasons to accept that "the properties observed through simulated manipulation are approximately real" are weaker (no matter how many parameters we introduce into the computer). This is the case of the simulation of the evolution of our Galaxy.

The simulation of the evolution of our Galaxy is based on information collected over 15 years from stars of spectral types $\mathrm{F}$ and $\mathrm{G}$, in a total of around 63.000 individual spectroscopic observations. This complete census of nearby stars provides information regarding distances, ages, spatial velocity and orbits in the general rotation of the Milky Way, and the identification of double or multiple stars (around 1/3). A Danish astronomer, Erik Heyn Olsen, took the first step during the 1980s by measuring the light intensity on various wavelengths of 30,000 stars of the types A, F and G, distributed across the whole firmament. Next, the satellite Hipparcos (ESA) determined the distances and velocities on the celestial plane of these and many other stars. However, the movements along the line of vision remained the missing link, although this was also eventually calculated by the CORAVEL instrument, on the basis of the Doppler shift of the spectral lines of the stars. ${ }^{25}$

All this information enables astronomers to simulate on their computers how the stars moved around the Galaxy in the past and how they will do so in the future. The initial results of the simulation indicate that objects such as molecular clouds, spiral arms and black holes would have fostered stellar displacement throughout the entire history of the galactic disk. As a result, the evolution of the Milky Way seems much more complex and chaotic than initially proposed by traditional and simplified models.

In this case, we are dealing with the computerisation of a huge amount of scientific data obtained by diverse means quite independent of the computer in which they are computerised. Nevertheless, the situation is not the same in the experiment with the hipbone subjected to extreme stress. Firstly, because no laboratory experiment has been carried out about the evolution of our Galaxy, whilst in the case of the hipbone structure they were done, although for other parameters. Secondly, because the results obtained from the simulation can only be extended to the system very partially, since current knowledge in this field does not enable us to control all the variables and disturbing causes acting on a phenomenon as complex as the evolution of the Galaxy. And thirdly, and very important, because we only have other theoretical models about how our Galaxy evolved, therefore, when the results obtained from simulation are extended, they are extended to these models not to the material system.

In the field of Galaxy evolution, current knowledge regarding material systems is closely related to the current theoretical model. The simulation is guided by theoretical model since the mathematically modelled inputs behave in accordance with certain theoretical hypotheses specific to said models. The assertion that objects such as molecular clouds, spiral arms and black holes have fostered stellar displacement throughout the history of the Galaxy is a hypothesis that has yet to be confirmed.

In order to understand the above arguments about the different epistemic status of the phenomena of Galaxy evolution and the behaviour of hipbone structure it is useful to clarify the relationship between experiment, simulated or not, and theory, and the relationship between data, phenomena and theory.

25 I summarize here from the Report: www.eso.org/public/news/eso0411 (access on 15 January 2010). 


\section{Data, Phenomena and Entities}

Returning to the idea that the data obtained from experimental (material) manipulations express the response of the reality being observed, does this mean that the empirical basis of science are completely independent from theories?

The difference established by new experimentalism perspective between data and phenomena is interesting to answer this question. ${ }^{26}$ Data are accessible to our senses and instruments, "are records that are visually detectable." ${ }^{27}$ They are produced by experimental practice and are independent from theories. Phenomena are the result of statistical inference from data registered in successive experiments and in most cases are unobservable. ${ }^{28}$ Phenomena are the general properties of the entities of the world that we infer from data, they are therefore independent from theories. ${ }^{29}$ As Bogen and Woodward note, "we are justified in believing claims about phenomena as long as data are available which constitute reliable evidence for such claims (...)." ${ }^{30}$ Phenomenological statements are fundamental in scientific knowledge and their truth content is independent from the theories about the entities mentioned in them. ${ }^{31}$

Phenomena such as "hipbones subjected to certain stress break" or "metals dilate when heated," are inferred from observable data manipulated in material or virtually experiment. They are general properties inferred from data, therefore are independent from theories. However, the inference of the evolution of our Galaxy implies some theoretical hypotheses specified by the current theoretical model. In the simulation of the evolution of our Galaxy, theory plays a more fundamental role than in the simulation of hipbone structure under conditions of extreme stress. Does this fact enable us to be less realist about the evolution of our Galaxy or the chaotic behaviour of Milky Way than about the behaviour of the hipbone under conditions of extreme stress? The answer to this question depends on whether we accept that phenomena and statement about phenomena are independent from theories.

In my opinion, the thesis that phenomena and claims about phenomena are independent from theories poses a number of problems. This thesis finds difficulties in material experiments since many phenomena are unobservable. In the case of unobservable phenomena the transformation of the data in phenomena are not carried out in complete theoretical independence. This does not mean that they are totally determined by theory since they also depend of the data themselves, of the experimental context and of the history of the experiment. But theory also does play a role in it. ${ }^{32}$

26 Cf. Bogen, J. and Woodward, J., “Saving the Phenomena," Philosophical Review, v. 97, (1988), pp. 303-352.

27 Massimi, M., "Saving Unobservable Phenomena," British Journal for the Philosophy of Science, v. 58, (2007), p. 239.

28 As Massimi has pointed out, according Bogen and Woodward, "data provide evidence for the existence of phenomena. On the other hand, phenomena are detected through the use of data, but in most cases are not observable in any interesting sense of the term," Massimi, M., "Saving Unobservable Phenomena," p. 238.

29 I thank to M. Massimi for having outlined me that the claim is not always true since some phenomena are unobservable and have a special epistemic status. These phenomena are result of two stretching process: an unexpected measured value in a data model and the use of theoretical models to achieve better fit with the data model. See interesting analysis of these phenomena in Massimi, M., "Saving Unobservable Phenomena," pp. 235-262.

30 Bogen, J. and Woodward, J., "Saving the Phenomena," p. 350.

31 Cf. Suarez, M., "Hacking Kuhn,” Revista de Filosofía, v. 28, n. 2, (2003), p. 275.

32 As Resnik has pointed out, "experimenters actually use full-blown scientific theories about the very entities they study...the gap between experimenter and theory is not nearly as large as Hacking supposes," Resnik, D. B., "Hacking's Experimental Realism," in Curd, M. and Cover, J. A. (eds.), Philosophy of Science: The Central Issues, W. V. Norton and Company, New York, 1994, pp. 1182-1183. 
As Massimi notes, "evidence and theory are inextricably intertwined in grounding our belief in colored quarks." 33

The process that leads to unobservable phenomena is similar from the process that leads to theoretical entities. In the case of causal properties of theoretical entities, which Hacking speaks about, we do not find a complete independence between statements of general properties (phenomena) and theories. ${ }^{34}$ Without a doubt, experimental results observed really happen (at the laboratory experiments). There is not problem for example in accepting that in the experiment with cathode rays Thomson found "particles bearing a minimal negative charge." "35 But the fact that these data become electrons is not independent of the theories of Lorentz and others. ${ }^{36}$ The entity referred to by the term electron has a cluster of important properties (mass, spin, electric charge, ...) which are described by scientific theories. ${ }^{37}$

Experiments in which entities that in principle cannot be observed produce a new phenomenon show the existence of causal effects of these entities. ${ }^{38}$ But that such effects become general properties of the entities of the world (phenomena) not only depends on the experimental data, but, at least partly, also on the theories that describe those entities. ${ }^{39}$ Faraday found "that the plane of polarization of a beam of light would rotate when sent through this borosylicate glass, parallel to the lines of magnetic force." ${ }^{40}$ Understanding this fact as a general and fundamental physical property (the connection between electromagnetism and light) depended on the theoretical assumptions, the mathematical representations, the physical models elaborated, the used arguments (Maxwell symmetry) and of the physical explanations formulated. ${ }^{41}$ As Massimi points out in her interesting analysis of parton and quark models of hadrons, "seeing the nucleon's constituents presupposes a massive amount of theory. For instance, it presupposes theoretical assumptions about scattering techniques (...) a theory about spectrometers work (...) an interlocking chain of low level generalisations as well as recourse to fundamental laws such as momentum and energy conservation. But, it presupposes also some batches of crucial theoretical assumptions about the very same facts under investigation." ${ }^{42}$

\footnotetext{
33 Massimi, M., "Non-defensible Middle Ground for Experimental Realism: Why we are Justified to Believe in Colored Quarks," p. 39.

34 Hacking affirms, "entities that in principle cannot be 'observed' are regularly manipulated to produce a new phenomena and to investigate other aspects of nature,"HACKING, I., Representing and Intervening, p. 262. This thesis is questioned by Zeidler, P. and Sobczynska, D., "The Idea of Realism in the New Experimentalism and the Problem of Existence of Theoretical Entities in Chemistry," Foundations of Science, v. 1, n. 4, (1995), pp. 517-535.

35 Cf. HACKING, I., Representing and Intervening, p. 83.

36 Thomson called them first "ultratomic particles" and after "corpuscles."

37 See the Resnik's critic of Hacking. ResniK, D. B., "Hacking's Experimental Realism,” pp. 395-412.

38 On the other hand, as Resnik has pointed out, experimentation is not nearly as theory-free as Hacking maintains.

39 Therefore, according to Resnik well-known statement of "the experimental realist can only have knowledge about theoretical entities if she assumes that the theories which describe those entities are at least approximately true," RESNIK, D. B., "Hacking's Experimental Realism," p. 395.

40 Cf. Hacking, I., Representing and Intervening, p. 211.

41 Enumerated by Hacking who add, "Often the big speculation comes first." HACKING, I., Representing and Intervening, p. 212. From Faraday effect was derived that "there might be a single theory unifying light and electromagnetism." The reason of this interpretation was that "(...) Faraday was convinced that all forces of the nature must be interconnected." Representing and Intervening, p. 210.

42 Massimi, M., "Non-defensible Middle Ground for Experimental Realism: Why we are Justified to Believe in Colored Quarks," p. 49.
} 
On the other hand, the inference of phenomena from data can presuppose assumptions, even non-scientific in little developed scientific contexts. One excellent example of this is 19th century physical anthropologists' interpretation of the differences in weight between men's and women's brains. From the weight data, they inferred a general property: the intellectual inferiority of women. Phenomena from differential research on human beings have proved highly sensitive to this type of interference.

We can accept that data express the response of the reality, but it is very different to accept that necessarily phenomenological statements about the general properties of entities cannot be linked to some theory. The realism that we are sustaining is less optimistic. It involves accepting the commitment to the existence of theoretical entities, while acknowledging that properties of said entities depend, to a certain extent, on theories about them. ${ }^{43}$ Properties may vary with the theory-change. Obviously, this is not always the case, and certain phenomena remain constant despite theoretical changes, while it is their explanation what varies. This does not mean to reject the possibility of theory-free observation in fields where observation is more independent from underlying theoretical assumptions nor it is being affirmed the thesis that all observation is theory-ladenness. The matter is that in some cases what counts as observation depends too upon our state of knowledge. ${ }^{44}$ It is true that the life of certain phenomena is much longer than the life of any theory designed to explain them. But this is not always the case. For instance, the property of intelligence as the result of differences in brain weight has not survived. In the computer based observation the situation is the same. It is easier for the phenomena of the simulation of the evolution of our Galaxy to change than it is for the property of a hipbone breaking when is subject to great stress. This second type of phenomena will remain despite the fact that it depends on data obtained by simulation and despite the fact that the way in which it is explained theoretically may change. However, the first type of phenomena will depend closely on the evolution of theoretical models of the universe.

Regarding the question formulated above of whether the role of the theory in the simulation of a phenomena, like the evolution of our Galaxy, prevent us to be realistic about this phenomena the answer is negative. The matter is not the role played by theories in the transformation (material or simulated) of data in phenomena, but the status of theories and if we have good reasons to be realistic about them.

\section{REMARKS}

Returning to the questions posed at the beginning, and according to the epistemological approach sustained, we can affirm that: a) virtually experiments with semi-material objects are a resource that increases scientific knowledge and provide information which is relevant to material systems since the results obtained can be extended to these systems; $b$ ) in the case of experiments on highly idealised representations of the material object we are basically deriving results inherent to the model that we construct, in accordance with the specified rules and hypothesis, as in the case of operations on mathematical models. It is possible to extend the results to the material systems only very partially. When we cannot extend the

\footnotetext{
43 Hacking affirms: "Various properties are confidently ascribed to electrons, but most of the confident properties are expressed in numerous different theories or models about which an experimenter can be rather agnostic." HACKING, I., Representing and Intervening, pp. 263-264.

44 As note Massimi, M., "Non-defensible Middle Ground for Experimental Realism: Why we are Justified to Believe in Colored Quarks," p. 50.
} 
results to the material system as in the evolution of our Galaxy, the knowledge obtained is very hypothetical and tentative. We can be realist regarding the behaviour of the structure of hipbone under conditions of great stress, but we cannot be realist in the same grade regarding the evolution of our Galaxy.

However, type $b$ experiments constitute an important scientific resource since they enable us to improve our comprehension of highly complex and yet not very well understood material systems, and they help us to define certain relationships and to formulate hypotheses, as indeed is the case, for example, of the simulations of the climate change and its effects. Finally, it is clear that the new forms of observation do not involve new epistemologies, although they do pose new challenges for existing ones.

\section{REFERENCES}

Agazzi, E., "Problemi di epistemologia contemporanea," Quaderni Della Società Filosofica Italiana, n. 1-2, (1979), pp. 5-61.

Agazzi, E., "Il significato dell'oggettività nel discorso scientífico," in Minazzi, F. (ed.), L'oggettività della conoscenza scientifica, Ed. Franco Angeli, Milano, 1996, pp. 19-35.

Bogen, J. and Woodward, J., "Saving the Phenomena," Philosophical Review, v. 97, (1988), pp. 303-352.

Curd, M. and Cover, J. A. (eds.), Philosophy of Science: the Central Issues, W. V. Norton and Company, New York, 1994.

Gómez, A., "Rational Choice Theory and the Economics Laws. The Rol of Shared Values," in Agazzi, E., Echeverría, J. and Gómez, A. (eds.), Epistemology and the Social, Rodopi, Amsterdam, 2008, pp. 191-206.

Gonzalez, W. J., "El realismo y sus variedades: El debate actual sobre las bases filosóficas de la Ciencia," in Carreras A. (ed.), Conocimiento, ciencia y Realidad, Seminario Interdisciplinar de la Universidad de Zaragoza-Ediciones Mira, Zaragoza, 1993, pp. 11-58.

Gonzalez, W. J., "The Philosophical Approach to Science, Technology and Society," in Gonzalez W. J. (ed.), Science Technology and Society: A Philosophical Perspective, Netbiblo, A Coruña, 2005, pp. 3-49.

Hacking, I., Representing and Intervening. Introductory Topics in the Philosophy of Natural Science, Cambridge University Press, Cambridge, 1983.

Keller, E. F., "Models, Simulation, and 'Computer Experiments'," in Radder, H. (ed.), The Philosophy of Scientific Experimentation, University of Pittsburgh Press, Pittsburgh, 2003, pp. 198-215.

Kukla, A., Studies in Scientific Realism, Oxford University Press, New York, 1998.

Longino, H., Science as Social Knowledge, Princenton University Press, Princeton, NJ, 1990.

Magnani, L. and Nersessian N. J. (eds.), Model-Based Reasoning: Science, Technology, Values, Kluwer/Plenum, New York, 2002, pp. 41-58.

Massimi, M., "Non-defensible Middle Ground for Experimental Realism: Why we are Justified to Believe in Colored Quarks," Philosophy of Science, v. 71, n. 1, (2004), pp. 36-60.

Massimi, M., "Saving Unobservable Phenomena," British Journal for the Philosophy of Science, v. 58, (2007), pp. 235-262.

Morgan, M. S. and Morrison, M. (eds.), Models as Mediators: Perspectives on Natural and Social Science, Cambridge University Press, Cambridge, 1999. 
Morgan, M. S., "Model Experiments and Models in Experiments," in Magnani, L. and Nersessian N. J. (eds.), Model-Based Reasoning: Science, Technology, Values, Kluwer /Plenum, New York, 2002, pp. 41-58.

Morgan, M. S., "Experiments Without Intervention: Model Experiments, Virtual Experiments and Virtually Experiments," in Radder, H. (ed.), The Philosophy of Scientific Experimentation, University of Pittsburgh Press, Pittsburgh, 2003, pp. 216-235.

Morgan, M. S., "Experiments versus Models: New Phenomena, Inference and Surprise," Journal of Economic Methodology, v. 12, n. 2, (2005), pp. 317-329.

Peschel, M. F. and Scheutz, M., "Explicating the Epistemological Rol of Simulation in the Development of Theories of Cognition," in Korta, K. and Larrazabal, J. M. (eds.), Truth, Rationality, Cognition and Music: Proceedings of 7th International Colloquium of Cognitive Science, Kluwer, Dordrecht, 2004, pp. 274-281.

Radder, H. (ed.), The Philosophy of Scientific Experimentation, Pittsburgh University Press, Pittsburgh, 2003.

Resnik, D. B., “Hacking's Experimental Realism," in Curd, M. and Cover, J. A. (eds.), Philosophy of Science: The Central Issues, W. V. Norton and Company, New York, 1994, pp. 1153-1168.

Shapere, D., “Astronomy and Anti-Realism," Philosophy of Science, v. 60, (1993), pp. 134-150.

Suarez, M., "Hacking Kuhn," Revista de Filosofía, v. 28, n. 2, (2003), pp. 261-284.

Zeidler, P. and SobczynsKa, D., "The Idea of Realism in the New Experimentalism and the Problem of Existence of Theoretical Entities in Chemistry," Foundations of Science, v. 1, n. 4, (1995), pp. 517-535. 


\section{III}

\section{Empirical Support and Experiments in Science}

4. Observation and Experiments in Economics:

Analysis of Herbert Simon's Approach

5. The Dynamics of Experimentation and

its Role within a Philosophy of Scientific Practices 


\title{
ObSERVATION AND EXPERIMENTS In ECONOMICS: Analysis of Herbert Simon's Approach
}

\author{
María G. Bonome
}

\section{Herbert Simon's Approach: The Primacy of Empiricism}

Herbert Simon frequently emphasizes the role of observation and experimentation in economic science to confront the main economic stream. He thinks there are too many economists who insist too much on the main role of theory, and they even justify not worrying about realism in economics assumptions, ${ }^{1}$ so he openly criticizes those that consider economics as an a priori knowledge. In this sense, his attitude towards Thomas Sargent —one of the most important economist of the "rational expectations conception" - is clear: "economists like Thomas Sargent who have paid the phrase 'bounded rationality' (...) miss the point of it when they continue to base their models on a priori hypotheses about behavior instead of grounding them in fact established by direct observation." ${ }^{2}$

Before working for Cowles Commission, where he contributed to the development of mathematical instruments to be used in economics, ${ }^{3}$ Simon had received the influence of Rudolf Carnap while he was a student at the University of Chicago. ${ }^{4}$ This important author of Vienna's Circle left an unforgettable mark on a young political science student. ${ }^{5}$ Since then, when he develops computer programs into computer science, his determination is always to make science with an intense empiric basis. He considers that the goals, processes and results of science have to go beyond (the filter of) empirical support.

Carnap's influence - the empirical epistemology that looks for the "basis" and the verificationism methodology of science - is reflected in Simon, mainly in the ideas he rejects. Firstly, he ruled out a Popperian rationalist epistemology, where theory prevails over experience (and where there is no basis for induction); and, secondly, the need of empirical foundations casts a doubt over a priori base for any scientific process (in economics or in any other nature).

\footnotetext{
1 Simon always showed a critical attitude with Milton Friedman's Methodology of Economics, cf. Simon, H. A., "Discussion: Problems of Methodology," American Economic Review, v. 53, (1963), pp. 229-231. Compiled in SimoN, H. A., Models of Bounded Rationality. Vol. 2: Behavioral Economics and Business Organization, The MIT Press, Cambridge, MA, 1982, pp. 369-371.

2 Simon, H. A., "Introduction," in Simon, H. A., Models of Bounded Rationality. Vol. 3: Empirically Grounded Economic Reason, The MIT Press, Cambridge, MA, 1997, p. xii.

3 It was "inside the Cowles Commission, when he developed what for some people is the most important part of his philosophy of science: the study of the axiomatization of the scientific theories and the status - within those theories - of theoretical concepts (as they are not directly observable)," in Gonzalez, W. J., "Herbert A. Simon: Filósofo de la Ciencia y economista (1916-2001)," in GonZALEZ, W. J. (ed.), Racionalidad, historicidad y predicción en Herbert A. Simon, Netbiblo, A Coruña, 2003, p. 10.

4 He deals with experiments very early: Simon, H. A. and Divine, W. R., "Controlling Human Factors in an Administrative Experiment," Public Administration Review, v. 1, (1941), pp. 485-492.

5 Cf. Simon, H. A., Models of my Life, Basic Books, N. York, NY, 1991 (reprinted by The MIT Press, Cambridge, MA, 1996), pp. 51, 53-55, 193 and 195.
} 
But it is also possible to see Carnap's influence in what Simon accepts: his own terminology has the trace of a logical empiricism when he writes that in cognitive psychology it is possible to "find strong empirical foundations for behavioral decision theory and bounded rationality as well as valuable suggestions on experimental and observational methodologies. All of these can be helpful for verifying the applicability to economics of the behavioral decision theory that has emerged from this research in other domains." ${ }^{6}$

Nevertheless, Simon had a long and extremely varied intellectual path: 60 years of work. During this time he did outstanding contributions in very different fields. It is in effect, a "multidisciplinary creativity," 7 but there are some common characteristics within the diversity of that field. One of them is that he always claimed the role of observation in the real world, thinking of giving a major realism to the models (for example, to develop economic theories). Another common characteristic is that besides the empirical foundation (the reason empirically grounded) he highlighted the role of experimentation (in economics too) as a methodological process to evaluate the validity of scientific hypotheses.

Being conscious of his "multidisciplinary creativity," Simon says that he has been "accused of flitting from one social science to another, but the secret really is that I have been preoccupied with one topic, decision making and rationality, all of my life. It just happens that that topic cuts squarely across all of the human sciences because it is what we human beings are doing a great deal of the time. You don't really have to change very much, except a bit of your vocabulary, to move from one of these fields to another if you stick to the topic of decision making." 8

His points of view are strongly compromised in trying to describe and understand economic reality from an objective point of view. And he claimed a model of economic real agent, removed from the simplified and ideal models that turn out to be so comfortable for some theoretical formulations of the main economics current (the neoclassical one). This took form on his study of bounded rationality in decision making, ${ }^{9}$ which was the cause of his Nobel Prize on Economics in 1978, an approach where he insisted that it is possible to verify empirically that the ability of agents to calculate information has a limit.

When he offers a retrospective vision of his path, Simon's position is the epistemological and methodological primacy of the empirical thing: firstly, as an observation and secondly, as experimentation. Besides, he stresses the link between the sciences of economics and psychology, where the empirical component of the work of the psychological laboratory reinforces the characterization of economic behavior. Thus, there is a reciprocal enrichment between both disciplines, again, against a priori approaches. Besides, it is a question of half a century of bidirectional relations between economics and psychology:

"The laboratory research extending from the 1950s to present day provided a large body of evidence for the theory of bounded rationality and for characterizing science as a social endeavor. Vastly more evidence was simultaneously gathered by other psychologists during this period of the 'cognitive revolution' in that domain.

\footnotetext{
6 Simon, H. A., "Introduction," in Simon, H. A., Models of Bounded Rationality. Vol. 3: Empirically Grounded Economic Reason, pp. x-xi.

7 Dasgupta, S., "Multidisciplinary Creativity: The Case of Herbert A. Simon," Cognitive Science, v. 27, (2003), p. 683.

8 Simon, H. A., "Decision Making: Rational, Nonrational, and Irrational," Educational Administration Quarterly, v. 29. (1993), p. 395.

9 Cf. Gonzalez, W. J., "Racionalidad y Economía: De la racionalidad de la Economía como Ciencia a la racionalidad de los agentes económicos," in Gonzalez, W. J. (ed.), Racionalidad, historicidad y predicción en Herbert A. Simon, Netbiblo, A Coruña, 2003, pp. 65-96.
} 
Numerous researchers in both psychology and economics have also been busy applying the jointly produced theory to economic phenomena (for example, Bromiley, Kahneman and Tversky, Vernon Smith, Selten, Gingerich, and so on). Perhaps this helps to explain why Simon devoted only a substantial fraction of his time to specific economic applications." ${ }^{10}$

\section{Need of Empirical Base for Economics: Behavioral Economics}

As he insists on the need of an empirical base for economics, Simon proposes an observable object of study for this science: the behavior of the economic agents. Besides, he thinks it is possible to carry out a "direct observation" of the behavior since the influence of the logical empiricism during his university stage leads him to conceiving the observation without theoretical load. The phenomena of economic behavior are seen by him in terms of methodological individualism (the behavior of individual agents that make decisions) and the social context is more a question of environment than something which is really significant to the process of economic behavior.

Ontologically, his "behavioral economics" assumes that economic reality is much more complex than the natural one, due to its human and social nature. But he sees it only as "behavior" instead of conceiving it as "activity," due to his strong empirical schemes. Because in my opinion, economics, it is human activity that does not develop in an isolated way, but is enriched by its interaction with other activities related to human beings of several kinds (social, cultural and political). In this way, we face a reality where its components do not keep invariable; what is more, they have a high degree of variation for the fact of being influenced by a wide scale of values of all kinds. ${ }^{11}$

Though Simon remains in the "behavior" without managing to reflect the complexity of the "activity," he has the merit of insisting, against the mainstream tendency, on the need to observe the economic reality to see how human beings reason at the moment of choosing among the different alternatives when they have to make decisions. "But most economists have found that empirical work of that kind is rather arduous and messy and that it's more fun to play with theory (...) There is a very strong tradition of accepting the utility maximization hypothesis and then seeing, often with the aid of very powerful and elegant mathematical tools, what kind of conclusions you can draw from those premises, preferably by mathematical means. And there are even some economists who think that the theory is analytic and not refutable (...) While economists have applied very sophisticated econometric techniques to these data, the data themselves are almost all highly aggregated and concerned with society as a whole or very large segments thereof. There are not detailed data about how individuals or individual business firms are behaving." 12

\subsection{Criticism to Mainstream Economic Theory}

According to the mainstream economic tendency, the agents maximize the utility when they make a decision, and they do it when they act in an individual level or when they act as a group. (i) On the one hand, the function of utility prevails (when we make our decisions we

\footnotetext{
10 Simon, H. A., "On Simulating Simon: His Monomania, and Its Sources in Bounded Rationality," Studies in History and Philosophy of Science, v. 32, n. 3, (2001), p. 502

11 About the presence of values in economy, cf. Gonzalez, W. J., "Prediction and Prescription in Economics: A Philosophical and Methodological Approach," Theoria, v. 13, n. 2, (1998), pp. 321-345.

12 Simon, H. A., "Why Economists Disagree," Journal of Business Administration, v. 18, n. 1-2, (1988-1989), p. 7.
} 
consult our function of utility, that says to us which and what quantity of goods and services we prefer to others); and (ii) on the other hand, we make our decisions dependent only on the objective environment (for example, the limits of the budget we have). In this case, we make our decisions in such a way that we get those goods and services that we prefer with the money we have, including the credit we might afford.

This position of the dominant economic tendency implies elements that do not fit with the observation of the economic behavior. a) It bears that each of us has a function of utility that is wide and consistent, though we are not conscious of it and there are no conscious calculations in this task. b) It assumes that we are able of arranging, in terms of preference, any quantity of goods and services we can get. So this tendency considers that the human being has a stable and well organized system of preferences; besides, the human being is supposed to have a capacity of calculation that would allow him/her to reach the highest point in his/her scale of preferences.

It seems to be clear when bearing the observations about economic behavior in mind, it is not correct to accept these elements: neither the expected subjective expectations as maximizations nor the limited capacity of computation. In this regard, in the middle of the 50 's, Simon perceived very clearly that the behavior of the economic agent was not as it appears in the dominant economic theory. ${ }^{13}$ He stimulated the studies on human behavior, which Richard Cyert and James March continued. They proved, by means of empirical studies, that the decision making process in business firms was very different from the model that appears in the standard economic theory. ${ }^{14}$

The approach of the utility maximization might make sense as a guideline of reasoning in the long term. But this approach, strictly differs in several factors. One of them has been pointed out by Daniel Kahneman: the worry for the emotions of the agents. Because "utility can not be divorced from emotion, and emotion is triggered by changes. A theory of choice that completely ignores feelings such as the pain of losses and the regret of mistakes is not only descriptively unrealistic. It also leads to prescriptions that do not maximize the utility of outcomes as they are actually experienced - that is, utility as Bentham conceived it." 15 This way, economists and psychologists worried about the controlled observation of the behavior, especially in decision making, like Simon, were who have emphasized the presence of cognitive factors, and even emotional, that influence the election of the economic agents.

\subsection{Appeal to the Psychology-Like Complement of Economics}

To form an economic theory closer to reality, Simon contributions to psychology as an epistemological and methodological complement of economics. He was interested in cognitive factors (the related ones to the process of thought, human intelligence and solution of problems) that connect with human behavior. This way, by means of many articles in the matter, he carried out an important contribution to the "cognitive revolution," which exceeded the field of

\footnotetext{
13 Cf. Simon, H. A., “A Behavioral Model of Rational Choice,” Quarterly Journal of Economics, v. 69, (1955), pp. 99-100. Compiled in Simon, H. A., Models of Bounded Rationality. Vol. 2: Behavioral Economics and Business Organization, pp. 239-258.

14 Cyert, R. M. and March, J. G., The Behavioral Theory of the Firm, Prentice Hall, Englewood Cliffs, NJ, 1963; and Simon, H. A., "Why Economist Disagree?," p. 9.

15 Kahneman, D., "Maps of Bounded Rationality: A Perspective on Intuitive Judgment and Choice," Nobel Prize Lecture, Nobel Foundation, Stockholm, 8/12/2002, www.nobelprize.org, (access on December 2007), pp. 464-465.
} 
psychology to enter the field of artificial intelligence. In fact, with a group of researchers, Allan Newell is one of them, he carried out a large contribution in the realm of computer sciences. ${ }^{16}$

Methodologically, Simon's approach consists of controlled observation. This way, from a correct observation of the behavior of the economic agents, it is necessary to conclude that the rationality that people use when they make their decisions is a bounded rationality. This goes against the mainstream tendency, where the theory of the perfect rationality is assumed in the economic agents. He thinks that "empirical evidence is overwhelming that people, consumers, employees, businesspeople, typically satisfice rather than optimize. The reason, summed up in the phrase 'bounded rationality', is that their computational means are far too limited to permit them to generate all alternatives (or even to calculate the optimal search rule) and to estimate a probability distribution of outcomes for each alternative." ${ }^{17}$

Instead of having a perfect rationality, which allows us to maximize our expectations to reach the highest level of utility in our decisions, the bounded rationality allows us to satisfy our needs, through decisions made with help of the knowledge and the tools we have in our scope. ${ }^{18}$ With the support of observational psychology of the behavior, he presents an economic thesis of bounded rationality in decision making:

"Bounded rationality is simply the idea that the choices people make are determined not only by some consistent overall goal and the properties of the external world, but also by the knowledge that decision makers do and don't have of the world, their ability or inability to evoke that knowledge when it is relevant, to work out the consequences of their actions, to conjure up possible courses of action, to cope with uncertainty (including uncertainty deriving from the possible responses of other actors), and to adjudicate among their many competing wants. Rationality is bounded because these abilities are severely limited. Consequently, rational behavior in the real world is as much determined by the 'inner environment' of people's minds, both their memory contents and their processes, as by the 'outer environment' of the world on which they act, and which acts on them." 19

From this description of an "imperfect" human rationality, in the opposite direction to the "perfect" maximized rationality of the dominant theory, Simon asks for a change of attention towards those phenomena that arise from the limitations that are imposed or that are modified in a substantial way by these ones. This turn is fundamental to be able to develop a theory about human decision making that is consistent with what we know about human thinking, from the empirical studies in all the social and behaviorial sciences. The auxiliary assumptions in economics, which are assumptions in fact, and the central theoretical assumptions will have to submit to a review through empirical verification of the proposed formulations or its consequences. "The social sciences require theories built around realistic models of human actors; that capture that realism only approximately, but avoid over-simplification where it makes a consequential difference." ${ }^{20}$

16 Dasgupta, S., "Multidisciplinary Creativity: The Case of Herbert A. Simon," p. 685.

17 Simon, H. A., "Satisficing," in Greenwald, D. (ed.), The McGraw-Hill Encyclopedia of Economics, 2nd ed., McGraw-Hill, New York, 1993, p. 883.

18 Cf. Simon, H. A., “A Behavioral Model of Rational Choice,” pp. 99-118.

19 Simon, H. A., "Bounded Rationality in Social Sciences: Today and Tomorrow," Mind and Society, v. 1, n. 1, (2000), p. 25.

20 Simon, H. A., "Bounded Rationality in Social Sciences: Today and Tomorrow," p. 30. 
In this direction a considerable work has been carried out in the last few decades. It has been made in the field of psychology, and it is due to Amos Tversky and Daniel Kahneman. This last one received the Nobel Prize in Economics in 2002 with Vernon Smith, an "experimental economics" author. His contributions allow one to estimate an effective consolidation of the change of direction in the economic research.

Kahneman and Tversky carried out research in the psychology of elections and intuitive beliefs to make a map of bounded rationality. Opposite the mainstream tendency in economics, the elections and optimal beliefs that are supposed in the rational agent models, they examined the systematical features in people's beliefs and in the choices they make. Although their research was initially a contribution to psychology that, as a secondary benefit, might provide some contribution to economics, they were won over towards an interdisciplinary confluence by economists who believe psychology is a profitable source of hypothesis for economic theorization, and indirectly, a source of hypothesis for economic research, bringing about an active research programme developed by behavioral economists. ${ }^{21}$

Nevertheless, Kahneman is aware of the criticisms of some economists: psychological research generates lists of errors and biases and, therefore, it fails to offer a coherent alternative to the model of rational agent. But here is where the controversy is: the descriptive and normative models of economic rationality in the dominant economic tendency are not realistic from a psychological point of view. At the same time, as Kahneman says, the alternative to precise and simple models is not chaos. Psychology offers integrative and generalizing concepts at an intermediate level, which are able to explain apparently different phenomena in different realms. ${ }^{22}$

If we look backwards, we can define the scientific analysis of human "rationality" as limited ${ }^{23}$ as the way it began in the second half of 20th century, although there is still a lot of empirical work to do. In the year 2000 - and after a large number of publications on this topic-, Simon summarizes this situation in three big generalizations related to human rationality in the context of social sciences, in general, and in economics, in particular.

1. "The fascination with maximization of expected utility as the core of the theory of economic (and other) rationality has waned rapidly in recent years with the discovery of a large body of empirical evidence of human behavior that diverges widely from this theory. Dissatisfaction has led to the introduction of ad hoc patches to the theory in the form of specific, but seldom empirically-grounded, assumptions of limits upon rationality. Economists have become increasingly cynical about the neoclassical formalism and increasingly interested in alternative theories and new empirical approaches." ${ }^{24}$ Economists have become more and more critics about the neoclassical formalism. They have increased their interest in alternative theories and new empirical approaches.

2. "Great strides have been made in the past forty years, largely within cognitive psychology, to formulate an empirically grounded theory of decision making and problem solving processes. The new theory does not exhibit the very high levels of abstraction and generalization that

21 Cf. Kahneman, D., "Maps of Bounded Rationality: Psychology for Behavioral Economics," American Economic Review, v. 93, n. 5, (2003), p. 1449.

22 Cf. Kahneman, D., "Maps of Bounded Rationality: Psychology for Behavioral Economics," p. 1449.

23 The concept of "rationality" is not empirical, but his manifestations do, cf. Rescher, N., Rationality: A Philosophical Inquiry into the Nature and the Rationale of Reason, Clarendon Press, Oxford, 1988.

24 Simon, H. A., "Bounded Rationality in Social Sciences: Today and Tomorrow," pp. 34-35. 
characterized neoclassical theory in the last half of our century, but it does lend itself very well to formal simulation with computer models, that is to say, with symbolic difference equations instead of the more familiar arithmetic differential equations borrowed from physics." ${ }^{25}$ This is a theory of decision that includes not only the processes of election among alternatives, but also the processes for generating new alternatives. So, in Simon's opinion, it has a basic requirement for any satisfactory theory of long-term economic phenomena.

3. "There remains a large task of organizing and systematizing the empirical picture of economic processes that has already been assembled, and of continuing to provide the body of facts that are necessary to guide an empirically sound reformulation of the theory." ${ }^{26}$ This means that, in Simon's opinion, the methodology has to be observational and inductive, where the empirical base precedes the theorization and the theory is conceived as the harmonization of the empirical available knowledge. But this bears more problems than he thinks, mainly if we agree to consider that there is "a theoretical charge" when scientific observation is done and theory does not simply harmonize the empirical available knowledge (for example, when it makes predictions).

\section{Acceptance of Experiments in Economics}

Regarding experiments, there has been an attitude of caution in economics, which is expressed by Tony Lawson when he publishes a chapter whose title is "Economic Science without Experimentation." ${ }^{27}$ There, he considers how the social scientific research can proceed in the absence of real possibilities of experimental control. ${ }^{28}$ Because it was still questioned in 1997 whether there existed an experimental control in economics equivalent to the existing one in the most natural sciences (physics, chemistry and biology).

One of the arguments given to explain this is the complexity of the phenomena that the social sciences have to study. In the case of economics it is said that there are a lot of variables taking part even in an individual decision making process. Besides, we have to realize that there is a very complex net of relations between the economic decisions made by agents and their environment. These are factors that worsen the control of the conditions to do research. Thus, even if we accept the possibility of the experiment, it would be considered "artificial" or with very restricted validity.

\subsection{Institutional Area and Thematic Field}

Opposite to the critical attitude related to experiments we can argue in institutional terms, the development in academic areas, and from a thematical point of view. First of all, there is a branch in economics that has for a long period, openly accepted the role of experiments and deals with the rationality in decision making. ${ }^{29}$ Simon paid special attention to the contributions of experimental economics. He has elements of confluence with this economic position, both

\footnotetext{
25 "Bounded Rationality in Social Sciences: Today and Tomorrow," pp. 35.

26 Simon, H. A., "Bounded Rationality in Social Sciences: Today and Tomorrow," pp. 35.

27 Lawson, T., "Economic Science without Experimentation," in Lawson, T., Economics and Reality. Routledge, London, 1997, chapter 15, pp. 199-226.

28 Cf. Lawson, T., Economics and Reality, p. 199.

29 Cf. Gonzalez, W. J., "Rationality in Experimental Economics: An Analysis of Reinhard Selten's Approach," in Galavotti, M. C. (ed.), Observation and Experiment in the Natural and Social Sciences, Kluwer, Dordrecht, 2003, pp. $71-83$.
} 
epistemological and methodological. Indeed, Simon's empirically grounded economics as well as R. Selten and V. Smith's experimental economics emphasize the empirical component of the discipline, both to conform the economic knowledge and to evaluate its validity.

From a thematic point of view, the question is what we understand when we talk about "experiment." Initially, when we think of an "experiment" we think of a process studied in a laboratory, where one of the key elements is the intervention in a certain event. Thus, to experiment consists of intervening in some of the elements or mechanisms of something real, isolating other factors, in order to investigate a series of parameters that are controlled. But there is not one single way to perform experiments. What is more, there is a diversity of experiments. The criteria of differentiation are divided into three types: epistemological, methodological and ontological. They are "mainly i) the range of controllability of the variables, ii) the level of materiality of the processes employed in the research, and iii) the sphere - real, ideal, and hybrid, ...- to be analyzed." ${ }^{30}$ Thus, when this diversity is accepted, it's possible to watch that economics uses a variety of experiments.

i) In regards to the epistemological issue of the range of controllability of the studied variables, there are at least three possibilities in economics: a) direct control; b) indirect control (or statistical control); and c) assumption in model. ii) Concerning the methodological issue of the level of materiality of the processes employed in the research, there would be three possibilities in economics: a) laboratory experimentation (when a material realm is under direct control); b) the "passive experimentation" of the econometric case (there is an indirect or statistical control); c) computer simulations (when the quasi-material realm or the pseudo-material sphere depends on the assumptions in the model). ${ }^{31}$ iii) The ontological issue of the sphere to be analyzed varies from real (a tangible object), ideal (a thought experiment or a purely mathematical model) or a hybrid (as in simulations about quasi-material or pseudo-material things). ${ }^{32}$

The need of making experiments in the area of economics increased with the consideration of uncertainty as a key element in human decision making. Any theory that tries to do a realistic analysis of how economic agents behave has to bear in mind the human uncertainty about the present and the future state of the world. In this regard, Simon mentions three events that brought about a drastic change in the situation: the probability theory, the game theory and the invention of rational expectations. ${ }^{33}$ Besides, he thinks the development of "experimental economics" is attributable to the concern with uncertainty.

First of all, the development of the probability theory incorporated the uncertainty to the study of human behavior. But it brought along new problems: a) the question of where the decision maker's probabilities originated and b) computational problems in decision making turned out to be much more difficult. Secondly, the game theory, which initially seemed to be able to solve situations with uncertainty (the one arising from mutual attempts of decision makers to outguess what the persons with whom they were competing think), was a surprise due to the conclusions of its own analysis: they proved that agents do not use perfect rational strategies. This has lead to the game theory community to complete its theory with experiments.

\footnotetext{
30 Gonzalez, W. J., "The Role of Experiments in the Social Sciences: The Case of Economics," in Kuipers, T. (ed.), General Philosophy of Science: Focal Issues, Elsevier, Amsterdam, 2007, p. 280.

31 Cf. Boumans, M. and Morgan, M. S., "Ceteris paribus Conditions: Materiality and the Application of Economic Theories," Journal of Economic Methodology, v. 8, n. 1, (2001), p. 20.

32 Cf. Gonzalez, W. J., “The Role of Experiments in the Social Sciences: The Case of Economics,” p. 280.

33 Cf. Simon, H. A., "Bounded Rationality in Social Science: Today and Tomorrow," pp. 27-29.
} 
Finally, rational expectations conception gave a solution to the problem of uncertainty related to the behavior of others. But it assumed that all the economic actors have the same economic model in mind when they make their decisions. Nevertheless, this principle of rationality proved to be wrong very soon. ${ }^{34}$

The other important development that Simon attributes to the concern with uncertainty is experimental economics. In this field, we can mention Reinhard Selten's contribution, which obtained the Nobel Prize for his contributions in game theory together with John Nash and John Harsanyi in 1994. Selten assumes Simon's approach about bounded rationality in human behavior and he works to bring experimentation in economics closer to the reality of the agents' behavior. Because of this, his approach has important differences with other economists who are closer to the theory of utility maximization. ${ }^{35}$

Epistemologically, Selten grants more importance to the empirical knowledge than to the theoretical knowledge. His position is closer to an empirical theoretical frame than to a rationalist approach. From a methodological point of view, his approach about experimental economics tends to identify some empirical regularities based on experimental data and, from there, he tries to build a formal theory to explain them, instead of starting with a formal theory submitted to verification in the laboratory. ${ }^{36}$

This way of facing up the research is far from other methodological approaches developed in experimental economics, in which experiments are designed to perform three tasks: a) to verify and modify the formal economic theories; b) to get data from interesting phenomena and relevant institutions, trusting to find no advanced regularities; or c) to relate them in a direct way with decision making in public policy. ${ }^{37}$

\subsection{Context for the Experiments}

But there is another important issue related to experiments and it is the context where they are made. Ironically, as Simon points out, experimental economics has its origin in experiments made in the university classrooms, using the students as subjects trading under specific market rules. The problem is that these economic agents have the same profile and the results of their experiments do not fit the complexity of real situations. ${ }^{38}$

There are some problems in experimental economics from a methodological point of view because "how much of what is obtained in the economic laboratory can be applied directly to the complex situation of economic activity within the real world?" Real data are much more difficult to obtain and to interpret. So this aspect can have repercussions in the characterization of economic activity as such and in the analysis of economic activity as interconnected with other human activities into a historical context. ${ }^{39}$

In spite of all, it seems that only in laboratory experiments the right conditions to control the environment can be obtained and in this way, the behavior of the variables in a certain

34 Cf. "Bounded Rationality in Social Science: Today and Tomorrow," pp. 27-29.

35 Cf. Gonzalez, W. J., "Análisis de la racionalidad y planteamiento de la predicción en Economía Experimental," in Gonzalez, W. J., Marqués, G. and Ávila, A. (eds.), Enfoques Filosófico-Metodológicos en Economía, Fondo de Cultura Económica, Madrid, 2002, pp. 145-172.

36 Cf. Gonzalez, W. J., “Análisis de la racionalidad y planteamiento de la predicción en Economía Experimental,” p. 149.

37 Cf. “Análisis de la racionalidad y planteamiento de la predicción en Economía Experimental,” p. 149.

38 Cf. Simon, H. A., "Bounded Rationality in Social Science: Today and Tomorrow," pp. 29-30.

39 Cf. Gonzalez, W. J., “The Role of Experiments in the Social Sciences: The Case of Economics," p. 290. 
situation can be accurately analyzed. Economics has typically ignored contextual variables, but "for experimental studies to be judged as 'representative', and thus to generalize, claims need to be established for this (relative to the theory being tested) on the dimensions of both experimental participants and situations." 40

It is clear that the design of experiments controlling the conditions by the experimenter provides interesting results, both to verify descriptive theories (economic theory) and to give advice to public policy (applied economics). ${ }^{41}$ As Selten stresses too, the focus of the issue "is often on designing new experiments to test the predictive value of a theory rather than or merely construing a new theory for describing the data observed. In addition, he proposes statistical tests to compare a new theory with the previously existing ones in order to show the superior predictive power for these experiments." ${ }^{42}$

Besides, new tools have been designed to help in experimentation and, so to build theories. The use of computer simulations allow to break some limits, as the ones that come from the computation capability, the characteristic of organization structure or human motivation. An example could be the use of neural networks, where players learn by constructing explicitly approximate models of their environment and updating these as the information they possess improves. ${ }^{43}$

Even though these tools have begun to show their power, "experimental work needs to be complemented by field studies in business firms of the actual decision processes employed for various kinds of decisions (for example, capital investment, discovery and development of new products, reorganization)." ${ }^{44}$

An important part of the experiments that are led nowadays to build economic theories closer to real world are developed within the psychological area. These mainstream research tendencies seek to elaborate a description of the human rationality that, from the cognitive processes of people, help to understand decision making. The results obtained indicate that there are mainly two ways of thinking that fit with the concepts of reasoning and intuition. The reasoning process is done deliberately and with a lot of effort, whereas intuitive thought seems to appear spontaneously in our minds without calculation or conscious search and without effort. Superficial observation and systematical research indicate that most of our thoughts and actions are usually intuitive in this sense. ${ }^{45}$

The experiments done by psychologists contribute to the economic research concepts which have been ignored until recent days, such as the adaptive function of the access to information, deliberate attention, relevant stimuli from an emotional point of view, the role of optimism in taking risks, or the heuristic of fondness. To reach some conclusions as the fundamental characteristic of the agents is not that they reason in a wrong way, but they usually act intuitively. The behavior of these agents is not ruled by what they are able to calculate, but by the things they see by chance in the moment they are going to make a decision. ${ }^{46}$ For this reason, those who do

40 Hogarth, R. M., "The Challenge of Representative Design in Psychology and Economics," Journal of Economic Methodology, v. 12, n. 2, (2005), p. 261.

41 Cf. "The Role of Experiments in the Social Sciences: The Case of Economics," pp. 281-282.

42 Cf. Gonzalez, W. J., "The Role of Experiments in the Social Sciences: The Case of Economics," p. 292.

43 Cf. Sent, E. M., "The Legacy of Herbert Simon in Game Theory," Journal of Economic Behavior and Organization, v. 53, (2004), p. 311.

44 Simon, H. A., "Bounded Rationality in Social Science: Today and Tomorrow," p. 37.

45 Cf. Kahneman, D., "Maps of Bounded Rationality: A Perspective on Intuitive Judgement and Choice," p. 450.

46 Cf. "Maps of Bounded Rationality: A Perspective on Intuitive Judgement and Choice,” pp. 449-489. 
research in this particular field, ask for the incorporation of a "common sense psychology of the intuitive agent in economic models." Though this is an issue that presents difficult challenges, mainly for the formal theory, it is gathering more followers as shown in the latest results. ${ }^{47}$

In spite of the difficulties pointed out by the critics of experiments in economics, it is clear that it has a place in economic research, both in experimental economics and in game theory. Some Nobel Prize winners for the first issue (in 2002) as for the second (in 1994 and 2005) have used experiments in the economic field. ${ }^{48}$ Experiments in the case of social sciences as economics can help, first of all, to explain observable and repeatable phenomena, which are analyzed by some theory, and, secondly, to create new situations that can generate new alternatives impossible to get by other means.

\section{BiBLIOGRAPHY}

Boumans, M. and Morgan, M. S., "Ceteris paribus Conditions: Materiality and the Application of Economic Theories," Journal of Economic Methodology, v. 8, n. 1, (2001), pp. 11-26.

Cyert, R. M. and March, J. G., The Behavioral Theory of the Firm, Prentice Hall, Englewood Cliffs, NJ, 1963.

Cyert, R. M., Simon, H. A. and Trow, D. B., "Observation of a Business Decision," Journal of Business, v. 29, (1956), pp. 237-248. Compiled in Simon, H. A., Models of Bounded Rationality. Vol. 2: Behavioral Economics and Business Organization, The MIT Press, Cambridge, MA, 1982, pp. 275-286.

Dasgupta, S., "Multidisciplinary Creativity: The Case of Herbert A. Simon," Cognitive Science, v. 27, (2003), pp. 683-707.

Gigerenzer, G., Swittink, Z., Porter, T., Daston, L., Beatty, J. and Krueger, L., The Empire of Chance: How Probability Changed Science and Everyday Life, Cambridge University Press, Cambridge, 1989.

Gonzalez, W. J., "Prediction and Prescription in Economics: A Philosophical and Methodological Approach," Theoria, v. 13, n. 2, (1998), pp. 321-345.

GonzalEz, W. J., "Análisis de la racionalidad y planteamiento de la predicción en Economía Experimental," in Gonzalez, W. J., Marqués, G. and Ávila, A. (eds.), Enfoques FilosóficoMetodológicos en Economía, Fondo de Cultura Económica, Madrid, 2002, pp. 145-172.

Gonzalez, W. J., "Rationality in Experimental Economics: An Analysis of Reinhard Selten's Approach," in Galavotti, M. C. (ed.), Observation and Experiment in the Natural and Social Sciences, Kluwer, Dordrecht, 2003, pp. 71-83.

Gonzalez, W. J., "Herbert A. Simon: Filósofo de la Ciencia y economista (1916-2001)," in Gonzalez, W. J. (ed.), Racionalidad, historicidad y predicción en Herbert A. Simon, Netbiblo, A Coruña, 2003, pp. 7-63.

Gonzalez, W. J., "Racionalidad y Economía: De la racionalidad de la Economía como Ciencia a la racionalidad de los agentes económicos," in Gonzalez, W. J. (ed.), Racionalidad, historicidad y predicción en Herbert A. Simon, Netbiblo, A Coruña, 2003, pp. 65-96.

Gonzalez, W. J., "The Role of Experiments in the Social Sciences: The Case of Economics," in Kuipers, T. (ed.), General Philosophy of Science: Focal Issues, Elsevier, Amsterdam, 2007, pp. 275-301.

47 Cf. "Maps of Bounded Rationality: A Perspective on Intuitive Judgement and Choice,” p. 489.

48 Cf. Gonzalez, W. J., “The Role of Experiments in the Social Sciences: The Case of Economics,” pp. $276-277$. 
Hogarth, R. M., "The Challenge of Representative Design in Psychology and Economics," Journal of Economic Methodology, v. 12, n. 2, (2005), pp. 253-263.

Kahneman, D., "A Perspective on Judgement and Choice: Mapping Bounded Rationality," American Psychologist, v. 58, n. 9, (2003), pp. 697-720.

Kahneman, D., "Maps of Bounded Rationality: Psychology for Behavioral Economics," American Economic Review, v. 93, n. 5, (2003), pp. 1449-1475.

Kulkarni, D. and Simon, H. A., "Experimentation in Machine Discovery," in Shrager, J. and Langley, P. W. (eds.), Computational Models of Scientific Discovery and Theory Formation, Morgan Kaufmann, San Mateo, CA, 1990, pp. 255-273.

Lawson, T., Economics and Reality. Routledge, London, 1997.

RESCHER, N., Rationality: A Philosophical Inquiry into the Nature and the Rationale of Reason, Clarendon Press, Oxford, 1988.

SEnt, E. M., "The Legacy of Herbert Simon in Game Theory," Journal of Economic Behavior and Organization, v. 53, (2004), pp. 303-317.

Simon, H. A. and Divine, W. R., "Controlling Human Factors in an Administrative Experiment," Public Administration Review, v. 1, (1941), pp. 485-492.

Simon, H. A., "A Behavioral Model of Rational Choice," Quarterly Journal of Economics, v. 69, (1955), pp. 99-118. Compiled in Simon, H. A., Models of Bounded Rationality. Vol. 2: Behavioral Economics and Business Organization, The MIT Press, Cambridge, MA, 1982, pp. 239-258.

Simon, H. A., "Discussion: Problems of Methodology," American Economic Review, v. 53, (1963), pp. 229-231. ${ }^{49}$ Compiled in Simon, H. A., Models of Bounded Rationality. Vol. 2: Behavioral Economics and Business Organization, The MIT Press, Cambridge, MA, 1982, pp. 369-371.

Simon, H. A., "E. B. Hunt, J. Marin and P. Stone: Experiments in Induction,” American Journal of Psychology, v. 80, (1967), pp. 651-653.

Simon, H. A. and Siklossy, L. (eds.), Representation and Meaning: Experiments with Information Processing Systems, Prentice-Hall, Englewood Cliffs, NJ, 1972.

Simon, H. A., "The Heuristic Compiler," in Simon, H. A. and Siklossy, L. (eds.), Representation and Meaning: Experiments with Information Processing Systems, Prentice-Hall, Englewood Cliffs, NJ, 1972, pp. 9-43.

Simon, H. A., "Behavioral Research: Theory and Public Policy," in: The 1979 Founders Symposium, The Institute for Social Research: Honoring George Katona, The University of Michigan, Ann Arbor, MI, 1980, pp. 11-16. Compiled in Simon, H. A., Models of Bounded Rationality. Vol. 3: Empirically Grounded Economic Reason, The MIT Press, Cambridge, MA, 1997, pp. 299-318.

Simon, H. A., "Why Economists Disagree," Journal of Business Administration, v. 18, n. 1-2, (1988-1989), pp. 1-19. Compiled in Simon, H. A., Models of Bounded Rationality. Vol. 3: Empirically Grounded Economic Reason, The MIT Press, Cambridge, MA, 1997, pp. 401-420.

Simon, H. A., "Satisficing," in Greenwald, D. (ed.), The McGraw-Hill Encyclopedia of Economics, 2nd ed., McGraw-Hill, New York, 1993, p. 884.

Simon, H. A., Models of my Life, Basic Books, N. York, NY, 1991 (reprinted by The MIT Press, Cambridge, MA, 1996).

49 It was published later with a different title: Simon, H. A., "Testability and Approximation," in Hausman, D. M. (ed.), The Philosophy of Economics. An Anthology, Cambridge University Press, Cambridge, 1984, pp. 245-248. And it was reprinted: Simon, H. A., "Testability and Approximation," in Hausman, D. M. (ed.), The Philosophy of Economics, 2nd edition, Cambridge University Press, Cambridge, 1994, pp. 214-216. 
Simon, H. A., "Methodological Foundations of Economics," in Auspitz, J. L., Gasparski, W. W., Mlicki, M. K. and Szaniawski, K. (eds.), Praxiologies and the Philosophy of Economics, Transactions Publishers, New Brunswick, NJ, 1992, pp. 25-42. Compiled in Simon, H. A., Models of Bounded Rationality. Vol. 3: Empirically Grounded Economic Reason, The MIT Press, Cambridge, MA, 1997, pp. 319-336.

Simon, H. A., "Decision Making: Rational, Nonrational, and Irrational," Educational Administration Quarterly, v. 29, (1993), pp. 392-411.

Simon, H. A., "Introduction," in Simon, H. A., Models of Bounded Rationality. Vol. 3: Empirically Grounded Economic Reason, The MIT Press, Cambridge, MA, 1997, pp. ix-xiii.

Simon, H. A., An Empirically Based Microeconomics, Cambridge University Press, Cambridge, 1999 (Lectures Mattioli, Universitá Commerciale Luigi Bocconi of Milan, 1993).

Simon, H. A., "Bounded Rationality in Social Science: Today and Tomorrow," Mind and Society, v. 1, n. 1, (2000), pp. 25-39.

Simon, H. A., "On Simulating Simon: His Monomania, and its Sources in Bounded Rationality," Studies in History and Philosophy of Science, v. 32, n. 3, (2001), pp. 501-505. 


\title{
The Dynamics of Experimentation and its Role within a Philosophy of Scientific Practices
}

\author{
José Ferreirós
}

\section{INTRODUCTION}

It's already been twenty-five years since Ian Hacking stated, provocatively, that philosophers should start to think about the adventure that began back in the 17th century. He meant modern science, of course — what was then termed "experimental philosophy." Hacking was intimating that the whole tradition in philosophy of science (including all 20th century proposals up until Lakatos, Laudan, and the semantic and structuralist conceptions, at least) is profoundly inadequate to analyse the scientific phenomenon. And the main reason would be that philosophers have not elaborated the tools for an adequate understanding of experimentation - nor therefore of its role in theory formation.

During these 25 years, a small trend of "experimentalist" authors has grown, among them names such as Hacking, Franklin, Cartwright, and also historians like Heilbron, Galison, Buchwald, Steinle - not to forget a good number of sociologists such as Collins, Schaffer, Pickering, etc. In my opinion, the emergence of new experimentalism has been one of the most exciting recent development in the theory of science, if not the most fascinating. The reaction among the community of specialists and teachers of philosophy of science still seems disappointing to me, being so scarce as it is. But perhaps we can be confident that the situation is changing.

Science's old name, "experimental philosophy," suggests already that modern science can be regarded as a hybrid of philosophy (logic, theory, argument) and experiment (intervention, technics, observation). Of course presenting it this way involves a simplification, but I believe it constitutes a useful idealisation, if our purpose is to provide a rudimentary model of how the cognitive activities of scientists are structured. (Above all, such a model hides the role of interactions among members of the scientific community, and between them and other social actors. However, the model can integrate social factors, especially if we understand that knowledge — data and models and theories — is a social product almost by definition.) ${ }^{1}$

Following that suggestion, let me propose a triadic model of scientific activity based on considering three 'phases' in its cognitive processes, or three broad categories of scientific practices (which no doubt would have to be subdivided into finer types): theoretical activities, experimental activities - subsuming here the particular case of observations - and also communicational activities. This in itself cannot sound new, but the key idea is to emphasize that the experimental 'phase' is not reduced or subordinated to the theoretical one, and that it calls for a deeper and novel analysis. Furthermore, both types of activities are in interaction, and the complexity of those interactions still defies philosophers of science.

\footnotetext{
1 Which does not mean (beware the non sequitur) that the analysis of knowledge can be merely sociological.
} 
Such a scheme is very different from the views offered by traditional authors, which by following the linguistic turn and emphasizing logic were led to something like a model where there is one principal 'phase' of theory formation, merely punctuated by the injection of basic statements (corresponding to what are usually called observational data). What is characteristic of experimental and observational activities remained outside the philosopher's analysis, be it because it was considered transparent (as with empiricism) or regarded as exasperatingly swampy (as Popper liked to say). In joint work with Javier Ordóñez, we have criticized such models for their theoreticism, and we have also traced the origins of this tendency back to philosophically inclined theoretical physicists such as Boltzmann. ${ }^{2}$

No doubt, betting for a philosophy of science that is able to analyse the experimental phase complicates matters for the aspiring philosopher, because it will force her to augment her panoply of tools. A fine analysis of the factors that enter into experimental activity should include questions belonging to the cognitive sciences; it cannot be reduced to a logical scheme, nor can it be treated in the style of the linguistic turn, and it is also insufficient to speak of "paradigms" or "values." Considered from this angle, the misery of theoreticism stems from the way it reduced the richness and complexity of scientific procedures to an affair merely of conceptual and theoretical elaboration.

A philosophy of science that closes its eyes to the epistemic specificity of experimental life will thereby renounce the goal of understanding what is most characteristic of scientific knowledge. Properly considered, this already offers an explanation for the peculiar situation we saw towards the end of the 20th century, when the rationalism and faith in progress of philosophers was confronted head-on by strong sociological approaches. The views originating in theoreticist and "logicistic" approaches to the philosophy of science were, malgré lui, feeding the sociologism of the 1980s and 90s. That is because of the way they promoted losing sight of the processes by which data are obtained (produced?) in science. They promoted excessive simplification of our models of scientific practice, and also rigidly formalistic conceptions of human rationality. ${ }^{3}$

In my opinion, the "third way" that can take us out of that bog consists in a reflection upon scientific practices, understood not as an attractive yet void formula, but rather as the decision to fully consider the epistemic and cognitive specificity of scientific activities, and in particular experimental activities. The plural form is of the essence: there is not scientific practice in the singular, but a plurality of coexisting practices, and the crux of the analysis has to do with their heterogeneous cognitive roots and their complex interactions. It is for this reason that, as a first step and to counter their traditional oblivion, we must consider the roots and the dynamics of experimentation. ${ }^{4}$ The way opened by studies of the philosophy of experiment opens a promising course for navigating the waters between the Scilla of theoreticism and the Caribdis of sociological reductionism.

2 Cf. Ferreirós, J. and Ordóñez, J., "Hacia una Filosofía de la experimentación,” Crítica, v. 34, n. 102, (2002), pp. 47-86.

3 The importance of formalistic rationalism as a stimulus for sociological conceptions is clear in the work of a central author like Harry M. Collins. See in particular his classic Collins, H. M., Changing Order. Replication and Induction in Scientific Practice, The University of Chicago Press, Chicago, 1992; original edition 1985). It is also abundantly known how simplified versions of the theses promoted by Popper, Lakatos, or Quine have been appropriated by specialists in STS or sociology of science.

4 Note that this formulation, properly understood, involves the theoretical phase, since both 'phases' are in almost constant interaction. But it emphasizes that which is still the least known and understood. 


\section{Experiment and its Interpretation: The Basic Structure}

In traditional speech about data and experimental results, these are presented as readymade elements emerging from some black box. The possible structural and dynamical complexities in the modus operandi of that black box, what I shall call the "processes of data formation," are not a focus of attention. Indeed, the traditional idea of empiricists is that we are actually talking of a "white box:" a transparent process of reception of impressions, which ends up in an automatic and infallible disposition to formulate basic statements. On a completely different line, we find Popper's peculiar idea that basic statements are like pillars introduced from above (theories rule) into the "swamp" of observational and experimental work, pillars ultimately justified "by convention." 5 Although Popper never extracted the radical conclusions that this position is calling for, others (e.g., Lakatos) did.

It will be worthwhile to pause for a note on terminology. Here, as in previous work, I follow the scientist's usual way of talking when it comes to experimental and observational data. An alternative terminology has been proposed by Bogen and Woodward, who contrast "data" and "phenomena" with connotations that are fundamentally different from mine, as their "data" mean the fluctuating outcomes of particular experimental trials, while "phenomena" are the stable constructs which are theories are meant to predict and explain. ${ }^{6}$ So the reader should beware: data in my sense are the "phenomena" of Bogen, Woodward and others, which is why I emphasize the need to speak about processes of data formation.

In detailed considerations, it is customary to think that the production of an experimental result involves at least three elements - a material procedure, an instrumental model, and a phenomenic model: ${ }^{7}$

a) The material procedure is a complex of objects and actions, or interventions, performed practically in the material world: arranging the apparatus and the specimens, and making them function properly (i.e., setting them to work in the proper sequence and controlling their performance).

b) The instrumental model expresses a certain conceptual understanding on the side of the experimenter about how the apparatus works; this is central to the design, realization, and interpretation of the experiment. Such models can be of a highly theoretical and mathematical nature, but sometimes they depend on a modest amount of low-level theory.

c) The phenomenic model codifies basic elements of the way in which the experimenter understands conceptually aspects of the phenomenal world that are under study; without it, the results would lack sense and meaning and could not be interpreted. And again, phenomenic models do not always depend on high theory. ${ }^{8}$

\footnotetext{
5 Cf. Popper, K. R., Logik der Forschung, Tübingen, Mohr, 1935, chapter 5. (Translated into English by the author with the assistance of Julius Freed y Lan Freed: The Logic of Scientific Discovery, Hutchinson, London, 1959.)

6 Cf. Bogen, J. and Woodward, J., "Saving the Phenomena," The Philosophical Review, v. 97, (1988), pp. 303-352. A good number of other philosophers (for instance, Mauricio Suarez) have adopted this peculiar terminology.

7 See, e.g., Pickering, A., "Living in the Material World," in Gooding, D., Pinch, T. J. and Schaffer, S. (eds.), The Uses of Experiment, Cambridge University Press, Cambridge, 1989, pp. 276-277.

8 Remember, e.g., the "taxonomies" of Kuhn's late work.
} 
To present these ingredients concretely, giving a clear and simple example that we shall continue using in the sequel - Newton's famous experiments on the decomposition of sunlight-, the three elements are as follows:

a') The material procedure includes the prisms (made of some or another kind of glass, sometimes filled with water), screens, procedures to modify the incident light (from simple holes on a window shutter, to lenses employed to colimate the light), etc.

b') The instrumental model is built upon an interpretation of the material procedure in terms of an antecedently established theory, geometrical optics, so that in this case it depends on high theory. (The model did not consider details about possible differences between different kinds of glass, and this was historically important.)

c') The phenomenic model is again formulated by means of geometrical optics, concretely by using the concepts of a ray of light and ideas about its behaviour upon reflection or refraction. The model assumed idealisations that are typical of geometrical optics, like ignoring the fact that shadows have fuzzy edges.

On this last point I should add a clarification. You know of course that Newton was a corpuscularist, believing light to consist in tiny corpuscles travelling at great speed, and that he opposed the wave theories that had been formulated at the time. However, in his optical writings he made an effort to establish key theses - in particular the principle that simple light rays are associated with colours and have a characteristic refrangibility — on a basis that was neutral with respect to the physical theories in dispute. This is why his phenomenic model does not presuppose corpuscularism and is based on geometrical optics, by then a classic theory, well established at least among "mathematicians."

Traditional images of experimentation would suggest that, at the stage of justification, the material procedure and the instrumental model remain fixed and unaltered. Their features would be relatively natural and uncontroversial, both for the particular scientist who first proposed them, and for the scientific community that must replicate the experiments and judge the results. Meanwhile, the phenomenic model would be more flexible or "plastic," since of course one allows for the possibility of competing theories defended by different scientists. Moreover, in what was traditionally (since the 19th century) presented as the prototype experiment, the main goal would be to measure in great accuracy some data to be contrasted with theoretical predictions, or perhaps some parameter fixed by theory (e.g., a physical constant, as a result of which the phenomenic model would be refined and specified to a greater level of precision).

But sociologists of science have challenged those assumptions, studying in detail cases where one finds the scientist showing almost no flexibility as regards the phenomenic model, but treating the other two components as very flexible indeed. Famous in this regard is Pickering's work on what he called "the hunting of the quark," some experiments performed by the Italian physicist Morpurgo during a period of 15 years. The studies of Harry Collins on the search for gravitational waves are also well known and have been celebrated. ${ }^{9}$ Pickering concludes that the three structural elements a), b) and c) are equally plastic resources that,

9 For discussion and questions about the details of the case studies offered by Collins and Pickering, see FrankLin, A., "Experiment in Physics," in Zalta, E. N., (ed.), The Stanford Encyclopedia of Philosophy (Summer 2003 Edition), http://plato.stanford.edu/archives/sum2003/entries/physics-experiment (access on November 2007) See also the abridged Spanish version: Franklin, A., "Física y experimentación," Theoria, v. 17, n. 44, (2002), pp. 221-242. An interesting exchange between Franklin and Collins took place in Studies in History and Philosophy of Science, v. 25, n. 3, (1994), pp. 463-503. 
far from being fixed and determined, can be modified at will until a result of coherence is attained. He believes that experimental work begins in such a way that there no definite relation between the structural ingredients: "incoherence and uncertainty are the distinctive seals of experiment," as shown abundantly by studies of laboratory life. But at the end of the day, some form of non-trivial coherence is obtained, a stabilization such that "material procedures, (...) when interpreted through an instrumental model, produce facts within the framework of a phenomenic model." ${ }^{10}$

The analysis of such processes of interactive stabilization between the three structural elements constitutes what, in the sociologist's perspective, would correspond to our dynamics of experimentation. Any conclusion we may finally extract about experimental activity, be it about its epistemic relevance, or say its dependence upon contextual factors, will obviously hang on the characteristics attributed to the structural ingredients, and to their interrelations.

If Pickering's position is somehow typical, the main point in dispute today would no longer be the "social construction" of experimental results, a conception of sociological reductionism that has been superseded by many promoters of social studies of science. But there remain the hot problems of the epistemic reliability of experimental data, the extent to which they provide information on natural processes, as opposed to the possibility of vicious circles, ${ }^{11}$ or a mere coherentist stabilization such as described by Pickering. ${ }^{12}$ All of this depends on whether the structural elements are "equally plastic" or not.

The coherentist thesis has been formulated again by Hacking, who speaks of a "selfvindication" of laboratory sciences, and presents the idea as a kind of expanded Duhem thesis. ${ }^{13}$ If correct, the thesis of Pickering and Hacking would have noteworthy consequences. It would be definitive confirmation of the "theory-ladenness" of results, certainly in the company of their correlative "technics-ladenness" and "social-ladenness," but forcing us to abandon as elusive or noumenical — to abuse of Kant's terminology — any possible "nature-ladenness." Maybe the business of science would have its continuity and production of technological effects guaranteed (albeit one could not quite understand why), but from an epistemic point of view it would lack any special justification.

Points like those are thus crucial to any conclusion with respect to the epistemic reliability of the whole scientific enterprise, hence to the project of a philosophy of science. After all Einstein, even during his period of greatest enthusiasm for the theoretical and mathematical components of science (and although he was willing to grant that "the creative principle resides in mathematics"), emphasized that "experience remains, of course, the sole criterion of the physical utility of a mathematical construction." And some years later, Feynman would begin his lectures saying: "The principle of science, the definition, almost, is the following: The test of all knowledge is experiment. Experiment is the sole judge of scientific 'truth'." ${ }^{14}$ So, is that "metaphysical" idea, the concept of Nature, totally foreign to this game?

\footnotetext{
10 Pickering, A., "Living in the Material World," in Gooding, D., Pinch, T. J. and Schaffer, S. (eds.), The Uses of Experiment, pp. 277-278.

11 Cf. Colnins, H. M., Changing Order. Replication and Induction in Scientific Practice, passim.

12 Cf. Pickering, A., The Mangle of Practice, The University of Chicago Press, Chicago, 1995.

13 Cf. Hacking, I., “The Self-Vindication of the Laboratory Sciences," in Pickering, A. (ed.), Science as Practice and Culture, The University of Chicago Press, Chicago, 1992, pp. 29-64.

14 Quoted from the famous Franklin, A., Feynman Lectures on Physics, Addison-Wesley, Reading, 1963, in Franklin, A., "Experiment in Physics," in Zalta, E. N. (ed.), The Stanford Encyclopedia of Philosophy, note 1.
} 


\section{The “EXPERIMENTER's REgRESS"}

Let us come back to Newton's famous experiments. Contrary to common lore, historians have established that his work on the composition of light, and in particular his experimentum crucis, were by no means an immediate success. Indeed, Schaffer has turned this case into another argument for the decisive influence of sociological factors in science's decision making. The experimentum crucis was contested during some fifty years, mainly — but not only — due to the difficulty of replicating its quantitative results. ${ }^{15}$ A quick reading of the controversies suggests that Newton was arguing as follows: "simple" rays of light behaved according to his statements, but this could only be detected using "good" prisms, and "good" prisms were those which produced "simple" rays.

Thus the case is presented as a clear illustration of what Collins has termed the "experimenter's regress," that menaces the epistemic reliability of experimental results. The experimenter's regress of Collins consists in a vicious circle that stems from severe problems with the replication of experiments and the calibration of scientific instruments. The main problem is that correct results are only obtained using apparatus that functions properly, while the apparatus is functioning properly only if it provides correct results. ${ }^{16}$ So in the last analysis the outcomes of a scientific controversy do not depend so much on what "Nature" has to "say," or on any special use of methods with some epistemic virtues, but on who is the experimenter in a social position of dominance, that enables her or him to determine what is correct and what functions properly. Collins offers as prototypical the case of J. Weber's experiments on gravitational waves, ${ }^{17}$ but the example of Newton's experiments, in Schaffer's interpretation, is by no means worse. In this case, Schaffer argues that it was well into the 18th century (around 1715), when Newton enjoyed a position of extraordinary influence as President of the Royal Society, that he displayed diplomatic activities ending up in the promotion of his scientific views in France.

I believe that this interpretation is incorrect, which incidentally shows that good history of science (such as Schaffer's) is still not sufficient for an in-depth philosophical analysis. I shall now offer my own revision of the case, where the third kind of practices mentioned above (practices of communication) plays an important role.

In good measure, the polemics generated by Newton's work and his experimentum crucis were caused by himself, by what we might call a youthful error in his strategy of argument. Retrospectively one can locate the main error, not in anything Newton did while investigating the matter, but in the way he wrote his first published paper on natural philosophy. ${ }^{18}$ The 'error' was motivated by Newton's great experience with mathematical texts, and his lack of experience in physical controversies. The young Newton believed that he could solve the question in great brevity and full precision by writing more geometrico: two carefully

\footnotetext{
15 See Schaffer, S., "Glass Works: Newton's Prisms and the Uses of Experiment," in Gooding, D., Pinch, T. J. and SCHAFfer, S. (eds.), The Uses of Experiment, pp. 67-104.

16 Cf. Coluins, H. M., Changing Order, chapters 4 and 5.

17 See Collins, H. M., Changing Order, chapter 4, pp. 79-111, and Franklin, A., "Experiment in Physics," passim. Collins makes a lot of the statement that "there are no formal criteria" that could be applied to decide whether the instruments are functioning properly. On this topic, see footnote 4 above.

18 Cf. Newton, I., "A Letter of Mr. Isaac Newton, Professor of the Mathematicks in the University of Cambridge; Containing his New Theory about Light and Colors," Philosophical Transactions of the Royal Society, v. 80, (1672), pp. 3075-3087. Available on the web, see www.newtonproject.sussex.ac.uk/prism.php?id=47 (access on November 2007). Reprinted (among others) as "Letter to Mr. Oldenbourg on Light and Colours," in Horsley, S. (ed.), Opera Quae Extant Omnia, J. Nichols, London, 1779-1785, vol. IV; reprinted by F. Frommann, Stuttgart, 1964.
} 
planned experimental "demonstrations," together with a series of definitions and propositions, would suffice to convince his readers. (The reader should notice that modern protocols for doing and reporting experimental research only consolidated during the 19th century, while the millenary Euclidean style of writing mathematics remained paradigmatic for scientists throughout the 17th and 18th centuries.)

Newton based all of his argument on two experiments, of which the first was extremely rudimentary, even though he offered some variations of the theme (one prism projecting an elongated image onto a screen), and the second was quite sophisticated, being offered in a single purportedly definitive version. This "experimentum crucis" employed two prisms and two screens by means of which a monochrome ray of light was isolated, with results that were meant to stamp the key proposition that sunlight consists in a mixture of coloured rays with different specific refrangibilities. The famous "crucial experiment" was thus made to support all of the weight of proof, single-handedly.

Both experiments turned out to be difficult to replicate, again in large measure because of their "mathematical" character, i.e., and perhaps surprisingly to the reader, precisely because the results were quantitative. The elongated image that Newton obtained in Cambridge was a palette of colours (an artificial rainbow) enlarged by a factor of 5, but the Jesuit Antoine Lucas working in Liège only obtained an elongation by a factor of 3. Was this perhaps because sunlight is different in both locations? When Lucas published his discrepancy in the Philosophical Transactions, Newton took it very seriously as an offence to his honesty as a gentleman and his reliability as a reporter of observed physical phenomena. The discrepancy was relevant in the context of discarding alternative explanations of the result, by an argument relying on Snell's law of refraction. Therefore Newton felt an imperious need to attack his opponent and annihilate him. Quite unfortunately, it never occurred to him that they could be confronting a real problem caused by differences in the nature of the prism's glass. As the crystalline composition of glasses produced in different places and factories differed greatly, it was plainly naïve to expect standardized quantitative results as an outcome!

Another source of difficulties was made manifest by a highly reputed French experimenter, Edme Mariotte, founding member of the Académie des Sciences. Around 1680, Mariotte set out to reproduce the supposedly "crucial" experimentum crucis, finding results that he interpreted to contradict and even refute Newton. Having isolated a "simple" violet beam of light, he obtained after the second refraction tones of red and yellow colouring both ends of the violet image. ${ }^{19}$ What the English was inclined to consider an understandable imperfection of the experimental setting, was interpreted by his much more empiricistic colleague as a very clear contrary result, a vindication of the old theory of the modification of light by the prism (that Newton was intent on refuting). It was "evident" that in this experiment a ray of light of the kind that Newton called "simple" had been modified or shown to be complex. Given Mariotte's deserved reputation as an experimenter, this episode brought as a result a very long delay — almost 40 years - for the acceptance of Newton's theory in France and other places.

This time the discrepancy between both actors can be located in their instrumental and phenomenic models, or more precisely in what we may term — following Hempel— the

19 See Guerlac, H., Newton on the Continent, Cornell University Press, Ithaca, 1981, pp. 98-99. Mariotte's work appeared as a book: MARiotTe, E., De la nature des couleurs, Estienne Michallet, Paris, 1681; which can also be found in his Oeuvres, vol. 1, Pierre Vander, Leiden, 1717. 
"bridge principles" necessary for Newton's interpretation of the results. Their discrepancy measures the conceptual distance between the simple ray promoted in geometrical optics, hence in Newton's models, and the concrete beam of light that the experimenter was able to isolate. In a sense, the epistemic character of modern science was at stake: whether it was to be crudely empirical, based directly upon the observed in the style of Mariotte, or inextricably linked with mathematical idealisations, as Newton advocated. In the latter's opinion, the study of Nature had to be mathematical, and the narrowest beam obtained by an experimenter was, self-evidently, very far from the "simple" ray in the model. The corresponding adjustments were more than enough to explain away Mariotte's observations.

Such incidents show the enormous difficulties encountered by scientific research in its infancy, and make us wonder how it was possible to obtain any clear advances given all the material and technical difficulties: inexistence of standardized instruments, lack of experimental protocols, unreliability of the practical and intellectual training on the side of the savants. Little wonder that, if you wish to look for rhetorical elements in writings and letters from the time, you will find plenty of material that can be used for the conclusion that Collins' regress was fully in action, that the dispute was impossible to close except by an appeal to politico-diplomatic operations. A clear example of social construction and negotiation, it seems.

\section{Complications in the Dynamics of Experiment}

Is that really so? Were there elements that made it possible to break the vicious circle of Collins and Schaffer? I believe the answer is yes. In the present case, those elements were elaborated by Newton himself in the initial researches during the period 1666-1670, and were presented to the public mainly in the Opticks of 1704. Let me argue the case.

The two polemics mentioned above indicate two important aspects of the complex dynamics of experimentation. First, experiments are dependent on technics, ${ }^{20}$ so that it has often happened like in Newton's case: it is impossible to strengthen the experimental results without a simultaneous advancement of technics, and this complicates experimental work enormously. Knowing the composition of light made it necessary to learn about glass, its composition, and the techniques for its production. Without this process of refinement of glass production techniques, the later development of spectrography would have been impossible. ${ }^{21}$ And of course, the process could not be completed quickly, but required many years. We have seen how this created considerable difficulties for the early attempts at quantification. And yet, all that is not sufficient to produce a vicious circle.

Second, we have encountered complications linked with the models employed (models of the experimental design and of the phenomena), and very especially difficulties linked with the "bridge principles," relating to the kind of theoretical development that was sought. Such problems could not be avoided, even with Newton's special effort to employ instrumental and phenomenic models that remained neutral between the theories in confrontation. Newton's idea was to force his results upon all parts, and so it happened with those who were favourable

\footnotetext{
20 I employ this uncommon term in order to try to capture the Spanish distinction between technology (a sophisticated form of technical development, dependent upon science) and the more primitive and basic "technics" (in my language, respectively, Tecnología and Técnica).

21 On this topic, see e.g., McGucken, W., Nineteenth Century Spectroscopy, Johns Hopkins University Press, Baltimore, MD, 1969, and SÁnchez Ron, J. M., Historia de la Física Cuántica, Crítica, Barcelona, 2001.
} 
to mathematisation, to an alignment between physical optics and the other mathematical sciences. But these were not "all" parties.

Looking at the long duration, modern science has sided with Newton, with the option to go "beyond the appearances;" it has made a bet for mathematised theories. By contrast, Mariotte's case is reminiscent of the later criticisms of Goethe against the theory of colours: An option for the empirical and the visible, sometimes based on (geometrically) very poor arguments, but sometimes offering an intelligent critique of insistence on the idea that Natura has an interior and an exterior, an apparent shell hiding a real content. Such insistence, however, triumphed due to the predictive efficiency of the models that were based on it, their high level of empirical adequacy, the considerable explanatory abilities shown, and not least their very important technological applications. ${ }^{22}$

But there are more aspects to be considered. Third, and already suggested, is the idea that the qualitative aspects of a series of experiments can be crucial. Experimental complexities have the effect that sometimes the attempt to quantify may be premature, as happened with Newton's experiments around 1670. This idea runs against the image of experimentation created in the 19th century, which depicts it mainly as quantification. The truth is that experiments always have an important qualitative component, which can be decisive not only in favouring some theory against some other, but also in supporting a certain interpretation of the experimental results themselves. ${ }^{23}$ Qualitative aspects of experimentation are a crucial theme for some recent authors like F. Steinle. ${ }^{24}$

And fourth, a central aspect of experimental research, which was severely misrepresented by the inherited conceptions (here theoreticism was quite efficient in biasing and distorting): It is absolutely essential to take into account that data are not obtained automatically, instantly, or transparently. I believe one must speak about processes of data formation; one has to emphasize that experimental research must be analysed in terms of series of experiments. Examples can be multiplied at will, and although I shall continue focusing my discussion on the case of Newton, let me mention that of Pieter Zeeman and the celebrated effect he discovered in 1896 (the influence of magnetic fields on spectral lines, splitting them). A first successful experiment was far from convincing him, and he proceeded to make some others with the aim to control some variables (density, temperature, distribution of the substance emitting the radiation) that could conceivably affect the outcome. (Conceivably, that is, according to what theory suggested, or sometimes according to what analogies with other experiments suggested.) Zeeman wrote the following sentence, which clearly suggests the topic of series of experiments as the source of data:

"The different experiments ... make it more and more probable that the absorption —and hence also the emission - lines of an incandescent vapour are widened by the action of magnetism." 25

\footnotetext{
22 Nevertheless, sometimes one may be inclined to think that the search for the simple ultimate element (that holy grail of physicists) could be illusory, the product of an erroneous approach.

23 This question was raised already in Kunn, TH. S., "The Function of Measurement in Modern Physics," Isis, v. 52, n. 2, (1961), pp. 161-193. Reprinted in Kunn, Tн. S., The Essential Tension, The University of Chicago Press, Chicago, 1977, ch. VIII, pp. 178-224. A very interesting paper that unfortunately founds no continuation in his work.

24 See, e.g., StEInLE, F., "Challenging Established Concepts: Ampère and Exploratory Experimentation," Theoria, v. 17, n. 44, (2002), pp. 291-316.

25 Pieter Zeeman in October 1896, quoted by Arabatzis, T., Representing Electrons: A Biographical Approach to Theoretical Entities, The University of Chicago Press, Chicago, 2006, p. 176. On this topic see also BuCHWALD, J. Z. and Warwick, A. (eds.), Histories of the Electron: The Birth of Microphysics, The MIT Press, Cambridge, MA, 2001.
} 
Incidentally, Zeeman's early experiments were rather exploratory, guided by vague considerations about the possibility of an interrelation, but later his research was guided by Lorentz's theory that spectral lines are caused by the vibration of atoms, and at the same time his experiments brought important modifications and refinements into this theory. ${ }^{26}$

To come back to Newton, the point I want to make is that his practice of argumentation differed from the practice of his experimental researches. As we saw above, his publication of 1672 was a clear bet for "decisive" experiments, carefully selected to support central elements of the theory; in this case, the experimentum crucis. In the midst of polemics, in 1776, he wrote: "For it is not the number of Exp[erimen]ts, but their weight that has to be considered; and when one may serve, what need is there of many?" 27

With such rhetoric he was trying to stop his opponents from trying new designs of their own invention, and restrict their attention exclusively to the experimentum crucis with two prisms. But his own practice in the 1660s had tended to multiply trials, exploring different designs and possible influences, trying to control alternatives and variables. ${ }^{28}$ It had been a long series of experiments, widely varied, which in my view reinforces the idea that is never the single isolated experiment, but a whole experimental series, in its complexity, what counts when it comes to establishing experimental results.

Newton himself seems to have learnt the lesson well through the polemics of the 1670 s, which he experienced as such an unpleasant thing. This may well be why the Opticks of 1704 is actually more similar to the university lectures of 1670-72 than to the famous paper, as far as the number and variety of experiments goes. While in the paper (Newton's letter to Oldenbourg, 1672) there was an attempt to base the key proposition - that sunlight consists in a mixture of rays of different refrangibilities - upon just one experiment, in the Opticks this is presented as a conclusion after 10 different experiments. ${ }^{29}$ It was not only Newton in the $1660 \mathrm{~s}$, but the whole scientific community of his time, that needed a wide variety of experiments before the "data" concerning refrangibilities of the different rays could be accepted. This is no exception, but rather the rule, and that is why I have been talking about series of experiments and processes of data formation.

Newton's liking for simple and "crucial" experiments (which was truly mathematical and very little Baconian) had its repercussion in later times, a long history. There emerged a tradition that counted some inheritors well into the 19th century, for instance, A. M. Ampère and W. Weber. But the tradition subsequently vanished. Here it is relevant that the 19th century was the time when experimental protocols were standardized and refined.

\footnotetext{
26 The intriguing predictions of Lorentz's theory of "ions" turned out to be correct, but the measurements of the ratio $\mathrm{e} / \mathrm{m}$ showed that the intervening particles were much smaller than those in electrolysis, they had to be sub-atomical —and thus the "ions" became "electrons." See Arabatzis, T., Representing Electrons: A Biographical Approach to Theoretical Entities, ch. 4: "The Birth and Infancy of the Representation of the Electron," pp. 70-111.

27 Cited in Guerlac, H., Newton on the Continent, p. 94.

28 The available information is broad and of high quality, because both Newton's notebooks and his university lectures of 1670-1672 are available. A brief and precise summary can be found in the excellent work of WESTFALL, R., Never at Rest: A biography of Isaac Newton, Cambridge University Press, Cambridge, 1980, pp. 156-175, 211-222, and 237-252.

29 Compare the exposition in Newton, I., "A Letter of Mr. Isaac Newton, ... Containing his New Theory about Light and Colors," with that found in his Opticks, S. Smith and B. Walford, London, 1704, Prop. II, Theor. II, pp. 18-44.
} 


\section{From the "Circle" to the Helix of Experimental Research}

To the question whether there existed elements that could break the vicious circle of Collins and Schaffer, I have answered yes. Let me make it even more explicit.

The circle is broken, and turned into a helix, mainly in two ways. First, strengthening the reliability of the experimental results according to criteria that are properly experimental, i.e., characteristic of experimental activity (and not of the theoretical 'phase'). And second, by Newton's insistence on the idea that one had to be careful with the notion of a "simple" ray. Let us consider both aspects in some detail.

Here is a concrete example of the characteristic criteria of experimental practice at work. In order to show that the prisms did not modify visible light, but merely decomposed or analysed it, Newton performed a diversity of experiments: One employing two prisms juxtaposed in opposite senses; another with three prisms that projected their spectra against the same screen, in such a combination as to recover white light; a third with a prism followed by a lens that made the rays converge.

In the series formed by all these experiments performed by Newton around 1670 or earlier, we find at work two of the key elements that Hacking and Franklin have isolated as properly experimental criteria. (For this question of properly experimental criteria, one should see the pioneering work of Hacking and also Franklin's discussion of experimental strategies. ${ }^{30}$ Above all, there is a convergence of results obtained in three different ways, by distinct material procedures. And there is also a good measure of control over the interventions, which is obtained through planning based on the phenomenic and instrumental models that are employed. Such interventions can be guided by theories as in this case (guided ultimately by the clever use and application of principles of geometrical optics) but in other cases they can be much more exploratory in character, or they can even be suggested by mere analogy.

Notice also that the results of those three experiments, being qualitative and not quantitative, can be reproduced without the problems created by the different dispersive powers of the prisms (due to the kind of glass employed), and so many of the difficulties derived from lack of technical knowledge disappear. Newton employed also prisms filled with water in an attempt to reduce the doubts caused by difficulties in the precise replication of his quantitative results.

The second element that Newton employed in order to break the circle was his insistence on the idea that one had to be careful with the notion of a "simple" ray. He repeated it time and again, but the point was not (as Schaffer wants to picture it) ${ }^{31}$ that only Cambridge prisms produced simple rays - it was that neither those nor the ones in Paris or Liège produced them. The point is merely to insist upon the difference between the simple ray of the mathematical model, a geometric line, and the experiment's beam, something that can only be more or less coarse. If Mariotte did not understand or want to concede the point, it was because he rejected the use of mathematical models of the phenomena, in favour of crude empiricism. And there is, of course, evidence that other scientists accepted Newton's proposal of geometrical models,

30 Cf. HaCking, I., Representing and Intervening, Cambridge University Press, Cambridge, 1983, and FrankLIN, A., "Experiment in Physics," passim. In my view, Franklin does not insist sufficiently on distinguishing what belongs to verbal argument from what constitutes cognitive factors that are characteristic of experimental research. See the comments in Ferreirós, J. and Ordóñez, J., "Hacia una Filosofía de la experimentación,”pp. 47-86.

31 Cf. Schaffer, S., "Glass Works: Newton's Prisms and the Uses of Experiment," pp. 67-104. 
if only tentatively in view of their predictive success, and that the scientific community at large ended up favouring such models wholeheartedly. ${ }^{32}$

In that way, the circle did not come back onto itself, but rather - to exploit the geometric metaphor - it "regressed" on a slightly higher plane, forming a helix. A helicoid can seem a circle to us, when we look upon it from a certain biased angle, as our sociologists often do. But while circles are fundamentally retrograde, bringing us back to the same point time and again, helices progress by ascending from plane to plane. (Concerning the progressive connotations of this "helical" metaphor of scientific research, let me just say that my discussion concerns only local behaviour, and does not predetermine what may happen more globally in the development of a scientific discipline.)

\section{Concluding Remarks}

Despite all that has been said in the past, experimentation enjoys relative autonomy with respect to theory formation. I have been emphasizing that both are interacting 'phases' within the cognitive activity of scientists, and no one reigns above the other. Experiment brings into play epistemic or cognitive factors that are distinctive and characteristic. These are features that cannot be reduced to formal criteria, except of course in the way in which the flight of a bird can be captured by a mathematical model. (Notice that "reduced" is not the adequate word, just like a "logicistic" insistence on basing everything upon explicit formal criteria can only impoverish the account and make it unable to deal with the richness of scientific activity.) One has to underscore that the "measures" of experimental validity or reliability are (in part) intrinsic to this kind of practice, and in this sense autonomous. The dynamics of the experimental phase is (partially) determined by its own peculiar restrictions.

I hasten to add that the dynamics of the theoretical phase is, in my opinion, also (in part) determined by its own peculiar restrictions. Here and at this crude level of analysis, there is no asymmetry between them. But if that analysis is correct, one has to conclude that experimental and theoretical practices complement and enrich each other. As emphasized at the start of this paper, there is not scientific practice in the singular, but a plurality of coexisting practices, and the crux of the analysis has to do with their heterogeneous cognitive roots and their complex interactions..$^{33}$

The aforementioned complementarity is likely to be the main source of the epistemic strength showed by scientific knowledge, and a clear reason why science is different from philosophy or religion. One has to conclude, furthermore, that a conception of the philosophy of science which self-imposes limitations on its methods, such that it can only analyse correctly scientific theories (such was the effect, e.g., of the linguistic turn), makes it ipso facto unable to account for the epistemic richness of scientific knowledge. Here lies the source of that solidarity between "logicism" and sociologism which was mentioned at the start (footnote 4).

From what has been said above, it is easy to extract examples of intrinsic characteristics of the experimental phase: such are the above-mentioned criterion of convergence between results or representations with diverse procedural and instrumental origins, or the heavy dependence of

32 None of my remarks is meant to deny that the process was long, winded, and far from straightforward.

33 Some interesting proposals concerning the role of models as "mediators" between theories and data can be found in the compilation Morgan, M. S. and Morrison, M. (eds.), Models as Mediators. Perspectives on Natural and Social Science, Cambridge University Press, Cambridge, 1999. 
experimentation upon instruments and technical practices (from Gilbert and Galilei until today, there is scarcely one experimental or observational datum of interest that does not depend on instrumentation). A third example, not mentioned before, is what might be called in somewhat naïve language "objective features" of some data or results, like regularities in observed movements (such as in Galilei's observations of Jupiter's moons), or evidence for entities with constant properties (as in the work of Thomson and Zeeman on the electron).

At the beginning I stated that calling for a philosophy of science that is able to analyse the experimental phase complicates matters for the philosopher, since it forces her to broaden the panoply of tools. Fine analysis of the factors that enter into experimental activity should include questions belonging to the cognitive sciences, with a strong basis on biology and physics, and it should also include the analysis of instrumental or technical practices. Experimentation is not a simple matter of observation, for it sets into play many diverse processes of manipulation and perception. (Notice that perception, a high-level cognitive process, must be neatly distinguished from the mere sensorial stimulation that was so dear to Quine.) It involves mechanisms of motor control, attention, perception, memory, language, etcetera, in short: the whole gamut of cognitive processes studied by psychology and neuroscience, and more.

This viewpoint does not seem to be accepted by many partisans of social studies, such as Pickering, who regards the three main structural ingredients of experiment - material procedure, instrumental model, phenomenic model; see sect. 2 above - as comparable elements, which can be treated as if they had very similar levels of material and cognitive complexity. ${ }^{34}$ Pickering defends that, starting from a situation of disparity and disunion, the scientist modifies those ingredients in search of compatibility and stability, and that such a process can be adequately understood from the assumption that all of them are eminently plastic resources. Among the factors that condition the process of interactive stabilisation of these resources, there are according to Pickering "material resistances," but also all kinds of limitations to which theoretical work can be subject, many of them arbitrary, and also, quite naturally, all kinds of sociological factors.

Once again we find the old temptation to which philosophy has yielded so often, the wish to solve everything too quickly, simplifying too much, relying on an impoverishing analysis, as if that should not put the main goal in jeopardy. Pickering's resulting scheme is too "philosophical," to use this adjective in its negative connotations. He esteems too highly our creative, modifying abilities, the margin of freedom that is open to our elaboration of artificial universes. In my opinion, the point is simply that the three ingredients mentioned above are not homogeneous - not by far. The material procedures and their operations are of far greater complexity than the models, and their complexity keeps defying our analytical abilities.

It is quite easy to say "material procedure," but think of some particular case, such as the prism experiments that we have mentioned repeatedly, or even more the experiments with tubes of cathode rays, electromagnetic plates, and substances like sodium or lithium, performed by Zeeman and Thomson. To analyse all the cognitive and biological, technical and physical processes that took place in any of these cases (both what concerns the apparatus and samples, and what relates to the experimenters) is a task of enormous, indeed forbidding complexity. To hide this high complexity, which calls for analyses of both technics and cognitive processes, is a way of falling into simplifications as abusive as those of old theoreticism.

34 Cf. Pickering, A. "Living in the Material World," pp. 275-298, and Pickering, A., The Mangle of Practice, pp. 21-26, and 144-147. 
The above comments may suffice to underscore once again what is specific and characteristic of a philosophy of experimentation. But I would not like to finish without making a new effort to eliminate one possible misunderstanding, and so I add a word about the intervention of theories in experiment. The thesis of a relative autonomy of experimentation is not a thesis against all forms of determination of experiment by theory: Certainly the celebrated thesis of "theory-ladenness," as usually presented, is very biased and incomplete, but the point is no to deny it outright. Theories and research frames do play an important role as guides of experimental research. As so many authors have emphasized, the elaboration of experimental results is too complex to be possible without the aid of maps and drafts that help to organize and simplify the work, as unilaterally as it may be. Which, however, does not turn theory into the queen of scientific activity. It is, therefore, fitting to conclude bringing to mind the general principle (which I have proposed as an elaboration on the old description of science as "experimental philosophy") that science is both philosophy and technics, a hybrid of theorisation and experimentation, which could not survive without the richness conferred upon it by the mestizo interaction of both dimensions.

\section{REFERENCES}

Arabatzis, T., Representing Electrons: A Biographical Approach to Theoretical Entities, The University of Chicago Press, Chicago, 2006.

Bogen, J. and Woodward, J., "Saving the Phenomena," The Philosophical Review, v. 97, (1988), pp. 303-352.

Buchwald, J. Z. and Warwick, A. (eds.), Histories of the Electron: The Birth of Microphysics, The MIT Press, Cambridge, MA, 2001.

Collins, H. M., Changing Order. Replication and Induction in Scientific Practice, The University of Chicago Press, Chicago, 1992 (original edition 1985).

Ferreirós, J. and Ordóñez, J., "Hacia una Filosofía de la experimentación," Crítica, v. 34, n. 102, (2002), pp. 47-86.

Ferreirós, J. and Ordóñez, J. (eds.), Theoria Experimentorum, monographic issue of Theoria, v. 17, n. 44, (2002).

Franklin, A., Feynman Lectures on Physics, Addison-Wesley, Reading, 1963.

Franklin, A., "Experiment in Physics," in Zalta, E. N., (ed.), The Stanford Encyclopedia of Philosophy (Summer 2003 Edition), http://plato.stanford.edu/archives/sum2003/entries/physicsexperiment (access on November 2007). There is an abridged Spanish version: FrankLIN, A., "Física y experimentación," Theoria, v. 17, n. 44, (2002), pp. 221-242.

Gooding, D., Pinch, T. J. and Schaffer, S. (eds.), The Uses of Experiment, Cambridge University Press, Cambridge, 1989.

Guerlac, H., Newton on the Continent, Cornell University Press, Ithaca, 1981.

Hacking, I., Representing and Intervening, Cambridge University Press, Cambridge, 1983.

Hacking, I., "The Self-Vindication of the Laboratory Sciences," in Pickering, A. (ed.), Science as Practice and Culture, The University of Chicago Press, Chicago, 1992, pp. 29-64.

Heidelberger, M. and Steinle, F. (eds.), Experimental Essays-Versuche zum Experiment, Nomos Verlag, Baden-Baden, 1998.

Kunn, TH. S., “The Function of Measurement in Modern Physics," Isis, v. 52, n. 2, (1961), pp. 161-193. Reprinted in Kunn, Tн. S., The Essential Tension, The University of Chicago Press, Chicago, 1977, ch. VIII, pp. 178-224. 
Mariotte, E., De la nature des couleurs, Estienne Michallet, Paris, 1681.

Mariotte, E., Oeuvres, vol. 1, Pierre Vander, Leiden, 1717.

McGucken, W., Nineteenth Century Spectroscopy, Johns Hopkins University Press, Baltimore, MD, 1969.

Morgan, M. S. and Morrison, M. (eds.), Models as Mediators. Perspectives on Natural and Social Science, Cambridge University Press, Cambridge, 1999.

Newton, I., "A Letter of Mr. Isaac Newton, Professor of the Mathematicks in the University of Cambridge; Containing his New Theory about Light and Colors," Philosophical Transactions of the Royal Society, v. 80, (1672), pp. 3075-3087. Available on the web, see www.newtonproject. sussex.ac.uk/prism.php?id=47 (access on November 2007). Reprinted, among others, as "Letter to Mr. Oldenbourg on Light and Colours," in Honsley, S. (ed.), Opera Quae Extant Omnia, J. Nichols, London, 1779-1785, vol. IV; reprinted by F. Frommann, Stuttgart, 1964.

Newton, I., Opticks, S. Smith and B. Walford, London, 1704. Also (among others) in HorsLey, S. (ed.), Opera Quae Extant Omnia, J. Nichols, London, 1779-1785, vol. IV; reprinted by F. Frommann, Stuttgart, 1964.

Pickering, A., "Living in the Material World," in Gooding, D., Pinch, T. J. and Schaffer, S. (eds.), The Uses of Experiment, Cambridge University Press, Cambridge, 1989, pp. 275-298.

Pickering, A., The Mangle of Practice, The University of Chicago Press, Chicago, 1995.

Popper, K. R., Logikder Forschung, Tübingen, Mohr, 1935. Translated into English by the author with the assistance of Julius Freed y Lan Freed: The Logic of Scientific Discovery, Hutchinson, London, 1959.

Sánchez Ron, J. M., Historia de la Física Cuántica, Crítica, Barcelona, 2001.

Schaffer, S., "Glass Works: Newton's Prisms and the Uses of Experiment," in Gooding, D., Pinch, T. J. and Schaffer, S. (eds.), The Uses of Experiment, Cambridge University Press, Cambridge, 1989, pp. 67-104.

Steinle, F., "Challenging Established Concepts: Ampère and Exploratory Experimentation," Theoria, v. 17, n. 44, (2002), pp. 291-316.

Westfall, R., Never at Rest: A Biography of Isaac Newton, Cambridge University Press, Cambridge, 1980. 


\section{IV}

Changes in the Framework on Observation and Experimentation

6. Dimensions of Clinical Observation in the Origins of Scientific Medicine

7. Probabilistic Causality, Observation and Experimentation 


\title{
Dimensions of Clinical Observation in the Origins of Scientific Medicine ${ }^{1}$
}

\author{
José A. López Cerezo
}

The history of medicine constitutes a documental source of great interest to the philosophy of science, one which, regrettably, has not received the attention comparably shown to that of other fields of science. One of the most exciting periods of this history was the anatomical-pathological revolution at the beginning of the 19th century, which many authors have generally established as the origin of both clinical and scientific medicine. Numerous historians have classified this period involving conceptual, organizational and technical innovations as a Kuhnian revolution; whatever the case may be, it warrants philosophical study in order to gain a better understanding of the historical episode and of the analytical instruments of philosophy itself.

Specifically, this contribution essays some of the main contextual, instrumental and conceptual determinants in the production and interpretation of clinical observation during the first decades of the anatomical-pathological revolution, focusing on the work of René Laennec and his invention of the first of the major medical instruments: the stethoscope. The theoretical framework adopted corresponds to the naturalistic conception of the philosophy of science, as found in the approaches of authors such as H. Longino, I. Hacking, M. Solomon or P. Thagard. It is from this approach that some interesting theses of contemporary philosophy of science are tested, such as the theoretical character of observation and experimenter's regress, and the main dimensions of the aforementioned revolution in medicine are analysed. To conclude, it is argued that a close interdependence existed between epistemic and nonepistemic elements throughout the development of a new nosological foundation for modern medicine at the beginning of the 19th century, that is to say, in the ways of producing and interpreting clinical information in the origins of present-day medicine.

\section{Invention And Uses of The Stethoscope}

One of the most representative authors in medicine at the start of the 19th century was the French physician, René Laennec (1781-1826). Trained as a surgeon, this fervent Catholic counterrevolutionary acquired extensive knowledge of pathological anatomy in the Hôpital Necker and Hôpital de la Charité, both in Paris. During the second decade of the 19th century, Laennec was especially interested in practical clinical diagnostics. He had three objectives in this respect: (a) to locate the pathological physical traits in the corpse which characterize the affected organ; (b) to recognize said traits in living patients from positive signs, separating the

\footnotetext{
1 Project FFI2008-06054 (Ministry of Science and Innovation of Spain) provided support for the development of this study. I also wish to express my gratitude to R. Mallet and the Direction des Services et des Réseaux of the National Library of France, as well as to Paul Barnes for the English version.
} 
accompanying symptoms; and (c) to fight disease by using the experience which had proven to be effective. ${ }^{2}$

The main contribution for which Laennec is known in the history of medicine is the second of these objectives and, particularly, for the invention of the stethoscope in 1816. The history of this scientific instrument and its uses will be useful to understand the way in which disease was conceptualised at the outset of scientific medicine, ${ }^{3}$ as well as the value of instrumentation and disciplinary standards in clinical observation during the period in question.

It is interesting to recall the circumstances of his invention. Laennec found himself at the time examining a young woman with general symptoms of heart disease at Hôpital Necker in Paris, where he had been named clinical chief that same year. ${ }^{4}$ He tried using the usual techniques of the time: he started by applying his hand and using percussion, but with little result due to the patient's obesity; he then considered auscultation (placing an ear on the patient's chest to listen to the heartbeats), but the patient's age and sex made him desist. ${ }^{5}$ Then, remembering a common acoustic phenomenon, he rolled up a quire of paper into a tube and placed one end on the patient's chest and the other to his ear. What he heard were clear, distinct sounds coming from inside the body. "It occurred to me," he later wrote about his invention, "that that circumstance could be a useful, applicable method not only for the study of sounds made by the heart, but also for all the movements which can produce sound within the chest." ${ }^{6}$ Laennec subsequently improved his invention, testing different types of apparatus, with diverse lengths, widths and thicknesses. Finally, he decided on a hollow wooden cylinder about $30 \mathrm{~cm}$. long, with two adjustable parts on either end. He called this instrument simply "cylinder" (cylindre), later using the name of "stethoscope" (stéthoscope), from the Greek for "chest" and "examine."

Laennec made his results public in his De l'auscultation médiate ou traité du diagnostique des poumons et du coeur, published in 1819, in which, as in other parts of his works, he attempted to make clinical practice more rigorous by basing it on the natural sciences. ${ }^{7}$ The book, which was sold together with the new instrument, was well-received from the moment it was published. ${ }^{8}$ Besides the actual mediate, or indirect, auscultation technique, ${ }^{9}$ Laennec accurately described

2 See Laennec, R. T. H., De l'auscultation médiate ou traité du diagnostique des poumons et du coeur, Brosson et Chaudé, Paris, 1819, especially the Préface, pp. XVIII-XXVI.

3 See Schaffner, K. F., Discovery and Explanation in Biology and Medicine, The University of Chicago Press, Chicago, 1993, especially ch. 3, pp. 64-99 and 119-128, for an extensive discussion of the habitual nature of scientific theories in biology and medicine.

4 In the times of Laennec, this hospital was one of the smallest in Paris, with only some 100 beds. It was situated in the Sèvres neighbourhood, in the outskirts of the city. Patients in this hospital suffered predominantly from pulmonary ailments, which were precisely Laennec's primary object of study. The centralized hospital administration of Paris made this concentration possible. Cf. Forbes, J., "Translator's Preface," in LAEnNEC, R. T. H., A Treatise on the Diseases of the Chest, ed. by John Forbes, Underwood, London, 1821, pp. viii-ix.

5 These were the usual techniques, although, as one physician of the age admitted, they then lacked any rules or principles -Portal, A., Mémoires sur la nature et le traitement de plusieurs maladies, Bertrand, Paris, 1800, p. 178. Quoted in Birtalan, G., "Laennec and Skoda, Classics of Internal Diagnostics," Communicationes de Historia Artis Medicinae, n. 97-99, (1982), pp. 33-34.

6 Laennec, R. T. H., De l'auscultation médiate ou traité du diagnostique des poumons et du coeur, p. 8.

7 See Birtalan, G., "Laennec and Skoda, Classics of Internal Diagnostics," pp. 33-41.

8 See Kervran, R., Laennec: His Life and Times, Pergamon, New York, 1960, p. 153.

9 Laennec took the term "auscultation" from Régis Buisson, who, in 1802, introduced the distinction between two methods of listening: a passive way called "audition" and an active way called "auscultation." Cf. LACHMUND, J., "Making Sense of Sound: Auscultation and Lung Sound Codification in Nineteenth-Century French and German Medicine," Science, Technology and Human Values, v. 24, n. 4, (1999), p. 443. The technique of auscultation was an invention of Leopold Avenbrugger, a Viennese physician who published his technique in a 1760 book which received no acclaim at the time. Cf. Kervran, R., Laennec: His Life and Times, p. 133. 
diverse thoracic affections and offered new clinical-pathological analyses of bronchial ailments such as emphysema, pulmonary oedema and pneumonia. Likewise, he applied the stethoscope to the diagnosis of fractures, hepatic abscesses and ear affections, although his greatest contribution was in the area of thoracic diseases, most especially, his study of pulmonary tuberculosis.

Tuberculosis was responsible for a high percentage of deaths in 19th-century Europe, as in the preceeding centuries. Today it is known to be caused by the bacillus Mycobacterium tuberculosis, which is airborne-transmitted, usually attacking the lungs first. In the days of Laennec, pulmonary tuberculosis was known as phthisis or consumption, as the disease consumed its victims little by little until they finally died. As opposed to his contemporaries, Laennec defended the specificity of tuberculous lesions and the possibility of spontaneous cure in certain cases. Relying on auscultatory exploration, ${ }^{10}$ he painstakingly described the different forms of tuberculosis and their corresponding lesions, while introducing order into the chaotic pulmonary pathology of the age, as well as hygiene and decorum in medical practice. ${ }^{11}$

\section{Disease Through the Stethoscope}

In order to appreciate the theoretical potentiality of the new instrument with respect to the understanding of disease, it is worth briefly considering a line of work within the modern naturalist school of philosophy of science: the study of the practical dimension of science, in authors such as R. Ackermann, A. Franklin, I. Hacking and A. Pickering. For example, in the terminology of Ackermann, ${ }^{12}$ diverse components in science can be characterised when approached as an activity: (i) the material resources of the apparatus and the experimental configuration in which the phenomenon to be studied is registered through data (data and instruments); (ii) the conceptual resources which explain the functioning of the material resources (the theory of the apparatus which justifies its reliability); and (iii) the theoretical model or set of models which account for the phenomenon (the theory of the phenomena). As Hacking in turn states, in accord with other authors who adopt this position, ${ }^{13}$ the maturation of a scientific theory consists precisely in the mutual adjustment of these types of elements (data, equipment, theories) until stabilizing in a

\footnotetext{
10 I am following common trends in philosophical literature by differentiating "observation" from "experimentation," and both of these from "exploration," as basic data production procedures in science. To start, the general term, "observation," as, for example, auscultation reveals, may refer to perception of a non-visual nature. As opposed to "observation," "exploration" implies a certain intervention in the phenomenon under study (as a physician does when performing an autopsy or a geologist, when obtaining a sample of the ground). "Experimentation," in turn, implies a systematic manipulation of the phenomenon to study a certain relation among variables and to test the null hypothesis. See, e.g., Harré, R., Great Scientific Experiments: Twenty Experiments that Changed Our View of the World, Phaidon Press, Oxford, 1981. Spanish translation by Luis Bou: Grandes experimentos cientificos, Labor, Barcelona, 1986, pp. 14-16.

11 In his Laennec: His Life and Times, p. 138, R. Kervran describes the state of chaos in which pulmonary pathology was then immersed. For example, in 1817, lung cancer, lung abscesses and bronchial emphysema were commonly confused with varieties of tuberculosis. This same book (e.g., pp. 134, 148) also emphasizes the importance which the considerations regarding hygiene, convenience and decency had in the invention and diffusion of the instrument.

12 Ackermann, R. J., "Allan Franklin, Right or Wrong," in A. Fine, A., Forbes, M. and Wessels, L. (eds.), PSA 1990, vol. 2. Proceedings of the 1990 Biennial Meeting of the PSA, Philosophy of Science Association, East Lansing, MI, 1991, pp. 455-457.

13 See, e.g., Hacking, I., "The Self-Vindication of the Laboratory Studies," in Pickering, A. (ed.), Science as Practice and Culture, The University of Chicago Press, Chicago, 1992, pp. 29-64. Andrew Pickering, for example, likewise explains to this effect in his particular historicist elaboration of the actor-network theory. For this author, scientific practice consists in the reciprocal "tuning" of human agency (scientists) and material agency (apparatus and phenomena). This process constitutes a "dialectic of resistance and accommodation," guided by interests and objectives which are continually being revised and modified parallel to interaction with material agency. See Pickering, A., The Mangle of Practice, The University of Chicago Press, Chicago, 1995.
} 
"symbiotic system" of mutual interdependence, in this case, a symbiotic system which, as will later be seen, was also to require in the case in hand a receptive social and professional context to achieve its consolidation.

As to our own case study, the data logically corresponds to the results of clinical observation, aided by the exploratory use of autopsy, as the basic technique, and the stethoscope, as the instrument. The theory of the apparatus is the theory of physics regarding the production, transmission and reception of sound waves, that is to say, acoustics. The theory of the phenomena consists of the explanation for said phenomenon from the perspective of pathological anatomy; for example, when explaining tuberculosis in terms of the presence of tubercles in the lungs (the anatomical lesion) and associating these with a temporally-ordered set of characteristic symptoms (fever, etc.) and, especially, with certain sonorous signs detectable by mediate auscultation. ${ }^{14}$

Thus, the stethoscope became a useful clinical instrument due to the possibility of relating two series of phenomena: on the one hand, the characteristic anatomical lesions of the different cardiac and pulmonary diseases and, on the other hand, the corresponding auscultory sounds. In fact, Laennec's work was guided by the heuristic principle of "one sign-one lesion." In order to link both sets of phenomena, he devoted himself to the painstaking empirical task of compiling and clarifying the extraordinary number of sounds which may be heard when auscultating the human thorax, reducing multiform sounds to their sonorous elements and relating these to elemental anatomical lesions. The proper use of the apparatus thus made linking lesions and signs possible, giving it a diagnostic and prognostic value, and guaranteeing its good performance through autopsies - "convincing us through our eyes of the accuracy of the signs which our hearing gives us." 15

In short, for Laennec, alterations in the organs which appear as anatomical lesions are the physical expression of disease understood as function disorder, and auscultatory sounds are the manifestation of these alterations. The result of this sign-lesion correlation was, in the words of López Piñero,

"the set of auscultatory sounds which, with practically no modification, continues to form part of current semiology: the vesicular, bronchial, cavernous and metallic breath sounds, bronchophony, pectoriloquy and egophony, the different crackles and wheezes (crackling, bubbling, sibilant, ronchus, etc.), amphoric buzzing, metallic tinkling, friction rub, cardiac click, diastolic and systolic sounds, diverse heart murmurs, crackles, thrills, etc." ${ }^{16}$

After Laennec's contribution, tuberculosis was "unified" so that phthisis or consumption, on the one hand, and the anatomical presence of tubercles, on the other, were associated as two aspects of one and the same disease. ${ }^{17}$

For Laennec, the reliability of auscultatory signs depended on two independent qualities: specificity and sensitivity. A sign is specific if it is invariably associated with one, and only one, type of lesion, in such a way that one cannot be present without the other. A hardlyspecific sign produces false-positives (incorrect rejection of the null hypothesis), ${ }^{18}$ which

14 See the difference between "symptoms" and "signs" discussed later.

15 LAENnEC, R. T. H., De l'auscultation médiate ou traité du diagnostique des poumons et du coeur, p. 14.

16 López Piñero, J. M., Ciencia y enfermedad en el siglo XIX, Nexos, Barcelona, 1985, pp. 37-38.

17 See Duffin, J., To See with a Better Eye: Life of R. T. H. Laennec, Princeton University Press, Princeton, NJ, 1998, pp. 156-157.

18 A false-positive is a type-I error, which consists in incorrectly rejecting the null hypothesis, i.e., the hypothesis which states that there is no relation between two variables. A false-negative is a type-II error, which consists in incorrectly accepting the null hypothesis. 
Laennec personally abhorred. A sign is sensitive if it is always present and is detectable when a lesion is produced, no matter how weak this may be. Lack of sensitivity produces falsenegatives, which Laennec considered more tolerable than false-positives. ${ }^{19}$ As Jacalyn Duffin states, Laennec's signs were little theories about the condition of his patients; they were more than sounds, "they incorporated visualization, imagination, calculation, and theory." 20

A close association thus seems to emerge among the observational base, data from the auscultatory exploration, and the theoretical framework characteristic of pathological anatomy, generating what, in more classical philosophical terms (e.g., Feyerabend), could be called a bi-directional flow of meaning. It is a result which contradicts the traditional uses of the philosophical argument of the theoretical burden of observation, where said "burden" is conceived as an obstacle to evaluation and objectivity. ${ }^{21}$

In contrast to this approach, and more in congruence with the case under study, a new understanding of the active role of scientific observation, as well as a restating of the theoretical character of observation (and, in general, perception), tends to be favoured by the study of science-as-practice. More than limiting and relativizing, this theoretical character tends to be emphasized as a possibilizing element, as a guarentee of legitimate experimental evidence with respect to real-world structures. ${ }^{22}$ In fact, the theoricity of observational data ceases to suppose an undermining of scientific objectivity when the base of science is no longer identified with elusive autonomous facts or neutral data, but rather, to the contrary, with exploratory or experimental constructs (mediatized by equipment or instruments and, in that sense, by anatomical, electromagnetic, optical, etc., theories) produced in laboratories or dissection halls, whether these constructs be populations of Drosophila or lung tissue from corpses. ${ }^{23}$

Furthermore, if the possibility of testing the reliability of these instruments through techniques such as calibration (for example, via immediate auscultation) is taken into account, then both "theoretical burden" of perception and robust and sound empirical evidence may be achieved. ${ }^{24}$ Laennec himself insisted on the need to compare the data from stethoscopic exploration with that obtained by other exploratory techniques, such as immediate auscultation or percussion, in order to lend robustness to the results. ${ }^{25}$

\footnotetext{
19 Laennec was, however, aware of the fact that a serious disease might lack an evident or symptomatically-manifested organic lesion. Moreover, although he was reticent in the beginning, due to his "one sign-one lesion" principle, he finally accepted the possibility that a given abnormal sound might be caused by more than one type of organic lesion (although within a limited range). See Duffin, J., To See with a Better Eye: Life of R. T. H. Laennec, pp. 173 and 202.

20 Duffin, J., To See with a Better Eye: Life of R. T. H. Laennec, pp. 201-202.

21 I am referring to the well-known philosophical argument which states that all perception is filtered through some theoretical framework: what we see or perceive depends as much on impressions of the senses as on previous knowledge, expectations, prejudices and the general internal state of the observer. Thus, in this interpretation of the argument, characteristic of the so-called "anti-positivist reaction" of the 1960 s, there is no neutral observational base which allows comparing incompatible rival theories or speaking of an accumulative growth in science.

22 In the French tradition of G. Bachelard, taken up again, for example, by M. Callon, closer to the spirit of Kant than is the English-speaking tradition of N. R. Hanson. See Rothbart, D. and Slayden, S. W., "The Epistemology of a Spectometer," Philosophy of Science, v. 61, n. 1 (1994), pp. 25-38.

23 One of the pioneers of laboratory medicine and continuator of the anatomical-pathological tradition, Rudolph Virchow expresses an analogous idea in few words: "Bare facts are doubtful weapons." See Virchow, R., Disease, Life, and Man: Selected Essays by Rudolf Virchow, edition and translation by Lelland J. Rather, Stanford University Press, Stanford, 1958 (the original texts are from 1847-1898).

24 Cf. Wimsatt, W. C., "Robustness, Reliability, and Overdetermination," in Brewer, M. B. and Collins, B. E. (eds.), Scientific Inquiry and the Social Sciences: A Volume in Honor of Donald T. Campbell, Jossey-Bass, San Francisco, 1981, pp. 124-163.

25 Cf. Laennec, R. T. H., De l'auscultation médiate ou traité du diagnostique des poumons et du coeur, p. 13.
} 
Contrary to audition (passive perception, listening) and immediate auscultation (active perception), stethoscopic auscultation is an active, instrumentally mediatized way of producing clinical data. Even with the simplest percussion, as Laín Entralgo points out, "the clinician intervenes in the semiological description and, to a certain extent, shapes it with his intervention." ${ }^{26}$ In the case at hand, auscultatory data proceeding from exploration is the basis of the theory of the phenomenon, and is supported by the corresponding theory of the apparatus - a theory independent of the theory of the phenomenon. In this regard, this case does not appear to exemplify the well-known argument of experimenter's regress either. According to the argument by Harry Collins, in order to evaluate the correct functioning of an innovative instrument, a hypothesis concerning the existence or inexistence of the phenomenon that is to be detected (or the attributes of the magnitude that is trying to be measured) must be taken into account; however, in order to put said hypothesis to the test, data must be produced by applying the instrument in question. ${ }^{27}$ The case at hand does not give rise to a situation of epistemic indetermination because, although estimating the correction of the theory of the phenomenon implies presupposing the correctness of the theory of the apparatus, it is not necessary to presuppose the correctness of the former theory in order to judge the correctness of the latter. The theory of the apparatus (acoustics) constitutes a firmly consolidated body of knowledge in physics, entirely independent of medical theories and traditions.

To this effect, A. Franklin and S. Culp argue that theoretical and instrumental mechanisms are normally available in science for evaluating the correct functioning of innovative or controversial techniques and instruments. ${ }^{28}$ When these mechanisms of comparison are based on principles of physics independent of the object in dispute, then, if the results are coincident, good reasons exist to affirm the reality of a given phenomenon or to trust the robustness of a result (in this case, auscultation taxonomy). ${ }^{29}$

\section{Consolidation of the Stethoscope}

Returning now to Laennec's story and the consolidation of his invention, it is interesting to examine other dimensions of the observational base of medicine at that time. After being named clinical chief of Hôpital Necker, Laennec's conservative ideology worked to his favour during the Restauration in France. During the five years prior to his death, he received the Legion of Honour and was named Professor of Clinical Medicine at Hôpital de la Charité, Professor of Medicine at the Collège de France and, finally, Royal Physician to the royal family. ${ }^{30}$ Laennec died of

26 Laín Entralgo, P., La historia clínica: historia y teoría del relato patográfico, CSIC, Madrid, 1950, p. 280.

27 In an example by Collins, in order to check whether the gravitational wave detector functions correctly, it must be previously known if these waves exist, if they are detectable and the causal process by which supposedly they are detectable; however, deciding on the existence or inexistence of such waves requires previous successful application of the detector. Thus, a situation of epistemic indetermination results. See Collins, H. M., Changing Order: Replication and Induction in Scientific Practice, The University of Chicago Press, Chicago, 1992 (first ed. 1985).

28 See, e.g., Franklin, A., "How to Avoid the Experimenters' Regress," Studies in History and Philosophy of Science, v. 25, n. 3 (1994), pp. 463-491, and Culp, S., "Objectivity in Experimental Inquiry: Breaking Data-Technique Circles," Philosophy of Science, v. 3, (1995), pp. 438-458.

29 For limitations to this approach, see Rasmussen, N., "Facts, Artifacts, and Mesosomes: Practicing Epistemology with the Electron Microscope," Studies in History and Philosophy of Science, v. 2, (1993), p. 233.

30 This same ideology also served to gain him countless enemies, especially his colleague, François Broussais, who reduced pathologies to inflammations and ferociously attacked the particular anatomical-pathological approach of Gaspart Bayle and Laennec himself (cf. LóPEZ PIÑERO, J. M., Ciencia y enfermedad en el siglo XIX, pp. 34-35). His ideological evolution is described by Kervran, R., Laennec: His Life and Times, p. 115. 
tuberculosis on 13th August, 1826, a few months after making the terrible discovery himself by means of the stethoscope and the appearance of the second edition of his book (April, 1826, in both cases). An autopsy was not performed.

The instrument, and its accompanying technique, was finally consolidated with the work of Joseph Skoda (1805-1881), an important author in the evolution of clinical diagnostics, to which he attempted to infer a scientific base. Skoda, an internist at the General Hospital of Vienna since 1832 (where he coincided and maintained close ties with Ignaz Semmelweis), published his work 20 years after Laennec's treatise: Abhandlung über Perkussion und Auskultation (Treatise on Percussion and Auscultation, 1839). ${ }^{31}$ Skoda remained faithful to the anatomical-pathological tendency which was the basis of his work on mediate auscultation, attempting to offer a new classification of the sounds subordinate to a scientific explanation of their anatomical origin.

Nevertheless, it must be pointed out that there exist discrepancies between the approaches of Laennec and Skoda concerning the classification of auscultatory sounds; even while both formed part of the same anatomical-pathological school, they gave rise to two different traditions in the French and German medical milieus. ${ }^{32}$ For Skoda, as opposed to Laennec, auscultatory signs should be based on acoustic principles and supported by a program of experimental research. This involved discovering in each case the mediating physical mechanism between, on the one hand, what had been observed in the body during the process of the disease and, on the other, findings in the body after death. As a result of requiring this physical explicability, the "one sign-one lesion" methodological principle was abandoned and a lesser degree of taxonomic refinement was acheived. ${ }^{33}$ These methodological differences, as Jens Lachmund points out, ${ }^{34}$ led to different codification systems; in one case (Laennec), the description of clinical cases and postmortems took priority, while, in the other (Skoda), the description of acoustic experiments and reasoning in physical theory were most important. In other words, theoretical principles took priority in Skoda over perceptive discrimination and its possibilities for associating visual (anatomical) and auditory (auscultatory) elements. In literary terms, sensibility was subordinated to sense, to reason.

These differences also reveal the "interpretative plasticity" (of the auditory experiences) which is found in the origin of the use of the stethoscope, as well as the importance of standardization as a universalising mechanism for knowledge and regulation of the practice. The history of the stethoscope, to this effect, is also a process of standardization of perceptions ${ }^{35}$ which, according to Lachmund, led not only to the reconfiguration of the objects of medical knowledge, but to perceptive competency in medical professionals as well.

31 Later, Head of the Department of Thoracic Diseases from 1840 and Professor of Medicine from 1846 to 1871 at the University of Vienna.

32 See Lachmund, J., "Making Sense of Sound: Auscultation and Lung Sound Codification in Nineteenth-Century French and German Medicine," pp. 427-436.

33 For example, where Laennec differentiated between three varieties of voice amplification (bronchophony, pectoriloquy and egophony), Skoda only identified one (bronchophony, weak or strong), attributing it to voice resonance in the lungs. Likewise, Skoda introduced a new notion, unbestimmte Geräusche (undetermined noise), as a residual category for those sounds for which sufficient physical explanation could not be offered. Cf. LACHMUND, J., "Making Sense of Sound: Auscultation and Lung Sound Codification in Nineteenth-Century French and German Medicine," p. 431.

34 "Making Sense of Sound: Auscultation and Lung Sound Codification in Nineteenth-Century French and German Medicine," p. 430.

35 This is what, shortly before the invention of the stethoscope, J. Corvisart called l'éducation médicale des sens, with regard to the need to foment and standardize the semiological value of percussion. Cf. LAín ENTRALGo, P., La historia clínica: historia y teoría del relato patográfico, p. 281. 
After its invention in 1816, and especially on account of the contributions made over the following decades by authors like Skoda, the stethoscope was quickly consolidated as a key instrument in medical practice and research. It proved to be tremendously useful due to the precision with which it aided in diagnosing pulmonary and cardiac diseases, as well as to its application in veterinary medicine or with deaf-mute patients (possibilities which Laennec had already recognised). ${ }^{36}$ With the aid of the stethoscope, physicians were able to gain direct access to information inside the body; they were able, in a manner of speaking, to perform an autopsy while the patient was still alive. It was able to extraordinarily increase the possibilities of the anatomical-clinical method of anatomical-pathological correlation, allowing not only for diagnosis and prognosis, as Rusell Maulitz states, ${ }^{37}$ but also for a certain degree of therapeutic intervention.

\section{The Anatomical-Pathological Revolution}

In fact, the stethoscope was also the best testimony to the prevailing medical paradigm during the first half of the 19th century, in which Laennec was of fundamental importance. Laennec (as well as Skoda) formed part of the anatomical-pathological revolution which, according to common understanding, placed medicine on the map of the sciences. ${ }^{38}$ At the core of this revolution was the transition from clinical symptomatology to pathological anatomy in the conceptualisation and classification of disease.

Until the 19th century, diseases were classified on the basis of the changes they produced in the human body, that is to say, on clinical symptomatology, which in turn had displaced the humoural theory of the Hippocratic-Galenic tradition. ${ }^{39}$ One of the main driving forces behind symptomatological nosology was the English physician, Thomas Sydenham (1624-1689):

"Nature," says Sydenham, "in the production of disease, is uniform and consistent; so much so, that for the same disease in different persons the symptoms are for the most part the same; and the selfsame phenomena that you would be observe in the sickness of a Socrates you would observe in the sickness of a simpleton." 40

Sydenham lent great importance to observation and experience, shunning theory and causal conjectures, and considered each patient to be a unique, dynamic entity in which disease manifested itself individually. Fighting against disease was akin to combating dysfunctional symptoms and the task of the medical scholar was to identify diseases through their characteristic clinical histories in order to later associate them with specific therapies. The observation involved in medical research is that characteristic of Baconian botanical

36 See Laennec, R. T. H., De l'auscultation médiate ou traité du diagnostique des poumons et du coeur, pp. xxxii ff.

37 Maulitz, R. C., Morbid Appearances: The Anatomy of Pathology in the Early Nineteenth Century, Cambridge University Press, Cambridge, 1987, pp, 100-101.

38 Laín Entralgo, P., Historia de la medicina, Masson, Barcelona, 1978, p. 464.

39 According to this last tradition, health depends upon the correct balance among the four organic fluids or humours: black bile, yellow bile, blood and phlegm. The predominance of one or another also gives rise to different types of temperament.

40 Observationes medicae circa morborum acutorum historiam et curationem (Medical Observations on the History and Cure of Serious Diseases) quoted in ReIser, S. J., Medicine and the Reign of Technology, Cambridge University Press, Cambridge, 1978, p. 9. For Sydenham, contrary to the Galenic tradition, symptoms are not mere accidents of the disturbance of vital functions in which consists the "essence" of the disease; symptoms are the defining operations of the disease and are endowed with biological meaning, cf. Laín EnTRALGo, P., La historia clínica: historia y teoria del relato patográfico, p. 141. 
observation: careful observation of numerous cases, exclusion of odd cases ("tricks of Nature"), description of similarities (identification of "constant symptoms" in a certain temporal order) and classification by type or "morbific species." ${ }_{41}$

Michel Foucault says of the symptomological approach: "Disease is perceived in a space of projection without depth, of coincidence without development... a space where analogies define essences." ${ }^{42}$ Diseases are understood as "morbific species," as regularities of Nature with characteristic clinical histories which are repeated from one patient to another. ${ }^{43}$

In opposition to this tradition, at the start of the 19th century diseases began to be characterised in terms of the internal structural lesions that they produced, which were revealed through autopsy. The anatomical lesion came to constitute the basis for pathology and clinical practice, overcoming the traditional subordination of these with respect to the symptom. "Open up some cadavers: you will immediately dissipate the darkness that simple observation could not make disappear," said Xavier Bichat, one of the leaders of this revolution, in 1802. ${ }^{44}$ From that point on, disease started to be understood as local lesions within the human body and to be classified according to the pathological alterations evidenced in the autopsy. ${ }^{45}$ It was the beginning of what is known as "scientific medicine," as Bichat claims in the prologue to his Anatomie Générale (1801):

"Medicine has long been rejected from the bosom of the exact sciences. It will have the right to be associated with them when rigorous observation (of the patient) has coupled with examination of the alterations which the organs present..." ${ }^{46}$

Methodologically speaking, it was a question of moving from a traditional approach based on generalizing inductive practice to one founded on the introduction of causal hypotheses about the seat of disease, thus subordinating the symptom to the lesion. In the suggestive words of Foucault:

"... medical experience is going to substitute the recording offrequencies with the fixed-point signal. The symptomatic course of pulmonary phthisis presents cough, respiratory difficulty, marasmus, hectic fever and, at times, purulent expectoration: however, none of these visible modifications is absolutely indispensable (there are tuberculosis patients who do not cough) and their order of entrance on the scene is not rigorous (fever may appear early on or not break out until the end of the evolution of the disease). Only one phenomenon is constant, a necessary and sufficient condition for phthisis to exist: lesion in the lung parenchyma ... The symptoms slide

41 See, La historia clínica: historia y teoría del relato patográfico, p. 144. One of the most influential classifications in symptomological nosology was precisely that of the physician and botanist, François Boissier de Sauvages, who, in his Nosologia methodica (1763), differentiated 10 classes, 40 orders, 295 genuses and 2,400 species of disease, cf. REISER, S. J., Medicine and the Reign of Technology, pp. 9-10.

42 Foucault, M., Naissance de la clinique, Quadrige/PUF, Paris, 1963, pp. 4-5 (Spanish translation by Francisca Perujo: El nacimiento de la clínica, Siglo XXI, Madrid, 1999).

43 See Riera, J., Historia, Medicina y Sociedad, Pirámide, Madrid, 1985.

44 Quoted in Lindemann, M., Medicina y sociedad en la Europa moderna: 1500-1800, Siglo XXI, Madrid, 2001 (orig. ed. 1999). Spanish translation by Ángela Pérez, p. 69. Besides Xavier Bichat (1771-1802) in France, other precursors of pathological anatomy are the Italian, Giovanni Morgagni (1682-1771), a professor at the University of Padua to whom the foundation of pathological anatomy is usually attributed, and the Scot, Matthew Baillie (1761-1823).

45 Cf. Lachmund, J., "Making Sense of Sound: Auscultation and Lung Sound Codification in Nineteenth-Century French and German Medicine," p. 423.

46 Quoted in López PiÑERo, J. M., Ciencia y enfermedad en el siglo XIX, p. 27. 
and disappear over this fixed point, ... 'It is necessary,' he continues, quoting Bayle, 'to consider individuals who do not have fever, or thinness, or purulent expectoration as consumptives: it is sufficient for the lungs to be affected by a lesion that tends to disorganize and ulcerate them; phthisis is this same lesion." 47

Laennec himself defended the new approach in an analogous way: "Pathological anatomy is a much more reliable science and presents more distinct objects of study than symptomological nosology. It is, for example, much easier to describe tubercles and relate their signs in detail than to define the disease solely on the basis of its external symptoms, to then order its varieties according to their causes." ${ }^{48}$

In this same regard, he continues: "The alteration of the organs is without doubt the most positive and least variable phenomenon of local disease; the danger and the possibility of cure always depend on the nature and extension of these alterations, and [this phenomenon] is therefore what should characterize diseases. In contrast, the functional disorder which accompanies these alterations is extremely variable, being the same under the influence of totally distinct causes and, subsequently, it can hardly serve to discriminate different diseases." 49

Due to the relevancy of the subject, it is worth pausing briefly to discuss a question of terminology, which nonetheless summarizes the rivalry between these two medical traditions. Laennec called any disturbance in biological functions a "symptom" and understood such disturbances to be the consequence of a fundamental organic lesion. He distinguished between two classes of symptoms: the "moral" or psychic (such as anxiety or moaning in pain), which would be the psychological correlate of the disease, and the "physical" or corporal (such as fever, vomiting or coughing), which would be the somatic manifestation of the disease. As far as "sign" is concerned, he considered it to be all the sensorial data which allowed the existence or the properties of this anatomical lesion to be inferred. All things considered, from the point of view of Laennec and the anatomical-pathological tradition, the fundamental difference between symptoms and signs lay in their semantic value as evidence for the observer of disease. ${ }^{50}$ For Laennec, the intentionally triggered sign, that is to say, the empirical evidence proceeding from exploration, constituted "the most positive and least variable phenomenon" of the disease. In contrast, symptoms were variable for each disease, too general (they could be common to several diseases) and misleading in their reading. ${ }^{51}$ By means of the physical sign, the physician could diagnose the disease and anticipate its development, that is, the course of the disease could be "seen": oedema zones, formation of effusions, cardiac dynamics, etc. ${ }^{52}$

The above reasoning resulted in his disdain for the symptom and regard for the sign, which established the link between the anatomical lesion and exploration. Laennec criticized the variability of the simple covariation on which the traditional approach was based and defended

\footnotetext{
47 Foucault, M., Naissance de la clinique, pp. 140-141. Spanish translation: El nacimiento de la clínica, pp. 196-197, his italics. The quote corresponds to BAYLE, G. L., Recherches sur la phthsie pulmonaire, Gabon, Paris, 1810, pp. 8-9.

48 Laennec, R. T. H., A Treatise on the Diseases of the Chest, p. xxxi, his italics. See also Laennec, R. T. H., De l'auscultation médiate ou traité du diagnostique des poumons et du coeur, p. xix.

49 LAENNEC, R. T. H., De l'auscultation médiate ou traité du diagnostique des poumons et du coeur, p. xx.

50 Foucault, M., Naissance de la clinique, pp. 89-90.

51 De l'auscultation médiate ou traité du diagnostique des poumons et du coeur, Préface, pp. XIX-XXI, XXXI-XXXII.

52 Laín Entralgo, P., La historia clínica: historia y teoría del relato patográfico, p. 307.
} 
the need to introduce those causal hypotheses where reference was made, not to the origin or ultimate causes of the disease, but to anatomical or physiological determinants on which the latter depended (the sedes morborum or seat of disease). ${ }^{53}$

\section{Physicians and Surgeons}

This involves what Laín Entralgo termed "the Copernican turn of the anatomicalpathological lesion." ${ }^{54}$ This was a change in worldview, produced when medicine was shaken by the most famous of political revolutions: the French Revolution of 1789. In the words of López Piñero:

"It is not by chance that the original stage for anatomical-clinical medicine was precisely that of post-revolutionary France. For obvious reasons, the new economic, social and political structures offered the appropriate conditions for producing a decisive rupture with medical tradition... In order to eliminate the dead weight of the ancien regime, the [medical] profession and teaching, scientific institutions and hospitals were organized on completely different bases. There was a desire to create a new medicine and this reorganization managed to put an end to the separation between physicians and surgeons, imposing instruction of a fundamentally practical nature and making hospitals the centres of medical life. All these were factors that weighed decisively on the appearance of the anatomicalpathological school, which would make the program of radical renovation a reality, at least as regards pathology." ${ }_{55}$

Neither was it by chance that the pioneers of the "Copernican turn" were surgeons or physicians with surgical training in the France of the time: Xavier Bichat, Jean Corvisart, Gaspard Bayle, René Laennec, etc. For these authors, disease should be conceptualised in terms of pathological lesions in tissues and organs, and medicine itself should focalise on the structural alterations or anatomical lesions which autopsy reveals after death, to later relate this knowledge to data from clinical observation. ${ }^{56}$

The effective leading force behind this medical reorganization in France was Antoine Fourcrouy, a physician and delegate to the Convention. In November of 1794, inspired by Vicq

\footnotetext{
53 Caution must be exercised with the causal subject in this tradition. For example, Russell Maulitz states in this regard, referring to the approach by G. Bayle: "The anatomical lesion ... establishes the class and possibly the specific type of a disease entity, but not its origin. Final causes must remain obscure. So, too, must immediate causes. It is often impossible to state the nature of the terminal event; only the organic lesions that (presumably) preexisted are discernible, and it is assumed they become causes of death only through some sort of mediating mechanism. Only rarely are the organic and inciting (that is, inciting to death) lesions one and the same ..." (MAulitz, R. C., Morbid Appearances: The Anatomy of Pathology in the Early Nineteenth Century, pp. 81-82, italics in the original). See also Laennec, R. T. H., De l'auscultation médiate ou traité du diagnostique des poumons et du coeur, $\mathrm{pp} . \mathrm{xx}$ ff. and Laennec, R. T. H., A Treatise on the Diseases of the Chest, p. 55, who assumed a position analogous to that of Bayle. Thus it appears that, in this tradition, the most common understanding of "cause," when referring to the anatomical lesion as seat of disease, was that of "contributing necessary condition." See Duffin, J., To See with a Better Eye: Life of R. T. H. Laennec, pp. 205-206, and Lachmund, J., "Making Sense of Sound: Auscultation and Lung Sound Codification in Nineteenth-Century French and German Medicine," p. 424.

54 Laín Entralgo, P., La historia clínica: historia y teoría del relato patográfico, p. 274. See, in general, Faure, O., Histoire sociale de la médecine (XVIIIe-XXe siècles), Anthropos, Paris, 1994, chs. 4 and 5.

55 LóPEZ Piñero, J. M., Ciencia y enfermedad en el siglo XIX, p. 13.

56 See Ciencia y enfermedad en el siglo XIX, pp. 11 ff. See also MaulitZ, R. C., Morbid Appearances: The Anatomy of Pathology in the Early Nineteenth Century, ch. 1.
} 
d'Azyr, the former Secretary General of the Royal Society of Medicine, Fourcrouy submitted a project to the Convention concerning the unification of medicine and surgery, which would allow for improvement in both the theoretical and practical aspects of teaching:

"Medicine and surgery are two branches of the same science; to study them separately is to abandon theory to the ravings of the imagination, and practice, to blind routine; to join and fuse them is to mutually clarify them and favour their progress." ${ }^{57}$

The Assembly approved the proposal to start up a clinical medicine, in which practice and theory would be united in the hospital bed and laboratory, in the training of physicians as well as midwives. Thus it may be said that the birth of the clinic, the launching of "hospital medicine" and the decisive move towards modern medical science all took place in the Parisian hospital wards of mid-1790. ${ }^{58}$ In this move towards modern medical science, as Olivier Faure notes, ${ }^{59}$ it is not easy to differentiate the scientific aspects from the professional and socio-political ones.

As Rusell Maulitz indicates, ${ }^{60}$ the physicians and surgeons of late 18th century Europe were different subcultures, each with their own codes and symbols and each speaking distinct dialects as regards the human body. For surgeons, with an approach based more on craft and lacking the social prestige of physicians, the body was a mosaic of individual parts. Most of the diseases subject to their attention, such as inflammations and gangrene, were targeted for one of the two standard surgical interventions: excision or amputation. For physicians, the body code was another: interdependent regions linked by fluids which transported substances responsible for the well-being or weakening of the body's economy, an economy which was expressed symptomatically. The convergence of these two cultures, with distinct visions regarding disease, involved institutional and professional changes as well as changes that were conceptual in nature and generally relative to intellectual resources. This is what Maulitz terms the creation of a new "body grammar": something towards which Bichat took the decisive step and which triumphed with the work of Laennec. ${ }^{61}$

Hence lies the importance of the invention of the stethoscope for a trained surgeon and anatomist like Laennec. Stethoscopic auscultation made it possible to perform a virtual autopsy, thus extending the study of pathological lesions to patients who were still living, allowing physicians "to make the invisible visible." ${ }_{62}$ By means of the stethoscope and the virtual autopsy which the former had enabled, the anatomical lesion was able to fully assume the explanatory role which it had lacked until then. Until the 19th century, the anatomical lesion had been limited to being a "confirmatory or rectifying finding," in the words of Laín Entralgo, ${ }^{63}$ but always a posteriori or post mortem. Since the invention of the stethoscope, the anatomical lesion was to acquire diagnostic and prognostic value, and was to become the basis for nosology and medical knowledge. As Lachmund states, "seeing pathological objects in the

57 Fourcrouy, A., "Rapport à la Convention du 27 novembre 1794," quoted in Beauvalet-Boutouyrie, S., Naître à l'hôpital au XIXe siècle, Belin, Paris, 1999, p. 67.

58 See Lindemann, M., Medicina y sociedad en la Europa moderna: 1500-1800, pp. 106 ff., as well as Foucault, M., Naissance de la clinique, chs. 3 and 5.

59 FAure, O., Histoire sociale de la médecine (XVIIIe-XXe siècles), pp. 43-44.

60 Maulitz, R. C., Morbid Appearances: The Anatomy of Pathology in the Early Nineteenth Century, p. 227.

${ }_{61}$ Morbid Appearances: The Anatomy of Pathology in the Early Nineteenth Century, p. 228.

62 Foucault, M., Naissance de la clinique, ch. IX: "L'invisible visible”, pp. 168-174.

63 Laín Entralgo, P., La historia clínica: historia y teoría del relato patográfico, p. 198. 
dissection room and hearing sounds and murmurs at the sickbed thus became complementary modes of ordering medical reality." ${ }^{64}$

\section{The Significance of the Revolution}

All things considered, what is the nature and scope of the so-called "anatomical-pathological revolution"? Was it really a revolution in the Kuhnian sense? In what sense is it fitting to speak of a link between the revolution in medicine and the political revolution? Following Kuhn, ${ }^{65}$ scientific revolutions basically constitute scientific developments with no epistemic continuity. They are episodes in which a normal scientific tradition is interrupted; an extraordinary scientific context then arises in which theoretical references and common epistemic values are substituted by controversy and persuasion; and finally these episodes are closed by the conversion of the community to a new paradigm or tradition of normal science, with a "change in the world" in which scientists work taking place during the transition. At least one change which supposes an epistemic break, and a professional context which propitiates this change, must therefore occur. Let us examine these two elements in order.

According to Hoyningen-Huene, ${ }^{6}{ }^{6}$ there are several ways in which a scientific revolution may produce a change in Gestalt, that is, a change in that region of the phenomenal world in which scientists carry out their work. ${ }^{67}$ In the first place, the post-revolutionary phenomenal world may contain previously absent phenomena and entities, provided that these discoveries (to differentiate them from analogous discoveries in normal science) lead to certain revisions of significant portions of previous theoretical knowledge, experimental techniques or the use of instruments and models of data interpretation. Secondly, even when new discoveries do not occur, the world of phenomena of scientists may change due to familiar phenomena and entities being seen in a different light, as instances of different laws or with different attributes. This latter case is precisely the one that basically occurred with the substitution of the classificatory tree in the move from symptomological to anatomical-pathological nosology.

The classification of diseases in terms of anatomical lesions rather than symptoms or balances of fluids certainly involved a profound conceptual change in the evolution of medicine. It instances the greatest of the types of conceptual change identified by P. Thagard in How Scientists Explain Disease: ${ }^{68}$ tree switching, that is, changing the organizing principle

\footnotetext{
64 Lachmund, J., "Making Sense of Sound: Auscultation and Lung Sound Codification in Nineteenth-Century French and German Medicine," p. 423.

65 Cf. Kunn, Th. S., The Structure of Scientific Revolutions, 2nd ed., The Chicago University Press, Chicago, 1970 (1st ed. 1962).

66 Cf. Hoyningen-Huene, P., Reconstructing Scientific Revolutions: Thomas S. Kuhn's Philosophy of Science, The University of Chicago Press, Chicago, 1993. English translation by Alexander Levine, pp. 201-206.

67 According to I. Hacking, we may now understand "world-change" in Kuhn nominalistically. The world in which we, including scientists, live and work is a world of classes of things, as every action takes place under description. In other words, all the choices we make, all our doings in and interactions with the world, the explanation of its phenomena or prediction of its events, is action under description: this means choices under descriptions in use in the social or scientific community in which we work and act. Descriptions require classification, the grouping of individuals into classes. Therefore, with a revolution, our world changes, that world of understandings and explanations (the world of classes of things), but not so the world (in the sense of the ontological inventory of what exists). See HACKING, I., "Working in a New World: The Taxonomic Solution," in Horwich, P. (ed.), World Changes: Thomas Kuhn and the Nature of Science, The MIT Press, Cambridge, MA, 1993, pp. 275-310. Other interpretations of "world-change" may be found, e.g., in Bird, A., Thomas Kuhn, Acumen, Chesham, 2000, ch. 4.

68 Cf. Thagard, P., How Scientists Explain Disease, Princeton University Press, Princeton, 1999, p. 150.
} 
of a hierarchical conceptual tree. The anatomical-pathological approach clearly implies what Kuhnian terminology would describe as a Gestalt shift, categorizing the available empirical evidence, data from clinical observation, in a new way, as well as broadening (and correcting) that traditional empirical base through exploration via autopsy and stethoscopic auscultation. Nosology is the cornerstone of both medical knowledge and professional activity, in which a very important change occurs in the way or ways of producing data and in their interpretation: these are substantial changes which imply a transformation in medical theory and practices (in physiology, in clinical medicine, in therapy, etc.). ${ }^{69}$

What were seen from the extreme empiricism of symptomological nosology as collections of specific symptoms, pertaining to the "nature" of each morbific species, ${ }^{70}$ from the hypothetical-causal view of the anatomical-pathological approach were considered simple external manifestations of organic lesions defining the disease. These distinct Gestaltsehen ${ }^{71}$ are revealed even in Sydenham's need to propose new names for the same phenomena: although a disease and its symptoms were closely associated, a disease could be distinguished from its symptoms in the Galenic tradition (as later in the anatomical-pathological tradition). ${ }^{72}$ Smallpox, for example, produces fever. For Sydenham, on the contrary, the fever from smallpox is variolous fever: it is (part of) the disease itself. ${ }^{73}$

In this understanding of the shift from the symptomological view of disease to the anatomical-pathological view, contextual elements should also be taken into consideration and the kind of influence these might have exercised on said revolution should be examined. As already pointed out, according to Kuhn, ${ }^{74}$ scientific revolutions constitute scientific developments with epistemic discontinuity. Nonetheless, this epistemic break requires a propitious context in order to spread and consolidate. It is important to bear in mind that the agent of a revolution is always a scientific community, ${ }^{75}$ for one reason especially: researching the factors that foster or hinder the revolution, a new research tradition and a world-change, implies researching the motives that make up the dynamics of decision-making

\footnotetext{
69 However, this does not imply a total substitution. Changes in the architecture of medical knowledge (the conceptual tree) do not have to substantially affect some elements of the structure (such as the clinical), which go on to fulfil other functions in said structure. Concerning the diversity of formats which, in principle, revolutionary change may adopt, see in general BIRD, A., Thomas Kuhn, ch. 2.

70 Laín Entralgo, P., La historia clínica: historia y teoría del relato patográfico, p. 145.

71 Ludwig Fleck defined Gestaltsehen as a "formative way of seeing" from a particular conceptual framework or thought-style. Fleck understood a "thought-style" (Denkstil) as a set of beliefs and mindsets shared by a "thought-colle ctive"(Denkcollectiv), which, in turn, he understood as a group of people who exchange ideas and maintain intellectual interaction, which, as is obvious, requires sharing the same scientific lexus, accepting the same basic theories and fundamental facts, etc. See FLECK, L., Entstehung und Entwicklung einer wissenschaftichen Tatsache. Einführung in die Lehre von Denkstill und Denkkollektiv, Schwabe, Basilea, 1935, and Suhrkamp, Frankfurt, 1980. English translation: Genesis and Development of a Scientific Fact, edited by T. J. Trenn and R. K. Merton, The University of Chicago Press, Chicago, 1979, ch. 4.

72 In a certain sense, the anatomical-pathological revolution supposes a regression to the Galenic tradion, with new instruments and approaches. "Regression" solely in the sense that the types of disease are defined by the organic dysfunction subjacent to the symptoms.

73 See Laín Entralgo, P., La Historia clínica: historia y teoría del relato patográfico, p. 151. With respect to the extreme empiricism of Sydenham, it may be interesting to note the friendship he had with the British philosopher, John Locke, and the fact that he was a contemporary of John Ray, who propounded an anti-essentialist empiricist foundation for the new botany of his time. They all appear to have shared one and the same idea: genera and species are only useful abstractions for ordering experience; however, reality is an attribute of the phenomena which are revealed to our senses.

74 See Kunn, Tн. S., The Structure of Scientific Revolutions, passim.

75 See Hoyningen-Huene, P., Reconstructing Scientific Revolutions: Thomas S. Kuhn's Philosophy of Science, pp. 200-201.
} 
in a human community, which, in this case, include a network of hospital institutions and health care systems.

The political antecedents created the circumstances which made the anatomicalpathological revolution possible, but its consolidation was to depend upon the effective transformation of the socio-professional context of medicine at the time in keeping with the disciplinary standards of the new approach. As to the said socio-professional context one should understand the organisation of healthcare in European hospitals in the early 19th century, an organisation that came to reflect the principles of pathological anatomy. It included such aspects as the division of medical work, the structure of clinical histories, instrumental support in hospital research, the favoured lines of research, epidemiological planning, the routines of medical care and even the physical distribution of hospital wards. In fact, this health reorganisation in hospital care and the anatomical-pathological approach itself jointly evolved from the association of surgery and medicine and the conversion of the hospital from a place where patients with no other recourse were admitted for observation and care to a teaching and testing centre - the birth of the clinic. As Bowker and Star point out, the way in which classificatory systems (and, in general, disciplinary standards) are reflected in infrastructures is something that only becomes visible at times of rupture and change. ${ }^{76}$

To this effect, in his classic Morbid Appearances, ${ }^{77}$ Russell Maulitz describes the expansion of pathological anatomy in Napoleonic Europe as a process not only of the spreading of ideas, but also as dependent on professional and socio-political contexts, and, to a certain degree, on other contingent factors. Specifically, the persistence of the separation between surgery and medicine in England hindered the assimilation of the anatomical-pathological approach there, in contrast with the other side of the Channel, where this approach was shown to be "... particularly consonant with the new professional realities of Napoleonic France." ${ }^{78}$ British students, as well as those from other nations, converged on Paris in the early decades of the 19th century to assimilate the new approach and then later to contribute to its international implantation.

By the mid-19th century, in such important hospitals as those of Paris and Vienna (and, by this time, Britain), the anatomical-pathological approach, outstandingly represented by such professors and researchers as Karl Rokitansky and Rudolph Virchow, was not only the dominant paradigm in the medicine of that time, but it also constituted a progressive research program, in the sense of Lakatos. With no serious anomalies to face, its positive heuristic clearly anticipated the pathway for the development of research: the reductionist line that it had followed in the characterisation of disease from the symptomatological manifestations to the body organ (Morgagni), from the complex body organ to the organic tissue (Bichat) and from the tissue to the cell (Virchow) as sedibus et causis morborum, to paraphrase the title of the pioneering work of Giovanni Morgagni dated 1761. ${ }^{79}$

\footnotetext{
76 See Bowker, G. C. and Star, S. L., Sorting Things Out: Classification and its Consequences, The MIT Press, Cambridge, MA, 1999, ch. 1. All considered, the socio-political context must be maintained as an independent variable as regards disciplinary standards, since it also responds to other macro variables such as health policy design, business strategies in pharmaceutical development and the bureaucratic organisation of healthcare personnel.

77 Maulitz, R. C., Morbid Appearances: The Anatomy of Pathology in the Early Nineteenth Century, pp. 134-157 and 224-229.

78 Morbid Appearances: The Anatomy of Pathology in the Early Nineteenth Century, p. 226.

79 The 1850 s constituted, in fact, the emerging years of cellular pathology led by Rudolf Virchow. See Hudson, R. P., Disease and its Control: The Shaping of Modern Thought, Greenwood Press, New York, 1983, ch. 6.
} 
The parallel development of laboratory medicine during the 19th century likewise offered soundness to this program through the appearance of new techniques for the detection of physical signs and the anatomical-pathological redefinition of old diseases. For example, in Richard Bright's redefinition of "renal dropsy" as "albuminous nephritis," the possibility of detecting albumin in the patient's urine by means of a chemical test allowed the lesion of an internal viscera, inaccessible to direct exploration, to be clearly evidenced, thus being able to dispense with the symptomatological charaterisation of the disease. ${ }^{80}$ Only the later development of the etiological approach and microbiology, in the work of L. Pasteur and R. Koch in the 1880's, would create the conditions for the substitution of pathological anatomy as the dominant paradigm in medical theory and practice. ${ }^{81}$

The predominant clinical-nosological paradigm thus constituted a methodological framework which afforded visibility to a certain class of phenomena, highlighting them as significant. It emphasized a certain kind of practice, anticipated anomalies and offered indications as to the way of developing theory. The anatomical lesion, the autopsy, the association between lesions and signs, as well as the physical explanation of these associations (in the tradition of Skoda) were especially the main principles or disciplinary standards of the anatomical-pathological approach in medicine, all within the framework of a hospital organisation appropriate to the "body grammar" of the new medicine.

\section{The Instrumentalisation of Health}

Finally, two interesting consequences of this anatomical-pathological revolution should be examined, consequences which may be termed the "depersonalisation" of disease and the "desubjectivisation" of medical information. The creation of modern medicine also supposed, or at least contributed decisively to, a redefining of health care through hospital reorganisation, the reconceptualisation of disease and an instrumentalisation of medical practice which led to rather significant changes in the physician-patient relationship.

The development of the anatomical-pathological view of disease and the instrumentalisation of medicine signified, in the first place, the consolidation of an "ontological" notion of disease, as opposed to the traditional "functionalist" notion. ${ }^{82}$ This actually involved a process which began with the symptomological definition of disease favoured by 17 th century physicians like Thomas Sydenham; it was given a boost by medical instrumentalisation and culminated with the later etiological view of disease, the development of microbiology and the spectacular improvement in public health care at the start of the 20th century. Since the so-called ontological approach, diseases have become "depersonalised" and "reified": every disease is considered as a real entity existing independently of the identity of the affected subject.

On the contrary, from the functionalist (or holistic) viewpoint, disease was understood as a dysfunction resulting from personal habits or from the particular action of the environment on the individual. The functionalist notion represents the classical conception, linked to the

\footnotetext{
80 As P. Laín Entralgo points out in La historia clínica: historia y teoría del relato patográfico, p. 324, this line of medical research permits raising laboratory data to the category of physical sign, in the sense of Laennec.

81 The definitive triumph of the etiological explanation, eventually favoured by laboratory medicine (and particularly by medical microbiology), did not occur until the last decade of the 19th century. Robert Koch, for example, did not publish his classic work on bacteriology (in which he establishes the rule that a specific microorganism must be considered as the specific agent of a given disease) until 1890. See LóPEZ PIÑERo, J. M., Ciencia y enfermedad en el siglo $X I X$, pp. 139-140.

82 See Lindemann, M., Medicina y sociedad en la Europa moderna: 1500-1800, pp. 2-3.
} 
Hippocratic-Galenic tradition, which maintained significant influence over Western academic medicine until well into the 18 th century. ${ }^{83}$ According to this tradition, diseases were specific to individuals, affections resulting from the actions of environmental agents which caused the humoural imbalance of an organism with its own constitutional idiosyncracy. Consequently, treatments were also highly individualised, acting allopathically on the symptoms, ${ }^{84}$ as the idea was to restore that particular balance of humours in each individual human being. Disease did not exist as a specific pathological entity in the way it has been understood ever since the consolidation of the ontological conception.

A second interesting consequence, related to the previous one, deals with what may be called the "de-subjectivisation" of medical information promoted by the diffusion of the stethoscope, as the spearhead to a later process of growing instrumentalisation and technological development in medical practice. As Jacalyn Duffin states in her excellent biography of Laennec:

"In Laennec's lifetime, disease concepts changed from constructs based on patient's subjective symptoms and feelings, described in the patient's history, to concepts based on specific changes in the patient's body, detected objectively through physical examination." ${ }^{85}$

The effects of the stethoscope are documented by Stanley Reiser in his classic Medicine and the Reign of Technology: “... [mediate] auscultation helped to create the objective physician, who could move away from involvement in the patient's experiences and sensations, to a more detached relation, less with the patient but more with the sounds from within the body. Undistracted by the motives and beliefs of the patient, the auscultator could make a diagnosis from sounds that he alone heard emanating from the body organs, sounds that he believed to be objective, bias-free representations of the disease process." 86

This growing differentiation between subjective symptoms and objective signs in fact constitutes a tendency associated with the implementation of the anatomical-pathological approach at the beginning of the 19th century, of which Laennec formed a fundamental link, but which has important precursors in other French physicians who accompanied him in this revolution. For example, Laennec's mentor, Jean Corvisart, used percussion profusely as a source of reliable medical information, differentiating between the homme physique and the homme morale. Dividing patients in this manner allowed him to group clinical information into three categories:

“... the 'sure and constant signs', univocal with respect to their immediate cause; the 'moral man's' expressions regarding disease, essentially ambiguous, variable and suspect; and, between the latter and the former, the organic symptoms which, like vomit and fever, lack a fixed and known semiological significance." 87

\footnotetext{
83 There are, of course, important exceptions, beginning with the Swiss physician, Paracelso (c. 1493-1541), forefather of symptomological nosology. Parecelso understood disease as a real entity which existed independently, as the result of the organism having been invaded by an external entity (the arqueo - a kind of spiritualised poison). See Lindemann, M., Medicina y sociedad en la Europa moderna: 1500-1800, pp. 4, 69-82. As regards the timeframe for the validity of Galenism, some basic physiological principles (like the humoural theory) or related therapeutic practices (like bloodletting to eliminate bad humours) continued to be widely practiced until the very 19th century - see, for example, the Nuevo compendio médico, Editores de la Biblioteca escojida de Medicina y Cirujía (sic), vol. I, Imprenta de la viuda de Jordán e hijos, Madrid, 1843.

84 That is to say, carefully choosing medicines and remedies which produce effects contrary to those of the disease in the organism in question.

85 Duffin, J., To See with a Better Eye: Life of R. T. H. Laennec, p. 25.

86 ReISER, S. J., Medicine and the Reign of Techonology, p. 38.

87 Laín Entralgo, P., La historia clínica: historia y teoria del relato patográfico, p. 281.
} 
The triumph of the anatomical-pathological paradigm and the instrumentalisation of medical practice also brought about quite a significant change in physician-patient relations. In the symptomological approach during the 17th and 18th centuries, the centre for medical practice was the home, either the physician's or the patient's, but not the hospital. The patient was a patron, not a client. ${ }^{88}$ The physician examined the patient's external appearance and fluids, asked questions and listened carefully to the patient's story about their ailment, to the personal narration of the symptoms. The change of paradigm and instrumentalisation would suppose, as, for example, S. Reiser or N. Postman observe, ${ }^{89}$ that medicine dealt with disease, not with patients, and that what patients knew and felt was not very reliable, whereas the information obtained from technical exploration or laboratory analysis was very much so. These were ideas which would gradually become consolidated with each new apparatus and technology that has been added to the medical instrumentarium since then. ${ }^{90}$

\section{Some Conclusions}

In light of the previous discussion, one initial concluding reflection which may be made is the support that this case study lends to the new naturalist approaches in the study of science as a practice, which also has been called "philosophy of experimentation," as well as the lack of support lent to both the antipositivist reading of the theoretical character of observation argument and the constructivist thesis on experimenter's regress. In both cases, the close tie between theoretical models and empirical evidence (and the non-circular nature of this tie due to the possibility of triangularisation based on independent theories) made reciprocal theory-experience reinforcement possible, rather than its weakening, in the conformation of a symbiotic system of mutual interdepence, in Hacking's terms.

A clear interdependence may be specifically appreciated between the instrumental, conceptual and contextual determinants in the production and interpretation of clinical observation as involved in the anatomical-pathological revolution. As regards instrumental determinants, the invention of the stethoscope allowed for the broadening of the observational base in medical practice and research through the results of mediate auscultatory exploration, but the efficacious use of this instrument presupposed, besides the acoustic principles of the physical theory of the apparatus, a certain conceptual innovation with regards to the characterisation of disease: a reifying nosology built upon a certain type of causal hypotheses and autopsy technique. In turn, the conceptual change, and the reclassification of clinical data on the basis of said conceptual change, involved and presupposed contextual and organisational changes in the medical profession. These were changes related to the new line drawn for

88 See Lindemann, M., Medicina y sociedad en la Europa moderna: 1500-1800, pp. 221-222.

89 See Reiser, S. J., Medicine and the Reign of Technology, passim, and Postman, N., Technopoly. The Surrender of Culture to Techonology, Knopf, N. York, 1992. Spanish translation by Vicente Campos González: Tecnópolis. La rendición de la Cultura a la Tecnología, Círculo de Lectores/Galaxia Gutenberg, Barcelona, 1994. See also ILLICH, I., Medical Nemesis: The Expropiation of Health, Pantheon, New York, 1976, pp. 155-173, as well as Foucault, M., Naissance de la clinique, ch. 9.

90 See ReISER, S. J., Medicine and the Reign of Technology, ch. 1, pp. 1-44. An antecedent of the stethoscope which provoked the same type of criticism in obstetrics were the forceps, which came into general use in 1723. In the 19th century, as Ignaz Semmelweis then noted (The Etiology, Concept, and Prophylaxis of Childbed Fever, ed. by K. Codell Carter, Madison: University of Wisconsin Press, Madison, 1983, p. 74, orig. ed. 1861), some obstetricians, such as Lucas Boër, the first Professor de Obstetrics at the General Hospital of Vienna (from 1789 to 1822), complained of the excessive use of the instrument due to the simple fact that it was available (see likewise Beauvalet-Boutouyrie, S., Naittre $\grave{a}$ l'hôpital au XIXe siècle, p. 178). 
disciplinary frontiers (the fusion of medicine and surgery) and the reorganisation of hospital care, which were to evolve jointly with the new disciplinary standards and to eventually place medicine on the scientific map.

\section{REFERENCES}

Ackermann, R. J., Data, Instruments, and Theory: A Dialectical Approach to Understanding Science, Princeton University Press, Princeton, 1985.

Ackermann, R. J., "Allan Franklin, Right or Wrong," in Fine, A., Forbes, M. and Wessels, L. (eds.), PSA 1990, vol. 2. Proceedings of the 1990 Biennial Meeting of the PSA, Philosophy of Science Association, East Lansing, MI, 1991, pp. 451-457.

BAYLE, G. L., Recherches sur la phthsie pulmonaire, Gabon, Paris, 1810.

Beauvalet-Boutouyrie, S., Naître à l'hôpital au XIXe siècle, Belin, Paris, 1999.

Bird, A., Thomas Kuhn, Acumen, Chesham, 2000.

Birtalan, G., "Laennec and Skoda, Classics of Internal Diagnostics," Communicationes de Historia Artis Medicinae (Budapest), n. 97-99, (1982), pp. 33-41.

Bowker, G. C. and Star, S. L., Sorting Things Out: Classification and its Consequences, The MIT Press, Cambridge, MA, 1999.

Coluns, H. M., Changing Order: Replication and Induction in Scientific Practice, The University of Chicago Press, Chicago, 1992 (first ed. 1985).

Culp, S., "Objectivity in Experimental Inquiry: Breaking Data-Technique Circles," Philosophy of Science, v. 3, (1995), pp. 438-458.

Duffin, J., To See with a Better Eye: Life of R. T. H. Laennec, Princeton University Press, Princeton, NJ, 1998.

Faure, O., Histoire sociale de la médecine (XVIIIe-XXe siècles), Anthropos, Paris, 1994.

Feyerabend, P. K., Against Method: Outline of an Anarchistic Theory of Knowledge, New Left Books, London, 1975.

FLECK, L., Entstehung und Entwicklung einer wissenschaftlichen Tatsache. Einführung in die Lehre von Denkstill und Denkkollektiv, Schwabe, Basilea, 1935, and Suhrkamp, Frankfurt, 1980. English translation: Genesis and Development of a Scientific Fact, edited by T. J. Trenn and R. K. Merton, The University of Chicago Press, Chicago, 1979.

Forbes, J., "Translator's Preface," in LaEnnec, R. T. H., A Treatise on the Diseases of the Chest, ed. by John Forbes, Underwood, London, 1821, pp. vii-xxviii.

Franklin, A., "How to Avoid the Experimenters' Regress," Studies in History and Philosophy of Science, v. 25, n. 3, (1994), pp. 463-491.

Foucault, M., Naissance de la clinique, Quadrige/PUF, Paris, 1963. Spanish translation by Francisca Perujo: El nacimiento de la clínica, Siglo XXI, Madrid, 1999.

Galison, P., How Experiments End, The University of Chicago Press, Chicago, 1987.

Hacking, I., Representing and Intervening, Cambridge University Press, Cambridge, 1983.

Hacking, I., "The Self-Vindication of the Laboratory Studies," in Pickering, A. (ed.), Science as Practice and Culture, The University of Chicago Press, Chicago, 1992, pp. 29-64.

Hacking, I., "Working in a New World: The Taxonomic Solution," in Horwich, P. (ed.), World Changes: Thomas Kuhn and the Nature of Science, The MIT Press, Cambridge, MA, 1993, pp. 275-310. 
Harré, R., Great Scientific Experiments: Twenty Experiments that Changed Our View of the World, Phaidon Press, Oxford, 1981. Spanish translation by Luis Bou: Grandes experimentos cientificos, Labor, Barcelona, 1986.

Hoyningen-Huene, P., Die Wissenschaftsphilosophie Thomas S. Kuhns. Rekonstruktion und Grundlagenprobleme, F. Vieweg, Braunschweig, 1989. English translation by Alexander T. Levine: Reconstructing Scientific Revolutions: Th. S. Kuhn's Philosophy of Science, University of Chicago Press, Chicago, 1993.

Hudson, R. P., Disease and its Control: The Shaping of Modern Thought, Greenwood Press, New York, 1983.

Illich, I., Medical Nemesis: The Expropiation of Health, Pantheon, New York, 1976.

Kervran, R., Laennec: His Life and Times, Pergamon, New York, 1960.

Kunn, Tн. S., The Structure of Scientific Revolutions, 2nd ed., The University of Chicago Press, Chicago, 1970 (1st ed. 1962).

Lachmund, J., "Making Sense of Sound: Auscultation and Lung Sound Codification in Nineteenth-Century French and German Medicine," Science, Technology and Human Values, v. 24, n. 4 (1999), pp. 419-450.

Laennec, R. T. H., De l'auscultation médiate ou traité du diagnostique des poumons et du coeur, Brosson et Chaudé, Paris, 1819.

Laennec, R. T. H., A Treatise on the Diseases of the Chest, edited and translated by John Forbes, Underwood, London, 1821.

Laín Entralgo, P., La historia clínica: historia y teoría del relato patográfico, CSIC, Madrid, 1950.

Laín Entralgo, P., Historia de la Medicina, Masson, Barcelona, 1978.

LaKatos, I., "Fasification and the Methodology of Scientific Research Programmes," in LaKatos, I. and Musgrave, A. (eds.), Criticism and the Growth of Knowledge, Cambridge University Press, Cambridge, 1970, pp. 91-196.

Lesky, E., The Vienna Medical School of the 19th Century, Johns Hopkins University Press, Baltimore, MD, 1976.

Lindemann, M., Medicine and Society in Early Modern Europe, Cambridge University Press, Cambridge, 1999. Spanish translation by Ángela Pérez: Medicina y sociedad en la Europa moderna: 1500-1800, Siglo XXI, Madrid, 2001.

Longino, H. E., The Fate of Knowledge, Princeton University Press, Princeton, NJ, 2002.

López Piñero, J. M., Ciencia y enfermedad en el siglo XIX, Nexos, Barcelona, 1985.

Maulitz, R. C., Morbid Appearances: The Anatomy of Pathology in the Early Nineteenth Century, Cambridge University Press, Cambridge, 1987.

Nuevo compendio médico, Editores de la Biblioteca escojida de Medicina y Cirujía (sic), vol. I, Imprenta de la viuda de Jordán e hijos, Madrid, 1843.

Pickering, A., The Mangle of Practice, The University of Chicago Press, Chicago, 1995.

Portal, A., Mémoires sur la nature et le traitement de plusieurs maladies, Bertrand, Paris, 1800.

Postman, N., Technopoly. The Surrender of Culture to Techonology, Knopf, N. York, 1992. Spanish translation by Vicente Campos González: Tecnópolis. La rendición de la Cultura a la Tecnología, Círculo de Lectores/Galaxia Gutenberg, Barcelona, 1994. 
Rasmussen, N., "Facts, Artifacts, and Mesosomes: Practicing Epistemology with the Electron Microscope," Studies in History and Philosophy of Science, v. 2 (1993), pp. 227-265.

ReISER, S. J., Medicine and the Reign of Technology, Cambridge University Press, Cambridge, 1978.

Riera, J., Historia, Medicina y Sociedad, Pirámide, Madrid, 1985.

Rothbart, D. and Slayden, S. W., "The Epistemology of a Spectometer," Philosophy of Science, v. 61, n. 1 (1994), pp. 25-38.

Schaffner, K. F., Discovery and Explanation in Biology and Medicine, The University of Chicago Press, Chicago, 1993.

Semmelweis, I., The Etiology, Concept, and Prophylaxis of Childbed Fever, ed. by K. Codell Carter, University of Wisconsin Press, Madison, 1983 (orig. ed. 1861). English translation by K. Codell Carter.

Solomon, M., Social Empiricism, The MIT Press, Cambridge, MA, 2001.

Thagard, P., How Scientists Explain Disease, Princeton University Press, Princeton, 1999.

Thagard, P., "Pathways to Biomedical Discovery," Philosophy of Science, v. 70, n. 2 (2003), pp. 235-254.

Virchow, R., Disease, Life, and Man: Selected Essays by Rudolf Virchow, edition and translation by Lelland J. Rather, Stanford University Press, Stanford, 1958 (the original texts are from 1847-1898).

Wimsatt, W. C., "Robustness, Reliability, and Overdetermination," in Brewer, M. B. and Collins, B. E. (eds.), Scientific Inquiry and the Social Sciences: A Volume in Honor of Donald T. Campbell, Jossey-Bass, San Francisco, 1981, pp. 124-163. 


\title{
Probabilistic Causality, ObSERVATION AND EXPERIMENTATION
}

\author{
Maria Carla Galavotti
}

\section{Preamble}

In the last fifty years, increasing attention has focused on the probabilistic notion of causality, and it is currently at the core of a vast debate. The issue of observation and experimentation bears on probabilistic causality in many ways. Observation and experimentation are assigned pivotal importance within the theories of causation developed by econometricians and statisticians, who typically take a model-based pluralistic approach, parallelled in the philosophical literature by the work of Patrick Suppes. Furthermore, experimentation acquires a special meaning within the manipulative views of causality. In particular James Woodward, who embraces this kind of approach, makes experimentation the main ingredient of the definition of causality. More generally, it is widely recognised that experimentation has a role to play in the process of detecting causal relations.

This paper addresses the problematic link between probabilistic causality, observation and experimentation, through a sketchy overview of the literature on the topic, with no pretension to being complete. Its purpose is to give an idea of the breath of the ongoing debate, and suggest possible connections between the viewpoints developed by philosophers of science, statisticians and econometricians.

\section{The Twofold Nature of the Debate on Probabilistic Causality}

An early attempt to define causality in probabilistic terms is to be found in Hans Reichenbach's book The Direction of Time, published posthumously in 1956. A few years later, in 1961-62, the statistician Irving John Good published two articles under the title "A Causal Calculus." Reichenbach and Good embrace utterly different standpoints. Reichenbach develops probabilistic causality as part of a causal theory of time, on the assumption that "time order is reducible to causal order." A central role in his theory is played by the principle of common cause, based on the idea that "if an improbable coincidence has occurred, there must exist a common cause." "This principle guides the search for genuine causes, by "screening off" from their effects those properties which become irrelevant in the presence of other more relevant properties. In other words, a spurious correlation - for instance, the correlation between the barometer's fall and the storm that follows - is "absorbed" by the dependence of each of these effects on the common cause, identified as a drop in air pressure in the area. Reichenbach frames the principle of common cause in a mechanical view of the world,

Reichenbach, H., The Direction of Time, University of California Press, Berkeley, 1956, p. 24.

2 Reichenbach, H., The Direction of Time, p. 157. 
subsequently expanded by Wesley Salmon, who developed a mechanical theory of causation and explanation revolving around the principle in question.

Good's approach starts from a distinction between two kinds of probabilistic causality: the tendency of an event of a certain kind to cause another event, and the degree to which one particular event caused another event. While the tendency to cause concerns types of events (type, or general, causation), the degree of causation concerns single events, considered after they have occurred (token, or singular, causation). Good regards them as different types of causal analysis, to be defined and measured by means of different conceptual tools. ${ }^{3}$

Good's viewpoint is quite distant from Reichenbach's mechanical perspective, and from the frequency notion of probability underlying it. By contrast, Good's approach brings causality within the domain of the subject's evaluation and makes the establishment of causal links depend on the researcher's judgment regarding the possible alternatives to the events which are taken as cause and effect. This gives causal analysis a contextual flavour. Good handles the problem of distinguishing genuine from spurious causes by taking causal speech relative to "the state of the Universe" just before the occurrence of the cause and "all true laws of nature" it holds.

Remarkably, Good does not establish a strong link between causation and explanation and defines a notion of "explicativity" taken as "the extent to which one proposition or event explains why another one should be believed." ${ }^{4}$ According to his perspective, causality and explanation are related, but not identical.

This sketchy outline of Reichenbach's and Good's theories discloses the twofold nature of the debate on probabilistic causality. On the one hand, we have a philosophical theory which associates causality with the old mechanical ideal revisited in a probabilistic fashion. On the other we have a statistical theory which points to the contextual character of causation and assigns it a role quite independent of explanation. Subsequent literature on probabilistic causality has proceeded along these two lines, with sporadical interactions.

A number of problematic issues were raised in subsequent literature and a wide array of solutions offered. The first problem that arises as soon as causality is taken as probable rather than constant conjunction is that of identifying causal as opposed to spurious relations, without getting muddled with problems of the Simpson's paradox kind. A further problem is that of defining the asymmetry of the causal nexus, which some authors associate with the temporal priority of the cause with respect to the effect, while others define quite independently of time. Moreover, the virtuous circle linking causality, explanation and prediction within classical determinism (of the Laplacean kind) breaks down in the case of probabilistic causality. In its probabilistic version, causality is not necessarily associated with explanation, but can be related to prediction and/or manipulation. Equally problematic is the distinction between those causal ascriptions referred to populations, or type causality, and those referred to single occurrences, or token causality. The proportions reached by the debate on these problems testify to the fact that they admit of no univocal solutions.

3 Good's theory of causality was first developed in Good, I. J., "A Causal Calculus," I British Journal for the Philosophy of Science, v. 11, (1961), pp. 305-318; Good, I. J., "A Causal Calculus," II, British Journal for the Philosophy of Science, v. 12, (1962), pp. 43-51; and Good, I. J., "Errata" and "Corrigenda," British Journal for the Philosophy of Science,v. 13, (1963), p. 88.

A modified version was published, together with other articles on causation, in Good, I. J., Good Thinking, University of Minnesota Press, Minneapolis, 1983, Part V. Se also Good, I. J., "Causal Tendency: A Review," in Skyrms, B. and Harper, W. (eds.), Causation, Chance and Credence, Kluwer, Dordrecht, 1988, pp. 73-78.

4 Good, I. J., Good Thinking, p. 219. 


\section{The Philosophical Debate}

The philosophical debate on probabilistic causality is inspired by two different intuitions. According to the first, causality is understood in mechanical terms, while the second associates it with manipulability, namely with the idea that a causal factor is one on which we can intervene to achieve a certain goal. These intuitions inspire two major trends, which find their most radical expression in Wesley Salmon's probabilistic mechanicism, on the one hand, and Huw Price's perspectivalism, on the other.

\subsection{Mechanicism}

Building on Reichenbach's work, Salmon's theory of probabilistic causality revives the old mechanical ideal of explanation, coached in probabilistic terms. Salmon's task is "to put the 'cause' back into 'because"": for him the "because" of explanation derives from that of causation. ${ }^{6}$

Salmon's theory includes two levels of explanation. At the first level we find the Statistical Relevance model, according to which events are explained by locating them in a network of statistical relations holding between the properties relevant to their occurrence. This is obtained by restricting the reference class to which the explanandum event belongs by progressive inclusion of relevant properties and exclusion ("screening off") of irrelevant ones, to the point where all and only relevant properties are taken into account. The canon yielding the proper (homogeneous) reference class is statistical relevance.

On the second level we have causal explanation in terms of causal processes, defined as spatio-temporal continuous entities able to transmit marks, or conserved quantities. Causal processes form the causal mechanisms of which the causal structure of the world is compounded. ${ }^{7}$ These two levels of explanation correspond to type causality, called by Salmon statistical causality because it can be defined in statistical terms, and token causality, called by him aleatory causality, defined in terms of processes. Given that causal processes are theoretical entities endowed with ontic import, aleatory causality exceeds a purely statistical formulation. For a long time Salmon thought that only aleatory causality carried explanatory power, but he revised his position in the late $90 \mathrm{~s}$, coming to the conclusion that statistical and aleatory causality are both necessary, and complement each other. In his words: "statistical relevance relations, in the absence of connecting causal processes, lack explanatory import and ... connecting causal processes, in the absence of statistical relevance relations, also lack explanatory import. ... Both are indispensable." 8

According to Salmon one can move in a relatively unproblematic way from types to tokens. One should keep in mind that Salmon's theory is devised for application in physics, and in

\footnotetext{
5 Salmon, W. C., "A Third Dogma of Empiricism," in Butts, R. and Hintikka, J. (eds.), Basic Problems in Methodology and Linguistics, Reidel, Dordrecht, 1977, p. 160. Reprinted in SALmON, W. C., Causality and Explanation, Oxford University Press, New York, 1998, p. 103.

6 In this sense Salmon's perspective stands opposite to that of other authors, like Philip Kitcher, as pointed out in Salmon, W. C., "Causality without Counterfactuals," Philosophy of Science, v. 61, (1994), pp. 297-312.

7 The most detailed and perspicuous version of Salmon's theory of explanation is contained in SALMON, W. C., Scientific Explanation and the Causal Structure of the World, Princeton University Press, Princeton, 1984. This book was followed by many articles containing important developments, a number of which are collected in his book Causality and Explanation, published in 1998. For an outline of Salmon's theory see Galavotti, M. C., "Wesley Salmon on Explanation, Probability and Rationality," in Galavotti, M. C. and Pagnini, A. (eds.), Experience, Reality, and Scientific Explanation. Essays in Honor of Merrilee and Wesley Salmon, Kluwer, Dordrecht, 1999, pp. 39-54.

8 Salmon, W. C., “A Reply to two Critiques,” Philosophy of Science, v. 64, (1997), p. 476.
} 
fact his mechanical picture of causality suits fields like statistical mechanics, characterized by a sound theoretical apparatus and by the use of general laws to describe the phenomena. In that realm, provided that the available information will identify causal mechanisms, statistical causality will match token causality. By contrast, in disciplines characterized by a weaker theoretical apparatus the description of phenomena rests on models, and the link between statistical and token causality becomes looser, as does that between explanation and prediction. One can say that Salmon's attempt to develop a theory of causality meant to combine property and token causality within a unified theory of explanation results in very restricted applicability. This is the price he pays for making the asymmetry of causation depend ultimately on spatio-temporal continuous processes, a notion that faces severe difficulties in fields like economics, psychology, medicine, and more generally the social sciences, which happen to offer the most extensive ground for the application of causal concepts.

Experimentation enters into Salmon's theory in a somewhat tangential way. Following a long standing-tradition dating back at least to John Stuart Mill, Salmon acknowledges the importance of controlled experimentation "to investigate cause-effect relations." 9 In addition, he grounds the notion of counterfactual on experimentation, in an attempt to avoid getting muddled with Lewis's possible worlds interpretation. After having tried for a long time to dispense with counterfactuals, Salmon accepted the suggestion put forward by a number of authors including James Woodward and Christopher Hitchcock that counterfactuals should be assigned an explanatory role. ${ }^{10} \mathrm{He}$ then turned to counterfactuals rooted in correlations expressing frequencies, supported by experimentation: "counterfactuals, like statistical relevance relations, are often effectively tested by controlled experiments." ${ }_{11}$ Again, this is bound to raise problems of applicability in a number of fields, where extensive information of that kind is not available.

Alternative forms of mechanicism have been proposed by a number of authors. Among them Phil Dowe, who develops a notion of physical causation based on a conserved quantity theory of processes. ${ }^{12}$ This is intended to be a refinement of Salmon's theory of causation, especially because it does not require the use of counterfactuals, and in his last writings Salmon adopted it with minor changes.

Other mechanical theories are due to Stuart Glennan, ${ }^{13}$ Peter Machamer, Lindley Darden and Carl Craver, ${ }^{14}$ who are primarily concerned with applications to complex systems, especially those occurring in biology. With respect to Salmon's perspective, the theories advanced by these authors are more flexible, as they admit of incomplete descriptions of mechanisms and stress the importance of contextual elements.

Having in mind applications to neurobiology, Machamer, Darden and Craver define mechanisms in terms of both the entities that compose them and the activities they perform.

\footnotetext{
9 Salmon, W. C., "A Realistic Account of Causation," in Marsonet, M. (ed.), The Problem of Realism, Aldershot, Ashgate, 2002, p. 129.

10 See especially Нітснсоск, C., "Discussion: Salmon on Explanatory Relevance," Philosophy of Science, v. 62, (1995), pp. 304-320, to which Salmon replied in his paper "A Reply to two Critiques."

11 Salmon, W. C., "A Reply to Two Critiques,” p. 476.

12 Cf. Dowe, P., Physical Causation, Cambridge University Press, Cambridge, 2000.

13 Cf. Glennan, S., "Rethinking Mechanical Explanation," in PSA 2000. Part II. Supplement to Philosophy of Science, v. 69, (2002), pp. S342-S353.

14 Cf. Machamer, P., Darden, L. and Craver, C., "Thinking about Mechanisms," Philosophy of Science, v. 67, (2000), pp. 1-25.
} 
Mechanisms are complex systems organised into a multi-level hierarchical structure, whose distinctive feature is the productive continuity between the various stages characterizing their activity. The components of mechanisms exhibit specific spatio-temporal features, and their productive stages are characterized by certain phases, a given duration, and so on. Phenomena are explained by describing which mechanism produces them and how. Mechanisms that are described only in part, or mechanism schemata to be formulated at different levels of abstraction, are also admitted.

Experimentation is assigned an important role in order to detect mechanisms. This role is pointed out by Craver, who describes various experimental strategies aimed at telling us "what the relevant entities and activities are, how they are nested in component/sub-component relations, and how the activities of the component entities fit into their mechanistic context." 15 Darden also calls attention to the need for an experimental phase in the complex process of "discovering" mechanisms. He draws an analogy with the procedures adopted by engineers when designing mechanisms: "the engineering process of designing a mechanism goes through cycles of construction, evaluation and revision as components are proposed, evaluated, and possibly redesigned. The goal is to construct a smoothly working mechanism. There is a strong analogy between an engineer designing a mechanism and a scientist discovering one that already works in nature." "The "evaluation" phase involves experimentation, which therefore becomes a crucial ingredient of these versions of mechanicism. ${ }^{17}$

\subsection{Manipulability}

The other mainstream in the philosophical debate combines causality with manipulability. A radical version of this tendency is represented by the agency account of causality developed by Huw Price, partly in collaboration with Peter Menzies. Here causality is related to the agent's perspective, in the sense that to think of $A$ as a cause of $B$ is to regard $A$ as a potential means for achieving the end $B$. Causal asymmetry is grounded in our experience as agents - an idea borrowed from the philosophy of Frank Plumpton Ramsey. This view of causality is openly anthropocentric, because causality is taken as "a manifestation of the fact that causal concepts originate in our experience as agents." ${ }^{18}$ Embracing a similar account involves regarding human beings as deliberating agents, rather than pure observers. This is reflected by the label perspectivalism attached by Price to his own viewpoint, that extends beyond causation, to laws, theories and probability, which are all made to depend ultimately on the agent's knowledge and beliefs. Obviously, this theory has a strong pragmatic flavour and regards causality as intrinsically context dependent. As Price puts it: "causation has a conceptual tie to intervention, and hence to deliberation. But the possibility of deliberation is epistemically constrained in several ways - it depends on both knowledge and ignorance, and these epistemic factors are contingencies, whose limits may well vary from agent to agent. Hence

\footnotetext{
15 Craver, C., "Interlevel Experiments and Multilevel Mechanisms in the Neuroscience of Memory," in PSA 2000. Part II. Supplement to Philosophy of Science, v. 69, (2002), p. S91.

16 Darden, L., "Strategies for Discovering Mechanisms: Schema Instantiation, Modular Subassembly, Forward/ Backward Chaining," in PSA 2000. Part II. Supplement to Philosophy of Science, v. 69, (2002), p. S364.

17 The role of experimentation within these mechanical theories is explored in some detail in CAMPANER, R., "Mechanisms and Counterfactuals: a Different Glimpse of the (Secret?) Connexion," Philosophica, v. 77, (2006), pp. 15-44.

18 Price, H., "Agency and Causal Asymmetry," Mind, v. 101, (1992), p. 501.
} 
causal judgments are correspondingly perspectival: they are necessarily 'situated', relative to some implicit boundaries to the knowledge and ignorance of the agent concerned." 19

The agency theory of causation is couched in probabilistic terms. In other words, the means-end relation on which the theory is grounded is characterized in terms of "agent probabilities," to be construed as conditional probabilities, "assessed from an agent's perspective under the supposition that the antecedent condition is realized ab initio, as a free act of the agent concerned. Thus the agent probability that one should ascribe to B conditional on A ... is the probability that B would hold were one to choose to realize A." ${ }^{20}$ According to its proponents this approach has several advantages, like that of representing a good substitute for the counterfactual theory, and offering a natural solution to the problem of spurious causation. In this connection, Price holds that statistical correlations are assigned an asymmetrical interpretation in the light of an agent's judgment in terms of the means-end relation, rooted in his own experience. Such a judgment drives deliberation towards asymmetrical correlations rather than to mere statistical correlations, which are usually symmetrical, and "correlations due to common causes don't translate into probabilistic dependencies from the agent's point of view." ${ }^{21}$

Salmon's and Price's theories stand opposed in various respects: Salmon's is ontic, Price's anthropocentric; Salmon's conjugates causality with explanation, Price's does not; Salmon relies on an objective notion of probability, namely the frequency interpretation, Price is not explicit on this point, but his reliance on Ramsey's ideas calls for the subjective notion of probability. Furthermore, Salmon gives a detailed account of causality meant to cover token causation, but his theory has restricted applicability; instead Price's view is very general and widely applicable, but it needs to be supplemented with more detailed accounts in order to fit specific contexts.

Although Price does not pay much attention to experimentation, he assigns a pivotal role to intervention. The fact that the asymmetry between cause and effect is captured in a natural way by the analogous asymmetry between interventions and the changes they produce in certain phenomena and/or variables, leads naturally to experimentation. This idea is clearly stated by the economist Daniel Hausman in his article "Causation and Experimentation," where he writes: "the fact that causes can be used to manipulate their effects, but not vice versa seems to capture a good deal of the notion that causes are 'effective' and that they necessitate their effects." 22

A similar idea underlies James Woodward's version of the manipulative view of causation that focusses on the link between causation and experimentation. Woodward feels the need to distance himself from the anthropocentrism characterizing Price's perspective and, borrowing some results from econometrics, defines causation in terms of invariance under a set of interventions. Laws are accounted for in a similar fashion, being taken as generalizations that are invariant, or stable across a broad range of varying conditions and circumstances. Relying on such a notion of law, Woodward develops a view of explanation reflecting the claim that "to explain an explanandum is to show how changes in it counterfactually depend on changes in the factors cited in the explanans ... The relevant notion of counterfactual dependence

\footnotetext{
19 Price, H., "Causal Perspectivalism," in Price, H. and Corry, R. (eds.), Causation, Physics, and the Constitution of Reality. Russell's Republicanism Revisited, Clarendon Press, Oxford, 2007, p. 282.

20 Menzies, P. and Price, H., “Causation as a Secondary Quality," British Journal for the Philosophy of Science, v. 44, (1993), p. 190.

21 Price, H., "Causal Perspectivalism," p. 281. See also Price, H., "Agency and Probabilistic Causality," British Journal for the Philosophy of Science, v. 42, (1991), pp. 157-176.

22 Hausman, D., “Causation and Experimentation,” American Philosophical Quarterly, v. 23, (1986), 150.
} 
(or of answering a what-if-things-had-been-different question) is captured by counterfactuals the antecedents of which have to do with interventions. ... When a generalization relating $\mathrm{X}$ and $\mathrm{Y}$ is invariant in this way, we may think of it as telling us how to manipulate $\mathrm{Y}$ if (perhaps contrary to actual fact) it were possible to intervene to change $\mathrm{X}$. In this sense the theory ... embodies a 'manipulationist' conception of explanation." ${ }^{23}$ An important feature of Woodward's position is that manipulation is not taken relative to experiments that are actually performed, but rather to hypothetical experiments, i.e., to potential "appropriately designed experimental manipulation." ${ }^{24}$ The transposition of causation from agency to manipulability in terms of hypothetical experiments is designed to contrast the halo of subjectivism surrounding Price's agency theory of causation, to embrace a form of "instrumental realism."

Woodward complains that "most philosophical treatments of causation leave the connection between the content of causal claims and the role of experimentation completely opaque." ${ }^{25}$ In an attempt to counteract this tendency, he brings experimentation to the foreground and assigns it a twofold role. First and foremost, experimentation is the essential ingredient of Woodward's definition of causation. As he puts it: "causal claims should be interpretable as claims about the outcomes of hypothetical experiments." ${ }^{26}$ Secondly, experimentation is the tool that will distinguish causal relations from observable correlations (that might be spurious).

The vast debate provoked by Woodward's theory cannot be described here. ${ }^{27}$ However, it is significant that Woodward's approach requires that invariance is assumed across observational and experimental situations. In his words: "using experiments to learn about causes requires that some relationships remain stable or invariant across the manipulated and unmanipulated systems." ${ }^{28}$ One may wonder to what extent invariance assumptions of this kind can be taken to hold. As we shall see in Section 5, one lesson that can be learned from the work of econometricians and statisticians is that invariance assumptions need to be justified with reference to the context in which they occur.

\section{Suppes' Pluralism}

In his monograph A Probabilistic Theory of Causality, published in 1970, Patrick Suppes takes a pluralistic approach to causality that does not resemble any of the views considered so far. Suppes does not attempt to work out a univocal definition of probabilistic causality, but gives a flexible, context-dependent account. He does not impose requirements on causal chains, and claims that causality can be defined both in terms of random variables and events,

\footnotetext{
23 Woodward, J., "Law and Explanation in Biology: Invariance is the Kind of Stability that Matters," Philosophy of Science, v. 68 (2001), p. 5. See also Woodward, J., Making Things Happen, Oxford University Press, New York, 2003, and the articles by Нiтснсоск, C. and Woodward J., "Explanatory Generalizations: Part I: A Counterfactual Account," Nous, v. 37, n. 1, (2003), pp. 1-24, and Hiтcнсоск, C. and WoodWARd J., "Explanatory Generalizations: Part II: Plumbing Explanatory Depth," Nous, v. 37, n. 2, (2003), pp. 181-199.

24 Woodward, J., "Experimentation, Causal Inference, and Instrumental Realism," in Radder, H. (ed.), The Philosophy of Scientific Experimentation, University of Pittsburgh Press, Pittsburgh, 2003, p. 90.

25 Woodward, J., “Experimentation, Causal Inference, and Instrumental Realism,” p. 87.

26 "Experimentation, Causal Inference, and Instrumental Realism," p. 105.

27 Among others, Paul Humphreys criticises Woodward for allowing manipulations to alter the structure (or mechanism) characterizing the situation in which a certain causal attribution is made, and Elliott Sober challenges Woodward's way of handling the type/token distinction. See the review symposium "Invariance, Explanation and Understanding," Metascience, v. 15 (2006), pp. 39-66, with papers by Paul Humphreys and Elliott Sober, and the "Author's Response" by James Woodward.

28 Woodward, J., “Experimentation, Causal Inference, and Instrumental Realism," p. 102.
} 
without specifying once and for all what counts as an "event." The notion of event, like that of cause, is linked to the specification of the set of concepts characterizing a given context. Coherently with his pluralistic epistemology, centred on models, Suppes adopts a model-based approach to causality. ${ }^{29}$

Experimentation plays an important role in this perspective. Suppes observes that "there are at least three kinds of conceptual frameworks within which it seems appropriate to make causal claims ... One conceptual framework is that provided by a particular scientific theory; the second is of the sort that arises in connection with a particular experiment or class of experiments; and the third is the most general framework expressing our beliefs with respect to all information available to us." ${ }^{30}$ After pointing out the relevance of the notion of causation to the sphere of experimentation, extensively dealt with by statisticians, Suppes calls attention to an important distinction, namely that between contexts characterised by extensive experimentation and contexts that are not. He does so in the course of a discussion of the problem of passing from causal relations regarding types to conclusions regarding tokens, and points out that, in spite of the fact that this passage is clearly unwarranted, predictions of individual events based on relations of the type kind are made every day, for instance by meteorologists. Undoubtedly, such inferential procedures can only depend ultimately on "judgment as to how the knowledge one has is used and assessed," ${ }^{31}$ but if such knowledge includes widely accepted generalizations backed by extensive experimentation, the shift from type to tokens is more warranted, though there will always be additional elements to be evaluated case by case. If the information available does not stand on a strong experimental basis, additional care will be required. Therefore experimentation - actual or potential— provides solid grounds for causal inferences from types to tokens.

Suppes' pluralism holds that any attempt at working out a notion of causality applicable to every situation in which causal speech occurs is deemed to failure, because different contexts call for a different characterization of causality. Grounded on this conviction, his theory of causality is conceived as a starting point from which to move on to more detailed accounts to be given within specific contexts.

\section{Model-Based Approaches in Statistics and Econometrics}

Statisticians and econometricians by and large share a model-based approach to probabilistic causality, which devotes great attention to observation and experimentation. Manipulability is a crucial ingredient of the notion of causation developed within econometrics and statistics, where it is associated with a functionalist notion of mechanism, taken to represent the structure of a model rather than a description of the world.

\subsection{Econometrics}

Causality has always been a major issue for econometrics, where it is conceived as a combination of functionalism and manipulability. One can distinguish two approaches to econometric model building. One is the "classical" approach started by the founders of

\footnotetext{
29 See Suppes, P., Models and Methods in the Philosophy of Science: Selected Essays, Kluwer, Dordrecht, 1993, and SuPPES, P., Representation and Invariance of Scientific Structures, CSLI Publications, Stanford, 2002.

30 Suppes, P., A Probabilistic Theory of Causality, North-Holland, Amsterdam, 1970, p. 13.

31 Suppes, P., "Conflicting Intuitions about Causality," in French, P., Yuehling, T. and Wettstein, H. (eds.), Causation and Causal Theories. Midwestern Studies in Philosophy IX, University of Minnesota Press, Minneapolis, 1984; reprinted in SupPes, P., Models and Methods in the Philosophy of Science: Selected Essays, p. 130.
} 
econometrics like Ragnar Frisch, Jan Tinbergen and Trygve Haavelmo. Such an approach is often associated with the names of Herbert Simon and Herman Wold and is characterized by the following steps: (1) building a simplified model (in general a linear model) of a deterministic economic theory; (2) adding an error term (also called residual or disturbance) to each relationship provided by the theory; (3) estimating the unknown parameters of the model on the basis of observable data; (4) applying a set of statistical tests to assess the fit of the econometric model to the given data; (5) using the accepted model to forecast and evaluate economic policy interventions. ${ }^{32}$ Causality is a feature of the model, which can be identified with the possibility of manipulating the relations it fixes. Manipulability is what distinguishes a causal model from purely predictive models. Within the Simon-Wold's approach causality is associated with exogeneity, which in turn depends on a priori assumptions, usually imposing some restrictions on the parameters of the model. When the conditions imposed on a model are justified by an appeal to economic theory, the model is called structural and interpreted as describing the behaviour of an economic system, according to some theory.

The second approach to econometric model building is characterised by the adoption of statistical models specified in terms of observable random variables. This approach strongly emphasizes observed data, and makes the validity of an econometric model depend more on the probabilistic structure of observed data than on theoretical assumptions. Statistical and theoretical models stand side by side, and both play an important role. A theoretical model represents a mathematically formulated construct making use of theoretical variables (such as for example demand and supply in relation to intentions and plans of economic agents). A statistical model supplies probability distributions for the observed variables and specifies a sampling model.

The probabilistic approach covers a number of different viewpoints. A well known theory is due to Clive W. J. Granger, ${ }^{33}$ whose notion of causality is based on data arranged in time series. Accordingly, a variable $y$ can be said to cause another variable $x$ if the information provided by the knowledge of $y$ at time $t$ is relevant to the value taken by $x$ at time $t+1$ (assuming that all considered variables are measured at pre-specified time points at constant intervals $t=1,2, \ldots)$. To give an operative import to his notion of causality, and to connect it with predictability, Granger works out the complementary notion of non-causality, based on conditional independence. Non-causality can be subjected to various testing procedures, which specify its operational meaning.

Granger's causality rests on the idea that causality is to be based in the first place on observed data, not on theory. As a matter of fact, Granger claims that theoretical knowledge has no role at all in his theory. However, to justify this claim he requires causal assertions to be conditional on knowledge of the history of the universe, which should also include information on which variables are to be taken as exogenous and which as endogenous. This is obviously an ideal requirement never to be fulfilled; for this reason Granger puts forward a weaker notion of causality in mean, which is easier to test and therefore more suitable for operative purposes.

\footnotetext{
32 For a more detailed account of the Simon-Wold approach see Galavotti, M. C. and Gambetta, G., "Causality and Exogeneity in Econometric Models," in Cooke, R. and Costantini, D. (eds.), Statistics in Science. The Foundations of Statistical Methods in Biology, Physics and Economics, Kluwer, Dordrecht, 1990, pp. 27-40.

33 See Granger, C. W. J., "Testing for Causality: a Personal Viewpoint," Journal of Economic Dynamics and Control, v. 2, (1980), pp. 329-352.
} 
In a recent paper addressed to philosophical readers, Granger illustrates the advantages of his own theory as follows "it is easily understood, is pragmatic, and can be used in testing and is also not clearly incorrect." ${ }^{34}$ For Granger, the suitability of a definition of causality can only be asserted on pragmatical grounds: "the effect of a causal definition on the decisions taken by a decision maker in a realistic setting is the only way that its usefulness can be discussed." 35 Causality is strictly linked with manipulation because it provides solid grounds for decisions regarding economic policy. Nevertheless, Granger maintains that causality should not be identified with control over economic variables, because control "is a much deeper concept than causality. ... many writers seem to want to find causality so that the relationship obtained can be used to control or manipulate the effect. However, for this to succeed one needs the assumption that the relation does not change when control is attempted." ${ }^{36} \mathrm{We}$ are warned that such an assumption cannot be taken to hold in all situations, and needs justification. Granger's recommendation that the assumptions underlying causal attributions, as well as prediction and decisions on policy making, be made explicit and justified is a distinctive trait of the approach taken by econometricians and statisticians.

A generalization of Granger's theory has been proposed by Robert F. Engle, David F. Hendry and Jean-Francois Richard, ${ }^{37}$ according to whom exogeneity, instead of being a distinctive characteristic of a variable as in the classical view (for example policy variables under direct intervention of the authorities), is a property that depends on the chosen parametrization of the model and on the use for which the model has been constructed. In this perspective endogenous and exogenous variables cannot be distinguished before the probability distribution of observable variables is considered. In other words, the distinction is not fully definable on a priori grounds, but is to some extent testable inside a specific model. Incidentally, this marks a difference with Granger's theory, which is model independent because it does not include restrictions on parameters.

A somewhat similar view is that of Christopher Sims, who defines as structural a model which is invariant under a certain set of hypothetical interventions. Here "whether a model is structural depends on the use to which it is to be put - on what class of interventions is being considered." ${ }^{38}$ One cannot decide whether a model is structural (whether it describes a structure) by examining the form of the system of equations, as in the classic view of Simon and Wold. By contrast, the property of being structural is related to the application of the system to the world. Such a property can be tested by comparing the predictions as to the effects of an intervention, made on the basis of a certain system, with the observed results of such intervention. Woodward's theory shares some traits with Sim's, but it should not pass unnoticed that Sim's definition of causality remains within the scope of econometrics and does not share the claim to generality that Woodward attaches to his own approach.

In general, the view of causality worked out by econometricians has a pragmatic flavour and qualifies as pluralistic and context-dependent. This tendency has been strengthened by the need to handle the problem of bridging the gap between macro and micro models (the so-called problem

\footnotetext{
34 Granger, C. W. J., "Causality in Economics," in Machamer, P. and Wolters, G. (eds.), Thinking about Causes. From Greek Philosophy to Modern Physics, University of Pittsburgh Press, Pittsburgh, 2007, p. 294.

35 Granger, C. W. J., “Causality in Economics,” p. 295.

36 "Causality in Economics," p. 294.

37 See Engle, R. F., Hendry, D. F. and Richard, J.-F., "Exogeneity,” Econometrica, v. 51, (1983), pp. 277-304.

38 Sims, C. A., "Scientific Standards in Econometric Modelling," in HazewinKEl, M. and Rinnooy KAN, A. H. G. (eds.), Current Developments in the Interface: Economics, Econometrics, Mathematics, Reidel, Dordrecht, 1982, p. 332.
} 
of aggregation). Put briefly, the problem arises from the fact that while variables taken to be manipulable (instrument variables) are assumed to be strictly causal with respect to single agents, in the sense that single agents cannot influence their value, at the aggregate level the behaviour of all agents can have feedback effects on the instruments of the policy maker, thereby altering the causal structure of the effect. In view of this, it is necessary to introduce a conditional concept of manipulability, according to which the efficacy of the intervention of the policy maker is subordinate to the body of information available to economic agents. The conclusion attained by the econometric literature is that the relationship between causality referred to statistical variables and causality referred to individuals can be handled only at the price of introducing a conditional notion of manipulability and a dynamical specification of causal structure, dependent on the expectations and the information available to economic agents, as well as on the purpose for which models are used. ${ }^{39}$

Econometrics exhibits a complex interplay between observable data and/or variables and theoretical assumptions (or variables) that calls for a systematic separation between them. In economics it is often the case that observable phenomena are measured by means of non-experimental data, namely only one sample can be generated for each situation. Given that proper randomization procedures cannot be applied, tests are extensively used in such situations, to guarantee the correct specification of models. Here manipulation plays a crucial role by comparing predictions with the results of intervention. Another peculiarity of econometrics lies in the fact that data are sometimes referred to the population (for instance, mean or marginal data on income, consumption, etc.) and sometimes to individuals (for instance, data expressed in terms of expectations). In this connection the issue of observation and experimentation intersects that of type and token causation.

\subsection{Statistics}

Statisticians have devoted great attention to causality, traditionally associated with the design and interpretation of experiments. Like econometricians, statisticians refer causality to models and associate it with manipulability. An influential theory of causality has been put forward by Judea Pearl. Building on the techniques of representing statistical associations by means of graphs, Pearl defines causal relationships on the basis of directed acyclic graphs (DAG), also called Bayesian networks. The causal interpretation attached to such networks combines the functionalist notion of mechanism with manipulability. Put briefly, causal Bayesian networks are taken to represent ordered structures of variables exhibiting certain stability conditions which can lead to manipulations. Such a "mechanism-based conception of interventions" ${ }^{40}$ is the cornerstone of a theory of causality that regards causality as a useful tool for prediction and intervention. A clear-cut distinction between seeing and doing underlies Pearl's treatment of causality, where the quantities determined through observation are systematically distinguished from those obtained through experiment. This distinction plays a crucial role in predicting the results of controlled experiments from observed probabilities, which from this perspective is the main task of causality.

39 For more details see Galavotti, M. C. and Gambetta, G., "Theory and Observation in Econometric Models: a Constructivist Approach,” in Rossini Favretti R., SAndri, G. and Scazzieri, R. (eds.), Incommensurability and Translation, Elgar, Cheltenham-Northampton, 1999, pp. 339-349.

40 Pearl, J., Causality. Models, Reasoning, and Inference, Cambridge University Press, Cambridge, 2000, p. 24. 
Pearl also considers the explanatory use of causal models "to provide an 'explanation' or "understanding' of how data are generated," or to convey information on "how things work." 41 A crucial role is assigned to the stability of causal structures, which should be durable over time and invariant across a variety of situations. Models characterized by such features of robustness allow for predictions and manipulations that are bound to hold for a wide range of circumstances. So conceived, "the explanatory account of causation is merely a variant of the manipulative account, albeit one where interventions are dormant." ${ }^{42}$ Remarkably, Pearl's recent work on "actual causes" and explanation, done in collaboration with Joseph Halpern, reaches the conclusion that when taken in the explanatory sense causality is context dependent. This simply follows from the fact that the whole edifice of causation is made to rest on modelling, which in turn requires various assumptions so strictly linked with the context as to justify the claim that "the choice of model is a subjective one" and "depends to some extent on what the model is being used for." 43

Although well received, especially among computer scientists and psychologists, ${ }^{44}$ Pearl's theory of causation has provoked much debate. Its most controversial aspect lies in the Markov condition required by DAGs, whose assumption is considered by many authors problematic in a number of situations. We will not go into the details of this highly debated topic, nor shall we deal with the related issue of randomization, which is also a matter of endless controversy. ${ }^{45}$

Another important theory developed within the statistical literature is the so-called potential response (PR) approach of Donald Rubin, Paul Holland and others. ${ }^{46}$ This is a model for inferring the effects of causes (type causation) that makes use of counterfactual reasoning couched in statistical terms. As described by its most resolute opponent, namely Philip Dawid, the "special feature of the PR approach is that it represents a response ('effect') variable $Y$ by two or more random variables, one for each of the possible values of the "cause variable' $X$." 47 The idea is to compare the (assumed) values of potential responses with the effects observed in experimental units, under appropriate assumptions. These are usually invariance assumptions, like "unit homogeneity" (for instance, experimental units of people who are treated for headache with a certain drug); "temporal stability" (constancy of response to treatment over time); "causal transience" (the effect of causes and measurement processes in control groups is transient and does not affect the response to treatment measured later); and "constant effect" (the effect of treatment on each and every experimental unit is the same). Potential responses are defined counterfactually, namely the model assumes that even though a certain response is observed (say a certain subject $u$ has given a certain response to drug treatment) "there is still a fact of the matter about what the subject's $u$ response would have been, had she been

41 Pearl, J., Causality. Models, Reasoning, and Inference, pp. 25-26.

42 Causality. Models, Reasoning, and Inference, p. 26.

43 Halpern, J. and Pearl, J., "Causes and Explanations: A Structural-Model Approach. Part I: Causes," British Journal for the Philosophy of Science, v. 56, (2005), p. 878.

44 See for instance Sloman, S., Causal Models, Oxford University Press, Oxford, 2005.

45 See for instance the discussion of randomization in Worrall, J., "Why Randomize? Evidence and Ethics in Clinical Trials," in Gonzalez, W. J. and Alcolea, J. (eds.), Contemporary Perspectives in Philosophy and Methodology of Science, Netbiblo, A Coruña, 2006, pp. 65-82.

46 See for instance Holland, P., "The Causal Interpretation of Regression Coefficients," in Galavotti, M. C., SuppeS, P. and Costantini, D. (eds.), Stochastic Causality, Stanford, CSLI, 2001, pp. 173-187, and the bibliography included.

47 Dawid, P., "Counterfactuals, Hypotheticals and Potential Responses: A Philosophical Examination of Statistical Causality," in Russo, F. and Williamson, J. (eds.), Causality and Probability in the Sciences, College Publications, London, 2007, p. 510. 
given [a different] treatment." ${ }^{48}$ Such a counterfactual assumption is really the gist of the PR method, which derives from it the capability of treating causes of effects. Stathis Psillos, who has called the attention of philosophers of science to this method, quite popular among statisticians, deems it "a big step forward" ${ }^{49}$ and argues in favour of a pluralistic approach to causality combining counterfactuals and mechanisms.

By contrast, the counterfactual assumption underlying the PR approach is judged metaphysical by Philip Dawid, who opposes to it a decision-theoretic approach (DT), which is entirely in terms of conditional probabilities and expectations based on information, known or knowable. The DT approach avoids counterfactuals, to use only "models and quantities that are empirically testable and discoverable." ${ }^{50}$ According to Dawid, type causality, or the analysis of effects of causes, can be done entirely with the DT machinery. However, the same cannot be said of token causality, or the analysis of causes of effects, which is more strictly related to counterfactuals. In that connection the DT approach leaves some problems open.

An important aspect of Dawid's work amounts to his insistence on the need to make explicit the assumptions (usually invariance assumptions) that are made, and systematically separate observational regime from interventional regime. The task of type causation analysis, he claims, is to use past data to make choices about future interventions, and ".. this requires that we understand very clearly the real-world meaning of terms such as 'observational regime' or 'interventional regime', since there are many possible varieties of such regimes." ${ }^{51}$ This can only be accomplished with reference to the context in which one operates, and the same holds for the justification of assumptions. In Dawid's words: “... appropriate specification of context, relevant to the specific purposes at hand, is vital to render causal questions and answers meaningful." 52 This passage contains a major lesson to be drawn from the statistical literature on causality.

\section{Closing Remarks}

The preceding overview addressed a variety of theories of causality. First we examined a number of viewpoints developed by philosophers of science, ranging from Salmon's monolithic account embodying a fully fledged definition of causality, to Suppes' pluralistic perspective, which leaves the specification of what counts as causal to the context. While Salmon's view is centred on physics and relies on theories and laws, Suppes has in mind a broad range of applications, including the social sciences, where heavy use of statistical models is made. Like Reichenbach, Salmon assigns a marginal role to experimentation, which is by and large regarded as belonging to the "context of discovery."

By contrast, Woodward makes experimentation an essential ingredient of his manipulative approach, where it enters in the definition of causality as well as laws. Salmon's and Woodward's theories embody different intuitions of causality and diverge in a number of important respects. Nevertheless, they seem to share the tendency to define causality in a

\footnotetext{
48 Psillos, S., "A Glimpse of the Secret Connexion: Harmonizing Mechanisms with Counterfactuals," Perspectives on Science, v. 12, (2004), p. 303.

49 Psillos, S., "A Glimpse of the Secret Connexion: Harmonizing Mechanisms with Counterfactuals,” p. 307.

50 DAwID, P., "Causal Inference Without Counterfactuals," Journal of the American Statistical Association, v. 95 , (2000), p. 408.

51 DAwID, P., "Counterfactuals, Hypotheticals and Potential Responses: A Philosophical Examination of Statistical Causality," p. 529.

52 Dawid, P., "Causal Inference Without Counterfactuals," p. 422.
} 
univocal fashion, to establish a strong connection between causality and explanation, and to regard type and token causation as readily combinable.

Applied scientists like statisticians and econometricians take a different stand. Their attitude towards experimentation is similar to Woodward's, but they keep type and token causation separate, do not link causality with explanation and take a model-based and contextdependent viewpoint.

Strong emphasis is put on context by Suppes, who holds that an investigation of causal attributions made in different fields shows that different causal notions can prove useful within different contexts. In tune with his attitude, it is here suggested that probabilistic causality is better conceived as context-dependent, and that local accounts of causality should be preferred to univocal definitions. In the first place this involves assumptions made case by case being fully specified. The need to support causal analysis by a careful consideration of context seems particularly compelling in the social sciences - including psychology, medicine, law, and so on - where various assumptions are made at every stage of causal analysis. The aims of enquiry, the nature of the "objects" (events, variables, time series, etc.) to which causal relations are referred and the predictive or explanatory use made of such relations are additional contextual elements to be taken into account. Also important is the distinction between type and token analysis, and the interplay between mechanical and manipulative causality. ${ }^{53}$ The same holds for the distinction between observational and interventional (experimental) regimes systematically made by statisticians.

A pluralistic approach to probabilistic causality goes hand in hand with a model-based approach. One could say that when applied to probabilistic causality models play the role of mediators described by Mary Morgan and Margaret Morrison. ${ }^{54}$ Models play a mediating role between the various uses to which probabilistic causality can be put, namely prediction, manipulation and explanation. Moreover, they mediate between mechanical and manipulative causation, and between type and token analysis. Last but not least, they mediate between theory, observation and experimentation.

\section{REFERENCES}

Campaner, R., "Mechanisms and Counterfactuals: a Different Glimpse of the (Secret?) Connexion," Philosophica, v. 77, (2006), pp. 15-44.

Campaner, R. and Galavotti, M. C., "Plurality in Causality," in Machamer, P. and Wolters, G. (eds.), Thinking about Causes. From Greek Philosophy to Modern Physics, University of Pittsburgh Press, Pittsburgh, 2007, pp. 178-199.

Craver, C., "Interlevel Experiments and Multilevel Mechanisms in the Neuroscience of Memory," in PSA 2000. Part II. Supplement to Philosophy of Science, v. 69, (2002), pp. S83-S97.

\footnotetext{
53 A case study taken from medicine testifying the usefulness of combining the mechanical and manipulative approaches is discussed in Campaner, R. and Galavotti, M. C., "Plurality in Causality," in Machamer, P. and Wolters, G. (eds.), Thinking about Causes. From Greek Philosophy to Modern Physics, pp. 178-199. A pluralistic view of causality is also heralded in Galavotti, M. C., "Causality, Mechanisms and Manipulation," in Galavotti, M. C, Suppes, P. and Costantini, D. (eds.), Stochastic Causality, pp. 1-13, and Galavotti, M. C., "Causal Pluralism and Context," in Galavotti, M. C., Scazzieri, R. and Suppes, P. (eds.), Reasoning, Rationality and Probability, Stanford, CSLI Publications, 2008, pp. 233-252.

54 See Morrison, M. and Morgan, M., "Models as Mediating Instruments," in Morgan, M. and Morrison, M. (eds.), Models as Mediators, Cambridge University Press, Cambridge, 1999, pp. 10-37.
} 
DARden, L., "Strategies for Discovering Mechanisms: Schema Instantiation, Modular Subassembly, Forward/Backward Chaining," in PSA 2000. Part II. Supplement to Philosophy of Science, v. 69, (2002), pp. S354-S365.

DAwID, P., "Causal Inference Without Counterfactuals," Journal of the American Statistical Association, v. 95, (2000), pp. 407-424.

DAwID, P., "Counterfactuals, Hypotheticals and Potential Responses: A Philosophical Examination of Statistical Causality," in Russo, F. and Williamson, J. (eds.), Causality and Probability in the Sciences, College Publications, London, 2007, pp. 503-532.

Dowe, P., Physical Causation, Cambridge University Press, Cambridge, 2000.

Engle, R. F., Hendry, D. F. and Richard, J.-F., “Exogeneity,” Econometrica, v. 51, (1983), pp. 277-304.

Galavotti, M. C. and Gambetta, G., "Causality and Exogeneity in Econometric Models," in Cooke, R. and Costantini, D. (eds.), Statistics in Science. The Foundations of Statistical Methods in Biology, Physics and Economics, Kluwer, Dordrecht, 1990, pp. 27-40.

Galavotti, M. C., "Wesley Salmon on Explanation, Probability and Rationality," in Galavotti, M. C. and Pagnini, A. (eds.), Experience, Reality, and Scientific Explanation. Essays in Honor of Merrilee and Wesley Salmon, Kluwer, Dordrecht, 1999, pp. 39-54.

Galavotti, M. C. and Gambetta, G., "Theory and Observation in Econometric Models: a Constructivist Approach," in Rossini Favretti, R., Sandri, G. and Scazzieri, R. (eds.), Incommensurability and Translation, Elgar, Cheltenham-Northampton, 1999, pp. 339-349.

Galavotti, M. C., "Causality, Mechanisms and Manipulation,” in Galavotti, M. C, Suppes, P. and Costantini, D. (eds.), Stochastic Causality, CSLI Publications, Stanford, 2001, pp. 1-13.

Galavotti, M. C., "Causal Pluralism and Context," in Galavotti, M. C., Scazzieri, R. and Suppes, P. (eds.), Reasoning, Rationality and Probability, Stanford, CSLI Publications, 2008, pp. 233-252.

Glennan, S., "Rethinking Mechanical Explanation," in PSA 2000. Part II. Supplement to Philosophy of Science, v. 69, (2002), pp. S342-S353.

GooD, I. J., "A Causal Calculus," I, British Journal for the Philosophy of Science, v. 11, (1961), pp. 305-318.

Good, I. J., “A Causal Calculus,” II, British Journal for the Philosophy of Science, v. 12, (1962), pp. 43-51.

Good, I. J., "Errata" and "Corrigenda," British Journal for the Philosophy of Science, v. 13, (1963), p. 88.

Good, I. J., Good Thinking, University of Minnesota Press, Minneapolis, 1983.

Good, I. J., "Causal Tendency: A Review," in Skyrms, B. and Harper, W. (eds.), Causation, Chance and Credence, Kluwer, Dordrecht, 1988, pp. 73-78.

Granger, C. W. J., “Testing for Causality: a Personal Viewpoint," Journal of Economic Dynamics and Control, v. 2, (1980), pp. 329-352.

Granger, C. W. J., "Causality in Economics," in Machamer, P. and Wolters, G. (eds.), Thinking about Causes. From Greek Philosophy to Modern Physics, University of Pittsburgh Press, Pittsburgh, 2007, pp. 284-296.

Halpern, J. and Pearl, J., "Causes and Explanations: A Structural-Model Approach. Part I: Causes," British Journal for the Philosophy of Science, v. 56, (2005), pp. 843-887.

Halpern, J. and Pearl, J., "Causes and Explanations: A Structural-Model Approach. Part II: Explanations," British Journal for the Philosophy of Science, v. 56, (2005), pp. 889-911. 
Hausman, D., "Causation and Experimentation," American Philosophical Quarterly, v. 23, (1986), pp. 143-154.

Нттснсоск, C., "Discussion: Salmon on Explanatory Relevance," Philosophy of Science, v. 62, (1995), pp. 304-320.

Hitchсоск, C. and Woodward J., "Explanatory Generalizations: Part I: A Counterfactual Account," Nous, v. 37, n. 1, (2003), pp. 1-24.

Нiтснсоск, C. and Woodward J., "Explanatory Generalizations: Part II: Plumbing Explanatory Depth," Nous, v. 37, n. 2, (2003), pp. 181-199.

Holland, P., "The Causal Interpretation of Regression Coefficients," in Galavotti, M. C., Suppes, P. and Costantini, D. (eds.), Stochastic Causality, Stanford, CSLI, 2001, pp. 173-187.

Humphreys, P., "Invariance, Explanation, and Understanding," Metascience, v. 15, (2006), pp. 39-44.

Lindley, D., "Seeing and Doing: the Concept of Causation," International Statistical Review, v. 70, (2002), pp. 191-197.

Machamer, P., Darden, L. and Craver, C., "Thinking about Mechanisms," Philosophy of Science, v. 67, (2000), pp. 1-25.

Menzies, P. and Price, H., "Causation as a Secondary Quality," British Journal for the Philosophy of Science, v. 44, (1993), pp. 187-203.

Morgan, M. and Morrison, M. (eds.), Models as Mediators, Cambridge University Press, Cambridge, 1999.

Morrison, M. and Morgan, M., "Models as Mediating Instruments," in Morgan, M. and Morrison, M. (eds.), Models as Mediators, Cambridge University Press, Cambridge, 1999, pp. 10-37.

Pearl, J., Causality. Models, Reasoning, and Inference, Cambridge University Press, Cambridge, 2000.

Price, H., "Agency and Probabilistic Causality," British Journal for the Philosophy of Science, v. 42, (1991), pp. 157-176.

Price, H., "Agency and Causal Asymmetry," Mind, v. 101, (1992), pp. 501-520.

Price, H., "Causal Perspectivalism," in Price, H. and Corry, R. (eds.), Causation, Physics, and the Constitution of Reality. Russell's Republicanism Revisited, Clarendon Press, Oxford, 2007, pp. 250-292.

Psillos, S., "A Glimpse of the Secret Connexion: Harmonizing Mechanisms with Counterfactuals," Perspectives on Science, v. 12, (2004), pp. 288-319.

Reichenbach, H., The Direction of Time, University of California Press, Berkeley, 1956.

Salmon, W. C., "A Third Dogma of Empiricism," in Butts, R. and Hintikka, J. (eds.), Basic Problems in Methodology and Linguistics, Reidel, Dordrecht, 1977, pp. 149-166. Reprinted in Salmon, W. C., Causality and Explanation, Oxford University Press, New York, 1998, pp. 95-107.

Salmon, W. C., Scientific Explanation and the Causal Structure of the World, Princeton University Press, Princeton, 1984.

SAlmon, W. C., "Causal Propensities: Statistical Causality vs. Aleatory Causality," Topoi, v. 9, (1990), pp. 95-100. Also in SALmon, W. C., Causality and Explanation, Oxford University Press, New York, 1998, pp. 200-207.

Salmon, W. C., "Causality without Counterfactuals," Philosophy of Science, v. 61, (1994), pp. 297-312.

Salmon, W. C., "A Reply to two Critiques," Philosophy of Science, v. 64, (1997), pp. 461-477. 
Salmon, W. C., Causality and Explanation, Oxford University Press, New York-Oxford, 1998.

Salmon, W. C., "A Realistic Account of Causation," in Marsonet, M. (ed.), The Problem of Realism, Aldershot, Ashgate, 2002, pp. 106-134.

Sims, C. A., "Scientific Standards in Econometric Modelling," in Hazewinkel, M. and Rinnooy Kan, A. H. G. (eds.), Current Developments in the Interface: Economics, Econometrics, Mathematics, Reidel, Dordrecht, 1982, pp. 317-340.

Sloman, S., Causal Models, Oxford University Press, Oxford, 2005.

Sober, E., "Invariance, Explanation, and Understanding," Metascience, v. 15, (2006), pp. 45-53.

Suppes, P., A Probabilistic Theory of Causality, North-Holland, Amsterdam, 1970.

Suppes, P., "Self-profile," in Bogdan, R. (ed.), Patrick Suppes, Reidel, Dordrecht, 1979, pp. 3-56.

Suppes, P., "Conflicting Intuitions about Causality," in French, P., Yuehling, T. and Wettstein, H. (eds.), Causation and Causal Theories. Midwestern Studies in Philosophy IX, University of Minnesota Press, Minneapolis, 1984, pp. 151-168; reprinted in SupPEs, P., Models and Methods in the Philosophy of Science: Selected Essays, Kluwer, Dordrecht, 1993, pp. 121-140.

Suppes, P., Models and Methods in the Philosophy of Science: Selected Essays, Kluwer, Dordrecht, 1993.

Suppes, P., Representation and Invariance of Scientific Structures, CSLI Publications, Stanford, 2002.

Woodward, J., "Law and Explanation in Biology: Invariance is the Kind of Stability that Matters," Philosophy of Science, v. 68, (2001), pp. 1-20.

Woodward, J., Making Things Happen, Oxford University Press, New York, 2003.

WOODWARd, J., "Experimentation, Causal Inference, and Instrumental Realism," in RADDER, H. (ed.), The Philosophy of Scientific Experimentation, University of Pittsburgh Press, Pittsburgh, 2003, pp. 87-118.

Worrall, J., "Why Randomize? Evidence and Ethics in Clinical Trials," in Gonzalez, W. J. and Alcolea, J. (eds.), Contemporary Perspectives in Philosophy and Methodology of Science, Netbiblo, A Coruña, 2006, pp. 65-82. 


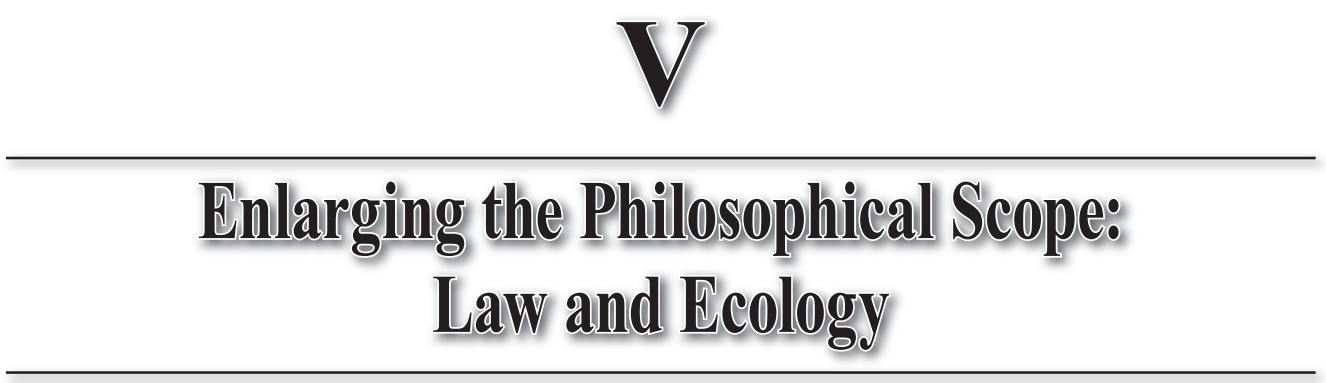

8. The Role of Experiments in the Theories of Distributive Justice

9. Observation and Experiment in Ecological Research 


\title{
The Role of Experiments in the Theories of Distributive Justice ${ }^{1}$
}

\author{
Obdulia Torres
}

The traditional role that has been assigned to experiments from the standard conception is to test the theories. It implies, as has been sustained, that experimentation has no relevance in the context of the theories of distributive justice, given that these are normative theories based on principles or ethical judgements. In this paper I will try to show that experiments not only can fulfil the role that traditionally has been assigned to them, namely to test the theories, but also that they can be a fundamental tool in the conceptual clarification, the evaluation and the political implementation of these theories, and further that they can be a source of stimulation for new theoretical developments.

\section{INTRODUCTION}

The traditional role that has been assigned to experiments from the standard conception is to test the theories. This implies, as has been sustained, that experimentation has no relevance in the context of the theories of distributive justice, given that these are normative theories based on principles or ethical judgements. Since the famous dictum of Hume, regarding the impossibility of inferring ought judgements from is, theoretical knowledge is generated by scholarly introspection and deduction from the general principles so founded. The general opinion is that popular beliefs about justice are one thing and a correct theory about it is quite another. Using the words of a theorist: "Evidently uninformed opinions of (a small and biased proportion of) the population do not have any authority over fundamental principles." ${ }^{2}$ The data obtained through empirical research are not relevant for the correction or validity of the theories. However in recent years there has been a growing interest in research in this area, which seems to indicate that this thought is not general and that experimentation does have a role to play in this field.

In the following pages I will try to show that with respect to the theories of distributive justice, first, experimentation can fulfil the role that traditionally has been assigned to it, namely to test the theories, and second, it can also be a fundamental tool in the conceptual clarification, the evaluation and the political implementation of these theories, and further that it can be a source of stimulation for new theoretical developments. This second approach is carried out according to the seminal work of I. Hacking ${ }^{3}$ and especially M. S. Morgan, ${ }^{4}$ who develops an important comparative analysis between models and experiments emphasizing that both fulfil identical functions as conceptual clarification tools and demonstrating the major epistemic power of the experiment compared to the model.

\footnotetext{
This work has been possible thanks to a research grant from the Ministry of Education and Science, which financed my stay as a guest researcher in the project "Equality and Plurality" at Copenhagen University. I am very grateful for the invitation to participate from the director of the project K. L. Rasmussen. An additional support was given by the Spanish Ministry of Science and Innovation, Research Project FFI2009-09483.

2 Devooght, K., "Measuring Inequality by Counting Complaints: Theory and Empirics," Economics and Philosophy, v. 19, (2003), p. 242.

3 Cf. HaCking, I., Representing and Intervening, Cambridge University Press, Cambridge, 1983.

4 Cf. Morgan, M. S., "Experiment versus Models: New Phenomena, Inference and Surprise," Journal of Economic Methodology, v. 12, n. 2, (2005), pp. 317-329.
} 
To show the above, I have selected a number of experiments performed by different authors which illustrate each of these functions. Even though it is not possible for reasons of space to describe such experiments in detail, each of them has been carried out by means of questionnaires in laboratory conditions. This methodology has been demonstrated to be very fruitful in other areas such as economy and psychology.

\section{Testing the Theory}

We will start by shortly characterizing the distributive theories. A distributive theory assigns to every individual a certain quantity of relevant resources according to some normative principle in a way that it can be said that the outcome is fair according to that principle. Thus, we have a selection of principles, some distributive mechanisms related to the principles and a series of rules that govern the distribution. These rules can be characterized as properties of these mechanisms. With very broad strokes these principles can be grouped under the labels necessity, desert and equality. The question to be answered is: "who should get what?"

One of the distributive theories that has frequently been subject to experimental studies is the theory of justice by J. Rawls. ${ }^{5}$ Broadly speaking, Rawls starts from the following assumptions: individuals are rational and self-interested, and under very specific hypothetical conditions ("original position") characterized by a restricted level of information (a "veil of ignorance"), the subjects will almost exclusively be concerned with the possibility of being placed in the worst-off class. From that he derives three fundamental hypotheses: 1) the individuals will come to a unanimous agreement, 2) the individuals will always select the same principle and 3 ) as distributive principle the individuals will select the difference principle which maximizes the welfare of the worst-off individual in the society.

Frohlich, Oppenheimer and Eavey subjected to empirical testing the three aforementioned hypotheses. "The experimental itself consisted of three parts. First, five subjects were each introduced to principles of distributive justice and given experience choosing a principle which governed their first earnings. Second, the subjects were given a chance to discuss and then to choose collectively a particular distributive principle that governed their next payments. Finally, the subjects answered a questionnaire about themselves. At four points in the experiment, subjects were asked to rank, according to their preferences, the principles of justice that were on the agenda and to indicate how sure they were of these rankings." ${ }^{6}$ The experimental results confirm 1 and 2, but deny 3: the individuals do not select the difference principle. Furthermore none of the 44 groups in the experiment selected that principle, not even in a modified experiment where theoretically the adoption of the difference principle was favoured. Instead of that, they selected a compound principle which maximizes the average income with a constraint on the floor, or the income of the worst-off.

Rawls' theory presents a series of characteristics that makes it especially suitable to be subjected to experimentation in which it has the same role as in any scientific theory. According to the authors of the experiment, this is due to the fact that Rawlsian theory is based on explicit assumptions of human behaviour: "Whenever an ethical theory implicitly contains a model of human psychology from which normative conclusions are derived, that model opens the possibility for testing." ${ }^{7}$

5 Cf. Rawls, J., A Theory of Justice, Harvard University Press, Cambridge, MA, 1971.

6 Frohlich, N., Oppenheimer, J. and Eavey, Ch., "Choices of Principles of Distributive Justice in Experimental Groups," American Journal of Political Science, v. 31, n. 3, (1987), p. 611.

7 Frohlich, N., Oppenheimer, J. and Eavey, Ch., "Choices of Principles of Distributive Justice in Experimental Groups," p. 634. 
It seems that Rawls' theory is testable as it is based on explicit assumptions of human behaviour $^{8}$, which is in contrast to the rest of the distributive theories. It is the behaviour generated by these assumptions that gives normative strength to the conclusions. However, most of the distributive theories are not expressed in a way that they can be captured by an experimental design, ${ }^{9}$ precisely because they do not provide a model of human psychology. This is especially important for consequentialist theories, where the strength of the ethical arguments derives from the consequences of their rules, ${ }^{10}$ in the same way that the theoretical implications derived from any scientific theory receive their strength from the results of testing. In this sense, experimentation has an important role to play in this field: testing the behavioural hypothesis derived from the models of human psychology.

\section{The Evaluation}

The theoretical testing is not the only function that experimentation could have in this type of theories. In the following we will illustrate the way in which the experiment could evaluate the theory and the meaning of evaluation in this context.

For this we will use the pioneer work by Yari and Bar-Hillel, ${ }^{11}$ who empirically researched the acceptance of different distributive mechanisms and suggested experimentation as a way to prove the sustainability of the theory. We will see the methodology developed in the theoretical work, illustrate it with an example coming from the egalitarian theory and finally analyse the role of experimentation as a mechanism to evaluate the theory.

The question that guides the theoretical work of Yari and Bar-Hillel is what properties a distributive mechanism should have. The research follows these stages: in first place it establishes a list of properties which this mechanism ought to have (Axioms). Then a mechanism must be determined that fulfils these axioms. If such a mechanism does not exist then we should redo the list of axioms until a mechanism is found that fulfils them. Once a mechanism is available we can continue with its characterization. That is, what is the whole set of properties (desired and undesired) that characterize this mechanism? The reason is that, as it is well known, occasionally some undesired results are derived from the whole set of axioms. Next, we will continue to evaluate its tenability. If the properties are found to be perverse, the mechanism is unsustainable and the process should restart. ${ }^{12}$ We will illustrate the first three steps by an example from an egalitarian theory.

In the definition of moderate egalitarianism, Bertil Tungodden establishes as desired axioms, the following: ${ }^{13}$

- Anonymity: for all the alternatives $\mathrm{x}$ and $\mathrm{y}$, if $\mathrm{x}$ is a permutation of the values of $\mathrm{y}$, then $\mathrm{x}$ is equally as good as $y$.

\footnotetext{
8 The fundamental assumption is that individuals are rational and self-interested. These are the assumptions accepted by microeconomic theory. However Rawls' theory differs from it when he puts forward that in the "original position", the individuals are exclusively concerned with the possibility of being among the worst-off.

$9 \quad$ I use the term replicate suggested by M. S. Morgan in the sense of reproducing or capturing the theory or the world. Morgan, M. S., "Experiment versus Models: New Phenomena, Inference and Surprise," p. 320.

10 For this argument, see Frohlich, N., Oppenheimer, J. and Eavey, Ch., "Choices of Principles of Distributive Justice in Experimental Groups," p. 634.

11 Cf. Yari, M. and Bar-Hillel, M., “On Dividing Justly,” Social Choice and Welfare, v. 1, (1984), pp. 1-24.

12 Cf. Yari, M. and Bar-Hillel, M., “On Dividing Justly,” pp. 2-3.

13 Cf. Tungodden, B., “The Value of Equality," Economic and Philosophy, v. 19, (2003), pp. 1-44.
} 
- Conditional Contracting Extremes: for all the alternatives $\mathrm{x}$ and y, if 1) all the better-off persons in $\mathrm{x}$ are better-off persons in $\mathrm{y}$ and their level of welfare is strictly lower in $\mathrm{x}$ than $y, 2$ ) all the worst-off in $x$ are worse in $y$ and their level of welfare is strictly higher in $\mathrm{x}$ than $\mathrm{y}$; and 3 ) the welfare of every one else is the same in $\mathrm{x}$ as in $\mathrm{y}$; then $\mathrm{x}$ is better than $\mathrm{y}{ }^{14}$

- Strict Priority to Equality Promotion: for all the alternatives $x$ and $y$, if 1) there are persons with higher well-being in $\mathrm{x}$ than $\mathrm{y}$, and there are persons with higher well being in $\mathrm{y}$ than $\mathrm{x}$; and 2) $\mathrm{x}$ is more equal than $\mathrm{y}$; then $\mathrm{x}$ is better than $\mathrm{y}$.

- Principle of Personal Good: for all alternatives $\mathrm{x}$ and $\mathrm{y}$, if everybody is as well off in $\mathrm{x}$ as in $\mathrm{y}$, and someone is strictly better-off (in $\mathrm{x}$ ), then $\mathrm{x}$ is better than $\mathrm{y}{ }^{15}$

Furthermore, the mechanism must provide a relation of order (reflexive and transitive).

We have established a list of axioms, but a simple example demonstrates that there is no mechanism that fulfils this ensemble. Together they generate an impossibility result. Let us suppose the following distributions: $x=(2,10,100) ; y=(1,100,100) ; z=(2,10,10)$. Any measure of inequality would say that $\mathrm{y}$ is more equal than $\mathrm{x} .{ }^{16}$ Therefore, according to the strict priority to equality promotion, $\mathrm{y}$ is better than $\mathrm{x}$. If we compare $\mathrm{x}$ with $\mathrm{z}, \mathrm{x}$ is better than $\mathrm{z}$ according to the principle of personal good, thus $x$ is better than $z$. Due to transitivity, $y$ is better than $z$, but this violates the condition of conditional contracting extremes that says that $\mathrm{z}$ is better than $\mathrm{y}$.

Therefore, we should turn back and redefine the axioms. One way to solve this impossibility is to impose the maximin condition.

- Maximin: for all the alternatives $x$ and $y$, if the level of welfare of the worst-off is strictly higher in $\mathrm{x}$ than $\mathrm{y}$, then $\mathrm{x}$ is better than $\mathrm{y}$.

In this way, in the ordering of $\mathrm{x}$ and $\mathrm{y}, \mathrm{x}$ is better than $\mathrm{y}$ according to the maximin, $\mathrm{z}$ is better than $\mathrm{y}$ according to the conditional contracting extremes, $\mathrm{x}$ is also better than $\mathrm{z}$ according to the principle of personal good and we have an ordering. Thus, the moderate egalitarianism is axiomatically defined by the principle of maximin.

We shall now proceed with its characterization. It is well known that the principle of maximin can produce results that may be considered undesired. Its absolute obsession for the worst-off, means that it orders situations like $(2,5,5,5,100)$ above situations like $(1,40,40$, $40,100)$, where the loss of the worst-off seems insignificant compared to the improvement of those other members of the society who are moderately better-off, but still far away from the best-off. ${ }^{17}$ However, it can be argued that a loss for the worst-off is unacceptable as he sees that the distance between his own situation and the second worst-off increases. ${ }^{18}$ How can we decide if moderate egalitarianism is an acceptable distribution mechanism? This means, how do we evaluate its sustainability?

\footnotetext{
14 What the condition says is that: "Where perfect equality does not obtain ... any benefit (no matter how small) to a worst-off person that leaves him/her still a worst-off person has priority (with respect to equality promotion) over any benefit (no matter how large) to a best-off person," Vallentyne, P., "Equality, Efficiency and the Priority of the Worse-Off," Economics and Philosophy, v. 16, (2000), p. 1.

15 As can be seen this is a reformulation of the principle of Pareto in the field of welfare.

16 The different measures suggested to evaluate the inequality produce the following values: range gives $\mathrm{x}=2,62$; $\mathrm{y}=1,4$; the relative mean deviation gives $\mathrm{x}=1,2 \mathrm{y}=0,6$, the variance would give $\mathrm{x}=52,90, \mathrm{y}=32,50$; the coefficient of variation gives $x=0,19 ; y=0,02$.

17 This is due to the fact that the maximin does not take into account the cardinality of benefits as it does not evaluate the losses compared to the benefits. In this way, the weight given to the worst-off is infinite.

18 B. Tungodden argues in this way. Tungodden, B., "The Value of Equality," p. 13.
} 
The suggestion from Yari and Bar-Hillel can serve to rescue the theory from this impasse. The authors claim: "A theory of distributive justice, like any theory is tested by how well it does when confronted with evidence. And it is our view that, in this particular case, the evidence with which the theory must be confronted consists of observed ethical judgements or moral intuitions. Thus, a distribution mechanism will be deemed untenable if its prescriptions are significantly at variance with observed ethical judgements." ${ }_{19}$

Let us return to our example: is the maximin principle tenable? That is, does it agree with the ethical judgements observed in the individuals in the different experiments carried out?

The maximin is an axiomatic formulation of the difference principle of Rawls. If we turn back to the previously mentioned experiments of Frohlich, Oppenheimer and Eavey, we find that no individual selected the maximin principle. Therefore, we should restart the process in agreement with the proposal of Yari and Bar-Hillel, given that moderate egalitarianism is not a sustainable mechanism of distribution. But it is not so easy! Why accept the experimental results, but not the reasoning by Tungodden who adds to the previous argument, that if the transitivity is accepted as a requisite for consistency then the maximin seems to be the only option? ${ }^{20}$ If any, what is the advantage of experimentation?

The proposal by Tungodden can be characterized as a model of equality. For this we will use the proposal by D. Hausman who considers models as definitions, ${ }^{21}$ or definitions of predicates and they are constituted by a set of assumptions. Paraphrasing Hausman: "but formulating the model not only provides a useful abbreviation, it makes possible conceptual, logical and mathematical explorations of the consequences of [equality] ${ }^{22}$ so defined." Let us return to our question: does the experiment have any advantage over the model? According to M. Morgan the answer is yes. This is because the experiment contrary to the model is constituted by the same materials as the world. "The shared ontology has epistemological implications. We are more justified in claiming to learn something about the world from the experiment because the world and experiment share the same stuff. In contrast, inference from the model experiment is much more difficult as the materials are not the same - there is no shared ontology, and so the epistemological power is weaker." ${ }^{23}$ Thus, Tungodden's model permits conceptual exploration and clarification of all the consequences of equality so defined, but does not give us the possibility, or at least not to the same degree, to make inferences back to the world, whereas the experiment does.

It is obvious that one single disagreement with the data does not contest the sustainability of the theory. But if we have accepted the relevance of the experiment in this area, we have travelled part of the road. The rest of the road will not be easier. A great part of the rejections of experimental methods in justice theories seems to come from a poorly articulated prejudice about problems of external and internal validity of the experiment. The former refers to the generalization of laboratory results to the real world. The latter refers to the extent that the experimental design captures the assumptions of the theory exactly. This is not the subject

\footnotetext{
19 Yari, M. and Bar-Hillel, M., “On Dividing Justly,” p. 3.

20 Cf. Tungodden, B., “The Value of Equality,” p. 14.

21 Cf. Hausman, D., The Inexact and Separate Science of Economics, Cambridge University Press, Cambridge, 1992; chapter 5, pp. 70-73.

22 In the original text it is "rationality." Hausman, D., The Inexact and Separate Science of Economics, p. 77.

23 Morgan, M. S., “Experiment versus Models: New Phenomena, Inference and Surprise," p. 323.
} 
of this paper, ${ }^{24}$ but some issues about internal validity are worthy of mention. Even though the results of Frohlich, Oppenheimer and Eavey seem robust, the authors themselves remark that some issues of the experimental design could be considered as lack of internal validity, principally the permeability of the "veil of ignorance" and the absolute value of the payments that, according to the authors "... would still fall far short of the "life chances" which Rawls posits for the original position." ${ }^{25}$ However, in a more general theoretical framework, the authors point out one condition of the experimental design that is relevant to certain distributive theories. Frohlich and Oppenheimer ${ }^{26}$ refer to those experimental situations where the subjects are placed in a situation of "impartial reasoning." As the authors show, this condition is often argued to be a precondition for introspection and moral knowledge. This impartial reasoning can be induced by means of restriction of information, just in the same way as the veil of ignorance in Rawls' theory. This is one way, and possibly not the only way, in which the empirical evidence can be relevant for the theory.

\section{Conceptual Clarification}

A third aspect, in which experimentation can play an important role, is in the definition and clarification of concepts. Here the suggestion is that experimentation fulfils the same function as Hausman assigned to models, that is, to make possible a conceptual exploration of the consequences of the definitions of the concepts.

One of the most important fields of research in egalitarian theories is the definition of the measures of inequality. The concept is highly complex and a great variety of measures has been suggested which order the social states in different ways. Although everybody knows when a distribution is inegalitarian with respect to an egalitarian one, it is more difficult to agree upon when one distribution is more unequal than another. Despite their apparent neutrality, the axioms are value-laden and if we keep to the formal language in which they are formulated, their application is followed by a series of consequences that are not always appreciable.

The research done by Yoran Amiel and Frank Cowell in 1991, ${ }^{27}$ tried to prove experimentally whether the suggested axioms as properties of the Lorenz curve, ${ }^{28}$ fitted to the definition of the concept of inequality that the individuals hold. They used a questionnaire which "....is designed with two, interrelated sections. The first section is numerical: it contains a set of simple choices between successive pairs of specific income distribution, A and B. The distributions are presented as vectors, without explicit currency units, and no hints were provided to the student as to what sort of living standards or welfare levels might correspond to those numbers. In each case the respondent is merely invited to state which of $\mathrm{A}$ and $\mathrm{B}$ appears to be the more unequally distributed. The second section is mainly verbal: respondents are confronted with

\footnotetext{
24 For a useful review of the threats to the internal and external validity, see McDERmotT, R., "Experimental Methods in Political Science,"Annual Review of Political Science, v. 5, (2002), pp. 31-61. For a short analysis of the ways to solve the problems of external validity in economics, see GuALA, F., "On the Scope of Experiment in Economics: Comment on Siakantaris," Cambridge Journal of Economics, v. 26, (2002), pp. 261-267.

25 Frohlich, N., Oppenheimer, J. and Eavey, Ch., "Choices of Principles of Distributive Justice in Experimental Groups," p. 616.

26 Frohlich, N. and Oppenheimer, J., "Preferences for Income Distribution and Distributive Justice: A Window on the Problems of Using Experimental Data in Economics and Ethics," Eastern Economic Journal, v. 20, n. 2, (1994), pp. 147-155.

27 Amiel, Y. and Cowell, F., "Measurement on Income Inequality, Experimental Test by Questionnaire," Journal of Public Economics, v. 47, (1992), pp. 3-26. The questionnaire is reprinted in full in the appendix of the article.

28 The Lorenz's curve is one of the most popular measures of inequality among economists.
} 
various general propositions about income distribution; they have to choose with which view among several about income inequality in hypothetical changes of income distribution they agree. The issues raised in the second section are closely linked to the numerical questions of the first." ${ }^{29}$ Both the numerical and the verbal section reflected the participants' agreement with the axioms that constitutes the Lorenz curve.

The Lorenz curve is defined by the following axioms:

- Anonymity: for all the alternatives $\mathrm{x}$ and $\mathrm{y}$, if $\mathrm{x}$ is a permutation of the values of $\mathrm{y}$, then $\mathrm{x}$ is equally as good as $\mathrm{y} .{ }^{30}$

- The principle of population. Replication of the population and its income should not affect the index of inequality.

- The principle of scale invariance: the only important thing is the relative benefit and not the absolute. This means that the index is not sensitive to proportional increments of the relevant benefit.

- The Pigou-Dalton principle of transfer: the inequality always decreases when there are transfers from the better-off individuals to the worse-off individuals with the condition that the mean income does not decrease and that the order among the individuals involved remains the same.

It has to be pointed out that accepting the Lorenz curve means accepting every one of these axioms. The first three may be more or less questionable given that they involve a choice between absolute measures and relative measures of inequality. For example, the principle of scale invariance requires that $\mathrm{A}=(5,8,10)$ and $\mathrm{B}=(10,16,20)^{31}$ should be evaluated as equal with respect to inequality. But it is possible to argue that B is more unequal than $\mathrm{A}$ given that the distance between the better-off and the worst-off has increased, or that $\mathrm{A}$ is more unequal than $\mathrm{B}$ given that the income of the worst-off has increased in B. ${ }^{32}$ With regards to the population replication that requires $\mathrm{A}=(5,8,10)$ and $\mathrm{B}=(5,5,8,8,10,10)$ to be considered equal with respect to inequality, it can be argued that equality has increased because now there are pairs of persons with the same income. On the other hand, it can be said that it has decreased because now there is one person more in the same situation as the worst-off. If there are more persons worse-off in B than in A then equality has decreased. ${ }^{33}$

The same does not occur with the Pigou-Dalton principle that has an almost unanimous acceptance among the theorists. By way of example: let us suppose that we have the following distributions: $\mathrm{A}=(1,4,7,10,13)$ y $\mathrm{B}=(2,4,7,10,12)$. According to the principle, the inequality decreases in the step from A to B given that, first, there has been a redistribution from betteroff to worst-off, second, the average income has not changed, and third, the order among the individuals involved remains the same. Let us now take a look at the following distributions: $\mathrm{A}=(1,4,7,10,13), \mathrm{B}=(1,5,6,10,13)$.

29 Amiel, Y. and Cowell, F., "Measurement on Income Inequality," p. 6.

30 Even though anonymity may seem trivial it is incompatible with the different rights that individuals may have.

31 All the numeric examples in this section come from Amiel, Y. and Cowell, F., "Measurement on Income Inequality," pp. 23-26.

32 This latter argument would imply using the maximin principle where the fairness of the results is evaluated only as a function of the worst-off.

33 For a criticism of the axiom of the population replication, see Temkin, L., Inequality, Oxford University Press, Oxford, 1993: "After all, not only are B's worse-off all the same level as A's, and not only are the gaps between the better- and the worse-off just as great in B as in A, but there are twice as many in the position of being worse-off than others through no fault of their own, and there are twice as many that they are worse-off than." p. 201. 
The same as in the previous case and in accordance with the transfer principle, the inequality has decreased in the step from A to B. However, not all the participants considered that as a decrease in inequality; $42 \%$ considered $\mathrm{B}$ more unequal than $\mathrm{A}$ and $22 \%$ considered them equal with respect to inequality. There are two explanations for this. First, the transfer did not take place between the best and the worst-off individuals, but in the mid-range of the vector. The experiments seem to show that agreement with the Pigou-Dalton condition depends on who transfers and who receives. When a better-off person transfers to a worse-off person, the principle counts with a high number of supporters, whereas when the transfer takes place in the extremes of the range, then the support of the principle decreases. ${ }^{34}$ On the other hand, it is possible to claim that, after the transfer, even though person 2 increases his income, the distance between the third and the fourth has increased and this can be seen as a sign of increased inequality.

Accepting the Lorenz curve as a measure of inequality implies accepting the four axioms. However, $85 \%$ of the participants rejected one or more of these axioms and thereby the Lorenz curve. What relevance do these findings have regarding the concept of inequality? Should the economists take them into account in the definitions of inequality? Should the principle of transfer be modified so that only transfers between the better and worse-off are allowed and not transfers in the lower part of the vector? Or do the economists have a privileged situation from which they can evaluate inequality? The role that we grant to experimentation in this field will depend on the answers given to these questions. The fact that, within the complete group of experimental subjects, the subset that showed the highest agreement with the principle of transfer was that of the students at Hebrew University who learn about the Lorenz curve as part of their introductory economic course may be revealing. As the authors note: "Perhaps the received wisdom of the profession is making its mark on perceptions of inequality comparisons at an early stage in students' intellectual development." ${ }^{35}$ In this case, the knowledge of the beliefs of the individuals about inequality is even more important and not only the belief of the economists.

Another example that elaborates on the role of experimentation in conceptual clarification is the studies made on the bases of desert. Three bases have usually been proposed: ${ }^{36}$ skill, contribution and effort. In this way, the rewards of the individuals depend on their skills in the actual task, the effort made, or their contribution to the final product. The majority view among the theorists is that the individuals can only deserve things based on factors like effort that are under their voluntary control. On the contrary, the experiments demonstrate that bases selected by the people depend on the context and the benefits being distributed. ${ }^{37}$ What relevance do these findings have for the definition of the concept of desert? Should we maintain the principle of responsibility as a constituent element of the concept or should we modify the concept?

We can conclude from the above examples that experimentation helps in conceptual clarification by specifying the definition of general concepts like equality or desert. Furthermore,

\footnotetext{
34 Amiel, Y. and Cowell, F., “Measurement on Income Inequality,” pp. 15-17.

35 "Measurement on Income Inequality," p. 17.

36 I think that the term was used for the first time in Feinberg, J., "Justice and Personal Desert," in Friedrich, C. J. and Chapman, J. W. (eds.), Nomos VI: Justice, Atherton, N. York, 1963, pp. 69-97; reprinted in Feinberg, J., Doing and Deserving: Essays in the Theory of Responsibility, Princeton University Press, Princeton, NJ, 1970, pp. 55-94. "Those conditions not specified in any regulatory or procedural rules whose satisfaction confers worthiness or desert," Feinberg, J., Doing and Deserving, p. 58.

37 See Miller, D., "Distributive Justice: What the People Think," Ethics, v. 102, n. 3, (1992), pp. 555-593. For a useful review of the literature.
} 
it isolates a new phenomenon, ${ }^{38}$ namely, that the individuals hold more pluralistic opinions regarding justice than the various general theories of justice state, and that the evaluation of the distributive mechanisms depends on the context and the item to be distributed.

\section{Political Implementation}

One aspect remains to be mentioned, where I think that empirical research is absolutely relevant, and that aspect is the political implementation of the redistributive systems.

The distributive theories range over a great variety of questions. When we ask "who should get what?," this "what" comprises things so different as income, taxes, social acknowledgement, the qualifications of students, legal punishments, the sharing of the children's party cake, ... questions that affect our daily life, but fundamentally imply the basic design of our social institutions. It seems inadmissible to claim that the beliefs held by the individuals do not have relevance for determining the principles that guide our institutional design. Let us return to the experiments carried out by Y. Amiel and F. Cowell about the transfer principle. If cognitive failures committed by the subjects are not adduced we could ask why some definitions about equality are considered valid when they were rejected by most of the subjects, especially when taking into account that this has consequences in our institutional design. For instance, a certain society yields certain inequality measurements, which may orient public policies in one direction or another, and indeed do so. It is not the same if the tax load that finances the redistribution falls to the high part of the range as to the mid-part. As we have seen, many individuals do not see this redistribution as a decrease in inequality and therefore they will have a negative perception about these policies.

Despite the doubts we may have regarding the role of the beliefs and the preferences of the individuals about distributive theories, it is undeniable that the selection of alternative policies depends to a greater or lesser extent on the preferences of the individuals and their beliefs about welfare and justice. Knowing these preferences is fundamental at the time of implementing one welfare policy or another.

A different related problem is: "How to make the empirical findings relevant for the real world?" That is, how to establish their external validity. I think that the road to follow has been well indicated by Frohlich, Oppenheimer and Eavey in one of the texts that we have analysed. "How can we claim policy relevance for our results? One possibility is to consider the future. We may all know where we have been, but none of us can know with certainty where we are going. Thus, voters can be thought of as sitting behind a (partial or 'thin') veil of ignorance: the future is not known to them. To the extent that the real world has a 'thin veil' similar to the one in our experiments, our results are relevant." ${ }^{39}$

A part of the criticism that denies the relevance of experimentation in the field of distributive theories, adduces problems of unrepresentative subject pool, others adduce cognitive defects that impede the subjects to make correct judgments. Finally, it is adduced that the subjects have selfish preferences and that their election of alternatives is guided exclusively by selfinterest, wherefore the results cannot be used to elucidate the justice principles that should

\footnotetext{
38 This is in accordance with the position by Ian Hacking to whom "To experiment is to create, produce, refine and stabilize phenomena,” НАCKING, I. Representing and Intervening, p. 230.

39 Frohlich, N., Oppenheimer, J. and Eavey, Ch., "Choices of Principles of Distributive Justice in Experimental Groups," p. 635 .
} 
govern the general interest. The first two criticisms can be answered by working with the representativeness of the subject pool; in any case it would not constitute a problem exclusively for the justice theories. The third criticism may be more problematic. Without entering into the discussion about whether human beings are purely egoist, uninterestedly altruistic or, the most likely, somewhere in between, the suggestion of the authors of incorporating the veil of ignorance could respond to this criticism. Its incorporation allows us to tackle to the problem of internal validity, given that in a general theoretical framework the veil of ignorance is recognized as a fairness condition. It also allows us to approach the problem of external validity inasmuch as uncertainty about the future allows us to establish a parallelism between experimental design and the real world.

\section{Concluding Remarks}

The argumentation of the preceding pages can be divided into two levels. One set of epistemic questions and a set of questions that, just in order to make a distinction, we can call practical questions.

On the one hand, it is argued that the role of experimentation is not limited exclusively to testing theories, but that it also has a role to play in the clarification and definition of the concepts and in the production of new phenomena, according to the arguments defended by I. Hacking, among others.

The second set of questions, or practical questions, refers to the role of experimentation in the theories of distributive justice. Concerning this topic, it has been held that experimentation has no relevance, given that these are normative theories based on principles or ethical judgements.

A great part of the epistemic questions have been taken for granted, but even for those who think that the only role that experimentation has to play is testing theories, I believe I have demonstrated that first, there is no significant difference between the theories of distributive justice and the scientific theories with regard to the role of experimentation. Second, experimentation is of great importance, especially in consequentialist theories, given that the strength of the normative arguments is derived from the consequences of its rules. For the analysis of the consequences of these rules, it is fundamental to have an explicit model of human psychology.

Many readers may find the differentiation between testing and evaluation in section two and three less clear, given that, moreover, the same set of experiments ${ }^{40}$ is used to illustrate two different functions. I think that the difference is important. Regarding testing, we saw that individuals do not behave according to the "prediction" by the theory, that is, they do not select the difference principle. In this sense the theory is considered inadequate because its predictions do not correspond with the reality observed. Regarding the evaluation, the theory is deemed inadequate or unsustainable because when it is put into practice (in the process of experimentation), consequences are deduced which are judged (evaluated) "perverse" by the individuals. Thus, testing and evaluation can be differentiated and experimentation plays a different role in each case.

In this paper we have made some comparisons between the role of experimentation and the role of models in scientific research, following the work of M. Morgan. A great part of the

40 Those performed by Frohlich, Oppenheimer and Eavey with respect to Rawls' theory. 
theoretical advances in recent years in the field of distributive theories has been the development of formal models and has been done by economists. These models are very useful tools for conceptual exploration and clarification and allow us to detect the inconsistencies in each system and explore their consequences. But there is another fundamental difference between the models and experimentation which I think has been perfectly illustrated in the preceding pages, namely that "where mathematical modelling results may surprise, experimental results may not only surprise but also confound." 41 That is, even though the model can have surprising implications, they can be traced back to and explained in terms of the model. Meanwhile the surprising implications of experiments, if they persist, constitute new phenomena that confound because they are not explicable within the theoretical framework. Let us go over the experiments expounded again, most of them are characterized by this element of confoundment. Not only did the subjects behave and make choices in a completely different way to that expected, but to some extent a new phenomenon has been created, namely, that the individuals hold more pluralistic opinions regarding justice than the various general theories of justice state, and that the evaluation of the distributive mechanisms depends on the context and the item to be distributed. Perhaps the moment has come to include this new phenomenon in the models that define our distributive mechanisms. It is not about choosing between models and experiments. It is about complementing models with experiments, given that the latter may be more epistemically powerful for making inference back to the world.

\section{REFERENCES}

Amiel, Y. and Cowell, F., "Measurement on Income Inequality. Experimental Test by Questionnaire," Journal of Public Economics, v. 47, (1992), pp. 3-26.

Devooght, K., "Measuring Inequality by Counting Complaints: Theory and Empirics," Economics and Philosophy, v. 19, (2003), pp. 241-263.

Feinberg, J., "Justice and Personal Desert," in Friedrich, C. J. and Chapman, J. W. (eds.), Nomos VI: Justice, Atherton, N. York, 1963, pp. 69-97. Reprinted in Feingerg, J., Doing and Deserving: Essays in the Theory of Responsibility, Princeton University Press, Princeton, NJ, 1970, pp. 55-94.

FeInBERG, J., Doing and Deserving: Essays in the Theory of Responsibility, Princeton University Press, Princeton, NJ, 1970.

Frohlich, N. and Oppenheimer, J., "Preferences for Income Distribution and Distributive Justice: A Window on the Problems of Using Experimental Data in Economics and Ethics," Eastern Economic Journal, v. 20, n. 2, (1994), pp. 147-155.

Frohlich, N., Oppenheimer, J. and Eavey, Ch., "Choices of Principles of Distributive Justice in Experimental Groups," American Journal of Political Science, v. 31, n. 3, (1987), pp. 606-636.

Guala, F., "On the Scope of Experiment in Economics: Comment on Siakantaris," Cambridge Journal of Economics, v. 26, (2002), pp. 261-267.

Hacking, I., Representing and Intervening, Cambridge University Press, Cambridge, 1983.

Hausman, D., The Inexact and Separate Science of Economics, Cambridge University Press, Cambridge, 1992.

McDermott, R., "Experimental Methods in Political Science," Annual Review of Political Science, v. 5, (2002), pp. 31-61.

${ }_{41}$ Morgan, M. S., "Experiment versus Models: New phenomena, Inference and Surprise," p. 324 (underlined in the original). 
Miller, D. "Distributive Justice: What the People Think," Ethics, v. 102, n. 3, (1992). pp. 555-593.

Morgan, M. S., "Experiment versus Models: New phenomena, Inference and Surprise," Journal of Economic Methodology, v. 12, n. 2, (2005), pp. 317-329.

Rawls, J., A Theory of Justice, Harvard University Press, Cambridge, MA, 1971.

Temkin, L., Inequality, Oxford University Press, Oxford, 1993.

Tungodden, B., “The Value of Equality," Economics and Philosophy, v. 19, (2003), pp. 1-44.

Vallentyne, P., "Equality, Efficiency and the Priority of the Worse-Off," Economics and Philosophy, v. 16, (2000), p. 1-19.

Yari, M. and Bar-Hillel, M., “On Dividing Justly," Social Choice and Welfare, v. 1, (1984), pp. 1-24. 


\title{
Observation And Experiment in ECOlogical Research
}

\author{
Rafael González del Solar* \\ and Luis Marone
}

The science of ecology studies the relations among living beings and their environment, both biotic and abiotic. Results of ecological research are descriptions, explanations, and predictions dealing with the temporal and spatial abundance and distribution of organisms, as well as with the movements of matter and energy through ecological systems. ${ }^{1}$

Partly due to the breath of its subject matter, ecology is as diverse as it is complex. One consequence of this characteristic is that the discipline is not a homogeneous endeavor but a somewhat loose collection of sub-disciplines that exhibit a variety of goals and methodological approaches. Think, for example, of the techniques used in studying interspecific relationships in community ecology, in contrast with those used in ecosystem ecology for the study of energy fluxes. Differences in styles of approach, however, are not restricted to differences among sub-disciplines, nor are they related only to matters of technique (e.g., the pros and cons of different sampling designs). General epistemological issues are also an arena for dissension in ecology. Among the latter, issues concerning the relevance of experiments and the role of explanation in ecological research, or the possibility of general ecological laws have elicited a number of articles in the ecological literature. Rather frequently, discussions on all three topics revolve around a more general debate between ecologists favoring so-called "mechanistic" or "reductionist" approaches and researchers who preconize the advantages of setting aside the "mind-boggling" details of ecological processes and concentrating in broad patterns in order to generate predictive, "useful" knowledge. ${ }^{2}$ While the former tend to have experiments in high esteem, the latter speak usually for non-manipulative observation.

In the specific case of community ecology, however, some authors defend a methodological approach that starts with observation, proceeds to theory building and ends

\footnotetext{
We are grateful to J. Lopez de Casenave for insightful discussion. RGS thanks the support of Fundación Carolina (Spain). This is contribution no. 73 of the Desert Community Ecology Research Team (Ecodes).

1 See Likens, G. E., Excellence in Ecology 3, the Ecosystem Approach: Its Use and Abuse, Ecology Institute, Oldendorf-Luhe, 1992.

2 E.g., Lawton, J., "Are there General Laws in Ecology?," Oikos, v. 84, (1999), pp. 177-192; Peters, R. H., A Critique for Ecology, Cambridge University Press, Cambridge, UK, 1991; Murray, B. G., "Universal Laws and Predictive Theory in Ecology and Evolution," Oikos v. 82, (2000), pp. 403-408; Turchin, P., "Does Population Ecology Have General Laws?," Oikos, v. 94, (2001), pp. 17-26; and AgrawaL, A. A. (ed.), "Forum. The Metabolic Theory of Ecology," Ecology, v. 85, (2004).

Philosophers too have paid attention to these problems, especially that of ecological laws, see, e.g., SHRADERFrechette, K. S. and McCoy, E. D., Method in Ecology. Strategies for Conservation, Cambridge University Press, New York, 1993; Waters, C. K., "Causal Regularities in the Biological World of Contingent Distributions," Biology and Philosophy, v. 13, (1998), pp. 5-36; Rosenberg, A., "How Is Biological Explanation Possible?," British Journal of Philosophy of Science, v. 52, (2001), pp. 735-760; Colyvan, M. and GinzBurg L. R., "The Galilean Turn in Population Ecology," Biology and Philosophy, v. 18, n. 3, (2003), pp. 401-414; and Lange, M., "Ecological Laws: What Would They Be and Why Would They Matter?," Oikos, v. 110, (2005), pp. 394-403.
} 
with experiment (Fig. 1). ${ }^{3}$ According to this traditional view, the observational stage serves the role of providing the ecologist with data, the raw material for empirical generalizations (i.e., propositions that describe patterns or trends or empirical regularities). Once a pattern is reliably established by means of observation, it would be related to other generalizations and conjectures in order to build "theory." ${ }^{4}$ After this modeling stage, a second empirical (ideally experimental) stage would follow, consisting of tests of the predictions deductively derived from theoretical constructs.

Summing up, according to this view, ecological research would involve two empirical phases - one observational and the other mainly experimental—, each with a quite distinct role. Observation would provide descriptions of patterns and suggest "theory," while experiment would be the means for accepting or rejecting the relevant hypotheses through the confirmation or refutation of the derived predictions. According to this model of knowledge production, the advancement of ecology would proceed by a helicoidal movement where the sequence observation-“theory”-experiment would successively iterate (Fig. 1).

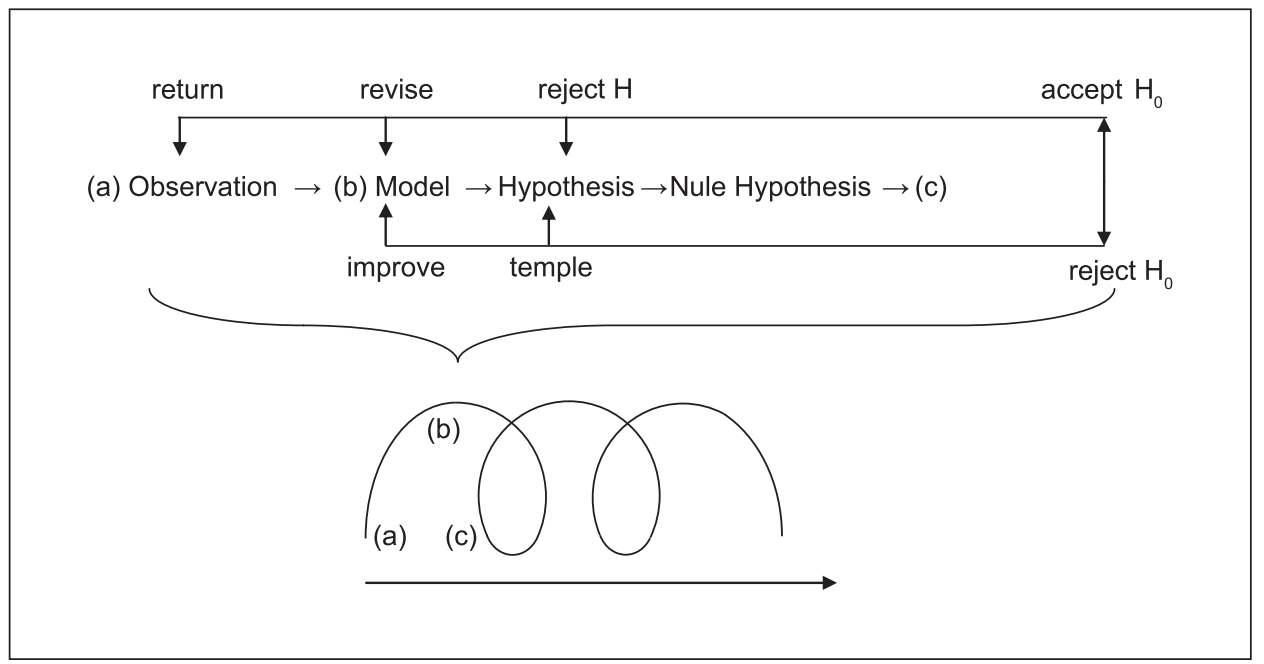

Figure 1. Schematic outline of the traditional methodological sequence in ecological research. The sequence in each loop of the helicoid is (a) observation, (b) theory building, and (c) experimentation. The arrow below the helicoid shows the general direction of advance of the inquiry. Arrows above the brace show the direction of the tactical procedure. Modified from Peckarsky, B. L., "The Dual Role of Experiments in Complex and Dynamic Natural Systems," in Resetarits, W. J. and Bernardo, J. (eds.), Experimental Ecology: Issues and Perspectives, p. 312.

3 See Underwood, A. J., "Design, Implementation, and Analysis of Ecological and Environmental Experiments. Pitfalls in the Maintenance of Logical Structures," in RESETARITS, W. J. and BERNARDO, J. (eds.), Experimental Ecology: Issues and Perspectives, Oxford University Press, Oxford, 1998, pp. 325-349; and Peckarsky, B. L., "The Dual Role of Experiments in Complex and Dynamic Natural Systems," in Resetarits, W. J. and Bernardo, J. (eds.), Experimental Ecology: Issues and Perspectives, 1998, p. 312.

4 Ecologists usually use the term "theory" in a somewhat loose way, meaning hypotheses of different levels, models and traditional theories (i.e., hypothethico-deductive systems). Here, we will maintain such ambiguity for the sake of the argument. 
This scheme is clearly based on a hypothethico-deductive view of scientific method. Subtleties apply, though, for observation here plays a major role in the generation of hypotheses and its importance in confirmation is greater than that assigned, for instance, by K. R. Popper. ${ }^{5}$ As for the adequacy of the view represented in Fig. 1, we admit that it represents a possible methodological sequence and that it may even be frequent in some realms and stages of ecological research. Yet, it has to be said that this is not the only possible methodological sequence, that it has proved inadequate as a research strategy in many cases, and that ecological research, like scientific research in general, is a much more complex process.

In this chapter, we shall try to illustrate three aspects: (i) observation itself is a rather complex procedure involving hypotheses about indicators ("theory") and a modicum of intervention; (ii) both experiment and observation play important roles in the creation of ecological knowledge, and each of them may be used for different immediate epistemic ends; and (iii) the iterative integration of experiment and observation (and "theory," of course, but we will not deal here with this interaction) within one and the same ecological research project allows one to solve complex problems unassailable by just one of these approaches or by the "traditional" methodological approach.

\section{Observation}

The point of making scientific observations is to provide a description of some of the properties of the entities under study. However, in contrast to the assumptions of the traditional research approach just described, such descriptions are not "basic" nor is their only role to provide raw data for generalizations. Indeed, ecological observations are not always direct or straightforward. As is the case with other sciences, the great majority of ecological data are a result of indirect observation techniques and, to a certain degree, a fruit of human intervention. ${ }^{6}$ Even though a large portion of ecological research deals with (in principle) observable entities, the processes in which they are involved are not, so indicators are a ubiquitous tool in ecological inquiry. In other words, most ecological data are constructions.

\subsection{Ecological Data Are Constructions}

In this subsection we will provide some examples as to the sense in which ecological data are constructed. In the first place, we will start by saying that ecological observations are not always direct or straightforward. Indeed, as in the case of any other science, the great majority of ecological data are a result of indirect observation techniques and, to a certain degree, a fruit of human intervention. ${ }^{6}$ Even though a large portion of ecological research deals with (in principle) observable entities, the processes they are or were involved in are not, so indicators are a ubiquitous tool in ecological inquiry. In other words, most ecological data are constructed.

\footnotetext{
5 A classical representative of this methodological perspective is Platt, J. R., "Strong inference," Science, v. 46, (1964), pp. 347-353. For differences between the Popperian and the Bayesian views on hypothetico-deductivism in ecology see, for example, Oksanen, L., "Logic of Experiments in Ecology: Is Pseudoreplication a Pseudoissue?," Oikos, v. 94, (2001), pp. 27-38.

6 For the role of intervention in the production of empirical knowledge, see HACKING, I. Representing and Intervening, Cambridge University Press, Cambridge, MA, 1983.
} 
In the first place, there is always the sampling design. More often than not ecological observations are made systematically, according to a particular design, at particular places and during particular periods. Second, in some cases observations involve a modicum of intervention on the part of researchers. Third, as we have said, observations do not always consist in the actual observation of the entity of interest, but rely on indicators supported by (ideally well-grounded and independently tested) indicator hypotheses.

The use of scent stations for assessing population tendencies of carnivores (and other animals as well) will illustrate this point. ${ }^{7}$ Since many carnivores are too secretive or live in habitats too dense to measure their numbers by means of direct observation or binoculars, a way to do that is through the "capture" of their tracks. Track samplings consist of "scent stations" (areas of soil of about $1 \mathrm{~m}^{2}$, with a standard plaster disc soaked in attractant) arranged in lines, whose role is to attract the target animals and make them leave their footprints on the soil. The latter must be previously cleared from any object that could hinder the "reading" of the tracks and, if necessary, covered with an ad hoc material (such as sand) for the tracks to print on its surface. Statistical requirements impose important characteristics on the design, such as total number of lines (the sampling unit), number of scent stations per line, number of nights they must remain active, etc. Materials involved in the sampling (plaster discs, attractant, etc.) are usually standard and used in standard quantities.

The idea behind the scent station technique is that a series of yearly samplings, carried out at the same area and time of the year, can show whether the target population is stable, or decreasing or increasing its numbers. The raw data each yearly sampling yields consist of the average percentage of scent stations visited (out of the number of scent stations operable) in each sampling line. The final yearly data is a grand average of the averages for each line. Of course, there are more subtleties to the technique than meets the eye. Yet, as an instance of how ecological data are constructed, it should suffice to add that yearly results are affected both by the size of the target carnivore population and by its activity level, and that the use of this technique requires calibration with other means of measuring population size. ${ }^{8}$ In short, ecologists can measure the relative density of, say, grey foxes without ever actually seeing a grey fox, and only because researchers intervene by attracting them to scent stations.

Since observations depend on sampling design and indicator hypotheses, they cannot be the proverbial bedrock upon which ecological knowledge would be built.

\subsection{Observations and Experiments Can Play Different Roles in Ecology}

As we saw in the introduction, the traditional methodological assumes that the research cycle starts from observation and ends with experimental testing of hypothesis. However, ecological studies do not always begin with observations, nor are experiments always a means to test hypotheses. In this subsection we will illustrate how both types of empirical tools can be used to assess the adequacy of ecological hypotheses.

\footnotetext{
7 For more details on the scent-station technique see Roughton, R. D. and SweEney M. W., "Refinements in Scent Station Methodology for Assessing trends in Carnivore Populations," Journal of Wildlife Management, v. 46, (1982), pp. 217-229.

8 Reports on population tendencies based on the scent station technique presuppose that the proportion of scent stations visited is positively related to abundance and not affected by activity. See, e.g., Sargeant, A. B., Johnson, D. H. and Berg, W. E., "Interpreting Carnivores Scent Stations Surveys," Journal of Wildlife Management, v. 62, (1998), pp. 1235-1245.
} 


\subsubsection{Experiments Can Be Used as Exploration Tools}

The traditional methodological approach notwithstanding, ecological studies do not always begin with observations and experiments are not always a means to test hypotheses. Both types empirical of tools can be used to explore the phenomena of interest and both can be used to assess the adequacy of ecological hypotheses.

It is true that the first steps of an investigation usually involve some exploratory actions, but these need not be performed through observations, nor is the usefulness of observations confined to the early stages of research. For instance, observations alone sometimes fail to reveal a pattern in an unambiguous way, and researchers have to recur to different empirical tools, namely to experiments. A study on the spatial ecology of stoneflies, small flying insects belonging to the order Plecoptera, whose larvae (called nymphs or naiads) are aquatic, will help illustrate this point.

Ecologist Barbara Peckarsky was looking for patterns in the use of habitat of the predatory nymphs of stoneflies. ${ }^{9}$ An exploratory sampling carried on in a water stream in the Rocky Mountains showed that the spatial distribution of the naiads was random and that individuals were more abundant in stones whose upper surface area exceeded $200 \mathrm{~cm}^{2}$. Which of the features of the habitat governed the spatial distribution of naiads?

Further observational studies failed to reveal any patterns that might help give an unambiguous answer to this question or give support to any hypothesis researchers might have had in mind. This was so even though they invested in an important sampling effort by registering a great number of factors that might affect the nymphs' spatial distribution (i.e., densities of naiads, densities of preys and of other predators, surface and interstitial water speed, water depth and temperature, biomass of algae and detritus).

In cases like this, in which observation proves insufficient for pattern detection, experiments, particularly the so-called phenomenological experiments, provide a useful alternative. Also known as "mechanism-free experiments," 10 manipulations of this kind are usually performed on a presence/absence basis of those factors suspect of being causally related to the variables of interest. Their main characteristic is that they do not involve hypotheses about the processes plausibly linking the behavior of the variables of interest (i.e., about mechanisms). However, they do involve hypotheses on what is and what is not possible (or plausible) in any given circumstances, and on what may and may not be relevant to measure. ${ }^{11}$ In other words, phenomenological experiments are tools for detecting or probing patterns.

\footnotetext{
9 See details in Peckarsky, B. L., "Why Predaceous Stoneflies Do Not Aggregate With Their Prey," Verhandlungen der Internationale Vereinigung für theoretische und angewandte Limnologie, v. 23, (1988), pp. 2135-2140; PECKARSKY, B. L., "Habitat Selection by Stream-Dwelling Predatory Stoneflies," Canadian Journal of Fisheries and Aquatic Science, v. 48, (1991), pp. 1069-1076. The corresponding methodological reflections can be found in PECKARSKY, B. L., "The Dual Role of Experiments in Complex and Dynamic Natural Systems," pp. 314-316.

10 Cf. Dunham, A. E. and Beaupre, S. J., "Ecological Experiments. Scale, Phenomenology, Mechanisms, and the Illusion of Generality," in Resetarits, W. J. and Bernardo, J. (eds.), Experimental Ecology: Issues and Perspectives, pp. 27-49.

11 This aspect, though rather obvious indeed, is relevant regarding the relationships among observation, experiment, and "theory," especially regarding the debates on the thesis of the theory-ladenness of observation. As already identified by Hacking in Representing and Intervening, a weak version of the thesis - i.e., that of the precedence of some conceptual constructions with respect to observation or experiment - is undeniable. The application of the methodological requisite of considering "all relevant factors" is simply not possible in the absence of some conceptual constructions that guide the selection of the relevant variables to be measured. Besides, even if it were possible in principle, all kinds of logistic constraints (e.g., resources such as time, money, personnel, etc.) would make it unfeasible, or at least unwise, to perform observations or conduct experiments without the counsel of previous empirical and theoretical knowledge (i.e., constructs). What is reasonable (and more efficient) is to begin with those factors that are more plausible in the light of preliminary observations and according to the (not necessarily formal) model/s the researcher has in mind.
} 
Returning to stoneflies, in the face of the failure of the observational approach, Peckarsky and her colleagues carried out a series of phenomenological experiments taking advantage of a watercourse that had dried and would naturally get flooded in the near future. They marked stones with different upper surface areas and registered their after-flood stability. The experiment showed that predatory Plecoptera preferred stones with a higher probability of remaining stable when water came back. ${ }^{12}$ These manipulations provided empirical support for the hypothesis that stoneflies prefer stones that provide them a more stable habitat. From further experiments involving manipulation of naiads in natural courses, another hypothesis arose that could explain their spatial distribution. Those studies showed that the nymphs of stoneflies avoided microhabitats already occupied by other individuals, suggesting that competitive interference was the mechanism explaining the spatial pattern. Eventually, this hypothesis was tested - and confirmed - in artificial and semi-natural systems by means of "mechanismic" 13 experiments. In sum, the use of observations and two types of experiments was necessary to understand the spatial distribution of the naiads.

\subsubsection{Observations Can Be Used to Decide Among Ecological Hypotheses}

The traditional methodological view schematized in Figure 1 also overlooks the fact that experiments, especially crucial experiments, are not always possible in ecology. Therefore, observation may sometimes carry the weight of deciding among ecological hypotheses. This is the idea underlying the "smoking gun" methodology, which has already done good service in other historical sciences. This approach represents an attempt to overcome the impossibility of observing or manipulating past causes or other factors that are not repeatable in artificial environments due to physical (e.g., temporal or spatial scales) or ethical impossibilities. The smoking gun approach does not exclude experiments, but emphasizes the use of nonexperimental observations in order to provide solid grounds for a given hypothesis or model.

The study of the causes of dinosaur extinction, at the end of the Cretaceous period, provides an example of the smoking gun style of research. ${ }^{14}$ According to the famous Alvarez hypothesis, the relatively rapid extinction of dinosaurs was a result of a dramatic environmental change, which in turn was a result of the collision of a large asteroid with Earth. ${ }^{15}$ Of course, an experiment proper was not possible, and there were other competing ecological hypotheses invoking epidemics, global climatic change, and volcanism as potential factors leading to the extinction of the formidable reptiles. Only when researchers found large

12 This is a nice example of how the underlying model influences the interpretation of the information provided by an experiment. Measurements of the stability of the stones were taken based on a plausible conjecture about the relation among stone area, stone stability, and habitat stability. In this case, the function of the phenomenological experiment was to enhance the plausibility of the hypothesis.

13 The term "mechanismic" is a neologism coined some four decades ago by Mario Bunge ("Phenomenological theories,") in Bunge, M. (ed.), Critical Approaches to Science and Philosophy, Transaction, New Brunswick, NJ, 1999 (originally published in 1964), pp. 234-254. The reason he gives for preferring "mechanismic" to "mechanistic" is avoiding some of the connotations of the latter term, an attempt we find particularly useful in ecology. Bunge's mechanismic view opposes the traditional mechanistic (physicalist) one in that the former is not radically reductionist, nor is causalist (though admits that most of the mechanisms revealed by the sciences are causal). In other words, in following Bunge's use of the term "mechanismic" we admit the possibility of mechanisms belonging in organization levels higher that that of the phenomenon to be explained, as well as the existence of random mechanisms.

14 Cf. Cleland, C., "Methodological and Epistemic Differences Between Experimental Science and Historical Science," Philosophy of Science, v. 69, (2002), pp. 474-496.

15 Cf. Alvarez, L. W., Alvarez, W., Asaro, F., and Michel, H. V., "Extraterrestrial Cause for the Cretaceous-Tertiary Extinction. Experimental Results and Theoretical Interpretation,” Science, v. 208, (1980), pp. 1095-1108. 
deposits of iridium at the C-T boundary (the limit between Cretaceous and Tertiary layers of sediments) did the asteroid hypothesis begin to gain attention. Some time later, geologists found relatively large amounts of a rare mineral — shocked quartz - in the same layers, and this gave more support to the meteorite-impact hypothesis. The reason is that no volcanic mechanism was known that could produce so much shocked quartz. However, researchers would have not considered the latter as a smoking gun, they had not realized that dinosaurs disappeared in a relatively short period.

Research on the processes leading to the assembly of any given ecological community is another case where observations serve a similar function. Evolutionary theory implies the progressive weakening of interspecific competition within a community by means of divergence in the use of resources. Thus, long past competitive processes (as opposed, for example, to predation processes) that might explain the present state of a particular ecological community cannot be subject to observation or to experiment in present day communities. If the process structuring the community was competition, researchers will only find the so-called "ghost of competition past." ${ }^{16}$ Experiments can only tell us whether competition is a plausible candidate for explaining the present state of a natural community; observations can enhance that plausibility by adding further favorable empirical evidence.

Summing up, according to the smoking gun view, historical explanations can be tested through a procedure similar to that of a police investigation: Searching for clues that indicate which hypothesis is the one that best explains evidence up to the moment, a procedure in which non-experimental observation plays a central role.

\section{EXPERIMENT}

As we saw in the example of the research on stoneflies, experiments may be useful in order to find and/or probe patterns where observation has failed to do it. Besides, as we saw in the example of the extinction of dinosaurs, observation can also be useful for discriminatin among different causal hypotheses.

One of the most utilized approaches in ecological research, particularly in community ecology, is that of perturbation experiments. These consist in manipulating diverse factors in order to determine whether some of them is/are associated to the variable of interest. As these manipulations typically do not involve mechanismic hypotheses, they are called phenomenological experiments. Now, experiments of this kind are useful for revealing or strengthening patterns, but are not adequate to reveal the causes of a phenomenon.

\subsection{Limitations of Phenomenological Experiments}

Carrying out phenomenological experiments without taking account of their limitations implies the risk of attributing causal relations arbitrarily, as is shown in the following case. This example draws on a classical community ecology work carried out in the Sonora desert (Portal, Arizona, USA). A group of ecologists led by James H. Brown wished to study the effects of interspecific competition on population size within a community of granivores (animals that feed on seeds). In order to do so, they built exclosures - i.e., areas enclosed by fences of different kinds to the effect of keeping outside individuals from particular species - that were treated in

16 Cf. Connell, J. H., "Diversity and the Coevolution of Competitors, or the Ghost of Competition Past," Oikos, v. 35, (1980), pp. 131-138. 
different ways ${ }^{17}$. All rodent species were removed from one third of these exclosures and the large kangaroo rats (Dipodomys sp.) were the only animals removed from the second third, while only ants were excluded from the last one. Brown and collaborators then measured the changes undergone by certain populations of animals and plants within the exclosures.

After the removal of kangaroo rats from the selected exclosures, an increase in the number of smaller granivorous rodents was registered. Researchers interpreted these data as a result of competitive relaxation -i.e., as one competitor decreases in numbers or disappears the other one thrives. However, in the particular way in which the experiment was carried out, competitive relaxation was not the only plausible explanatory hypotheses. More precisely, the exclusion of kangaroo rats had been performed by means of a wire mesh fence. Small holes were made in the mesh to allow rodents other than Dypodomys to pass through it. The fences, however, also excluded from these plots some relatively large snakes that were the usual predators of the smaller rodents, and this should have prevented Brown and his group from interpreting the data the way they did. The phenomenological experiment they conducted was not suited to answer unambiguously the question of why the number of smaller rodents had increased within the exclosure. There were at least two plausible (and not mutually exclusive) hypotheses: (a) competitive relaxation due to the removal of kangaroo rats and (b) the (unwitting) exclusion of a natural predator (snakes). ${ }^{18}$ This is a usual situation in community ecology. Since the same pattern can be a result of different processes, at some time in research, it is necessary to perform mechanismic experiments in order to tell which of those mechanisms is effectively responsible. ${ }^{19}$

Mechanismic models and experiments have other properties, such as making it easier to understand how "transportable" (from the particular system under study to other similar systems or to the same system in the future) the knowledge obtained is. In other words, understanding on how particular systems work, derived from mechanismic experiments, provides more control on the possibility of generalizing that knowledge (even though mechanismic models are inherently less general than phenomenological ones). ${ }^{20}$ Another property of such models within an ecological context, at least when performed within a reductionist framework, is (a) the possibility of obtaining quantitative predictions generated from the individual level, i.e., independently from those obtained at community level, and (b) the possibility of trying to reconstruct the processes by which communities assemble from models of processes related to individuals. Both advantages contribute to enhancing control over the results obtained through other research tactics. ${ }^{21}$

\footnotetext{
17 For details on the study see, e.g., Brown, J. H. and Heske, E. J., "Control of Desert-Grassland Transition by a Keystone Rodent Guild," Science, v. 250, (1990), pp. 1705-1707 and references therein. For further analysis on the methodological aspects of the study see Brown, J. H., "The Desert Granivory Experiments at Portal," in ReSETARITS, W. J. and Bernardo, J. (eds.), Experimental Ecology: Issues and Perspectives, pp. 71-95, and Dunham, A. E. and BeAuPRE, S. J., "Ecological Experiments. Scale, Phenomenology, Mechanisms, and the Illusion of Generality," in ReSETARITS, W. J. and Bernardo, J. (eds.), Experimental Ecology: Issues and Perspectives, pp. 27-49.

18 Cf. Dunham, A. E. and Beaupre, S. J., "Ecological Experiments. Scale, Phenomenology, Mechanisms, and the Illusion of Generality," pp. 27-49.

19 See Marone L., Lopez de Casenave, J., Milesi, F. A. and Cueto, V. R., “Can Seed-Eating Birds Exert Top-Down Effects on Grasses of the Monte Desert?," Oikos, v. 117, (2008), pp. 611-619.

20 Cf. GonzÁlez del Solar, R. La explicación en ecología, Treball de Recerca (Master's Thesis) submitted as a partial requisite for attaining the Diploma of Advanced Studies (Department of Philosophy, Universitat Autònoma de Barcelona, 2006.)

21 See Werner, E. E., "Ecological Experiments and a Research Program in Community Ecology," in Resetarits, W. J. and Bernardo, J. (eds.), Experimental Ecology: Issues and Perspectives, pp. 3-26.
} 


\subsection{Realism and Rigor in Ecological Experiments}

As we have shown in the preceding examples, ecological experiments offer interesting possibilities for advancing knowledge on natural systems. However, they also exhibit some constraints that need to be taken into account when planning their use in a given research project. In the previous section, we saw one limitation of mechanism-free experiments; now we will deal with a limitation that affects all kinds of experiments - whether phenomenological or mechanismic_-, namely the need to compromise between "realism" and "rigor."

Ecological manipulations carried out in artificial environments (e.g., the laboratory) provide maximum control on the variables of interest, as well as maximum precision in their measurements (i.e., rigor). Yet, laboratory experiments involve far less factors than those acting in natural systems, and may produce results so influenced by artifacts of the experimental technique that may end up representing little or not at all the natural facts under study. On the other hand, experiments conducted in natural settings provide maximum realism in the sense that they involve far more factors than laboratory experiments, and are less prone to be affected by artifacts. However, manipulations in natural environments are not without shortcomings, since the mere complexity of the experimental setting leaves many factors unattended, with the consequent decrease in control and/or precision (rigor). In sum, there are unavoidable trade-offs between realism and rigor in choosing the setting for an experiment. ${ }^{22}$ The fact that experiments conducted in the laboratory can yield results completely opposed to those from experiments carried out in natural environments or from non-experimental observations is a good indication of the complexity of the situation. Let us see an example.

In a study on the competitive mechanisms at play between the wood frog (Rana sylvatica) and the leopard frog (Rana pipiensis) experiments at different scales (i.e., at the lab and in progressively more natural environments) were performed. ${ }^{23}$ The goal of the study was to analyze the effects of activity level and body size on the interactions between the two types of frogs, so researchers conducted an experiment in highly controlled (artificial) conditions. Eventually, the results of the trial unambiguously showed that leopard frogs were more active than - and dominant relative to - wood frogs. In contrast, all other studies carried out by the same research group - as well as those performed by other groups - either experimental or observational, clearly indicated that the relationship between these two frogs species was exactly the other way round: It was the wood frogs which were dominant.

Because there is no way to know in advance whether - and to what extent - technical artifacts have biased the results of an experiment, it is advisable to perform several experiments with different degrees of naturalness and to include observational procedures as an attempt to answer the same question or similar versions of the question. Convergence of results coming from environments representing a gradient between complete naturalness and complete artificiality works as a control of the adequacy of its results.

22 Cf. Morin, P., "Realism, Precision and Generality in Experimental Ecology," in Resetarits, W. J. and Bernardo, J. (eds.), Experimental Ecology: Issues and Perspectives, pp. 50-70.

23 Cf. Werner, E. E., "Competitive Interactions between Wood Frog and Northern Leopard Frog Larvae: The Influence of Size and Activity," Copeia, n. 1992, (1992), pp. 26-35; see also Werner, E. E., "Ecological Experiments and a Research Program in Community Ecology," pp. 3-26. 


\section{Final Remarks}

One of the consequences of ecological systems being complex and historically contingent is that, if we wish to understand present ecological phenomena, we will often need to undertake a reconstruction of the system's past. ${ }^{24}$ As historical trajectories - and complex processes in general - are not directly accessible to our senses, observation alone will not suffice. This situation calls for other research tactics, namely experimental and theoretical ones, which can be combined with observations in order to widen and/or deepen ecological knowledge.

Richard Levins and Richard Lewontin, respectively ecologist and evolutionary biologist, have already noted the convenience of considering that it is the entities under study - and not some methodological a priori - that should dictate which are the most adequate research tactics in each circumstance. ${ }^{25}$ Thus, it is possible to think that, as inquiry advances, iterative shifts from observation to experiment (to "theory"), and back, will probably be necessary in long-term research projects, depending on what the particular questions to be answered in each stage dictate. Furthermore, such iteration between different methodological tactics provides a source of mutual control.

The cases we have briefly discussed in this paper illustrate that where one empirical tactic fails, another one may be successful, and that ecological research needs observation and experiment (phenomenological as well as mechanismic, conducted both in artificial and in natural settings) in order to advance. Consequently, we believe that much of the fervor of the methodological debates between supporters of observation (or the comparative approach) and more or less radical experimentalists seems not to be justified.

We have not provided examples on the advantages of the interaction between theoretical and empirical tactics, but we think that it is defensible in similar terms to those used here to defend the integration of observation and experiment. ${ }^{26}$ Observing, conjecturing, modeling and manipulating natural systems iteratively and at different scales would provide ecologists with an opportunity to explore the present and the past of the system under study, and eventually show whether the hypotheses put forth to describe or explain its trajectory are plausible enough to be accepted. This is a rather different view from that of the traditional methodological approach described in the introduction of the present paper, which pictures ecological research as too rigid a procedure, not taking into account that observations and experiments can serve different purposes depending on the particular epistemic needs of the research project. Not all research projects start with observations, nor are these always the source of patterns, nor are experiments always used to put hypotheses to test.

Some ecologists have defended the need to integrate the diverse conceptual constructions that coexist in ecology, ${ }^{27}$ and philosophers of different schools have preconized the unity of science at theoretical and methodological levels. ${ }^{28}$ There is, however, another possibility. This

24 Cf. Marone, L., "Los alcances y límites de la investigación en ecología evolutiva," in Gotthelf, R. (ed.), La investigación desde sus protagonistas. Senderos y estrategias, EDIUNC, Mendoza, 2006, pp. 231-247.

25 Cf. Levins, R. and Lewontin, R., "Dialectics and Reductionism in Ecology," in SaArinen, E. (ed.), Conceptual Issues in Ecology, D. Reidel, Boston, 1982, pp-107-138. The precedence of ontology with respect to methodology has also been preconized by philosophers, see, e.g., Bunge, M. A., Chasing Reality. Strife over Realism, University of Toronto Press, Toronto, 2006.

26 See Werner, E. E., "Ecological Experiments and a Research Program in Community Ecology," for an example.

27 Cf. Pickett, S. T. A., Kolasa, J. and Jones, C. G., Ecological Understanding. The Nature of Theory and the Theory of Nature, Academic Press, San Diego, CA, 1994.

28 Remarkably the logical empiricists and many realists, such as Karl Popper and Mario Bunge. 
is still a kind of methodological integration, but one that stresses tactics, rather than strategies. More precisely, we believe that the combination of observational, experimental and theoretical approaches within one particular research project offers multiple advantages. One of them is that when any particular tactic fails to guide the next step of the inquiry, it is possible that a different tactic provides such guidance, as shown by the example of Plecoptera studies. Yet, perhaps the most attractive feature of this proposal is that in the same way that consistency is one source of reliability of our knowledge, procedural integration provides a source of reliability for the results of the research project. This idea, of course, is not new. William Whewell defended the notion of "consilience of inductions" in the XIX century and insisted on the importance of the convergence of results as a source of reliability of inductions. ${ }^{29} \mathrm{We}$ believe that ecology is a field where this notion of consilience or convergence is particularly useful and deserves further development.

Concluding, methodological pluralism within one research project in ecology is an interesting possibility. Lack of constructive dialog between different forms of scientific experience and between these and theory hinders the advancement of ecological science. Each methodological approach has its possibilities and limitations, thus adherence to one of them, to be reasonable, has to be moderate. Those that deserve our sternest criticism are not the approaches in themselves, but their abusive or unjustified utilization. ${ }^{30}$

\section{Bibliography}

Alvarez, L. W., Alvarez, W., Asaro, F. and Michel, H. V., "Extraterrestrial Cause for the Cretaceous-Tertiary Extinction. Experimental Results and Theoretical Interpretation," Science, v. 208, (1980), pp. 1095-1108.

Agrawal, A. A. (ed.), "Forum. The Metabolic Theory of Ecology," Ecology, v. 85, (2004), pp. 1771-1821.

Brown, J. H., “The Desert Granivory Experiments at Portal," in Resetarits, W. J. and Bernardo, J. (eds.), Experimental Ecology: Issues and Perspectives, pp. 71-95.

Brown, J. H. and Heske, E. J., "Control of Desert-Grassland Transition by a Keystone Rodent Guild," Science, v. 250, (1990), pp. 1705-1707.

Brown, J. H., Gillooly, J. F., Allen, A. P., Savage V. M., and West G. B., “Toward a Metabolic Theory of Ecology," Ecology, v. 85, (2004), pp. 1771-1789.

Bunge, M. A., "Phenomenological Theories," in Bunge, M. A. (ed.), Critical Approaches to Science and Philosophy, Transaction, New Brunswick, NJ, 1999 (originally published in 1964), pp. 234-254.

Bunge, M. A., Chasing Reality. Strife over Realism, University of Toronto Press, Toronto, 2006.

Cleland, C., "Historical Science, Experimental Science, and the Scientific Method," Geology, v. 29, (2001), pp. 987-990.

Cleland, C., "Methodological and Epistemic Differences Between Experimental Science and Historical Science," Philosophy of Science, v. 69, (2002), pp. 474-496.

Colyvan, M. and Ginzburg L. R., “The Galilean Turn in Population Ecology,” Biology and Philosophy, v. 18, n. 3, (2003), pp. 401-414.

29 See Whewell, W., Novum Organon Renovatum, John W. Parker and Son, London, 1858.

30 See Werner, E. E., "Ecological Experiments and a Research Program in Community Ecology," pp. 3-26; and Morin, P., "Realism, Precision and Generality in Experimental Ecology," pp. 50-70. 
Connell, J. H., "Diversity and the Coevolution of Competitors, or the Ghost of Competition Past," Oikos, v. 35, (1980), pp. 131-138.

Dunham, A.E. andBeaupre, S. J., "EcologicalExperiments. Scale, Phenomenology, Mechanisms, and the Illusion of Generality," in RESETARITS, W. J. and BERNARDO, J. (eds.), Experimental Ecology: Issues and Perspectives, Oxford University Press, Oxford, 1998, pp. 27-49.

GonzÁlez DEL Solar, R. La explicación en Ecología. Research study submitted as a requisite for attaining the Diploma of Advanced Studies at the Doctorate in Philosophy of Universidad Autònoma de Barcelona, 2006.

Hacking, I., Representing and Intervening, Cambridge University Press, Cambridge, MA, 1983.

Lange, M., "Ecological Laws: What Would They Be and Why Would They Matter?," Oikos, v. 110, (2005), pp. 394-403.

Lawton J., "Are there General Laws in Ecology?," Oikos, v. 84, (1999), pp. 177-192.

Levins, R. and Lewontin, R., "Dialectics and Reductionism in Ecology," in SaArinen, E. (ed.), Conceptual Issues in Ecology, Reidel, Boston, 1982, pp. 107-138.

Likens, G. E., Excellence in Ecology 3, The Ecosystem Approach: Its Use and Abuse, Ecology Institute, Oldendorf-Luhe, 1992.

Looljen, R. C., Holism and Reductionism in Biology and Ecology: The Mutual Dependence of Higher and Lower Level Reseach Programmes, Kluwer, Dordrecht, 2000.

Marone, L., "Los alcances y límites de la investigación en Ecología evolutiva," in GotTHelf, R. (ed.), La investigación desde sus protagonistas. Senderos y estrategias, EDIUNC, Mendoza, 2006, pp. 231-247.

Marone L., Lopez de Casenave, J., Milesi, F. A. and Cueto, V. R., "Can Seed-Eating Birds Exert Top-Down Effects on Grasses of the Monte Desert?," Oikos, v. 117, (2008), pp. 611-619.

Mikkelson, G., "Complexity and Verisimilitude: Realism for Ecology," Biology and Philosophy, v. 16, (2001), pp. 533-546.

Morin, P., "Realism, Precision and Generality in Experimental Ecology," in ResETARITS, W. J. and Bernardo, J. (eds.), Experimental Ecology: Issues and Perspectives, Oxford University Press, Oxford, 1998, pp. 50-70.

Murray, B. G., "Universal Laws and Predictive Theory in Ecology and Evolution," Oikos, v. 82, (2000), pp. 403-408.

Oksanen, L., "Logic of Experiments in Ecology: Is Pseudoreplication a Pseudoissue?," Oikos, n. 94, (2001), pp. 27-38.

Peckarsky, B. L., "Why Predaceous Stoneflies Do Not Aggregate with Their Prey," Verhandlungen der Internationale Vereinigung für theoretische und angewandte Limnologie, n. 23, (1988), pp. 2135-2140.

Peckarsky, B. L., "Habitat Selection by Stream-Dwelling Predatory Stoneflies," Canadian Journal of Fisheries and Aquatic Science, n. 48, (1991), pp. 1069-1076.

Peckarsky, B. L., "The Dual Role of Experiments in Complex and Dynamic Natural Systems," in Resetarits, W. J. and Bernardo, J. (eds.), Experimental Ecology: Issues and Perspectives, Oxford University Press, Oxford, 1998, pp. 311-324.

Peters, R. H., A Critique for Ecology, Cambridge University Press, Cambridge, UK, 1991.

Pickett, S. T. A., Kolasa, J. and Jones, C. G., Ecological Understanding. The Nature of Theory and the Theory of Nature, Academic Press, San Diego, CA, 1994.

Platt, J. R., "Strong inference," Science, v. 46, (1964), pp. 347-353. 
Rosenberg, A., "How Is Biological Explanation Possible?," British Journal of Philosophy of Science, v. 52, (2001), pp. 735-760.

Roughton, R. D. and SweEney, M. W., "Refinements in Scent Station Methodology for Assessing Trends in Carnivore Populations," Journal of Wildlife Management v. 46, (1982), pp. 217-229.

SAgoff, M. "The Plaza and the Pendulum. Two Concepts of Ecological Science," Biology and Philosophy, n. 18, (2003), pp. 529-532.

Sargeant, A. B., Johnson, D. H., and Berg, W. E., "Interpreting Carnivores Scent Stations Surveys," Journal of Wildlife Management, v. 62, (1998), pp. 1235-1245.

Shrader-Frechette, K. S. and McCoy, E. D., Method in Ecology. Strategies for Conservation, Cambridge University Press, New York, 1993.

Turchin, P., “Does Population Ecology Have General Laws?,” Oikos, v. 94, (2001).

Underwood, A. J., "Design, Implementation, and Analysis of Ecological and Environmental Experiments. Pitfalls in the aintenance of Logical Structures," in Resetarits, W. J. and Bernardo, J. (eds.), Experimental Ecology: Issues and Perspectives, Oxford University Press, Oxford, 1998, pp. 325-349.

Waters, C. K., "Causal Regularities in the Biological World of Contingent Distributions," Biology and Philosophy, v. 13, (1998), pp. 5-36;

Werner, E. E., "Competitive Interactions between Wood Frog and Northern Leopard Frog Larvae: The Influence of Size and Activity," Copeia, n. 1992, (1992), pp. 26-35.

Werner, E. E., "Ecological Experiments and a Research Program in Community Ecology," in Resetarits, W. J. and Bernardo, J. (eds.), Experimental ecology: Issues and perspectives, Oxford University Press, Oxford, 1998, pp. 3-26.

Whewell, W., Novum Organon Renovatum, John W. Parker and Son, London, 1858. 


\section{SubJeCt Index}

abduction, 12

Académie des Sciences, 105

acceptability as experiment, 31

accommodation, 119n

accuracy, 32, 102

action(s), 22, 58n, 65n, 89, 101, 106-107, 129n, 132

- and behavior, 26n

- exploratory, 175

— intentional human, 26

- political, 34

- scientific, 34

- social, 24

active experiment, 21

active intervention, 75

activity(ies), 119, 142-143, 174n

- cognitive, 99, 110

- communicational, 99

— experimental, 99-100, 103-104, 109, 111

- observational, 100

- scientific, 110, 112

— theoretical, 99

actual experiment, 36

advance, 22, 34, 106, 172, 179-180

agency, 143

agent(s), 13, 34, 91-92, 94, 143

— ability(ies), 86

- act(s), 144

— beliefs, 143

- behavior, 93-94, 149

- environmental, 133

- intuitive, 95

— judgment(s), 144

— knowledge, 143

— probability(ies), 144

— single, 149

- specific, $132 \mathrm{n}$

aims, processes and results, 20, 28-30, 37

ancien régime, 127

anatomical-pathological school, 127

anonymity, 161, 165

anti-positivist reaction, $121 \mathrm{n}$

anti-realism, 13 anthropology, 58

application(s) of science, 19

applied,

— economics, 28, 38

- science, 9, 17, 19, 22, 35, 38, 94

- social sciences, $17 \mathrm{n}$

$\operatorname{artifact(s),~75,~} 179$

artifacts of experimental technique, 179

artificial,

— economic reality, $32 \mathrm{n}$

- experiment, 91

— nature, 37

artificial intelligence, 22-24, 89

assumption(s), 31, 80, 90, 102, 111, 139, 145, 147-148, 150-152, 160-161, 163, 173

- auxiliary, 89

— background, 75n

- behavioral, 32

- domain, 31

— economic, 85

- heuristic, 31

- invariance, 145,151

— justification of, 151

- negligibility, 31

— theoretical, 79-80, 89, 147, 149

- unreal, 31

asymmetry between explanation and prediction, 12

audition, $118 \mathrm{n}$

auscultation, 118n, 120, 122, 133

axiom(s), 161-162, 164-166

Baconian tradition, 58

basic science, 9, 17, 22, 35, 38

behavioral science(s), 89

biology, 10, 30, 71, 91, 111, 142

biomedical science(s), 67

biotechnology, 67

black box, 101

BSE (mad cow disease), 56n

budget, 59, 66, 88

business firm(s), 94 
capital holders, 65

category(ies) of scientific practices, 99

causal,

— analysis, 152

- assertions, 147

— asymmetry, 143

- attributions, 148, 152

- claim(s), 146

- explanation(s), 141

— inferences, 146

- $\operatorname{link}(\mathrm{s}), 54 \mathrm{n}, 140$

- mechanisms, 141-142

- process(es), 122n, 141

— property(ies), 79

— relation(s), 139, 177

- structure, 150

- subject, $127 \mathrm{n}$

— theory of time, 139

- transience, 150

causality, 21, 139-140, 142-144, 146-149, 151-152

- aleatory, 141

- and explanation, 152

— in mechanical terms, 141

- manipulative, 152

— probabilistic notion of, 139-141, 145-146, 152

— statistical, 141-142

— token, 140, 142, 151

- type, 140

causation, 141, 143, 150

— asymmetry, 142

- general, 140

- physical, 142

— shift, 146

- singular, 140

— token, 140, 144, 149-152

- type, 140, 149-152

cause(s), 13, 126-127, 145, 151, 176-177

- actual, 150

- common, 144

— disturbing, 73-74, 77

- effective, 144

- final, $127 \mathrm{n}$

- genuine, 139

- immediate, $127 \mathrm{n}$

- of death, $127 \mathrm{n}$

— past, 176 ceteris paribus, clause(s), $74 \mathrm{n}$

change(s), 34, 54-55, 62, 76, 80, 86, 88-89, 92, $124,129-134,142,144,148,178$

- climate, 81

- conceptual, 129

- cultural, 62

- environmental, 176

- global-climatic, 176

- hypothetical, 165

- revolutionary, 130n

- substantial, 130

- theoretical, 80

chaos, $90,119 \mathrm{n}$

chemistry, 11, 91

Child Poverty Action Group, 59

classical determinism, 140

classical mechanics, 72

clinical,

- observation, 117-118, 120, 127, 134

- practice, 118, 125

— trials, 12

cognitive psychology, 86,90

cognitive science(s), 23-24, 71, 100, 111

coherence, 103

coherentist thesis, 103

complex, 53, 62n, 76-77, 81, 87, 93, 101, 105, $112,131,143,149,164,171,173,180$

— information processing, 23

- phenomena, 71

- reality, 28

complexity, 17, 36, 87, 91, 93, 100-101, 107-108, 111, 179

computational models, 23

computer,

- based observation, 80

- experiments, $37,71-76 \mathrm{n}$

- models, 91

- science(s), 24, 85, 89

— simulation(s), 10, 23-25, 31, 34-37, 92, 94

— tournament(s), 36

computerisation, 77

concepts of experiment, 10

conceptual innovation, 134

conditional contracting extreme(s), 162

confirmation, 14 ,

consilience of inductions, 181

context of discovery, 151 
control, 72, 91, 109, 111, 166, 178-179

- lack of, $74 \mathrm{n}$

- mutual, 180

— of conditions, 179

- of economic conditions, 30

— of economic variables, 148

- of social conditions, 30

- of the environment, 30

- of the phenomena, 11, 25, 36

— of variables, 12, 25, 27, 31, 37, 73, 77, 107-108

— process(es), 28

controllability, 92

controlled experiment(s), 27, 142

controlled observation, 18,89

convergence, 181

Copernican turn, 127

corpuscle(s), 79n

counterfactual(s), 142, 144-145, 151

- assumptions, 151

— theory, 144

crucial experiments, 108, 176

DAG (directed acyclic graphs or Bayesian Networks), 149-150

data, 27, 72, 74-80, 87, 94, 99-101, 107-108, 110n-111, 119-120, 127, 129, 147, 150, 159, $163,172-173$

— analysing, 21,

- auscultatory, 122

- available, 17

- basic, $119 \mathrm{n}$

- clinical, 122, 134

- ecological, 173-174

- economic, 35

- experimental, 93, 101, 103

- generation process, 21, 107-108

- model, 78n

— non-experimental, 149

- neutral, 121

- observable, 78, 147, 149

- observational, 17, 100-101, 121

— primary, 26

- raw, 174

- real, 93

— weight, 80

decision-making, 22-23, 62, 64, 86, 88-94, 104, 130

decisive experiments, 108

decision-theoretic approach (DT), 151 deduction, 12, 159

deliberation, 143

description, $62,75,89,94,112,122-123,129$ n, $142,146,171-173$

design, 28, 72, 108, 149, 171, 174

— basic, 167

- experimental, 23, 29, 106, 161, 163-164, 168

- human, 20

— institutional, 167

- particular, 174

development, 181

— of microbiology, 132

- scientific, 72, 76, 129-130

- technical, 106n

— technological, 133

- theoretical, 106, 159

direct control, 31, 92

discovery(ies), 55, 129

disease(s), 118-120, 123-130, 132-134

disturbance, 147

ecological community, 177

ecology, 172, 173n, 176, 180-181

- classical community, 177

- community, 171, 177-178

- science of, 171

econometric models, 37, 146-147

econometrics, 21-22, 37, 144, 146-149

- as a case of experimentation, 21

- case, 31, 92

- experiment (s), 21

- research, 21

economic(s), 10, 18-19, 22-23, 28-30, 35, 55n, $58-59,64,85-87,89-94,142,149,164 \mathrm{n}$

- $\operatorname{activity(ies),~21,~36,~} 93$

— affair(s), 32, 51, 57

- application, 87

- behavior, 23, 28, 86-88

— crisis, 59

- $\operatorname{cycle}(\mathrm{s}), 62$

— decision(s), 91

- descriptive, 28

- event(s), 36

- experiment(s), 20, 95

- method(s), 23

- participant(s), 32

- phenomena, 22, 28, 36, 87

- process(es), 28, 91

— research, 28, 90, 94-95

— tendency, 87-88, 90 
economic agents, 22, 28-29, 86-87, 92-93, 147, 149

economic models, 93, 95

economic science, 85

economy, 21, 59-60, 62, 64, 128, 160

economy event(s), $67 \mathrm{n}$

Edinburgh School, 34n

effect(s), 13, 79, 103, 140, 142, 144, 148, 151, 177

empirical,

- assertion(s), 72

- event(s), 75

- knowledge, 13, 26, 91, 93, 173n

- phenomena, 12, 17

- science(s), 9, 17, 22, 24, 31

- studies, 33

empiricism, 75, 100, 109, 130n

- constructive, 14

- extreme, 130

- logical, 13-14, 86-87

ends, procedures and outcomes, 11

engagement, 51

engineering, 71

epistemology(ies),

- civic, 66-68

— of experimentation, 9-10

- of observation, 9-10, 12

- empirical, 85

- national civic, 67

- new, 81

- pluralistic, 146

Erklären-Verstehen controversy, 18, 20

ethical,

— argument(s), 161

— impossibility(ies), 176

— judgement(s), 159, 163-164, 168

ethnomethodology, 10, 33

evolutionary biology, $36 \mathrm{n}$

exogeneity, 147-148

expectation(s),

— rational, 85, 92-93

- subjective, 88

experienced expert(s), 53, 57-59, 63, 66

experiential knowledge, 61

experiment(s), 10-11, 13, 19-21, 27-35, 58, 72-74, 77, 81, 91-93, 99, 102-108, 110, 112, 145, $149,159-160,163,166-168,171-173,175-178$

- analysis of, 19n

- as a common ground, 20

- as a human activity, 30

- as active interference, 30

— as human intervention, 27
- as intervention, 30

— as methodological procedure, 18

— by theory, 11

- conduct, $175 \mathrm{n}$

- demonstration, 73

- diversity of, 10, 29, 31, 92, 109

- ecological, 179

- external view, 33

- hypothetical, 145

— interpretation, 149

- $\operatorname{limit}(\mathrm{s}), 18$

- material, 72-73, 78

- mechanism-free, 175,179

- mechanismic, 178

- outcomes of, 11

— particular, 146

- perturbation, 177

— phenomenological, 175-180

- prototype, 102

- regular, 73

- replication, 104

— research, 123

- role, $18,74 \mathrm{n}$

- series of, 107-108

- successful, 107

— traditional view, 30

— trial(s), 101

— uncontrolled, 21

experiments,

— in applied science, 27

- in basic science, 27

— in economics, $27,74 \mathrm{n}, 95$

- in natural sciences, $17 \mathrm{n}$,

— in social sciences, $27,30,32,74,95$

experimental,

- control, 18, 38, 91

- criteria, 109

- economics, 19-20, 30, 32, 90-93, 95

- philosophy, 99

— research, 32, 105, 107-109n, 112

- validity, 110

experimentation, $6,9-13,17,24,27 \mathrm{n}, 37-38$, 79n, 85-86, 94, 99-100, 102, 107, 110-112, 119n, 139, 142-146, 149, 151-152, 159-161, 163-164, 166-168, 172

- as tool, 145

- conception, 20

- controlled, 30, 142

- dynamics, 103, 106

- external validity, 32-33

— in human affairs, 19 
— in science, 4-5

— in social sciences, 20n-21,

— internal validity, 32-33

- material, 71

— problem of, 10,18

- process of, 11

- reliable, 32

- scientific, 34

- social dimension, 34

experimentum crucis, 104-105, 108

expert patient, $55 \mathrm{n}$

explanation(s), 38, 54, 80, 100, 105, 120, 129n, 140-141, 144, 150, 152, 171

- etiological, 132n

— historical, 177

- manipulationist conception, 145

- physical, 79, 123n, 132

- scientific, 5, 12, 123

explicativity, 140

Explanation-Understanding, 18, 26

exploration, 119, 121-122, 126, 134

external validity, 10

fallibilism, 26

field experiments, 28

forecast, 147

foundational propositions, 16

Friedman's dictum (F-twist), 31

functionalism, 146

Galaxy, 77-78, 80-81

Galenism, 133n

game theory, 20, 92-93, 95

Gestalt, 16, 75, 129

Gestalt shift, 130

Gestaltsehen, 130

geometrical optics, 102, 109

goals, proccesses, results, 85

goods and services, 88

Great Depression, 62n

Hippocratic-Galenic tradition, 124, 133

historical,

— data, 36n

- knowledge, 26

- science, 176

— turn, 19n history, 18, 30, 58, 117

— of experiments, 78

— of medicine, 54n, 117-118

- of science, 13, 28, 104

Homme physique, 133

Homme morale, 133

human,

— activity(ies), 28, 34, 87, 93

— affair(s), 19, 27

— agency, 119n

- behavior, 23, 36, 90, 92, 160-161

- community, 131

- event(s), 18

- intervention, 28

- motivation, 94

- psychology, 161, 168

— rationality, 89-90, 94, 100

— science(s), 58, 86

Hume dictum, 159

Huw Price's perspectivalism, 141

hypotheses, 13, 31, 37, 75, 80-81, 90, 120, 122, 172-177

- a priori, 85

- behavioural, 161

- causal, 125, 127, 134, 177

- ecological, 174-176

— formal, 28

— fundamental, 160

— indicator, 174

- mechanismic, 177

— plausible explanatory, 178

— plausibility, 176n

- scientific, 86

— theoretical, 77-78

hypothetico-deductivism, $173 \mathrm{n}$

impartial reasoning, 164

incoherence, 103

incommensurability, $75 \mathrm{n}$

independent reality, $74 \mathrm{n}$

indirect control (statistical control), 31, 92

induction(s), 12, 85, 181

inductive practice, 125

inductive process/method, 12-13, 25 
information, $22,35,37,75-77,80,86,94$, $103,108 \mathrm{n}, 134,142,146-147,149-151$, $164,176 \mathrm{n}$

- clinical, 11, 117, 133

- experimental, $54 \mathrm{n}$

- medical, 132-133

— restricted level, 160

- scientific, 51, 57

input(s), 72

input(s) mathematically modelled, 77

instrument(s), 11, 30, 71-72, 74-76, 78, 104n, 111, 119-123, 129-130n, 134

— analytical, 117

- application, 72

- clinical, 120

- innovative, 122

- key, 124

- mathematical, 85

- mechanism, 122

- medical, 117

- scientific, 104, 118

- standardized, 106

instrumentalisation, 132-134

instrumentation, 111, 118

interpretation, 130, 142

intervention, 10, 71, 92, 99, 112

interventional regime, 151-152

intuition(s), 94, 141, 151, 163

justice, 163, 166-169

- experimental method(s) of, 163

- principle(s), 167

— theories, 163, 166-169

justification, 102-103

knowledge, 55-58, 61n-67, 74, 76, 81, 89, 99, $123,127,143,146-147,166,178$

- a priori, 85

- accumulated, 57

- accurate, 63

— articulated, 58, 67

— available, 54

— boundary(ies), 55, 144

- case-based, 54n

- complementary, 62, 64

— craft, 58

- current, 77

- ecological, 173-174, 180

- economic, 29, 92

- expert, 58

- factual, 57

- future, 26

- general, 63

- human, 14n, 24, 26

- medical, 52-55, 123, 128, 130

- model, 172

- moral, 164

- new, 26

- objective, 14

— personal (o experienced), 56-59, 61-68

- professional, 62n

- reliable, 27-28

- social science, 56, 66

- social scientist, 57,68

- statistical, 57

— tacit, 58, 66

- technical, 66, 109

— theoretical, 93, 129, 147, 159

- useful, 171

— valid, 67

laboratory,

— data, 132n

- economics, 37, 93

- experimentation, 28-34, 38, 71n, 73, 76-77, 79,179

— medicine, 121n, 132

- research, 86

law(s), 16, 65-66, 140, 143-144, 151-152

- ecological, 171

— fundamental, 79

- general, 142

— theoretical, 27

linguistic turn, 100, 110

linguistic vision of observation, 15

Logic of science, 5

logic of science, $99-100$

logical positivism, 13-14

logicism, 110

logicistic approache(s), 100

Lorenz curve, 164-166

manipulability, 141, 143, 145-147, 149

manipulation(s), 38, 72-73, 75, 111, 140, 145n, $148-150,152,175$

- ecological, 179

- experimental (material), 76, 78 
- simulated, 76

— systematic, 119n

material,

- agency, 119n

— object, 72, 74-76, 80

- procedure, 101-103, 109, 111

- resistance(s), 111

materiality, 71, 92

mathematical (or statistical) models, 10, 21, $32,35,37-38,73,80,92,109-110$

mathematics,

- demonstration, 73

- methods, 20,

- tool, 87

mathematisation, 107

maximin principle, 162-163, 165n

maximization, 22, 88-89

mechanicism, 142-143

mechanism(s), 143, 175-176n

- distributive, 161, 167, 169

— random, 176n

mechanism schemata, 143

mechanismic, 176n

mechanistic, 176n

medical,

— instrumentalisation, 132

— instrumentarium, 134

- microbiology, 132n

- practice, 119, 124, 132-134

- science, 56, 67, 128

- tradition, 122, 126

- treatment, 55

medicine, 11-12, 122, 125, 127-129, 131-132, $134-135,142,152$

- clinical, 117, 127-128, 130

- hospital, 128

- modern, 117, 132

- private, $54 \mathrm{n}$

- scientific, 117-118, 125

— veterinary, 124

— Western academic, 133

methodology,

— of economics, $85 \mathrm{n}$

- of experimentation, 9-10, 86

- of observation, 10-12, 86

— of science, 19, 33, 38

microeconomic theory, $161 \mathrm{n}$

Milky Way, 77-78 model(s), 17, 24, 27, 58, 71-74, 77, 80, 85-86, 88, 94, 99-101, 106-107, 110-111, 129, 139, $142,146-152,159,163-164,169,175 n-176$

— as definition(s), 163

- as mediator(s), 110n

- assumption in, 31, 92

- causal, 150

- deficit, 52, 62

- descriptive, 35, 90

- experimental, 35, 163

- explicit, 168

— formal, 169

- human psychology, 160-161

— ideal, 86

— influence(s), 176n

— instrumental, 101-104, 106, 109, 111

- intervention, 73

- linear, 147

- mechanismic, 178

- micro and macro, 148

— normative, 90

— object, 76

- of equality, 163

- phenomenic, 101-103, 105-106, 109, 111

— rational agents, 90

- realistic, 89

- research, 52n

- role of, 168

— sampling, 147

- simple, 90

- simplified, 77, 147

- statistical relevance, 141

- strategy(ies), 23

- structural, 147

— theoretical, 36, 78, 80, 101, 119, 134, 147

— traditional, 77

— triadical, 99

models,

- geometrical, 109

— in natural sciences, 5

— in social sciences, 5

— physical, 79

moderate egalitarianism, 161-163

modern naturalist school of philosophy of science, 119

MMR (Meanles, Mups and Rubella), 51-53, 55

- case, $52-53,55 n$

- debate, 56n

— vaccine, 51-52, 54-55, 58

moral intuition(s), 163 
National Health Service, 59-60

natural science(s), 9-10, 17-18, 20, 22-23, 26,

$28,31,35,51,55,61-63,67-68,91,118$

natural experiments, 20-21

Nature, 20-21, 103-104, 106, 125

nature-ladenness, 103

neoclassical,

- economics, 22, 86

- formalism, 90

- theory, 91

neurobiology, 142

neuroeconomics, 22 ,

neuroscience, 23,111

new experimentalism, 78, 99

new scientific realms, 23

Newton's models, 106

NICE (National Institute for Clinical

Excellence), 55

Nobel Prize in economics, 86, 90, 93, 95

non-experimental observations, 176-177, 179

non-manipulative observations, 171

normal science, 129

objectivity, 74n, 121

observable characteristic, 14

observable event, 15

observable

— fact(s), 17

- object(s), 87

observation, 9-18, 20, 23-27, 35-36, 38, 51, 53-54, 58, 62, 67, 71, 74-75, 80-81, 85-88, $99,106,111,117,119 \mathrm{n}, 121,125,130-131$, 139, 149, 152, 171-177, 180

- actual, 25

— as a methodological tool, 18

— as an active process, 15

- as an effective cognitive control, 10

- as human activity, 17

- as human skill, 11

— as test, 13, 18

— direct, 85, 87, 174

— different from experiment, 13

- ecological, 173-174

- empirical, 72

— ends, 11

- expressions, 14

— indirect techniques of, 173
— individual, $55 \mathrm{n}$

- limitation, 16

- loaded, 16

- new, 13

- of nature, 14

- outcome of, 11

- participant, 34

- naive, 15

- neutral, $121 \mathrm{n}$

- personal, 57

- predicate, 14

— problem(s), 16

- procedure/process of, 11-12, 15

- scientific, 4, 25, 72, 91, 121, 173

- sentence, 14

— spectroscopic, 77

— statement(s), 11, 14-17

- superficial, 94

— traditional, 51

observation,

— in applied science, 11

— in basic science, 11

- in empirical science, 11

— in natural science, 10-11

- in science, 5, 10-11

- in social sciences, 10

observational regime, 151-152

Official Secrets Act, $65 \mathrm{n}$

One Parent Families, 59

one sign-one lesion principle, 121n, 123

paradigm(s), 16, 100, 129

- anatomical-pathological, 134

- change, 134

- clinical-nosological, 132

- dominant, 131-132

- medical, 124

passive data, 21

passive experimentation, 21, 31, 92

pathology, 119

pattern(s), 172, 175-178

perception(s), 14, 111, 119n, 121, 123, 167

- active, 122

- negative, 167

- passive, 122

perspectivalism, 143

phase(s), 99-100, 109-111, 143, 172 
philology, 18, philosophy of religion, 110

philosophy of science, 5, 19-20, 33, 72, 85n, 99-100, 103, 110-111, 117, 119

philosophy of experimentation, 112, 134

phlogiston theory, 75n

physical optics, 107

physics, 11, 17, 30, 71, 91, 111, 122, 141, 151

— principle(s), 76

— theory, 76

Pigou-Dalton principle of transfer, 165-166

policy(ies), 28, 61

- economic, 59-60, 66, 148

- health, $55 \mathrm{n}$

— instruments, 149

— intervention, 147

— orient public, 167

— public, 93-94

— welfare, 167

political science(s), 31

Popperian rationalist epistemology, 85

potential inference, 38

potential response (PR), 150-151

precision and accuracy, 32n

predictability, 147

prediction(s), 12-13, 17, 21, 29, 91, 101, 129n, $140,142,146,148-150,152,168,171-172$

— as test, 29

- efficiency, 107

- falsify, 29

- problem of, 16 ,

- quantitative, 178

- scientific, 32

- successful, 31

— theoretical, 102

predictive knowledge, 171

predictive models, 147

predictive success, 110

premise(s), 87

prescribe, 17

prescription(s), 38, 88, 163

prescriptive models, 35

Pre-theoretical observation statements, 11

principle of common cause, 139

principle(s),

— of justice, 160

— of Pareto, 162n

— of Personal Good, 162
— of population, 165

- of scale invariance, 165

probability(ies), 5, 143-144, 149

- conditional, 144, 151

— reasoning, 53

— theory, 92

probabilistic causation, 5

probing patterns, 175

problem solving, 90

progress, 22, 100, 110, 128

progress in social sciences, 18

prognostic, 120, 128

protocol sentences (protokollsätze), 14

psychology, 18-19, 22, 33, 58, 86-90, 95, 111, $142,152,160$

rationalism, 12, 100

rationality, $23,66,86,89,93,163 \mathrm{n}$

— bounded, 22-23, 85-86, 89-90, 93

- economic, 90

— imperfect, 89

— in decision making, 91

— perfect, 89

realism, $75,80,86,179$

— instrumental, 145

- maximum, 179

reality, $76,80,88,129$

- computerised, 75

- economic, 86-87

- material, 75

reasoning, 53n, 88, 94, 123, 126

received view, 13-14

reductionist, $176 \mathrm{n}$

regression, 130n

regularity(ies), 28, 74, 111, 125

- advanced, 93

— empirical, 93, 172

— social ("partial regularities"), 30

relative autonomy, 110, 112

relevant evidence, $75 \mathrm{n}$

repeatability, 21, 27-28

replicability, 21,

representation(s), 25, 76, 110

- computerised, 72, 76

— idealised, 72, 80

— imitative, 35

- mathematical, 79

— of material object, $74 \mathrm{n}$

— realist, 76 
representativeness, 60

reproducibility, $21,27,30$

research, 33, 35, 62, 71, 93, 112, 130, 173, 175, 180-181

- ecological, 171-173, 177, 180

- empirical, 159, 167

- experimental, 123, 180

- hospital, 131

- medical, 53, 124, 132n

- scientific, 19, 24, 33, 71, 106, 110, 168

- social, 65,91

— strategy, 173

- $\operatorname{tactic}(\mathrm{s}), 178,180$

— theoretical, 180

Restauration, 122

revolution, 129-130

— agent, 130

- anatomical-pathological, 117, 124, 129-132, 134

- cognitive, 86,88

- French, 127

— in medicine, 117, 129

— Kuhnian, 117

— political, 127, 129

— scientific, 129-130

rigor, 179

satellite Hipparcos (ESA), 77

science(s), 30, 33-34, 59, 61, 66, 71, 78, 85, 87, 106n, 110, 117, 119, 121, 126, 128, 173, 180

- activity(ies), 20, 100

- agricultural, 67

- as a human activity, 11, 19

— as experimental philosophy, 112

- as knowledge, 19n

- as practice, 121,134

— as social endeavor, 86

- ecological, 181

- economics, 10, 18, 22, 86

- exact, 125

— laboratory, 103

— management, 58

- mathematical, 107

- modern, 12, 28, 99, 106

- of design, 9-10, 22-23, 25-26, 35

— of the artificial, 9-10, 22-24, 26, 31, 35

— traditional, 10, 22, 61 scientificity, $54 \mathrm{n}$

scientific,

- community, 63, 72, 99, 102, 108, 110, $129 \mathrm{n}-130$

— enquiry, 52

- knowledge, 19, 51-52, 55-57, 62-63, 66-67, $71,76,78,80,100,110$

- practice, 19, 110, 119n

semi-material object, 72, 75-76, 80

sense and reference, 26

sense data, 15

sensitivity, 120

sensorial data, 126

simplicity, 71

Simpson's paradox kind, 140

simulation(s), 10, 23, 26, 31, 34, 36, 71, 73, 75, 77-78, 80-81, 92

— analog, 23

- as approximation to facts, 35

- as new experiment, 34

- cognitive processes, 23

— formal, 91

— digital, 25

— imitative, 25

- innovative, 25

- of human thought, 24

- of mental state(s), 24

- of phenomena, 80

Snell's law of refraction, 105

social,

— affair, 51, 57

- constructivism, $74 \mathrm{n}$

- construction, 103-104, 106

- science(s), 9-10, 17-18, 20, 22-23, 26, 28, 30, 35, 55-56, 58, 61-64, 66n-68, 71, 86, 89-91, 142, 151-152

— turn, 33-34n

social-ladenness, 103

society, 87

sociological reductionism, 100, 103-104

sociologism, 100, 110

sociology, 18, 58, 100n

specificity, 120

stabilization, 103-104

stake-holders, $67 \mathrm{n}$ 
standard economy theory, 88

state of affair(s), 75

statistical,

- assumptions, 21

- control, 21, 92

— data, 32, 37, 53

- experiments, 21 ,

- models, 35, 147, 151

- relevance, 141

statistics, 5, 146

— analysis, 57

— inference, 78

stethoscope, 118-121, 133-134

Strict Priority to Equality Promotion, 162

STS (Science, Techonology and Society), 100n

symmetry between explanation and prediction, 12

system(s), 33, 77, 80, 148, 169

- classificatory, 131

- codification, 123

- complex, 142-143

- ecological, 180

- economic, 147

- empirical, 71

- experimental, 76

- health care, 131

- manipulated, 145

— material, 71, 73-74n, 76, 80

- natural, 179-180

— particular, 178

- redistributive, 167

— semi-natural, 176

- symbiotic, 120

— unmanipulated, 145

technic(s), 72, 99, 106, 111-112, 118, 149, 171, 174

- basic, 106n, 120

- computational, 72

- econometric, 87

- experimental, 129, 179

- primitive, 106n

technics-ladennes, 103

techniques, 63, 72, 121, 123, 132, 174

- auscultation, $118 \mathrm{n}$

- controversial, 122

— scattering, 79

- usual, 118

technology, 33, 63, 66, 72, 106n, 134

test(s), 28, 149

- conditions, 31

— of hypotheses, 119n, 122, 175, 180
— of knowledge, 103

- of prediction(s), 172

— of theory(ies), 11, 27, 29-30, 74-75, 159

— statistical, 94, 147

theoretical advances, 169

theoreticism, 100, 107, 111

theorisation, 112

theory(ies), 16-17, 27, 31-33, 63, 74-75, 77-80, $85-87,92,99,102,106-112,119-121,128$, 147, 150-151, 159, 168, 172-173, 175n, 180

— actor-network, 119n

— building, 172

- causality, 142, 146, 151

- causation, 139, 144-145

- choice, 88

- consequentialist, 161, 168

- decision, 86, 91

- descriptive, 94

— deterministic economic, 147

- distributive, 160-161, 164, 167, 169

- distributive justice, 159, 163, 168

- economic, 28, 30, 34, 74n, 93-94, 147

- egalitarian, 161, 164

— ethical, 160

— evolutionary, 177

- explanation, 142

— formation, 110

- high, 101-102

- limitation (s), 16

- mechanical, 140, 142-143n

- medical, 122, 130, 132

- normative, 159, 168

— of colours, 107

— of light, 105

- of perfect rationality, 89

- phenomenological, 176n

- physical, 102, 120, 123, 134

— political, 34

- relation with experiment, 34

- rival, $121 \mathrm{n}$

- scientific, 15, 17, 71, 85n, 110, 119, 146, 160-161, 168

— statistical, 140

- sustainability of, 163

— traditional, 172n

— validity, 159

— wave, 102 
theory-change, 80

theory-free observation, 80

theory-ladenness, 10, 16-17, 74-75, 80, 103,

$112,175 n$

theory of knowledge, 26

thought-collective (Denkcollectiv), 130n

thought experiments (Gedanken experiment), 10, 21, 25, 30-32, 35-37, 92

thought-style (Denkstil), 130n

time-series data, 35

truth, 78, 103, 107

Tungodden's model, 163

uncertainty, 89, 92-93, 103-104, 168

undetermination (of scientific theories and data), 16-17

understanding, 51, 100, 117, 119, 121, 124, 127n, 129n, 150, 178

- conceptual, 101

— traditional, 53

undeterminated noise (unbestimmte

Geräusche), 123n

utility, 88-89, 103

- function, 87-88

— maximization, 87-88, 90, 93

validity,

- external, 32-33, 163-164n, 167-168

— internal, 32-33, 163-164, 168

value(s), 27, 32, 58, 78n, 100, 118, 120, 128, 149-150, 161

— absolute, 164

- assumed, 150

- contextual, 33

— epistemic, 129
- external, 33

- local civic, 66

— predictive, 94

— right political, 58

- scale of, 87

- semantical, 126

- semiological, 123n

value-laden, 164

variable(s), 27, 148, 175

— behavior of, 93

- contextual, 94

- control, 179

— controllability, 31-32, 92

— instrument, 149

- observable random of, 147

- range of controllability of, 31, 92

— statistical, 149

- theoretical, 147

veil of ignorance, 164, 167-168

verifiability, 14 ,

verification, 14, 89, 93

verificationism, 85

verisimilitude, 72

Vienna's Circle, 85

virtual experiments, 35-36, 72-73

virtually experiments, 35n, 73, 75-76, 78, 80

voice(s), 51, 62, 64-65, 68

- amplification, 123n

- contrast with engaging, 66

— public, 60

Wesley Salmon's probabilistic mechanicism, 141

white box, 101

world-changes, 129n-130 


\section{INDEX OF NAMES}

Achistein, P., 38

ACKermann, R. J., 119, 135

AgAzZi, E., 5, 72, 74n, 81

Agrawal, A. A., 171n, 181

Alcolea, J., 12n, 19n, 41, 48, 150n, 155

Allen, A. P., 181

Alvarez, L. W., 176n, 181

Alvarez, W., 176n, 181

Amiel, Y., 164-167, 169

AMpère, A. M., 108

AMSTERDAMSKA, O., 54n, 68

Anderson, E., 60n, 68

Andersson, G., 48

Anguera, M. T., 38

Arabatzis, T., 107n-108n, 112

Aristotle, 13, 38

Asaro, F., 176n, 181

Auspitz, J. L., 97

Ávila, A., 93n, 95

Ayer, A. J., 13n-14n, 38, 42

AXELROD, R., 36, 38

BACHELARD, G., 121n

BACON, F., 12-13, 38

BAILlie, M., 125n

BALSOM, A., 57

Bar-Hillel, M., 160, 163, 170

Barberousse, A., 25n, 39

BARdsley, N., 39

BARNes, B., 34, 39

BAYle, G. L., 122n, 126-127, 135

BEATTY, J., 95

Beaupre, S. J., 175n, 178n, 182

Beauvalet-Boutouyrie, S., 128n, 134n-135

Bentham, J., 88

BERG, W. E., 174n, 183

Bernardo, J., 172, 175n, 178n-179n, 181-183

Bichat, X., 125, 127-128, 131

BIRD, A., 129n-130n, 135

Birtalan, G., 118n, 135

Blaug, M., 19n, 47

Boden, M., 25n, 46

Bö̈R, L., 134n
Bogdan, R., 155

Bogen, J., 9n, 13n, 33n-34n, 39, 78, 81, 101, 112

Boissier de Sauvages, F., $125 n$

Boltzmann, L., 100

Bonome, M. G., viii, 5, 85

Boumans, M., 4, 21n, 30n-31n, 39, 55n, 92n, 95

Bowker, G. C., 131, 135

BREWER, M. B., 121n, 137

BRIGHT, R., 132

Bromberger, S., 44

Bromiley, Ph., 22, 87

Broussais, F., 122n

BRown, H. I., 39

Brown, J. H., 177-178, 181

Buchwald, J. Z., 99, 107n, 112

Bunge, M. A., 176n, 180n-181

ButTs, R., 141n, 154

Callon, M., 121n

CAMpaner, R., 143n, 152

Campbell, D., 33n, 39

CARNAP, R., 85-86

Carreras, A., 13n, 40, 81

Cartwright, N., 99

Chakravarty, E. F., 11n-12n, 39

Chang, H., 17n, 39

Chapman, J. W., 166n, 169

Clark, P., 5

Cleland, C., 176n, 181

Cohen, I. B., 30n, 43

Colburn, T., 24n, 39

Collins, B. E., 121n, 137

Collins, H. M., 52n, 61n, 66n, 68, 99-100n, 102-104, 106, 109, 112, 122, 135

Colyvan, M., 171n, 181

Concato, J., 12n, 39

Connell, J. H., 177n, 182

Cooke, R., 147n, 153

Coombs, C. H., 20n, 42

Copeland, A. H., 39

Copeland, B. J., 25n, 39

Corry, R., 144n, 154

Corvisart, J., 123n, 127, 133 
Costantini, D., 5, 147n, 150n, 152n-154

Cover, J. A., 78n, 81-82

Cowell, F., 164-167, 169

Craver, C., 142-143, 152, 154

Creech, A., 57n, 68

Cueto, V. R., 178n, 182

Culp, S., 39, 122, 135

Cummins, S. C. J., 39

Curd, M., 78n, 81-82

Cyert, R. M., 39, 88, 95

Dalton, E. H. J. N., 165-166

DARDEN, L., 142-143, 153-154

Dasgupta, S., 5, 86n, 89n, 95

DASTON, L., 95

Davis, D. D., 39

DAvis, R. L., 20n, 42

Dawid, PH., 150-151, 153

D’Azyr, V., 127-128

DEN Butter, F., 55n, 67n-68

Devooght, K., 159n, 169

Dieks, D., 36n, 41

Diller, A., 26n, 39

Divine, W. R., 85n, 96

Dowe, PH., 142, 153

Downie, R., 54n, 68

DufFin, J., 120n-121, 127n, 133, 135

Dummett, M. A. E., 13

Dunham, A. E., 175n, 178n, 182

Dunwoody, S., 55n, 68

EARMAN, J., 12n, 45

Eavey, Сн., 160-161n, 163-164, 167-169

ECHEVERRÍA, J., 74n, 81

EDWARdS, P. N., 44

Einstein, A., 30n, 39, 103

ENGLe, R. F., 148, 153

EvANS, R., 61n, 66n, 68

FARADAY, M., 79

FAure, O., 127n-128, 135

FEINBERG, J., 166n, 169

FERBER, R., 40

Ferreirós, J., viii, 5-6, 99-100n, 109n, 112

FetZer, J. H., 26n, 40

Feyerabend, P. K., 121, 135

Feynman, R. Ph., 103

Fine, A., 119n, 135

FIRES, J. F., 11n-12n, 39

FisHER, R. A., 10n
FitzGerald, M., 52n, 68

FLECK, L., 130n, 135

FLORIDI, L., 24n, 26n, 39-40

FODOR, J., 75n

Forbes, J., 118n, 135

Forbes, M., 119n, 135

FORD, K. M., 24n, 46

FouCAULT, M., 125-126n, 134n-135

FourCrouY, A., 127-128

FRANCESCHELLI, S., 25n

FrankLIN, A., 9n, 40, 99, 102n-104n, 109, 112, $119,122,135$

FrenCh, P., 146n, 155

FRIEDMAN, D., 30n, 40n

Friedman, M., 31, 40, 85n

Friedrich, C. J., 166n, 169

FRISCH, R., 147

Frohlich, N., 160-161n, 163-164, 167-169

Galavotti, M. C., ix, 4-6, 9n-10n, 20n, 23n, $32 \mathrm{n}, 40-41,46,91 \mathrm{n}, 95,139,141 \mathrm{n}, 147 \mathrm{n}$, 149 n-150n, 152-154

Galileo Galilei, 13, 111

Galison, P., 19n, 40, 99, 135

Gambetta, G., 147n, 149n, 153

GasparsKi, W. W., 97

GAYON, J., 5

GIERE, R. N., 71

Gigerenzer, G., 22n, 46, 95

GINGERICH, W., 22, 87

GilberT, W., 111

Gillies, D., 5, 17n, 40

Gillooly, J. F., 181

Gilman, D., 40

GinZBURG, L. R., 171n, 181

GlenNAN, S., 142, 153

Glymour, C., 24n, 40, 46

Goethe, J. W. von, 107

Goldman, A., 24, 26n, 40

Goldstein, J. H., 55n, 68

Gomez, A., viii, 5-6, 40, 71, 74n, 81

GonZalez, W. J., vii, 3, 5-6, 9-10n, 12n-13n, $17 n-20 n, 23 n, 26 n-27 n, 29 n, 31 n-33 n$, 35n-36n, 40-41, 43, 48, 51n, 74n, 81, 85n-87n, 91n-95, 150n, 155

GonzÁlez DEl Solar, R., x, 5, 171, 178n, 182

Good, I. J., 139-140, 153

Gooding, D., 19n, 41, 48, 101n, 103n-104n, $112-113$

GotThelf, R., 180n, 182 
GRANDY, R. E., 41

Granger, C. W. J., 147-148, 153

Greenwald, D., 89n, 96

GrifFIN, D., 47

GRÜnBAUM, A., 44

Guala, F., 30n, 41, 164n, 169

Guerlac, H., 105n, 108n, 112

Haavelmo, T., 20-21, 30n, 41, 147

HACKING, I., 11-13n, 15n, 28n, 41-42, 73-74, 76, 79-81, 99, 103, 109, 112, 117, 119, 129n, 134-135, 159, 167n-169, 173n, 175n, 182

Haldane, J. B. S., 10n

Hallam, S., 57, 68

HALPERN, J., 150, 153

HannaWay, O., 38

Hanson, N. R., 16, 42, 74, 121n

HARPER, W., 140n, 153

HARRÉ, R., 17n, 42, 76, 119n, 136

HARrison, G. W., 23n, 42

Harsanyi, J. C., 42, 93

Hartman, S., 36n, 41

Hausman, D. M., 5, 96n, 144, 154, 163-164, 169

Hayes, P. J., 24n, 46

Hazewinkel, M., 148n, 155

HeIDELbERGER, M., 112

Heertje, A., 20n, 46

HeILBRon, J. L., 99

Hempel, C. G., 14, 42, 105

Hendry, D. F., 4, 22n, 42, 148, 153

Herschel, J. F. W., 13, 42

Heske, E. J., 178n

Hey, J. D., 19n, 28n, 36n, 42, 45, 47

HiNTIKKA, J., 141n, 154

Hirsch, C., 44

Hirsch, W. Z., 40

Hirschman, A. O., 65n, 68

Нітснсоск, Сн., 142, 145n, 154

Hogarth, R. M., 94n, 96

Holland, J. H., 42

Holland, P., 150, 154

Holt, Сн. A., 39

Holton, G. J., 42

HOLYOAK, K. J., 42

HorsLEy, S., 104n, 113

Horton, R., 52-53n, 55, 68

HoRwich, P., 129n, 135

Horwitz, R. I., 12, 39

Howlett, P., 65n, 68
Hoyningen-Huene, P., 129-130n, 136

Hudson, R. P., 131n, 136

Hume, D., 159

HuMPHREYS, P., 145n, 154

ILLICH, I., 134n, 136

IMBERT, C., 25n, 39

IRWIN, A., 52n, 54n-55n, 69

JACQuetTe, D., 17n, 42

JANIS, A., 12n, 45

JASANOFF, K., 61n, 64, 66-68

JEFFERSON, T., 56-57, 68-69

JoHNSON, D. H., 174n, 183

JoNes, C. G., 180n, 182

JONES, K., 52n, 54n-55n, 69

Kagel, J. H., 19n-20n, 45

Kahneman, D., 19, 22, 42, 47, 87-88, 90, 94n, 96

KaLisCh, G. K., 20n, 42

KANT, I.,103, 121n

KAZDin, A. E., 24n, 47

Keller, E. F., 35n, 37n, 42, 71n, 76n, 81

Kervran, R., 118n-119n, 122n, 136

Keynes, J. M., 62n

Kitcher, PH., 5, 19n, 42, 141n

KNETSCH, J. L., 19n, 42

KNeZ, M., 42

$\mathrm{Koch}, \mathrm{R} ., 132$

KÖHLER, E., 46

Kolasa, J., 180n, 182

KÖRNER, S., 42

Korta, K., 71n, 82

KRISCHKER, W., 46

Krueger, L., 95

Kunn, Th. S., 16, 30n, 33-34, 42-43, 101n, 107n, $112,129-130,136$

Kuipers, T., 10n, 18n, 41, 92n, 95

KuKLA, A., 75n, 81

KulKarni, D., 43, 96

LACHMUND, J., 118n, 123, 125n, 127n-129n, 136

LAENnEC, R. T. H., 117-124, 126-128, 132n-133, 135-136

Laín EnTralgo, P., 122-124n, 126n-128, 130n, 132n-133n, 136

LAKATOS, I., 16, 99, 101, 131, 136

LANGE, M., 171n, 182

LANGley, P. W., 43, 96 
LAUDAN, L., 5, 99

LARRAZABAL, J. M., 71n, 82

LATOUR, B., 10, 33-34, 43

Lawson, T., 18, 30, 43, 91, 96

LAWTON, J., 171n, 182

LEINFELLNER, W., 46

LENHARD, J., 34n, 43

Lennox, J. G., 5, 10n, 31n, 43

LEPLIN, J., 5

LESKY, E., 136

LEVINS, R., 180, 182

LEWIS, D. K., 142

LEWONTIN, R., 180, 182

LiKens, G. E., 171n, 182

LiNDEMANN, M., 125n, 128n, 132n-134n, 136

LiNDLEY, D., 154

Little, D., 43

LOCKE, J., 130n

Longino, H. E., 74n-75, 81, 117, 136

LoOIJEN, R. C., 182

Loomes, G., 19n, 28n, 36n, 42, 45, 47

Lopez de CASEnAVe, J., 178n, 182

López Cerezo, J. A., ix, 5-6, 117

López Piñero, J. M., 120, 122n, 125n, 127, 132n, 136

LORENZ, M. O., 164-166

LORENTZ, H., 79, 108

LuCAS, A., 105

LuCAS, R. E., 44

LyNCH, M., 33n, 43

Machamer, P. K., 5, 9n, 13n, 39, 43, 142, 148n, 152-154

Magnani, L., 37n, 41, 43-44, 81

Magnus, J. R., 4

Mantzavinos, C., 43

MARCh, J. G., 88, 95

Marchi, N. DE, 4, 19n, 47

Mariotte, E., 105-107, 109, 113

MARKov, A. A., 150

Marone, L., x, 5, 171, 178n, 180n, 182

MARqués, G., 93n, 95

Marshall, T. W., 43

Marsonet, M., 142n, 155

Martínez Solano, J. F., 6, 43

Mason, K., 24, 26n, 40

Massey, G., 12n, 45

Massimi, M., 76n, 78n-81

Maulitz, R. C., 124, 127n-128, 131, 136

Maxwell, J. C., 79
McCABE, K. A., 19n, 22n-23n, 43, 47

McCoy, E. D., 171n, 183

McDermott, R., 164n, 169

McGucken, W., 106n, 113

McGuire, J. E., 5

McKinney, W. J., 44

Menzies, P., 143-144, 154

Michel, H. V., 176n, 181

Mikkelson, G., 182

MiLCKi, M. K., 97

Milesi, F. A., 178n, 182

Miller, C., 44

MilLer, D., 166n, 170

Miller, K., 18n, 41

Milnor, J. W., 20n, 42

MinAZZI, F., 72n, 81

Morgagni, G., 125n, 131

Morgan, M. S., viii, 4-6, 21n, 28n, 30n-31n, $35 n, 37-39,44,51,65 n, 68,72-74 n, 76,81-$ $82,92 \mathrm{n}, 95,110 \mathrm{n}, 113,152,154,159,161 \mathrm{n}$, $163,168-170$

Morgenstern, O., 44

MoRIn, P., 179n, 181n-182

Morpurgo, G., 102

Morrison, M., 4, 44, 81, 110n, 113, 152, 154

Murray, B. G., $171 \mathrm{n}, 182$

Muth, J. F., 44

Musgrave, A., 31, 44, 136

NAGEL, E., 14-15, 44

NASH, J. F., 20, 42, 44, 93

Nering, E. D., 20n, 42

Nersessian, N. J., 37n, 41, 43-44, 81-82

Newell, A., 89

Newton, I., 16, 102, 104-109, 113

NickLes, Th., 5, 34n, 39

NiIniLuoto, I., 5, 9n, 19n, 44

NisBet, R. E., 42

Nordhaus, W. D., 18n, 45

NORTON, S., 44

NorwOOD, R. H., 16

OBerkampF, W., 44

Ockenfels, A., 46

OKsanen, L., 173n, 182

Olsen, E. H., 77

OMELIANOVSKy, M. E., 44

OPPENHEIMER, J., 160-161n, 163-164, 167-169

OrdóÑEZ, J., 100, 109n, 112

ORESKes, N., 65n, 68 
Pagnini, A., 141n, 153

Paracelso, $133 \mathrm{n}$

Parker, W. S., 31n, 35n-36n, 44

PASCAL, B., 13

Pasteur, L., 132

Pearl, J., 149-150, 153-154

PeCKARSKY, B. L., 172, 175-176, 182

Peschel, M. F., 71n, 82

Peters, R. H., 171n, 182

Pickering, A., 42, 101n-103, 111-113, 119, 135-136

Pickett, S. T. A., 180n, 182

Pigou, A. C., 166

Pinch, T. J., 19n, 41, 48, 52n, 68, 101n, 103n$104 n, 112-113$

Platt, J. R., 173n, 182

Plott, Ch. R., 44

Plowys, A., 61n, 68

Polanyi, M., 57n, 68

Poling, B. E., 76n

Poltorak, M., 52n, 69

Popper, K. R., 14-15, 44-45, 100-101, 113, 173, $180 n$

PORTAL, A., 136

Porter, T., 95

Postman, N., 134, 136

Prausnitz, J. M., 76n

Price, D., 56n, 69

Price, H., 141, 143-145, 154

Proudfoot, D., 25n, 39

Psillos, S., 151, 154

Quine, W. v. O., 11, 15, 45, 100n, 111

RADDER, H., 19n-20n, 27n, 35n, 42, 44-45, 47, 71n, 73n, 81-82, 145n, 155

RADNITZKY, G., 48

Ramsey, F. P., 143-144

RANDALL, F., 54n, 68

Rasmussen, N., 122n, 137

RAsSENTI, S. J., 19n, 47

Rawls, J., 160-161, 163, 168n, 170

RAY, J., 130n

REICHENBACH, H., 139-141, 151, 154

REISER, S. J., 124n-125n, 133-134, 137

Reiss, J., 18n, 30n, 45

RESCHER, N., 5, 12n, 16-17, 28n, 37n, 45, 90n, 96

Resetarits, W. J., 172, 175n, 178n-179n, 181-183

RESNIK, D. B., 78n-79n, 82
REY, J., 6

RICHARD, J-F., 148, 153

RIERA, J., 125n, 137

RinnoOy Kan, A. H. G., 148n, 155

Rip, A., 61n, 69

ROGERS, L., 57n, 68

ROKITANSKY, K., 131

Rosenberg, A., 171n, 183

Rossini Favretti, R., 149n, 153

Roth, A. E., 19n-20n, 28n-29n, 36, 42, 44-46

Rothbart, D., 121n, 137

Roughton, R. D., 174n, 183

Rubin, D., 150

Russo, F., 150n, 153

RUTHERFORD, M., 4

SAARINEn, E., 180n, 182

SAGOFF, M., 183

SAlmon, M. H., 5

Salmon, W. C., 5, 12n, 45, 140-142, 144, 151, 154-155

SAMUElSON, P., 18n, 45

SÁnchez Ron, J. M., 106n, 113

SANDRI, G., 149n, 153

SAntos, E., 43

SARgeant, A. B., 174n, 183

SARGENT, R. M., 45

SARgEnt, Th. J., 44, 85

Sauermann, H., 45

Savage, V. M., 181

SCAZZIERI, R., 5, 10n, 23n, 41, 149n, 152n-153

SCHAFFER, S., 19n, 41, 48, 99, 101n, 103n-104, $106,109,112-113$

SCHAFFNER, K. F., 118n, 137

Scheutz, M., 71n, 82

Schram, A., 32n-33n, 45

SCHUMPETER, J., 58n, 69

SEARle, J. R., 25, 46

SECORD, A., 62n, 69

Selleri, F., 43

Selten, R., 20, 22, 29n, 32, 36, 45-46, 87, 92-94

Semmelweis, I., 123, 134n, 137

SEnt, E. M., 94n, 96

SHAH, N., 12n, 39

SHAPERE, D., 76n, 82

SHEA, W. R., 13, 46

Shrader-FrechetTe, K. S., 5, 171n, 183

Shrager, J., 43, 96

SiKLOSSY, L., 46, 96 
Silberstein, M., 9n, 13n, 39

Simon, H. A., 9n-10n, 22-25, 29n, 35n, 39, 43, 46-47, 85-97, 148

Simpson, E. H., 140

Sims, CH. A., 148, 155

SintonEN, M., 5, 18n, 41

SKoDA, J., 123-124, 132

SKYRMS, B., 140n, 153

Slayden, S. W., 121n, 137

SLOMAN, S., 150n, 155

Slovic, P., 47

SMeETh, L., 52n, 69

Sмiтн, V. L., 19, 22, 42, 47, 87, 90, 92

SNELL, W. v. R., 105

Sobczynska, D., 79n, 82

Sober, E., 145n, 155

Solomon, M., 47, 117, 137

StACEY, R., 47

STADLER, F., 36n, 41

StAR, S. L., 131, 135

Steinle, F., 99, 107, 112-113

Stilgoe, J., 52n, 54n-55n, 69

StOeCKer, R., 36, 46

Stuart Mill, J., 142

STrawson, P. F., 14n, 26n, 47

SuArez, M., 78n, 82, 101n

SUNDER, S., 30n, 40

SupPe, F., 13n, 44, 47

SupPEs, P., 5, 10n, 23n, 41, 139, 145-146, $150 \mathrm{n}-155$

SweEney, M. W., 174n, 183

Swijtink, Z., 95

Sydenham, Th., 124, 130, 132

SzAniaWsKi, K., 97

TATON, R., 30n, 43

Temkin, L., 165n, 170,

Thagard, P. R., 5, 24n-26n, 39-40, 42, 47, 117, 129,137

Thaler, R. H., 19n, 42

Thomson, J. J., 79, 111

Thrall, R. M., 20n, 42

Tiels, J. E., 47

Tietz, R., 46

Tinbergen, J., 147

Torres, O., ix, 5, 159

Trow, D. B., 39, 95
TRucano, T., 44

Tungodden, B., 162n-163, 170

Turchin, P., 171n, 183

Turner, S., 58, 61n, 69

Tversky, A., 22, 47, 87, 90

Uebel, Th., 36n, 41

UNDERGOOD, A. J., 172n, 183

URBACH, P., 12-13n, 27n, 47

VAllentyne, P., 162n, 170

Van Fraassen, Bas C., 13, 47

VIRCHOW, R., 121n, 131, 137

WARWICK, A., 107n, 112

WATERS, C. K., 171n, 183

WeBER, J., 104

Weber, M., 36n, 41

WEBER, W., 108

WERNER, E. E., 178n-181n, 183

Wessels, L., 119n, 135

West, G. B., 181

WestFall, R., 108n, 113

Wettstein, H., 146n, 155

WHEWELL, W., 181, 183

Williamson, J., 150n, 153

Wimsatt, W. C., 121n, 137

WinsBerg, E., 23n-24n, 26n, 47

Wold, H. O. A., 21, 47, 148

Wolters, G., 148n, 152-153

WoODWARD, J., 20, 47, 78, 81, 101, 112, 139, 142, $144-145,148,151-152,154-155$

Woolgar, S., 10, 33, 43, 48

Worrall, J., 5, 12n, 16, 48, 150n, 155

Wright, S. G., 10n

WynNe, B., 52n, 61n-64, 66n, 69

YARI, M., 161, 163, 170

YLIKOSKI, P., 18n, 41

Yuehling, T., 146n, 155

ZAHAR, E., 48

ZaLtA, E. N., 102n-103n, 112

ZeEman, P., 107-108, 111

ZEIDLER, P., 79n, 82

ZimAN, J., 52n, 54n, 69 


\section{Serie de Fllosofíá Y \\ Metodología de la Ciencia}

Títulos publicados en la Serie:

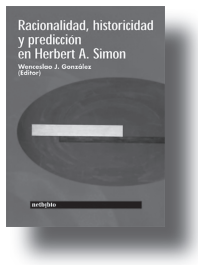

Racionalidad, historicidad y predicción en Herbert A. Simon

W. J. Gonzalez (ed)

ISBN: 84-9745-021-3

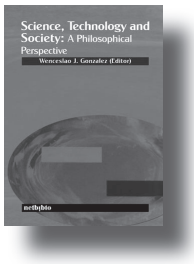

Science, Technology and Society: A Philosophical Perspective

W. J. Gonzalez (ed)

ISBN: 0-9729892-2-6

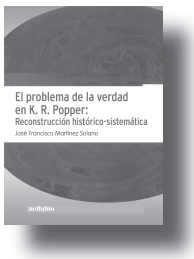

El problema de la verdad en K. R. Popper: Reconstrucción histórico-sistemática

J. F. Martínez Solano ISBN: 84-9745-102-3

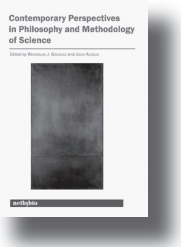

Contemporary Perspectives in Philosophy and Methodology of Science

W. J. Gonzalez y

J. Alcolea (eds)

ISBN 13: 978-0-9729892-3-7

ISBN 10: 0-9729892-3-4

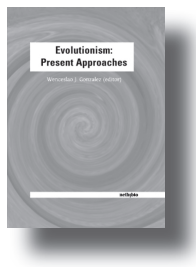

Evolutionism:

Present Approaches

W. J. Gonzalez (ed)

ISBN: 978-0-9729892-8-2

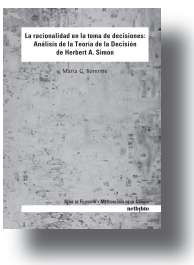

La racionalidad en la toma de decisiones: Análisis de la Teoría de la Decisión de Herbert A. Simon M. G. BonOME

ISBN: 978-84-9745-459-9

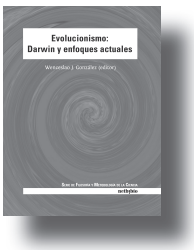

Evolucionismo: Darwin y enfoques actuales

W. J. GonZalez (ed) ISBN: 978-84-9745-409-4

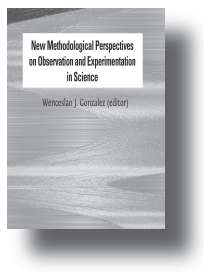

New Methodological Perspectives on Observation and Experimentation in Science

W. J. Gonzalez (ed)

ISBN: 978-84-9745-530-5

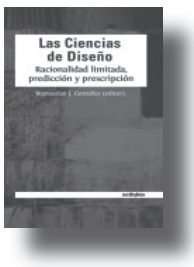

Las Ciencias de Diseño:

Racionalidad limitada, predicción $y$ prescripción

W. J. Gonzalez (ed)

ISBN: 978-84-9745-212-0

\section{netbiblo}


